\title{
Beatrix Schmidt
}

\section{Stilelemente \\ der mündlichen Literatur}

in der vorrealistischen Novellistik

der Serben und Kroaten

Verlag Otto Sagner München · Berlin · Washington D.C.

Digitalisiert im Rahmen der Kooperation mit dem DFG-Projekt „Digi20“

der Bayerischen Staatsbibliothek, München. OCR-Bearbeitung und Erstellung des eBooks durch den Verlag Otto Sagner:

http://verlag.kubon-sagner.de

( bei Verlag Otto Sagner. Eine Verwertung oder Weitergabe der Texte und Abbildungen, insbesondere durch Vervielfältigung, ist ohne vorherige schriftliche Genehmigung des Verlages unzulässig. 


\section{SLAVISTISCHE BEITRÄGE}

BEGRUNDET VON ALOIS SCHMAUS

HERAUSGEGEBEN VON HENRIK BIRNBAUM UND JOHANNES HOLTHUSEN

REDAKTION. PETER REHDER

Band 74 


\section{BEATRIX SCHMIDT}

\section{STILELEMENTE DER MÜNDLICHEN LITERATUR IN DER VORREALISTISCHEN NOVELLISTIK DER SERBEN UND KROATEN}

VERLAG OTTO SAGNER • MÜNCHEN

1974 
Bayerische Staatsbibliothok Müncien

ISBN 3876900840

Copyright by Verlac Ot to Sagner, Munchen 1974 Abtellung der Flrme Kubon und Sagner, Munchen Drucks Alexander Grobleann

8 Munchen 19, Yeenburgstrabe $7^{I}$ 
Se1te

I. E1n1e1tung

II. Situation und 21eleetzuns der Jungen Literaturen

1. Die Lage der Literatur

14

1. Serbieche L1teratur

14

2. Kroat1eche L1teratur

16

3. Mindliche Uberlieferung

2. D1e Frage der Literatureprache

al. Kernproblem

3. Im Vordergrund: auBerlitererloche Funktionen

24

4. Das Problem der Leserschaft

5. Theoretische Forderungen an die jungen Literaturen

1. Serben

1. Vuk Stefanovit Karadžit 3n

2. Borde Malet1t

3. Jovan Subot1t

38

41

4. Jovan Rist1t

45

5. Jakob I Enjatovit

49

6. Svetozar Markovit

51

2. Kroaten

1. Ljuderit Gaj

2. Stanko Vraz und Dimitrije Demeter

3. Mirko Bogovit

4. Bogoslav Sulek

5. Adolf Veber-Tkal cevit

63

64

6. Janko Jurkovit 67

7. Auguet Senoa

8. Franjo Markovit

70

74 
der Jungen Literaturen $\quad 77$

1. Funktionen der mundlichen Literatur 77

2. Entstehung der mundlichen Literatur 85

3. St1l1stische Merkmale der serbokroatischen Volkserzkhlung

90

1. Allgemeines 90

2. Lokalkolorit 92

3. Komposition 95

4. Stilmittel - "Kunsterifre" 98

1. Wlederholung-Varlation-Drelzahl 98

2. Zahlen allgemein 100

3. Anfang und Schlub 102

4. Direkte Rede und andere Redeformen 107

5. "Verfestigten Stelien - Formeln, Retme 112

6. Epltheton - Vergle1ch- Metapher Paraile11smus - semantische Reduplikation - Figura etymologica 115

7. Tempus 127

8. Satzbau 130

5. Der Erzkhler 135

6. Typisterung oder Charakterisierung? 137

7. Weltbild und Ethik 141

1. Allgemeines 141

2. Der Held 142

3. Das mythische Weltbild in der

4. Rechtsdenken 145

5. S1ppe, Fami110, Freundschaft 147

6. D1e Frau 148

7. Sitte und Brauch 149

8. Wert der Arbe1t 149

9. Sch1cksals - und Wunderglaube 1,51

10. Nationale Komponente 152

8. Vuks St11181erung im Vergleich zum Originaltext: Geschriebenes Wort und mindliche Rede 153

IV. Be1sp1e1e

1. Vorbemerkung: die Begriffe "Novelien und "novela"

2. Zur Auswahl der belspiele

3. Imitation und Addition: "narodnost" als HuBerliches Dekor 
4. Einbeziehung von St1lelementen der

Volksilteratur in die innere struktur

des Erzuhlwerko

1. Antun $N$ C 16 : "Udee l Judsk1"(1854)

(84, Se1te 273-29n)

1. Gesamtwerk und Vorbilder 173

2. Das Sprachproblew 174

3. Kommentare 175

4. "Udes l judsk1": Gattung - Komposition Erzanl technik - Milieu

5. Romant 18che St1lelemente

6. Elemente der Volksilteratur in Stil Nemeits

a. Nemcits Beziehung zur ftokaviechen und zur Volkeliteratur

178

178

b. "Müd 11 che" Rede in "Udes 1 judek1"

178

180

c. Stilmittel der volksilteratur in "Udes l judek1"

7. Zusamenfase ung

182

185

2. Luka B o $t 1 t$ : "n11ber-Hasan" (1854)

(21. Se1te 345-402)

1. Gesamtwerk - ge1stiger Hintererund Einflusse - Kommentare

188

2. Themat1k, duberor Aufbau und Kompo-ition der Novelle "Dilber-Hasan"

192

3. Raum und Zeit - Erzuhltechnik

4. Romant 1 sche Filemente

5. Elemente der Volksdichtung alo lyrische St1lmittel

6. Elemente der Volkedichtung als real1stische stilinttel

7. Realistische Elemente

8. Zusammenfassung

3. V111m K o r a J a c : "Š1jac1" (1868)

(57, Se1te 255-288)

1. Orientierung - Vorbilder Geeamtwerk

2. "Šljac1", Gattung - Komposition 212

3. Erzuhl technik

4. Korajac' Erzuhl st11

a. Romant1sche St1lverfahren

216

b. Stllattel des wundlichen Erzuhlers

c. Realistische Elemente 224

5. Zusammenfassung 
4. Stjepan Mitrov L ju b 1 a:

"Štepan Ma11" (1868)

(66, Se1te 7-46)

1. "Vukova ékola"

2. Vorbllder - Gesamtwerk

3. "Štepan Mal1": Fabel - Komposition

4. Erzuhl technik

230

5. Lexik, Morpholog1e, Syntax

231

6. Stllverfahren der Volkserzahlung

233

a. Dreizahl

b. Sprichworter, Sentenzen, Rede-

235

239 wendungen

c. Rhetorische Piguren

7. Charakterisierung der Personen

236

8. Ethik und Tendenz

238

9. Zusammenfassung; Romant1k und Real 1smus

239

242

246

5. August $\zeta$ o 0 a "Barun Iv1ca" (1874) 248 (1in, seite 7-83)

1. Bedeutung - Gesamtwerk 248

2. Vorbllder - Vorluufer 250

3. "Barun Irica": Novellentyp - Fabel Komposition - Tendenz 252

4. Erzbhltechnik 256

5. Pormale Elemente der Volkserzahlung in
der Novelle "Barun Ivica" 260 a. Dreizahl 261

b. Ant1these 263

c. Sprichworter, Sentenzen, Rede-

d. Rhetorische Figuren 265

- Elemente der mündlichen Rede 267

6. Das patriarchalische Weltbild 268

7. Charakter1sierung oder Typ1sierung? 270

8. Senoas küntierlscher skaz 272

5. Zusammenfassung $\quad 277$

v. We1tere Entwicklungen $\quad 278$

1. Serbische Literatur 278

2. Kroat1sche Literatur 281

vI. Zus a m

$\begin{array}{ll}\text { Abkürzungen } & 289\end{array}$

Literaturverzelchnis

$\begin{array}{ll}\text { Originalzitate } & 298\end{array}$

NACHBDMERUUNG 
I. E 1 n 1 e 1 t

In der neueren serbischen und kroatischen Literatur gibt es eine Anzahl von Schriftstellern und Dichtern, deren Schaffen in besonders engem Zusammenhang mit der Volksliteratur steht. Dies gilt für zahlreiche Anhänger Vuk Karadzits, die insbesondere in der zweiten Halfte des 19. Jahrhunderts die Anregungen Vuks z.T1. allzu wortlich befolgten, es gilt aber auch für verschiedene spätere Autoren bis ins 20. Jahrhundert, deren persönliche Verbundenhelt mit einer bestimmten landschaft und Ihrer Erzähltradition sich in ihrem Werk niedergeschlagen hat.

Auf solche Zusammenhange ist zwar bfters hingewiesen worden, melst aber beschränken sich die Hinweise auf allgemein gehaltene Formulierungen, die nicht ins Detall gehen. M.BoškoviCSTULLI sagt in Ihrem Aufsatz "Usmena književnost u sklopu povijesti hrvatske književnosti" (20,5.31-58):

Meist haben unsere bisherigen Literaturgeschichten auf die Einflusse hinsichtlich der Motive und auf die Namen epischer Helden in literarischen Werken hingewiesen, während uber den Einflub und die wechselseitigen Ubernahmen von Ausdrucksformen, z.B. des Verses, bedeutend wentger und am allerhaufigsten impressionistisch gesprochen wurde. Unsere literaturgeschichten waren nicht in ausreichendem Maße bestrebt, vor Augen zu fuhren, wieviel und auf welche Art die Gegenwart mündicher Literatur zu der Schaffung der künstlerischen Merkmale einzelner Schriftsteller oder der Literatur ganzer Epochen beigetragen hat. $(20,5.35)$

Im Zuge der romantisch-nationalen Begeisterung, von der die Anfinge der serbischen und der kroatischen Literatur des 19. Jahrhunderts getragen sind, begegnet man häufig der Formulierung, daB ein Werk vom Geist des volkes durchdrungen sei, daB es den Gelst des Volkes verkörpere; linnliche Wendungen treten uberall dort auf, wo die wesentlichsten Anspruche an die Nationalliteratur zum Ausdruck Gebracht werden. Diese, auf Herders Volksbegriff zuruckgehende, mystifizierende Vorstellung vom Geist des Volkes, den man in der mundlichen literatur realisiert sah, lieb zunlichst eine genauere Definition oder Analyse nicht zu, da man hierin bereits eine Art Profanierung eines nationalen Heiligtums erblickt hätte. 
Den heutigen Anspruchen genugen diese vagen Umschreibungen nicht mehr; so versucht man bei der Erforschung der münd11chen Literatur, jene Strukturen im Text aufzudecken, die ihre spezifische Elgenart ausmachen und die tragenden Elemente threr besonderen A tmosphkire und des "Volkstons" sind, und man ist bemuiht, aus den in ihr vorgegebenen Verhaltensschemata inre Wertrorstellungen und Leitbilder abzulesen.

In der vorliegenden Arbeit wird der versuch unternommen, am Beispiel der Fruhen Novellistik der Serben und Kroaten zusammenhange zwischen der mündlichen tberlieferung und den jungen Literaturen nachzuweisen. Der Begriff "Novelle" wird hierbel verhältnismbibig grobzügig gehandhabt, zumal er auch in den entwickelteren Literaturen whrend des ganzen 19.Jahrhunderts unstritten war und insbesondere die Abgrenzungen zur Erzinlung hin nach oft ganz unterschiedlichen kriterien erfolgte.

Bei den Serben und Kroaten muBte sich zugleich mit der Nationalliteratur deren Instrument, die Schriftsprache, erst herausbilden, und das unter sehr verschiedenartigen, immer aber schwierigen Gegebenheiten. Die ausgeprägte nationale Funktion der Literatur wirkte sich einerseits als Antriebsfeder, andererseits als Belastung aus, weil nicht alle aufgerufenen Kráfte schöpferische Krifte waren. Zeitgenösische und spatere Kritiker sind mit den Novellisten der vorrealistischen Periode hart ins Gericht gegangen; es läbt sich diesen Autoren aber das Verdienst nicht absprechen, durch ihre Bemuhungen um die Sprache und den Erzbihlstil die Voraussetzungen für die späteren kunstlerischen Leistungen geschaffen zu haben.

Jene Literaturen, die sich aufgrund historischer Gegebenhesten erst verspitet und dann, wie es der russische literaturhistoriker GAČEV formuliert hat, "beschleunigt" entwickelt haben (33, S.13), sind immer wieder unter dem Aspekt der Beeinfiussung von auBen her, der Ubernahme bereits auggebildeter Formen untersucht worden. A.FLAKER spricht in diesem zusamenhang von "gesetzgebenden" (d.h. stilbildenden) und "nicht gesetzgebenden" Literaturen $(33,5.13)$. Es ist ganz selbstverständich, daB die serbische und kroatische literatur, die 
aus dem erwachenden Nationalbewubtsein whrend dee 19.Jahrhunderte den Impuls zu elner juhen Entfaltung empring, alle verfugbaren literarischen Moglichkelten in 1 ch aufnahm, die thr forderlich oeln konnten. Hier bot olch neben den Vorbildern der "groben" Literaturen, die den geblldeten Kreloen weltgehend zuganglich waren, der Relchtum der Volksdichtung an, d1e selt Herder europkische Anerkennung genoB und gerade 1m udslavischen Raum noch lobend1g-produkt1v und von beeonderer vielfalt war.

D10 zuntchst ganz konkret gesehene, national-d1dakt1sche Aufgabe der zu schaffenden verke $110 B$ elne Anknüpfung an d1. Volksuberlieferung angemessen erschelnen. Diese Forderung trat daher in den theoretiochen äuberungen der literaten oelt Karadžlt und den Illyrern lmaer wieder auf, wahrend die Frage nach der bothetiochen Funktion der literatur erst allmahlich Raum gowann. Sulek oprach 1846 rom notwendigon Glelchgowlcht zwischen der kunstlerlochen und der nationalen Komponente im literarischen werk, und erst um 1870 erscheint In Franjo Markovit der erste kroatische Ästhetiker, der aber Immer noch den nationalen standpunkt mit Nachdruck vertrat. D1e politischen Verhultnisse in der Donaumonarchie, im b1s 1878 türkschen Bosnien und 1 m autorituren serblschen staat brachten 68 mit $81 \mathrm{ch}$, daB die nationale Funktion der literatur allmkhlich mit sozialkritischen Aufgaben zusammenfiel, so dab auch nach der Absago an die Romantik der mythologisierende Volksbegriff selbst in den Werken des Realismus und der Moderne nachhallt.

D1e Hinwendung zur mundlichen Literatur, die nicht nur elnen ldeellen Vert, ondern zugletch die reale Grundlage der zu formenden Literatursprache darstellte, uuberte sch am deut11 chsten In der Sanelertut1gke1t Karadżts und selner Nachfolger. Auch die Illyrer, für die die Sprache das wichtigete Instrument in Kamp um die nationale selbstbehauptung war. samelten Volkslieder und -erzuhlungen, z.B. Gaj, Vraz, Kukul jerit und andere. Schon in den orsten Jahrgungen der "DANICA" wurden eplsche Lleder aus Vuks samiung verbrfentilcht. Dand trat die Volks 11 teratur erstallg glelchberecht1et, d.h. In gedruckter Form, neben d1e auslundische Literatur 
und wurde auch jenen lesern nahegebracht, d1e die direkte Verbindung zu thr verloren hatten.

D1e Beschaftigung wit der Volksdichtung schuf in Verbindung at der nationalon Begeloterung der sich formierenden Intelligenz Jene Atmosphare, In welcher der Ruckgriff auf Thenen der glorrelchen Vergangenhelt und der mindlichen tberlieferung des Volkes weltaus motivierter war als in der westeuropulschen Romant1k. Inwtewelt elnzelne Schriftetelier solche stoffe bearbeltet haben, $18 t$ vielfach nachgowiesen worden. Dafur, daB d1e blobe Verwendung nationaler Themen kelnesfalls zwangsluuf16 zur Erneuerung der Literatur aus den Gelote der Volksdichtung fuhren muB, bletet die Novellistik (und die Dramatik und Epik) Serbiens w1e Kroatiens genugend Beisplele. Andererse1ts 1st os bekannt, daB z.B. auf den Geblet der Epik gerade das Melsterwerk des Illyrismus, Mažuranils "Smrt Small-age Čnglta", von den Heldenliedern inspiriert und von lhren stilformen, wenngle1ch in elner einmaligen Synthese mit anderen Elenenten, getragen 1st; Mažranit hat diese formalen Mittel nicht als folkloristisches Dekor bleichsan "von auBen" aufgesetzt, sondern aus selner persönlichen, Inneren Bezlehung heraus at subtilem, kunstlerischem Gefunl in seln Werk elnbezogen. Dantt gelang inm ach die erste kunstlerische Roalisterung olner neuen literatursprache, wahrend fast glelchzeltig die Gedichte Branko Raditevits den Durchbruch der Volkseprache in der serbischen Lyrik kennzelchnen.

Auch in der vorreal 1stischen Novellistik, die frellich nie das Niveau von Mažuranits Epos errelcht, gibt es neben oberrluchllcher Nachahmung von Volkserzuhlungen oder der viedergabe eplscher Lieder in Rahmen romantischer, oft genug ron Sentinentalismus gefarbter Prosa gelegentlich Belopiele elner t1eferen Beziohung zur müdlichen Erzahlwelse, zum eplschen oder lyrischen Volkslied. Obwohl stcher auch uber die Inttation oder die etwas gewaltsame Elnflechtung von Volksiledern in Prosatexte solche Formen in die Belletristik Elngang 60funden haben, durfte dies erst recht auf die werke jener Autoren zutreffen, die unnittelbarer an die mundliche Erzuhlkunst, an d1e Schmuckformen der lieder anknupften, nicht nur in der Fabel oder eintgen Deta1ls. Elne solche Anknipfung uuberte sich vor allem in elner volksnahen Ausdruckswe1se, die elne 
lebendige Bereicherung der noch unsicheren literatursprache bewirkte. whingend sie glelchzeltig zur verselbstandigung der Literatur beltrug, auch dann, wenn die betreffende Erzahlung kein uberdurchschnittliches Niveau erreichte; denn hier wurden zusbtzliche Ausdrucksmbglichkeiten eroffnet, deren sich spatere Autoren bedienten. Dies gilt z.B. Fur die serbischen Realisten, füderen z.Tl. melsterhafte Novelien nicht nur das Dorfmllieu von den vorgangern "erschlossen" wurde, sondern zuglelch eine relche skala angemessener, aus der elgenen Sprache hervorgegangener stilmittel. In ahnlicher Welse wirken solche Elemente noch bel Schriftstellern fort, deren zielsetzung bereits bewubt uber die orientierung an der volksliteratur hinausging, z.B. bel Senoa oder Ante Kovacit.

Nach Absteckung des historischen Rahmens werden in dieser Arbelt zunachst die theoretischen Forderungen skizziert, die an die entstehenden Literaturen gestelit wurden. Um Verglelchsmöglichkeiten zu schaffen, folgt eine detaillierte Darstellung der serbokroatischen volkserzahlung; sodann wird versucht, in elner Rethe von frühen serbischen und kroatischen Novelien Elemente der Volksuberlieferung aufzuspuren. Der Terminus "serbokroatische" Volksliteratur wird in iberelnstimung mit den Ansichten von Forschern wie M.BolkovitStulli, I.Slamnig u.a. gebraucht, die sich dariber einig sind, dals eine Abgrenzung zwischen serbischer und kroatischer volksliteratur grundsitzlich nicht olnnvoll ist. 


\section{D1e Lage der Literatur}

Die politischen und sozialen verhaltnisse, unter denen die Serben und Kroaten In der ersten Hulfte des 19.Jahrhunderts lebten, erschwerten d1e Entwicklung der Jungen Literaturen, dadiese volker auf mehrere staaten vertellt, unter politischem Druck und oft ohne jeden Kontakt zwischen den elnzelnen Volksgruppen lebten; vor allem aber fehlte es an einer zahlrelcheren geblldeten Schicht wit nationaler Orientierung. Elne solche schicht gab es lediglich bel den ungarlschen serben, whrend die kroatische Intelligenz, zu der zunkchst fast nur der Adel zahlte, melst dem elgenen Volk entfremdet war; dies gilt auch fur die 1 talianisierte Intel11genz Dalmatiens. Die ubrige, bauerliche Bevölkerung hatte in vielen Gebleten einen auBerordentlich harten Existenzkanpf zu bestehen, auch dort, wo es keine Fremdherrschaft gab, wie in Montenegro, und setzte sich fast ausschlleBlich aus Analphabeten zusammen.

\subsection{Serbische Literatur}

Obwohl die Unterweriung durch die Osmanen die kulturelle Entwicklune serbiens jăh unterbrochen hatte, fand die wittelalterliche Literatur in den Klostern lhre Fortsetzung, wenn auch in vermindertem Umfang. Die Abschrelbtatigkeit der Mónche wurde noch $1 \mathrm{~m} 18$.Jahrhundert von den nach Österreich Ausgewanderten welter gepflegt, wobel es berelts zu Versuchen kam, das K1 rchenslavische durch die Ungangssprache zu ersetzen (z.B. Gavrilo Stefanovit venclovit).

Durch die Anlehnung der serbischen Kirche in österreichUngarn an die russisch-orthodoxe K1rche erfolgte un die Mitte des $18 . J a h r h u n d e r t s$ bekanntlich elne Unstellung des kirchlichen Labens auf die russisch-kirchenslavische sprache, die damit auch in die Literatur Eingang fandi einige Autoren schrieben sogar fast in relner russischer sprache(Rajlt, Trlajit). Durch die Ubernahme russisch-k1rchenslavischer, aber auch zeltgenössicher russischer flemente entstand eine Mischsprache, die als Literatursprache diente und auch in die Umgangssprache der Geblldeten elndrang. So konnte es 
geschehen, dals z.B. Mat1ja Rel jkorlte "Satir", In reiner štokavisch-1kavischem D1alekt geschrieben, 1793 in "einfache serblsche Sprache" ubersetzt wurde, d.h. In die slarenoserbische Mischsprache.

Unter diesen Umstanden lot es kein Wunder, dab ach die Erkenntnisse Jener schriftsteller, die schon fruh die Notwendigke1t elner volkseprachlichen literatur einsahen, Theorie bleiben muBten(z.B.orfelin). Selbst Lositej Obradovit gelang es nicht, seine Schriften von russisch-kirchenslavischon Ausdricken und Konstruktionen frelzuhalten, obwohl er sich um die Volkssprache bemihte, z.B. In selnen Fabeln, wie A.SchMaUs im einzelnen dargelegt hat $(98,5 \cdot 39-72)$. Um die Wende zum 19.Jahrhundert hatte $81 \mathrm{ch}$, von der K1rche gestutzt, die slavenoserbische Sprache im serbischen Schrifttum weitgehend durchgesetzt, doch fehlte es lhr an einer prazisen Norm, was elne allgemelne Unsicherhelt des Ausdrucks und auch der orthographie zur folge hatte.

Aus der fill le unbedeutender historischer, belletristischer und pádagogischer Schriften ragt das verk obradovits hervor, welches alle Tendenzen der Aufklurung reprasentiert. In den Oden Lukijan Mušickis klingt bereits jenes ausgepragte Nationalgefül an, das die spatere Literatur al lgemeln auszelchnet; doch schrieb Muślcki slavenoserbisch und In klassischen Metren. Muślcki gehörte zu jenen Autoren. die den gebildeten Serben die europálsche gelsteswelt der Zeit durch ibbersetzungen erschlossen.

Wăhend die Schriften der melsten Autoren wegen des Beharrens auf der slavenoserblschen sprache und ihres gelehrten Inhalts auf elnen kleinen Krels beschrankt blieben, erreichten die sentimentalen, nach deutschen vorbildern verfabten und oberflachlich "serbielerten" Romane Milovan Vidakovits, die bis zur Jahrhundertait te Immer neue Auflagen erlebten, ein gröberes Publikum, da seine Spreche trotz vieler Russismen und der von Karadzit angeprangerten Fohlerhaftigke1t immerhin der Umgangssprache naher stand; selbst eln so großes ralent wie J.St.Popovit begeisterte sich in der Jugend fur diese Homane. Sterija selbst begann seine literarische Tutigkelt In slavenoserblscher Sprache, un ich Mitte der 20 er Jahre unter dem Elnflub Karadżles der Volkseprache zuzurenden. 
AuBer Vidakovit stammten fast alle serbischen Schriftsteller dieser Perlode aus österrelch-Ungarn; Ausnahmen bildeten Sima Milutinovit Sarajlija und der montengrinische Bischof Petar I, die belde berelts Elemente der Volksilteratur in lhre Dichtungen elnbezogen; die elgenwillige Sprache Milutinovits in ihrer "seltsamen Schónhelt" allerdings blieb den melsten serblschen Losern ebenso unzuganglich wie die slavenoserbische Kunstsprache.

Zu Beginn des 19.Jahrhunderts 18 die situation der serbischen Literatur mithin trotz guter Ansatze, ubrigens auch auf dramaturgischem Geblet, und trotz der zunahme der weltlichen Autoren durch thre Beschrankung auf die ungarischen Serben - und hier wleder auf den klelinen Krels der Kenner des Slavenoserblschen - gekennzelchnet; sie hat, mit wenigen Ausnahmen, keine Beziehung zur Masse des serbischen volkes, zu ihrer elgenen alten Tradition und zur miindlichen Uberlieferung.

\subsection{Kroatische literatur}

In der kroatischen Literatur 1 st gegen Finde des $18 . J a h r-$ hunderts ein Auselnanderstreben in verschiedenen Richtungen zu beobachten. Noch zu Beginn des Jahrhunderts hatte Pavao Ritter Vitezovit die Idee elner einheltilichen Literatursprache und Schrift aller sidslaven vertreten, wobel ihm auch eine politische vereinigung - unter dem Zepter Habsburgs vorschwebte. Die kroatische literatur entwickelte sich in entgegengesetztem sinne: wahrend die letzten vertreter der Dubrovniker Tradition atokavisch-1jekavisch schrieben, entstand im engeren Kroatien elne kajkavische und in slavonien eine fokavisch-1kavische Literatur.

Die Werke der spten Dubrovniker Literatur waren ebenso wie eln Tell der slavontschen Literatur (Kanižlit)barocke vichtungen, die auf die geblidete schicht, den Adel und den Klerus, abgestimmt waren. Die kajkavischen Autoren bedienten sich der Volksiprache, wie sie sich lm zentralen kroatischen Gebiet herausgeblldet hatte; 1hr hervorragendster Vertreter, Tito Brezovackl, ubte in selnen Gedichten und Dramen tellwelse berelts Sozialkritik. Aus slavonien, das nach der Befrelung von der Turkenherrschaft in der $2 . H a 1 f t e$ des 18.Jahrhunderts elne kurze Blite der literatur erlebte.

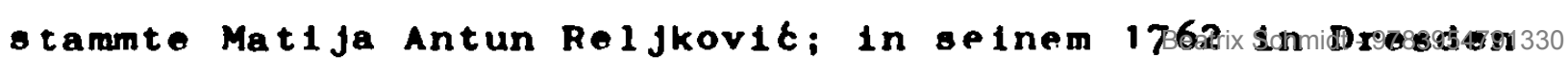


gedruckten "Satir" kritisierte er die Verhaltnisse in selner ruckstandigen Helmat, wobel er slch der slavonischen Volkssprache und des volkstublichen Deseterac bediente. Diase vichtung gehörte neben KaCit-Miobits "Razgovor ugodnt naroda slovinskoga"(1756) zu den wenigen Werken, die die Masse des Volkes errelchten. Auch Katit, der als Franziskaner in Bosnien und Dalmatien wirke, gebrauchte In seinen "historisch richtipgesteliten" Nachdichtungen den epischen Deseterac.

whrend ein Grobteil der kroatischen Literatur dieser Epoche auf ihr Entstehungsgeblet beschrankt blieb, was auf dialekta1e und konfessionelle Schranken, auf thematische Fxklusiv1tłt oder elnfach auf fehlende Kommunikationsmöglichkeiten und geringes Interesse zuruckzufuhren ist, erlebte karits "Razgovor" elne Verbreitung in samtlichen kroatischen, teilweise auch in serbischen Gebieten $(6,6 n)$. Dab Kačits ikavischštokavischer Dialekt sowohl in štokavisch-wie in čakavisch sprechenden Gebleten verstanden wurde, erklart A.BELIC durch die ehemalige, jahrhundertelange Wechselwirkung zwischen dem štokavischen und dem cakavischen Dialekt, die mindestens bis Ins XIV.Jahrhundert angedauert und $z$. B. den Dubrovniker D1dtern die Ubernahme cakavischer klemente in ihren btokavischen Nialekt ermöglicht hatte $(10,5.72 / 73)$.

In jener fpoche, die der 111 yrischen Bewegung vorausging, gab es also in der kroatischen literatur nur wenig allgemeln verbreitete Werke in kroatischer sprache und keine gemeinsame sprachliche Entwicklung. Auch die reiche Dubrovniker Tradition kam mit dem Fall der alten Republik zum Erliegen. Die deutsche Uberfremdung der gebildeten Krelse wirkte sich aus; wie trostlos die allgemelne Lage der kroatischen Literatur von den wenigen national elngesteliten Schriftstellern empfunden wurde, schildert A.BARAC im 1 .Kapltel seines Buches "Il1rizam" (5).

\section{II.1.3. Müd l1che Uberl leferung}

whrend die serbische und die kroatische literatur zu Beginn des 19.Jahrhunderts die Verbindung zu lhren blteren Traditionen eingebübt hatte und durch die Vorherrschaft der slavenoserbischen sprache elnerselts, das Auseinanderstreben der Dialekte und die Uberfremdung andererselts eine kritioche 
Situation alngetreten war, gab es elne relche aindliche tberl1ererung an eplschen und lyrischen liedern sow1e an Marchen, Sagen und Erzuhlungen. Die nündlche Tredition relchte nicht nur b1s in die zelt vor der rurkenherrschart zuruck, also in die glorrelche zeit des grobserbischen Re1ches, sondern unfaBte noch alte slavische Mythen aus vorchrlstlicher 2 elt, und sie war auch noch produkt1r lobendibi dies bestatigen die neuentstandenen lieder aus der Zelt des ersten serbischen Aufstandes, deren Schupfer noch namentilch bekannt sind. In Montenegro hielt diese Produkt1vitut bis in die zwelte Hifte des Jahrhunderts hineln an. In den von den rurken besetzten Gebleten hatten sich besondere Formen der epik und der Lyrik herauggeblidet.

Die wundlichen Schupfungen elnzelner, von der Gemelnschaft akzeptiert und weltergerelcht, ubernahmen alle runktionen des Schriftums, da die Mehrzahl der Serben und Kroaten noch unter jenen Bedingungen lebte, die die besten Voraussetzungen fur die Entstehung aundlich tradierter plchtungen darstellen. Hierauf wird ausührich unter III.1.und III.2. eingegangen. 
II.2. Dle Frage der L1teraturepreche ale Kernproblea.

11: durch das Zusamenw1rken gesanteuropalscher Strbmungen und opeleller politischer Gegebenhelten bel den Serben und Kroaten zunkchet Elnzelnen und dann Gruppen von Intellektuelien die Notwendigkelt elner Erneuerung der Literatur bewubt wurde, ergab sich als zentrales Problea die rrage der Literatureprache.

In der Pereon Karadżte fand $81 \mathrm{ch}$ fur Serbien a in Mann, der sich dank selner Herkunft ein spontanes Sprachgefül bewahrt hatte, das nicht durch slavenoserbische lekture und fruhe deutsche oder ungarische Einflusse vorzeltif verunslchert war wie bel vielen der in österrelch-Ungarn aufgewachsenen serben. Selne Forderung nach einer literatur in der Volksoprache ot1eB selbstrerstandlich auf den widerstand der Schriftsteller, da sich die slavenoserbische sprache bereits seit mehr als alner Generation elngeburgert hatte; zudem hielt man ole für die "relne" altslavische sprache, die Volkssprache aber fur verdorben. Die gesamte Thtigkelt Karadžits, angefangen von selner ersten bescheidenen Grammat1k von 1814 b1s zur B1belubersetzung von 1847 und dem erwelterten "Srpski Rjelnik" von 1852 elnschlieblich seiner Volksilteratur-Samiungen und Polemiken lot nichts anderes als elne unermudliche verteldigung der volkssprache gegen den vorwurf der Unzulanglichkelt fur die Bedurfnisse einer zeltgembiben Literatur und visenschaft - der sie zunkchst tatsuchlich ohne Anlethen bel der slavenoserbischen bzw.der kirchenslavischen Sprache nicht genügte. Zu dem Widerstand der Literaten geselite sich die starre haltung der Kirche, fur die die slavenoserbische Sprache eln Politikum war, und, mit der Kirche in Elnvernehmen, des serbischen staates. Karadžlts Bemüungen richteten sich also hauptsachlich auf das Zuruckdrangen des Slavenoserblschen und auf die Schaffung elner vereinfachten, elnheltilchen Orthographie. Er mubte nicht nur der Lexik der slavenoserbischen sprache die der volkssprache entgegensetzen, sondern auch in morphologlocher Hinsicht Richtilnien aufotelien. In der Orthographio strebte ar anstelle der alten etyelogischen elne phonetische Schreibweise an. 


\section{$-20-$}

D1e Finzelhelten des Kampres us die Durchsetzung der Reformen Karadžlts sind bekannt; ste elnd u.a. von BELId und JONke eingehend dargestellt worden'. Von Bedeutung 1st. daß Karadžlt in dew von inm befurworteten sud-btokavischen Dialokt oin Mittel zur Annkherung zwischen der serblschen und der kroatischen literatursprache erblickte; so schrieb or in den "Plsma o spskon pravoplsu" (abgekurzter T(tel) von 1845:

...d1es let auch der Dialekt der Dubrovniker Dichter. und so können wir uns nur durch lhn wit unseren Brudern romischen Glaubens vereinigen, die uns freudig dte Hand entgegenstrecken. (z1tiert nach $11,5.75$ )

Diese Broschure stellte die vorbereltung fur die vereinbarung von wien (1850) dar, In der sich elne Rethe fürender serblscher, kroatischer und sloventscher Persönlichkelten fur elne gemelnsame Literatursprache entschied.

Obwohl die Zahl der Gegner Karadzits allmhhlich zurückging, blieb das 1832 fur Serbien erlassene Verbot selner Rechtschrelbung bekanntlich b1s 1859/b0 bestehen (noch in den 50er Jahren wurden slavenoserbische Schulfibeln gedruckt). Erst 1868 wurde die Orthographie Karadżte in Serbien und in der vojrodina allgemein elngefunrt.

Hel den Kroaten stellte sich das Problem der Literatursprache anders dar als bel den serben; auch hier ging es zwar um das Zuruckdrängen von Fremdelnflussen, doch rührten diese nicht aus elner slavlschen Kunstsprache her, sondern unittelbar aus der kulturelien vominanz anderer, nichtslavischer völker. Unter dem deutschen kulturelien Elnflub standen fast alle Anhanger der 111 yrischen Bewegung, und selbst zu der klteren kajkavischen Literatur ihrer engeren Helmat hatten ste weniger beziehunp als zur deutschen; d1e Dubrovniker Dichter wurden erst langsam von ihnen "entdeckt".

Das Problem der Orthographle hatte Gaj schon 1830 in Angriff genommen, wobel er aber, Im Gegensatz zu Vuk, die etymologische Schrelbwelse belzubehalten bestrebt war. Als der Kreis der Illyrer 1836 den gtokavischen Dialekt zur Literatursprache whilte, waren zwar alle uberzeugt, nichts Free'A.Belit: Vukova borba za naradn1 1 knjlzern1 jezik.Bgd. 1948 Lj.Jonke: Knjlževni jezik u teorij1 1 praks1. Zagreb 1966. 
doo $2 u$ libernehmen, dennoch aber bedeutete dieser Entschlub für sie elne betrachtliche Erschwerung lhrer elgenen literarischen Tatigkeit.

Trotz der bereits in den 3ner Jahren bestehenden Knntakte mit Karadžlt whlte der erste Grammatiker der Illyrer, vjokoslav Babukit, für die "1llyrische" Sprache nicht den von Vuk propagierten neuétokavischen, sondern elnen blteren Sprachtypus als Grundlage; diesen Typus hielt man für allgemeiner und für die sprachliche Elnhelt aller sudslaven angemessener.

Nachdem die bsterrelchische Heglerung den Namen "Illyrer" aus politischen Grunden 1843 verboten und das Jahr 1848 eine Einschrankung des 111 yrischen Programm mit sich gebracht hatte $(49,5.62)$, kam es $185 n$ zu der achon erwahnten Vereinbarung von Nien, in der es u.a. hieß:

Da wir wissen, dals ein Volk elne literatur haben muls und demzufolpe mit Bedauern sehen, wie aufgesplittert unsere Literatur 1st, nicht nur in bezug auf das Alphabet, sondern auch auf Sprache und Orthographie, sind wir dieser Tage zusammengekommen, um zu besprechen, wle wir uns in der literatur verstandigen und vereinigen könnten, so weit es vorerst irgend möglich $18 \mathrm{t}$. Und so haben wir einstimmig anerkannt, dais es keinen Sinn hat, durch Vermischung der Dialekte einen neuen zu schaffen, den es im volk nicht fibt, sondern das es besser lot, elnen der volksdialekte zur literatursprache zu wahlen...

...elnstimmig haben wir anerkannt, dals es am richtigsten und am besten ist, den südlichen lialekt als den der Literatur zu bestimmen...

Wenn Gott es glbt und diese unsere Gedanken auch von der Bevölkerung akzeptiert werden, sind wir uberzeugt, dals sich die groben verwirrungen unserer literatur beseitigen lassen und dals wir uns der wirklichen Einhelt um vieles nahern werden. Daher bitten wir alle Schriftsteller, die lhrem Volk wirklich Gluck und Fortschritt winschen, auf diese unsere Gedanken einzugehen und dementsprechend ihre werke zu schrelben... (zitiert nach $127,5.246$ )

JONKE schrelbt hierzu:

la die ersteren(adie Illyrer) mit Ihren ideologischen Konzeptionen $1 \mathrm{~m}$ Jahre 1843 und 1848 einen bedeutenden Ruckschlag erlitten hatten, war es kein vunder, dab Karadžlt in Wien den Sieg davontrug. $(49,5.02)$

Damit bezieht sich JoNkr vor allem auf die Annahme der neutokavischen Pluralformen, auf die Schrelbung des alten 
als 1 je/je und auf die Beauftragung Karadžlts mit der Ausarbeltung der Grundregeln für die Schriftsprache.

Dennoch stellt dan Jahr 1850 keinen Wendepunkt dar, von dem an sich die serblsche und die kroatische Literatursprache gemeinsam im Sinne Karadżls entwickelt hatten, wie es sich die Unterzelchner der Vereinbarung erhofft hat ten.

Whrend sich in Serbien anstelle der 1 je/je-kavischen die ostserb1sche e-kavische Variante durchsetzte, wandte sich In Kroatien der sputere Fihrer der "Pravaśl" Ante starčevit ebenfalls gegen die Beschlusse von 1850. Die sprachlichen Neuschöpfungen Ivan Trnsk1s, der durch selne Gedichtbande "Kriesnice" I/II(1863/05) popular wurde, schufen Verwirrung (116,5.153) unter der kroatischen leserschaft, die gerade die Germanisierungsperlode der 50er Jahre erlebt hatte. Auf die "unwahrscheinliche Elgenwilligkelt seines kroatischen lyrischen Vokabulars" welst SKREB hin:

Trnskl verblegt, schneldert und schmiedet sein "lyrisches" Vokabular ohne jede Hemmung. (116,5.169) Zwischen Karadzit und dem bedeutenden kroatischen lexikographen Šulek kam es wegen Vuks Aufsatz "Srb1 svi 1 ovuda" ("KuvČř̌̌ićn 1849) zu Differenzen, da šulek in diesem Artikel die Integritat der kroatischen Nation angegriffen sah. Auch zwischen fuhrenden kroatischen Literaten entstanden Sprachstreltipkelten (Frane Kurelac und Ad.veber-Tkalčevit).

Selbstverstandlich darf man neben diesen verwirrenden Erscheinungen die auserordentlichen Lelstungen nicht ubersehen, die gerade für die Fundierung der schriftsprache vollbracht wurden. Hierzu gehören Danic̈lts"Rat za srpaki jezik 1 pravop1s"(1847), die von Antun Mažranit und Tkal Cevit herausgegebenen Grammatiken, die Wörterbucher von Mažurante/Użarevit (1842) und vor allem von Sulek (1859,1874) ebenso wie die Bemuihungen der"Matica serbska" (se1t 1826) und der "Matica hrvatska" (se1t 1842, zuerst"Matica 111rskan) und des "nruštvo serbske slovesnost1" (se1t 1841, spater, ab 1864, "Srpsko učeno druśtro").

Welche ganz konkreten Schwierigkeiten sich berelts bald nach der viener Vereinbarung ergaben, zelgte die Arbelt an dem 1853 in Wien gedruckten Werk "Jurid1sch-pol1t1sche Terminologie für die slavischen sprachen Österreichs. Deutsch- 
-kroatische, -serbische und -slovenische separatausabe", an der auch Karadzit und Demeter beteiligt waren. Demeter, der schon frib zu den Verehrern Vuks zahlte, stellte in Vorwort zu diesem Buch fest, dab sich die serbische und kroatische Terminologie nicht volikommen in Einklang bringen lasse:

Die serbischen Schriftsteller haben slch bereits so sehr an einige kirchliche und russische Ausdricke gewöhnt, daB man befurchten mulste, elnstwellen noch auf au groben Widerstand zu stoßen, wenn man sie ganz beseltigt hatte; andererselts konnte man sie, da ste dem Gelst der lebendlgen Jugoslavischen Sprache vollkommen entgegengesetzt sind, nicht in den kroatischen Dialekt aufnehmen, der erst in neuerer Zeit zur Schriftsprache erhoben worden lst und sich daher weltgehend in selner urspringlichen, volkstumlichen Schlichtheit erhalten hat. (128.5.247).

Vatroslav Jagit setzte sich 1864 ausdrucklich für de Schriftsprache und Rechtschrelbung in der von Karadżlt und Daničit erarbelteten Form ein ("Nar pravopis"). Nach der Grilndung der Akademie in Zagreb 1867 entfalteten hier junge Gelehrte der Vukschen Schule ihre Tatigkeit; der erste Herausgeber des Akademie-wörterbuchs der kroatischen und serbischen sprache war Pure Danicit. Der Neuentwurf Ivan Broz' einer phonetischen kroatischen Rechtschreibunf(1892) und Tomo Maretits "Gramatika 1 stilistika hrvatskoga 111 srpskoga književnog jezika" (1899) stellten - nach JONKE - "den endgiltigen Sieg der schriftsprache Karadžlts iber den kntwurf Gajs dar" (4y,S.60).

Unter diesen schwierigen Bedinfungen vollzop sich parallel mit der Schaffung literatursprachlicher Normen die Entwick- . lung der Jungen literaturen. Obwohl hinsichtlich der Sprache bis zum Finde des 19.Jahrhunderts elne gemelnsame Basis errelcht war, verlief die gesamte Entwicklung bel serben und Kroaten trotz Uberschneldungen und gegenseitiger Ubernahmen infolge buberer Umstande und Tendenzen so unterschiedilch, dals sich sowohl die Literatursprache als auch die Literatur heute in zwei Varianten, der kroatischen und der serbischen, darstellen. 


\section{II.3. In Vordergrund: auBerliterar1sche Funktionen}

Wie bel anderen kleineren Nationen ruhrten die Impulse zur Entwlcklung der neueren Literaturen der serben und Kroaten aus gesanteuropulschen strbmungen her, die das allakhliche Mundigwerden der volker anzelgen. Da all diese Bestrebungen primbr auf politische und soziale Verunderuncen, dh. Verbesserungen abzielen, tehen auberliterarische Funktionen be 1 den neuen Literaturen zunkchet in Vordergrund.

Aus der Vernunftgluublekelt, die elch whrend des $18 . \mathrm{Jahr}-$ hunderts durchsetzte, resultierte die Auffaseung von der Literatur als Mittel zur Hebung der Moral und zur Bekampung von Unwisenhe1t und Aberglauben; daher rihrte die haufige Uberbewertung ihrer didaktiochen vor ihren kunstlerischen Qualituten. Diese Elnstellung hielt $1 \mathrm{ch}$ gerade bel den Sudolaven b1s we1t uber die M1t te des 19.Jahrhunderts, wie vie10 Stellungnahmen zur z1eletzung der Literatur zeigen, angefangen von den fruhen äuberungen Karadžlte und den Aufrufen der Illyrer ble zu den formulierungen der serblochen und kroatischen "Vukovci" der 70er Jahre oder auch Senoas, der d1e Blidung des elnfachen Mannes zu den wichtigsten Aufgaben der Literatur zahlt(109,S.139). Senoas Novelien elnd, wie FLAKF, sagt, "1mmer noch belastet mit elner geradezu aurklurerischen Didakt1k" $(32, \mathrm{~S} \cdot 10)$. D1e 1 mmer wieder betonte Idee von Schriftetelier als Lehrer des Volkes let die Triebfeder der literariochen Akt1vitut einer Anzahl von Autoren, d1e nicht persónliches Ausdruckestreben, sondern Rflichtgefuhl dew Volk gegenuber dazu drangt. Den rowantiochen Gedanken vom Dichter als "auserwhitem Musensohn" greifen nur olnige aur, z.B.Stanko Vraz und Laza Kostit.

A18 weitere bestimende auberliterarische Punktion der L1teratur erschelnt 1hre Aufgabe zur verbreltung des nationalen Gedankens. Ausgehend vom Volksbegriff Herders, entetent die Idealvorsteliung vom Nationalstan wit ethnisch elnheltlicher Bevblkerung und elner elnzigen Landeseprache, die die Mutteroprache aller Elnwohner $18 \mathrm{t}$; damit wird gerade 10 vielvblkerstaat österrelch-Ungarn jede Unterdrückung nat1onaler Lebenstuberung noch ochmerzlicher empfunden als bisher und ruft umso heftigere Reaktionen hervor. In den vorherge- 
henden Jahrhunderten spielen relifiöse und soziale Gegensatze elne viel gröbere Rolle als nationale; dort, wo nun relifiöse Vorelngenommenhelt und lns Bewuibsein gehobenes Nationalfefül mitelnander verschmelzen, erfahrt dieses eine besondere Potenzierung.

Auch der panslavische Gedanke, von Kollár in seiner Gedichtsammlung "Slávy dceray 1824 bzw.1832) kilnstlerisch gestaltet, wirkt als auberliterarischer Faktor auf die entstehenden Literaturen ein und gibt zu der ursprunglichen weitrámigen 1llyrischen Konzeption AnlaB. Panslavisches Denken spiegelt sich auch z.B. In den Worten des ersten Redakteurs des "Serbskij letopiso", Uoref Magarakevit, der den Aufgabenberelch deg "l,ftopist" so umreibt:
Alles, was lmmer das slavische Volk vom Adriatischen bis zum Elsmeer, und vom Baltischen bls zum Schwarzen Meer allgemein betrifft, und insbesondere uns Serben, und zwar in literarischer Hinsicht - all das ist Ge- genstand des Serbskij létopiso.
(zitiert nach $127,5.322$ ).

Vie Unmöflichkelt eliner politischen kealisierung des panslavischen Gedankens liels die von Kollar und $\zeta$ túr ausgeganpenen Anregungen in elner stärkung des spezifischen Nationalbewulstseins - sowohl bel den Serben wie bel den Kroaten eluminden. Der vandel der schlafworte bel den serben macht dies hesonders anschaulich:

Vor 1848 nennen sich die Serben, in den Ideen ihrer unmit telbaren Lehrer Jan Kollar und I,judevit Stúr befanpen. "Slaven" (slavjani) und traumen von elnem "Grobslavien"(Velika Slavija) und elnem "Slavischen Keich". doch auch das Gefiul des Serbentums und das Ideal vom "serbischen Wesen" sind immer stark; 1848 ist der Höhepunkt slavischen Emptindens bei den Serben; danach wird dieses schwlicher, aber das ausschlieislich serbische Nationalgefühl verstärkt $s 1 \mathrm{ch}$.

(Fewib ist das slavische Empfinden bel den Serben auch später stark; dies zelfte sich anläilch des Krimkrieges, der slavischen ethnographischen Ausstellung in Moskau (1867); davon zeugen die bruderlichen Bande zur russischen Jugend, die Zusammenarbelt mit den bulgarischen Emieraiten und den kroatischen und slovenischen Patrioten, aber trotz alledem herrscht doch das vor, was Stúr bitter "egolstischen Patrintismus" genannt hat. An die Stelle des Ideals vom "Slavischen Relch" tritt das Ideal des "Zarenrelchs Dułans" (Duśanovo carstro). und aus dem Panslavismus der 40er Jahre entsteht der enfere serbische National 1smus. (103,S.221) 
Das - zungchst bekanntich auf ein politisches verbot zurückgehende - Verschwinden der Bezelchnung "111rek1" dokumentiert die analoge Erschelnung bel den Kroaten.

D1e Ausblidung des Nationalbewulstelns entspricht der al1gemelnen europalschen Entw1cklung des 19.Jahrhunderts, die durch zahlrelche Aufstunde, die italienische und die deutsche Statsgründung und die Entstehung der Nationalstaten auf dem Balkan charakterisiert 1st. Die Literatur ordnet sich politischen zielen unter und wird als elnes der Mittel zu lhrer Errelchung verstanden. Uberall dort, wo das Problem der Literatursprache noch zu lösen 1st, stehen auch diese Bemulungen unter pol1tischem Vorzelchen wie bet den serben und Kroaten, und uberail ist der Ruckgriff auf die mund11che Uberlieferung elner der vege zur nationalen selbstbesinnung. wie z.B. bel den Pinnen und Esten im zaristischen RuBl and.

Fur die jungen literaturen der Serben und Kroaten ergibt sich aus den Notwendigkelten des historischen Augenblicks jene Uberbetonung des Nationalen, die elne Gegenuberstellung von nicht verglelchbaren Begriffen wie "umjetnost" (Kunst) und "narodnost" (Volkhaftigkelt) möglich macht und zu verturtellen nach auberliterarischen Gesichtspunkten fürt. 


\section{II.4. Das Problem der Leserschaft.}

Neben diesen auberliterarischen Funktionen, die die serbische und kroatische literatur in ihren Anfangen zu erfilien hatte und die daher ihren Charakter bestimmten, und neben der Schwierigke1t des Sprachproblems gab es elnen welteren Faktor, der s1ch auswirkte: die Notwend1gke1t, d1e Leserschaft an d1e L1teratur heranzufuhren. Diese Leserschaft war te1lwe1se berelts vorhanden in den mehr oder wenlger geblldeten Krelsen der öterrelchischen serben und des kroatischen Klerus und Adels, sie war aber melst auf auslandische und anfangs sogar noch auf slavenoserbische literatur elngestellt. Ihr mubte man etwas äquivalentes bieten. In den Krelsen des sich langsam bildenden M1telstandes buuerlicher Herkunft und unter der Landbevblkerung konnte man elne Leserschaft erst mit zunehmendem B1ldungsetand "anwerben". Es war daher nicht 1mmer d1e Fixierung auf bestimmte auberliterar1sche z1ele oder die Ubernahme herrschender Moden, sondern auch der standige Blick auf den potenziellen Leser, der die Schriftsteller zu Konzessionen veranlabte und thre Anspruche an thr Werk niedrig hielt.

Bel den Bemiihungen um elne national orlentierte, nationalsprachige Literatur ging es den Schriftstellern auch nicht primar darum, originale Werke zu schaffen. Hierfür epricht d1e umfangre1che Ubersetzungeliteratur, mit der ubrigens schon die savenoserbischen Schriftsteller angefangen hat ten. Von Vidakovits Romanen, die das serbische Leserpublikum entscheldend vergrbBerten, waren die ersten direkte Ubersetzungen, d1e skteren Bearbeltungen auslandischer Werke. Für d1e $111 y-$ rlsche Bewegung 1st es charakteristisch, dab sie besonders Ubersetzungen Schlllerscher Gedichte schatzte, In denen der Gedanke der Freihe1t zum Ausdruck kommt und die damit der Forderung des nationalen Freiheltsgedankens dienen konnten, wahrend d1e Gedichte der Romantiker, auf deren Konzeptionen Ihre Bewegung beruhte, verhaltnismbig wentg ubersetzt wurden. Hierin, wie in vielew anderen, zelgt sich das literarische Zweckdenken der Zelt: es ging nicht um die Kultivierung bsthetischer Empfindungen, sondern un die Mob1lisierung des nationalen Bewubtseins. 
In der Novellistik surt man neben dem nationalen Engagement und der moralielerenden Tendene mit aller Deutlichke1t die Anpasoung an den romantioch-sentimentalen Geschmack des Publikuas. Un d1e Mitte des Jahrhunderte, nachden elch eowohl bel den Serben wie bel den Kroaten e1ne etwae eturkere Sch1cht des Mitteletandes ontwickelt hatte, wandten eich elnige Schriftsteller ausdrucklich an die weibliche Loserechaft, von deren Einflub auf die heranwachsende Jugend wan viel erwartete. Bogobo Atanackorif nannte selne belden Norellenbunde "Daraks Srbk1no1", und in don Schriften der Illyrer und Splililyrer eohrten elch di Aufrorderungen an die "kroatiochen und savoniechen Schbnhelten" sur Pfiege der Muttereprache, womlt auch das lesen in dieser Sprache gemeint war. D10 emprohlenen Erauhlungen folgten nelet den Kllechees der deutschen Unterhaltungsilteratur. Hinter dem Aufgrelfon der dörflichen Thenatik sand nicht nur der Wunsch, das Milleu der Erzuhlung den elnes landlichen Lesers anzugle1chen, ondern auch der Vereuch, in der elgenen Sprache etwae anzubleten, was den in Deutechland in Mode gokommenen Dorfgeochichton enteprach (Auerbachs orfolgrelche "Schwarzwalder Dorfgeschichten" erschienen in vier Banden zwischen 1843 und 1853).

D1. L1teratur wurde inebesondere in Form von Almanachen, Zeitschriften und Zeltungsbeliagen an die Leserechaft herangetragen. Der zunehmende Bedarf an Buchern luBt sich an den Auflageziffern und an der Zahl der Neuerschelnungen ablesen. Un 1830 gab os schon Auflageziffern b1s zu 4000, whrend diese Ende des 18.Jahr hunderte 1m Durchechn1tt nur 200 b1s 300 betrugen; die 2 ahl der Neuerscheinungen belief elch zwlechen 1800 und 1820 auf ca.19, zwischen 1830 und 1850 auf ca.45 pro Jahr (d1es gilt für die serbische Literatur; Vgl.103,S.139). Da es z.B. In Serbien erst ab den 30er Jahren Buchhandlungen gab, erfolgte der Vertrieb luber Vorbestellung bel den Hundlern in Wien, Pest, Venedig eta.; taradžlf beklagte elch 1833 bltter uber dieses syeten der "prenumeracija"; als Autor brauchte or die Hilfe Wohlgesinntar, die fur lbn Bestellungen sammelten. Dieses System bl1eb noch lange bestohen, nachder lungst Buchhandlungen existierten. Auch an Hand dieser Vorbestellungen, deren Zahl naturlich nlcht der Endverkaufsziffer entepricht, kann man sich oln reletives Bild von der Lesersahl machen; so fanden elch für Karadżles "Srpeke narod 
priporijetke" von 1832 ca. 70 vorbeteller, und dies war fur d1e damal1ge Ze1t elne beacht11che Zahl'.

Selbstrerstandlich geben solche Zahlen nur eln sehr unrollstund1ges Bild, weil hier z.B. d1e Lesersahl der in den $400 r$ Jahren in den groberen Studten gegrundeten "narodne čitaonice" nicht berucksichtigt wird und woll damit nichts uber die Verbreltung von 201 tungen und Zeltschriften, In denen die 11 terarischen Erzeugniseo verstreut waren, oder uber d1e wosersahl der Kalender ausesagt lot. Hber die Qualitut dieser Kalender haben sich ubrigens Jurkorlt und Senoa vernichtend gekuBert ("Nał1 kalendar1", 1862; "Nała knj1ževnost", 1865).

Dafur, daß die Zahl der literarisch Interesierten noch in den 60er Jahren nicht grob war, spricht die auf Abonnentenmangel zuruckgehende Kurzlebigke1t der meisten literarischen Ze1tschriften dieses Zeltraumes, wenn auch die Zahl der Neugríndungen auf elne bewundernswerte Aktivitut des kleinen Kre1ses der Literaten hinwelst. So gab es z.B. an kroatischen Ze1tschriften: 1861-1866 "NAŠE GORE IIST"; 1861-1865 "GLASONOŠ "; 1867-1868 "DRAGOLJUB"; 1864-1866 "KNJIŽEVNIK"(m1t w18senschaftlicher Orientierung von Vatrosiav Jagit herausgegeben). D1e "DANICA" und Vraz" Grundung "KOLo" hatten zu Bepinn der 50er Jahre 1hr Erecheinen eingestellt; "NEVFN" hielt sich von 1852-1858. Von serbischen literarischen zeltschriften beien genannt: "DANICA", 1860-1871; "JAVOK", 1862-1863, "MATICA", 1865-1870, "VILA", 1865-1868 und d1e sat1rischen Blatter "KOMARAC" 1861-1869 und "ZMAJ", 1864-1871. Erst d1e langere Lobensdauer der Ze1tschriften "VIJENAC",1869-1y03, (Zagreb) und "OrabžBINA", 1875-1876 und 1880-1892, (Beograd), der belden wicht1geten 11terarischen Zeltschriften gegen Ende des Jahrhunderts, bestut1gt das zunehmende Interesse elnes groberen Pubilkums an der Literatur.

'Branko Magará̌evit: Narodne pripovijetke.Zagreb 1951, "Pogovor", S.26n. 
II.5. Theoret $18 \mathrm{che}$ Forderungen an die jungen Literaturen.

I. S.1. Serben.

II.5.1.1. Vuk Stefanovit $K$ a $r$ a d ̌̌ 1 t $(1787-1864)$

Wo 1 mer. wie in der vorliegenden Arbelt, die Frage nach den Elementen der Volksdichtung in der frühen serbischen oder kroat1schen Literatur des $19 . J a h r h u n d e r t s$ gestellt wird, mub thre Beantwortung mit der Erwahnung des Namens Vuk Stefanovit Karadžlt beginnen. Die Ausfuhrungen zum Sprachproblem unter II.2. haben berelts gezelgt, welch aulserordentliche Bedeutung die w1rksamkelt Karadżle für die Formung der Schriftsprache gehabt hat; da diese das Instrument der Literatur 1st, steht der Name Karadżts auch hier am Beginn der Entwicklung.

Obwohl sich Karadžlt ketneswegs von Anfang an uber den Umfang der von thm in Angriff genommenen Aufgaben klar war, an die thn Kopitar herangefuhrt hatte, war die Gesamtrichtung setner Bemilhungen von vornherein national bestimat. Karadzit war Im wahren Sinne des Wortes ein Mann aus dem Volke, ein Bauprnsohn, der die Sprache und die Lebensgewohnhelten der Dorfbevölkerung Serbiens kannte; er hatte den ersten Aufstand als Schrelber mitgemacht und hatte 181.3 - obwohl berefts 1e1dend - an den Kämpfen gegen die Türken tellgenommen. Die Begegnung mit Kopitar in Wien ( 1.813 ) vermittelte 1hm die romantische Auffassung vom Volk als Ursprung des Echten, Unverbildeten und gab den Anstob zur Bescháftgung mit der volksiberlieferung, zu der er elne lebendige Bezlehung hatte; Ihre Bedeutung für die kulturelle Entw1cklung Serbiens - als historisches Erbe und Ausdruck nattonaler Elgenstädigkelt, ols sprachliches Vorblld und als Ausgangspunkt der neuen Literatur - erkannte er erst im Laufe der Jahre in vollem Unfang. we selne eigenen Äuberungen zelgen.

Karadžıts erste Sammlung ("Mala prostonarodbna slavenoserbska pesnarıa", 1814) enthielt 100 lyrische ("ženskih") und 6 epische("muškıh") Lleder att nicht ganz einwandfrel volkseprachI1chen und tellweise uberarbelteten Texten (103.S.245); Vuk selbst sagte hieriber 1842: 
-..jenen Wert unserer Volkslieder, den Grimm und Goethe und Kopitar in thren fanden und von dem ole der Welt berichteten, habe ich noch nicht einmal erkannt, als $1 \mathrm{ch}$ das erste Buchlein drucken l1eB..."

(z1tiert nach 103,5245).

Die zwe 1te Sammlung ("Narodna srbska pěsnarica",1815) enthielt neben unveränderten Aufzelchnungen von Liedern der volkssanger Filip višnjit und Tésan Podrugovit auch einige "von gebildeten Lewten verfalite" Lieder, doch war hier die Sprache bereits viel unverfalschter als in der ersten Sammlung, so dab sie als das erste Werk in reiner serbischer Volkssprache gilt(103,5.246).

Je mehr sich der gelstige Horizont Karadźlts weitete und Je deutlicher er seine ziele ins Auge fabte, umso ausgepräter wurde die nationale Komponente in seiner gesamten Tatipkeit. Die Widerstande gegen selne keform der sprache und der orthographie seltens der Kirche, des serbischen staates und der Schriftsteller, welche in slavenoserbischer sprache schrieben, bewirkten, das er seinen standpunkt standig uberprufen und dabel zu umso präziserer Elnsicht knmen mulste. Dem oft wiederholten Vorwurf mangelhafter Ausdrucksfähigkelt der Volkssprache begegnete er nicht nur mit der umfangreichen Arbeit des "Srpsk1 rječnik" (1.818, vervollstandigte Ausgabe unter Finbeziehung von Wörtern aus Montenegro, Dalmatien, Kroatien und auch aus Altserbien $7^{2}$, sondern auch mit der Ubbersetzung des Neuen Testaments, deren erste Fassung bereits 1820 als Handschrift vorlag ${ }^{1}$, die aber erst 1847, von vuk erneut uberarbeltet, In threm volien Umfang in Wien gedruckt wurde.

Die Widerstände, mit denen Karadżt zu kämpfen hatte, trugen u.a. dazu bel, dals der Gesamtkomplex seiner Reformen umso enger mit der Beschäftigung mit der miindlichen Uberlieferung verschmolz, denn das Festhalten an der slavenoserbischen

1 Atanasije stojkovit, der ein verfechter der slavenoserbischen literatursprache war und dem Karadžits Text zur Beurtellung vorgelegt wurde, lehnte die Ubersetzung ab und erbot sich, selbst eine neue anzufertigen. Sein Text, der nichts als eine - teliweise sogar sinnentstellende - Uberarbeltung der Ubersetzung Karadzits im Sinne der "alten" Sprache darstellte, wurde 1824 in St.Petersburg gedruckt, der vertrieb aber bald untersagt, nachdem man selne Qualitat uberpruft hatte. - Im glelchen Jahr wurde Karadžlts Text teilweise in Leipzig unter dem Titel "Ogledi Svetog Pisma na srpskom jeziku" abgedruckt. 
Literatursprache seitens vieler Schriftsteller bis in die 4 Oer Jahre hinein verwies Vuk unmittelbar auf die einzige lebendige Dichtung, die sich der Volkssprache bediente. Die Idee der Romantik, die dichterischen Schbpfungen des "unverdorbenen" Volkes aufzuspüren und zu sammeln, verband sich für Vuk mit einer ganz konkreten Notwendigkeit, namlich der einer brauchbaren, allgemeln verstandlichen, lebendigen Sprache, die elne echte Alternative zur slavenoserbischen Sprache der auf einen ganz kleinen Krels beschränkten serbischen Literatur bieten mulste. Da man zudem mehr und mehr in der sprache eines der wichtigsten, wenn nicht das wichtigste Kennzeichen nationaler Elgenständigkelt erkannte, deren sich die Völker während des 19. Jahrhunderts allmălich bewulb wurden, war jede Bemiihung in dieser Richtung ohnehin uberall national geprägt - und naturlich ganz besonders bel vilkern, die von anderen beherrscht, durch staatsgrenzen auselnandergerissen waren. Da sich In Serbien die Volkssprache besonders augenfallig in eplschen Liedern manifestierte, deren Thema die elgene glanzvolle Vergangenheit war, war jede Beschăftigung mit dieser Epik eln Beitrag zur Verbreitung des nationalen Gedankens.

Karadžlts Liedersammlungen waren denn auch der wichtigste Anknipfungspunkt der 11 lyrischen Bewegung an sein Gesamtwerk, da in thenen eben nicht nur der zur Schriftsprache bestimmte stokavische Dialekt, sondern auch der Geist des volkes, die nationale Idee realislert waren. Fin Dichter vom Range des "Spät-Illyrers" Preradovit wählte mit Selbstverstiindlichkelt den serbischen Helden Kraljevit Marko als zentrale Figur einer seiner Dichtungen. Die bereits selt den $30 e r$ Jahren bestehenden Knntakte Vuks mit Persönlichkelten der lliyrischen Bewegung wie Gaj, Vraz, Demeter, Brlit, den Brüdern Mažuranit und anderen fuhrten schließlich - trotz gelegentlicher polemiken zwischen elnzelnen Illyrern und Vuk (Šulek!) - zu der Vereinbarung von Wien (1850), die als ziel ausdrucklich eine gemeinsame, nationale Literatur in elner gemeinsamen sprache deklarierte. 
Dragiša ŽIVknvić hat in selner umfangreichen studie "Počecl srpske književne kritiken" (128) darauf hingewiesen, dals Vuk sich auch in seinen Kritiken an den Romanen Vidakovits aus den Jahren 1815 und 1817 - wie in seinen polemischen Schriften - hauptsächlich $\mathrm{mlt}$ dem Sprachproblem auselnandergesetzt hat, das ja neben der Orthographie sein Hauptanliegen war. Das gleiche gilt für selne nicht veröffentlichte Kritik an der Ode Mứlckis "Glas Narodoljubca", die In einem Brief an Mušlcki enthalten 1st (aus dem Jahre 1820). In diesem Brlef erklärt Karadžlt ausdrücklich:

Ich werde mehr die sache und die Sprache rezensieren aber in die Poesie werde lch mich nicht einmischen'.

Lob und Beurtellung der rein dichterischen Werte musse er anderen leuten iberlassen, die darin geschickter seien und sich selbst damit beschätigten ${ }^{2}$.

ŽIVkoví́ betont, dals Vuks literarische Kritiken als Tell se1nes Kampfes um Sprache und Orthographie anzusehen seien, daB Vuk aber nicht als Vorlaufer der positivistischen, philologischhistorischen Literaturkritik gelten könne, da es ihm selbst zu einem so fruhen zeitpunkt neben der Sprache auch um die "Sache", d.h. um Idee und Inhalt elnes Werkes gegangen se1, wenneleich kaum um die Komposition, die aber bis heute zum schwierigsten Geblet der Kritik gehöre(128,s.66,5.70; s.77/78). Wichtig ist, dals die Kritik Vuks auber der sprache auch die Inkonsequenz der Charaktere, die mangelnde psycholngische Motivation, die verfalschende Darstellung des serbischen Volkslebens und der Geschichte in den Romanen Vidakovits betraf(128, .79). Mit diesen Vorwurfen nahm Karadzit ubrigens die ca.50 Jahre später geaußerte Kritik Śenoas an den Novellen seiner Epoche vorweg("Naza knj1zevnost",109,5.137-146).

Die Intoleranz Vuks gegenuber den sprachlichen Mangein der Romane Vidakovits lieB Ihn gewisse Vorzuge ubersehen und hat zur Folge, dals seine stellungnahmen nicht in winschenswerter He1se bereits während der Anfange seiner Aktivitat wirksam werden konnten, obwohl nach ŽIVKovIĆ kein späterer serbischer Kritiker

1 Skupljenl gramat1čki 1 polemičkl spisi I, S.115-116;

2 Skuplent gramatitk1 1 polemičk1 sp1s1 IV,S.40;

(be1de Z1tate nach 128,S.70/71). 
bis In die 50er Jahre hinein so viele Aspekte eines Werkes erfabte.

Wie lange es gedauert hat, bis sich die Reformen Vuks allgemein durchsetzten, ist bekannt; A.BELIĆ bezelchnet bereits das Jahr 1839 als das Jahr des Steges( $12, \mathrm{~S} .62)$, die saat11 che Anerkennung erfolgte aber erst in den 60er Jahren.

Immerhin konnte zumindest die herangewacheene jungere schriftstellergeneration an den Problem der Sprachreform und einer persönlichen Stellungnahme zur Volkspoes1e nlcht wohr vorbelgehen, Inshesondere seit der Polemik zwischen Karadzit und selnem friheren Anhanger Jovan Hadžıt (M1loł Svetil), die sich uber die Jahre 1837-1847 hinzog.

Obwohl sich Karadžits kînstlerisches Gefuhl, wie ŽIvxović sagt, "an der elnzigen belletristischen Lektüre, die er gelesen hatte dem Volkslied und der Volkserzahlung" (128,S.78) ausgeblldet hatte, blieb er in seinen Forderungen an die Literatur nicht dabel stehen. Nachahmungen der Volksdichtung zu verlangen, wennglelch diese oft das elnzige Ergebnis der literarischen Bemilhungen selner Anhänger blieben. Vuk, der in der deutschorientierten Blidung der österrelchischen Serben die Gefahr der Entfremdung vom Serbentum erkannte, In der Volksuberlieferung aber jenen Kraftquell $\mathrm{sah}$, an der das Nationalbewultseln erstarken konnte, richtete seine Hoffnung auf elnen kunftigen Dichter, der thre Gesetze erfassen und aus lhrem Gelst heraus neue Dichtungen schaffen werde:

..dann wird sich einer finden, den Gott mit der Gabe der Dichtkunst beschenkt und dem er die Gelegenhelt gegeben hat, In latelnischer oder deutscher Sprache die GesetzmäBlgkelten all dessen zu erfassen; der wird all diese Sammlungen zusammenstellen und elngehend besprechen, und eInige Gedichte wird er auch selbst nach Geschmack und Art seines Volkes verfassen und so aus all diesen klelnen Sammlungen eIn grobes Ganzes gestalten'.

ŽIVkoví́ schrelbt zu diesem zitat:

So hat Vuk als erster die Bedeutung der volkspoesie fur die kunstlerische, nationale Poesie hervorgehoben. Zu dieser zeit steht or mit dieser Auffassung noch allein da; die lobenden Äuberungen liber unsere volkslieder koamen von Fremden (Grimm, Kopltar) und finden $81 \mathrm{ch} 1 \mathrm{n}$ verschledenen Besprechungen serblscher Volkslleder in auslandischen Zeltungen und Zeitschriften. Die serbischen

1 srpske narodne pesme $I^{4}$ S.V-VI; zitiert nach 128,5.72. 
Schriftsteller fassen die Volkslieder, hauptsachlich unter dem Elndruck dieses auslandischen Lobes, als einen "wertvolien nationalen Besitz" auf, auf den die Serben stolz sein können, sind aber noch welt entfernt davon... das linnen diese "Blindenlieder" als Grundlage und als Vorbild beim kunstlerischen Schaffen dienen. $(128,5 \cdot 72)$.

Es muls aber 1 mmer wieder betont werden, daßs Karadzit, aus dessen Äußerungen stets seln Leltgedanke -"dem Volk zu dienen" - herausklingt, sein Ideal elner nationalen Lteratur nicht so eng fabte wie mancher spatere verfechter seiner Ideen. Dies zelgte sich z.B. anlaBlich der Polemik, die sich zu Beginn der $20 e r$ Jahre im Zusammenhang mit den Wieland- und Jung-Ubersetzungen Magarałevils entspann. In den von Magarałevil ausgewălten Texten'kam zum Ausdruck, daß der Schriftsteller sein Talent zur Erreichung der erhabenen ziele der Aufklarung und der Humanisierung der Menschen verwenden misse; zuglelch habe er $81 \mathrm{ch}$ um eine mïglichst grobe Vollkninmenheit seliles Werkes zu bemihen, um das dichterlsche Ideal zu erreichen.

In der sich an diesen Ubersetzungen entziindenden biskussion waren sich zwar alle Hetelligten darin einig, dab die Junge serbische literatur unbedingt gefördert werden musse, doch hielten elnige die von Wieland und Jung gesteliten Anspruche fü zu hoch fiir diese, "noch in den Kinderschuhen steckende" Literatur; solche Forderungen gälten nur fur berelts entwickelte Literaturen, wahrend sie den serbischen Schriftstellern nichts niitzten; diese könnten noch nicht nach "Volikommenhe1t" streben, und daher sel die kritik, insbesondere die negative, thr nur schädlich. Die serbischen Schriftsteller mübten schre1ben, so gut es eben ginge, wie ein Kind, das erst gehen lernt. Vuk vertrat demgegenuber die entgegengesetzte Auffassung: wennglelch die von Wieland und Jung vormulierten Postulate fur die serbischen Schriftsteller sehr hoch sien, könnten sle thm doch kelnesfalls schaden, da jeder schriftsteller, also auch der serbische, nach Vollkommenhelt selnes Werkes streben musse; sonst könne es der serblschen Literatur ergehen wie einem stammelnden Kind, das unter lauter stotternden eben fur $1 \mathrm{mmer}$

1 Magarałevit hatte von Wieland die Kap.XII und XIII aus "Meine Sympathien", von Jung ein an den Papst gerichtetes sendschre1ben zur Ubersetzung ausgewhit. (128,5.85) 
ein Stotterer bleibe. Um dies zu verhindern, sel die Kritlk notwiend1 6 , denn

den wahren Schriftsteller fuhren die Rezensenten...zu groberer Vollkowmenhelt: durch sie welb er, daB er vor der Helt fur jedes seiner Horte Rechenschaft ablegen nuB, und deshalb bemilht er sich bein Schreiben bel jeden Wort um Klarhe1t daruber. warup er es so und nicht anders niedergeschrieben hat...

Diese Betonung der Verantwortlichkelt des Schriftotellers. selner Verpflichtung, nach 1deeller und kingtierlacher vollkommenhe1t zu streben, zeigt, daB Vuk schon zu einem so fruhen Ze1tpunkt seiner gesamten W1rksamkelt von elner nationalen Literatur nicht - wie man thm vorwarf - eine Beschrankung auf den engen Krels des elgenen M111eus, elne blobe W1ederholung volkstiullcher Formen und Inhalte erwartete, sondern vielmehr die schopferische Verwirklichung serbischen Gelstes In werken, die allgemelnen kunstierischen Prinziplen folgten.

Vuks elgene Bearbeltungen von Volkserzahlungen bewelsen, dab er In der Volksilteratur das Ideal noch nicht verwirklicht sah. Er bemilhte stch, bel den Liedern vor allem durch Auswahl und Strelchung, bei den Erählungen durch st11181erung, Stre1chung und Ergánzung, aus dem relchen Fond der mündichen Uberlieferung Vorbilder. "Muster" für Poeste und Prosa zusammenzustellen. Die Betonung der Forderung nach elner Orientierung an der Volksdichtung ergibt sich einfach aus den Gegebenhelten der Zelt - der gesamteuropäischen romantischen Strömung. der zunächst völ11g ablehnenden Haltung der geblldeten Krelse Serbiens, aus der Reaktion auf die Ubbefremdungsgefahr etc. Gerade in seiner Polemik uber die Wieland- und Jung-Ubersetzungen forderte Vuk, dals die serbischen Autoren sich am Belspiel der besten europaischen Schriftstelier scliulen soliten. So hat, wie ŽIVKovIĆ sagt, gerade Vuk den Grundstein nicht nur zur "Nationalisterung", sondern auch zur "Europälsierurg"der serblschen Literatur gelegt, Indem or diese belden Prozesae $1 n$ elner schöpferischen, nationalen literarischen Wirkarkelt verknupfte. (128S.82).

Henn Vuks Vorstellung von elnem wirklich nationalen, dabel aber auch schöpferischen Dichter später in der Erscheinung 1 Gramat1čk1 1 polemickt sp1s1'II,S.98.

21 tert nach $28,5.89$. 
Branko Raditevits realisiert wurde, so bedeutete dies mehr als den Sieg der serbiechen Volkssprache in der Literatur; In dieser schrieben ja auch sterija, Nikanor Grujit, P.Popovit Sapčanin und andere. Brankos Gedichte aber bedeuteten die erste kunstlerische Verwirklichung serbischen Nationalgefüls. ŽIVkOVIĆ schrelbt:

Dies liegt daran, daß die sprache am küstlerischen Schaffen nicht als grammatische Kategorle, sondern als Ausdruck des Denkens und Pühlens des Volkes, als Ausdruck des Volksgelstes betelligt ist. Und Branko hat te sich diesen Volksgeist nicht einfach aus der Volksiprache an sich zu elgen gemacht, sondern aus der Volkssprache als Ausdrucksmittel unserer Volkslieder. In ihnen, In den Volksiledern und Volksdichtungen, die diese anderen Dichter geringer schatzten als die "gebildete" Poesie, entdeckte Branko den Geist des Volkes und machte ihr sich in seinen poetischen werken zu eigen.

$(128,5.69)$. 
II.5.1.2. Worde Ma 1 et 1 t (1816-1888)

Der Im Banat geborene Dorde Maletit war einer der ersten Theoretiker der serbischen Literatur des 19.Jahrhunderts. wahrend die gesamte Tatigkeit Karadzits durch die Begegnung mit Kopitar von Anfang an auf die Richtung der Romantik im Sinne Herders und Jakob Grimms festgelegt war, herrschten bel den gebildeten Serben In österrelch-Ungarn infolge des vom Josefinismus gepragten Schulsystems noch lange die strengen Dogmen der lateinisch-klassischen Poetik in Verbindung mit der didaktisch-utilitaristischen Auffassung der Aufklarung hinsichtilch der Aufgaben der Literatur. In diesem Gelst war auch Maletit aufgewachsen, und er behielt diese Grundkonzeption bel, obwohl er im Lauf der zeit mit der zunehmenden Verbreitung der deutschen Klassik deren theoretische Gedankenginge aufgriff. Maletits vèrdienst ist es, uberhaupt bsthetische Probleme angeschnitten und eine Reihe auslandischer Theorien wenigstens teliwelse dem serbischen publikum vermittelt zu haben.

Ausgehend vom Erziehungsoptimismus der Aufklirung und den formalen Prinzipien der alteren Rhetorik und Poetik, entwickelte sich Maletil zum elfrigsten Verbreiter der Idealistischen Ästhetik Schillers, dessen Grundgedinken er aber, wie D.KADACH(51, S. 143) feststellt, nie erfaßte. In dem von Hadźlt redieierten Almanach "G(ouHICA" veröffentilchte Maletit 1840 eine Teilibersetzung von Schillers "Zerstreuten Betrachtungen uber verschiedene ästhet1sche Gegenstände"(1793) unter dem Titel "Razlicha smatranja o raznim estetıčkim predmetima". In seinen Kritiken, z.B. der Gedichte Vukašin Radišils (1844) oder des von der Matica Srpska preisgekrönten Epos "Kralb Dečanskij" von Jnvan Subotit (1846), referierte er einige Gedanken Schillers. Źrvković sagt hierzu:

So wie Schiller die Kunst als eine Brücke betrachtet, die das Relch der naturlichen Botwendigkelt mit dem Reich des frelen menschilchen Wiliens verbindet, so sagt auch Malet1t, das die Kunst jener Tempel sei, in welchem sich unsere voneinander getrenten Krafte des Gefunls und des Gelstes durch die Gewalt der erhabenen Empfindune (d.h. der bsthetischen Empfindung) vereinen soliten... - wie Schiller fordert er, dab der Kiinstier den Menschen nicht in der Realitat, sondern in den Ideen suchen solle.. 
. wle Schiller sieht or das höchste ziel der Kunst in Hewrteffen der Realitat durch die Kunst. In der Schaffung elnes moralischen Ideals, nach dem die Menschen zu streben haben.

Aber auch hier wiederholt Maletit die enggefabte Forderung der rationalistischen Ästhetik: "In der Dichtkunst vermag die Vorstellungskraft allein nichts zu volibringen, wenn der Verstand sie nicht leitet".

$(128,5 \cdot 178 / 179)$.

Maletits wichtigste theoretische schriften sind: "Teorija poezije, 12 različni lzvora crpljeno"(beograd 1854) und "Ritorika" (Beograd 1855/56), die belde bis in die 7oer Jahre hinein als Schulbücher in Gebrauch blieben.

Maletit, der seinen theoretischen Prinziplen auch als nichter streng folgte, war ein typischer vertreter der "gelehrten" Poesie und der"Schule der objektiven tyrik", deren Grundatz es war, dals der Dichter nicht Gefihle, sondern Gedanken auszudrucken habe. Neben Gedichten verfalste er eine Reihe von Dramen, um das kargliche Repertolre der serbischen Theater zu bereichern. SKFKI.IĆ stellt zusammenfassend fest:

Maletit glaubte an das ideale schöne, an ewige und bestandige bsthetische Wahrheiten, an rhetorische Hegeln und Schablonen, und er war gepen jede Poesie, die nicht bisthetischen Regeln entsprach und nicht rational, reflektierend und objektiv war. $(103$, s. 196/197).

Im Rahmen der vorliegenden Arbeit interessiert selbstrerstandlich die Finstellung eines zu selner beit als Theoretiker wie als Dichter anerkannten Mannes wie Maletit zur volkspoesie. Obwohl Maletit - sowohl in setner Kritik an Subotits preisgekröntem Epos als auch an anderer stelle-einige positive Bemerkungen uber die Schönheit der eplschen lieder gemacht hat, unterscheldet sich seine grundsktzliche Einstellung hierzu wesentlich von der Karadžits oder auch subotits. Maletit hat sich nie die romantische Auffassung vom Volk als Trager besonderer ethischer und küstlerischer werte zu elgen gemacht, er sah im Volk auch nicht eine durch nationale Elgenart gepragte Gemelnschaft von urspringlicher Kraft, sondern vielmehr elne auf einer niedrigen sittlichen stufe stehende, rohe Masse, die der Dichter, der "Lehrer des Volkes" im Sinne Dositejs, formen und emporheben musse. Aus diesem Grunde knnnte er ach nie zu elner so hohen Elnschatzung der Volksdichtung gelangen, wie sie fiur vuk und seine Anhanger charakteristisch war und wie 
sle die Schriftsteliergeneration nach der Jahrhundertait te fast ausnahmslos Ubernahm. Da Maletit auBerdea auch auf die Volksdichtung die allgemelnen Regeln selner normativen ïsthet1k anwandte und s10 mit den schopfungen der besten Dichter verglich(Schlller, Shakespeare), kam er zu elner sehr vorsichtigen und elnschräkenden Bewertung.

Un Malet1ls Hal tung gegenuber der Volkspoesie su 1llustrieren, sel nachstehend ein zitat aus selner kritik an Subotits "Kral6 Decansk1 j" wiedergegebens

Unsere Volksl1eder können uns hier uberhaupt nicht als Richtilinie dienen. In thnen findet sich nur die simple Natur ohne jede Kunst, begrenztes Hisen und Frfahrung im bunten Gewand der Phantasie.

ŽIVKOVIĆ, dessen studie dieses zitat entnommen 1st, fügt hier hinzu:

Aber Phantasie 1st, nach Maletit, fur d1e Kunst "verderb$11 \mathrm{ch}^{n}$.

Das Z1tat lautet weiter:

Viele geblldete Leute haben thr Urtell uber unsere Volkslieder ausgesprochen, Indem sle diese von lhrer guten selte betrachteten, und andere haben, viellelcht aus Unfihigke1t, dieses Urtell als allgemelngultig ubernomen, so dab s 1e sie als Muster für alles ansahen, was die schone Kunst betrifft. Daher in letzter zelt so viele grobe Fehler infolge blinder Nachahmung.

Maletil forderte elne grindliche Untersuchung der Volkslieder, um lhren wirklichen Wert und thre Schönhelt nach den Regeln der Ästhet1k zu erforschen, damit diese "Ansteckung", nämlich die Bemihung, eln Volksdichter zu werden, nicht uberhand nehme. $(128,5 \cdot 1,99)$.

Obwohl auch Maletit mit den Jahren In seiner Kritik suruckhaltender wurde und $z$.B. den Inttlator der nationalen Richtung In der serbischen Literatur. Karadzit, den er fruher angegriffen hatte, 1858 als den "beruhmten Nestor unserer Literatur" bezelchnete und 1887 sogar elne "Apoteoza Vuku Karadžltu" d1chtete $(128,5.2 \%)$, hat aleh selne Grundkonzeption trotz aller Anpassung an die Gegebenhelten der Zelt nie geandert. Solange Maletits Elnfiub groB war, wirkte er der nationalen Entwlcklung der serbischen Literatur entgegen; selne spateren Konzessionen hatten kelne Bedeutung mehr fur eine Generation, die den Gedanken elner nationalen Literatur bereits voll akzeptiert hat te. 
II.5.1.3. Jovan S u b o t 1 t $(1817-1886)$

Der in der Fihe von Ruma geborene Jovan subotit, der wie Maletit sowohl als Dichter wie als Theoretiker hervortrat, war wie dieser im Gelste der klassischen Poesie und in den Ideen der Aufklarung erzogen; in selnen Gedichten richtete er sich zunjachst nach latelnischen vorbildern, um $81 \mathrm{ch}$ aber dann unter dew Elndruck der Bemuihungen Karadzits an der volkspoesie zu orientieren. In seiner 1843 verdffentilchten Gedichtsammlung "Bosile" bequhte er sich um elne Nachahmung der serbischen Volksdichtung, verwendete aber z.Tl. klassische Metren und Ansplelungen auf die griechische Mythologie nach Art der herrschenden "gelehrten" Poesie, was mit Recht als stilbruch empfunden wurde(128, 539$)$. In seinen Dramen hahm subotit storfe aus der serbischen ceschichte zum Vorwurf, die er nach den erlernten klassischen Regeln gestaltete; als elner der ersten serbischen Autoren schrieb er Erzahlungen, meist nach deutschem Vorbild. SKFRLIĆ bezelchnet subotit als einen "geblldeten, fleluigen schriftsteller voll guter absichten, der in der lage war, nach fremden Vorlagen zu arbeiten, Jedoch ohne Originalitut, ohne Inspiration, ohne Poesie und ohne schwung.." (101, S.198).

Fiir die Durchsetzung der Ideen Karadžlts jedoch war die Erscheinung Subotits durchaus von Bedeutung, da sich subotit grundsätzlich zu dem Gedanken elner nationalen Literatur auf der Basis der Volksdichtung bekannte. Als Mitarbelter des "Serbskij Narodnyj List" veröffentlichte er seit 1837 eine Rethe von Aufsatzen zu Fragen der Literatur, z.B. 1841 "Nekoliko rečlj za srbskog splsatelja" und 1843 "Stihotvorac 1 Narodno Stihotvorenje". elne Tellubersetzung der Kritik Schlllers an den Gedichten Bürers. Als Redakteur des "Serbskij létopis" verfaßte er ebenfalls literaturtheoretische Aufsutzo, die sich mit Fragen der Metrik anseinandersetzten. In den Jahren 1846/47 erschien im "Serbsk1J Letopis" ein AbriB der serblschen Literaturgeschlchte: "Neke čerte 12 povéstnice serbskog knjlžestvar, 1845 wurde in budin das Buch "Nauka - srbskom stihotvorstru" gedruckt. AnluBlich der Kritik Maletits an seinem pre1sgekrönten Epos "Kralb Dečanskij" lieb Subotit als Antwort hierauf die Ahhandlung "Teorlja eposa Gdna.DJ.Malet1ta" 1847 im Serbsk1J Narodnif List erscheinen. (51.5.27). 
Während Subotit in selnen theoretischen schriften seine Herkunft von der lateinischen Poetik und seinen engen Anschluß an die deutsche Klassik nicht verleugnen konnte und weltgehend, Insbesondere in seinen Definitionen der einzelnen literarischen Gattungen, deren Formulierungen ubernahm, stellt nach D.KADACH die "Nauka o srbskom stihotrorenju" fur die damalige zelt eln revolutionares Verk dar, da er In diesem, aus den Quelien der Romant1k gespelsten Buch "den allgemelnen Gedanken elner nationalen Verwurzelung der Dichtung und der Theorie in die Tat umsetzte, indem er seine Verslehre auf der Grundlage der Volkspoesle aufbaute". (51.5.143) 144). Der Umstand, daB ein auch als Dichter anerkannter Mann, welchen ein Grobtell der Gegner Karadzits schutzte, well er trotz seiner nationalen orientierung in vieler Hinslcht der herkömmlichen Vorstellung vom "gelehrten Poeten" entsprach, die Ideen Vuks verfocht, durfte viel zu deren Durchsetzung belgetragen haben.

Auch Subotit sah, wie Dositej und wie Maletit, In der Literatur In erster Linie ein Mittel zur Hebung der Moral und der Blldung des Volkes; deshalb schutzte er die Fabeln Dositejs als besoniers geelgnete Volksliteratur. Von der kinftigen Literatur forderte er, daB sie dem Volk verstandilch sein misse, wozu Kraft der Darstellung, guter St1l, psycholog1sches Einfühlungsvermögen und richtige Charakterzelchnung erforderlich seien.

In selnem Abrils der serblschen $L_{1}$ teraturgeschichte wies Subotit energisch auf die Bedeutung und den kunstlerischen wert der serblschen Volksdichtung hin, die er mit der griechischen Poesie verglich; beide zeichneten $\mathrm{s} 1 \mathrm{ch}$ nach subotit durch Ihr ganz und gar elgenständges Wesen aus. Subotit formulierte:

Was den Leser in den serblschen Volksliedern entzuckt, 1st die wirklichke1t, elne durch und durch poet1sohe Wirklichkelt, die dennoch volikommen wahrhaftig ist. Die Elnhe1t der Materie und der Form 1 st das zwe1te grobe Verdienst der serblschen Volksdichtung, aber die E1gentumlichke1t in der Gestaltung, als nationeles Merkmal, ist das dritte, welches diesen Liedern einen besonderen platz in der Poesie der Welt, neben anderen selbstandigen Poesien, sichert...die serblsche Poesie 1st. wie die griechische, elne echte Individualitut (e1gentl1chipersönl1chke1t:"prava osoba") m1t best1mutem, elgenem, sie auszeichnendem Charakter; in 1hr 
findet sich ein Individuelles Material, elne Individuelle Form und eine individuelle Farbung, also ein vollkommener Charakter... Die serblschen Volksileder sind nicht "Volksileder" sondern "Nation-Lieder"... (21t1ert nach 128,5.241/242).

D1e Gegenuberstellung von "Volkslieder" und "Nat1on-L1eder", so von subotit Innerhalb des serbischen Originaltextes formuliert, zelgt, daB fur den in der Atmosphare deutscher B11dung aufgewachsenen Serben das Wort "Volk" noch den Beiklang von "ungeblidet, primitiv" im Sinne der Aufklarung hat, whinrend er für die Bezelchnung völk1scher Elgenart den Ausdruck "Nation" whit.

In der Kritik Maletits am Epos "Kralb Decanskij" und In Subot1ts umfangrelcher stellungnahme hierzu kamen die gegensatzlichen Standpunkte der belden widerstreitenden Gruppen in der damaligen serblschen Literatur deutlich zum Ausdruck, wie ŹIVKOVIĆ schrelbt: der antinationale-imitatorische Maletits und der nationale, speziell serbische subotifs: Maletitwiederholte im wesent11chen fruhere Formulierungen Hadzits, Sava Tekelijas, Pavle Popovits, whihrend subotit hier als erster das Wesen der serbisch-nationalen $L_{1}$ teratur formulierte $(128$, s.277-278). Abgesehen davon, dab Subotit bel dieser Gelegenheit dem als hnchgelehrt geltenden Maletit die Oberfluchlichkeit selner Kenntnisse nachwies, druckte er in dieser Abhandlung einen wichtigen Gedanken aus:

ks ist falsch, den Anfang der eplschen Dichtung in der eriechischen Epik zu sehen und die Epik aller anderen völker als deren Fortsetzung zu betrachten. Die eplsche Pnesie 1st so viele Male neu entstanden, als es vólker glbt, deren Eplk wir als nationale Epik ansehen.

(z1t1ert nach $128,5.284$ ).

M1t dieser Feststellung deckte Subotit die falschen Voraussetzungen auf, von denen Maletit bel selner Beurtellung der serbischen Eplk ausgegangen war. Subotit erklarte, dab die Epik der elnzelnen Volker unterschiedlichen Gesetzen unter11 ege:

Wenn Irgendein Werk elne serbische Epopöe sein will, und nicht elne grlechloche, so mul man dieses Werk an Hand der Gesetze und des Wesens der serblschen Epopöe beurtellen. (z1tiert nach 128,S.285) 
ŽIvkoví́ schließt aus diesen Ausfuhrungen subotits, daB er berelts zu jenem Zeitpunkt elne klare theoretische vorstellung vom Charakter und den Eigenschaften der kunftigen serbischen Poesie gehabt habe; man kobme daher der Bemerkung in seiner viel spater geschriebenen Autoblographie Glauben schenken, er habe bel der Abfassung selnes Epos "Kralb DeCansk1j" 1 meer vor Augen gehabt, dab"alle Flguren echte serben sein mübten, die nur so dächten und sprachen, wie eln serbe denkt und spricht" $(128,5.287)$.

1847 veröffent11chte Subotit im "LETOPIS" unter dem Titel "Źckovski. Romantika u Rusij1" die Ubersetzung des Buches von J.P.Jordan "Geschichte der russischen Literatur" (1846). welches wiederum nichts anderes war als die tbersetzung von Abhandlungen Belinskijs uber Puśkin und Žukovskij. Ohne den Ursprung dieses Buches zu kennen, empfand Subotit den kritischen Wert dieser Texte, in denen elnerselts der heroische und nationale Charakter der Poesle Puškins hervorgehoben, andererselts an den Dichtungen Zukovskijs gerade jene Ziige kritislert wurden, die, wie ŽIvković sagt, auch unter den serbischen Verhaltnissen eine Demob1lisierung der nationalen Krafte bedeutet hatten: Fxaltiertheit, Mystizismus, Ruhrseligke1t, antinationaler Historismus (128,S.293). Auch mit dieser verófentlichung lelstete Subotil elnen Beitrag zur fintwicklung der nationalen serbischen Literatur.

wichtig ist noch die Tatsache, dab es Subotit war, der in selner Elfenschaft als Zensor fur serbische und rumänische Bücher 1847 die Genehmigung für den Druck von Daničlts Werk "Rat za srpski jezik 1 pravopis"gab.

Obwohl Subotit ebenso wentg wie Maletit ein systematisches Lehrgebăude elner serbischen ästhetik oder Poetik schuf, stellte selne Präzisierung der Forderung nach elner nationalen serbischen Literatur elnen Fortschritt auf dem von Karadžlt elngeschlagenen Weg dar. 
II.5.1.4. Jovan R $18 t 1 \in(1831-1899)$

Durch die Verbreitung der deutschen Klassiker, die zuerst bel den ungarischen serben einsetzte', wurden die alten latelnischen Vorbllder der serbischen Poesie allmählich durch deutsche abgelóst. Gegen die Uberfremdung jeglicher Provenienz wandten sich Manner wie Subotit in theoretischen Schriften und durch das Beispiel ihrer Dichtungen. Auch die rationalistische Ästhetik wurde um die Jahrhundertmitte iberwunden; neben der Schillerschen ïsthetik wurden nun auch die Theorlen Hegels bekannt, wiederum durch die Vermittlung Maletits. Einer der wichtigsten Befurworter elner national-serbischen Literatur war in den 5Ber Jahren Jovan Ristit, der in Berlin, Heldelberg und paris studierte und spter als staatsmann eine wichtige Rolle in der serbischen Geschichte spielte. Nachdem er schon 1850 eine "Kurze Charakterlstik des geistigen und sittlichen $Z$ ustandes von serbien" verfabt hatte, veröfentlichte er 1852 sein Buch "Die neuere literatur der serben"(beides in deutscher sprache).

In diesem, in Berlin gedruckten Buch gab Ristit elne Beschreibung. und Beurtellung der Fintwicklung der serbischen Literatur von Dositej bis zu branko Radilevit und Njegoś, wobel er insbesondere das nationale Moment hervorhob. Fr bemuite sich, die Bedeutung der einzelnen Schriftsteller herauszuarbeiten, und erkannte $2 . B$. auch das Verdienst vidakovits an, die leserschaft überhaupt an die Literatur heranzufuhren; um elnen so markanten Autor wie Sterija in die nationale Richtung elnbeziehen zu können, gelangte er zu elner Uberbewertung der Dramen Popovits gegenüber selnen Komödien; er uberschätze elnen Dichter wie Jovan Ilit wegen des volkstumlichen Charakters seiner Gedichte. Maletit beurteilte er sehr negativ-er habe von Schiller nur das Schlechteste, die Rhetorik, übernommen-während er Subotits "Kralb Dečanskif" als Belspiel eines nationalen Fpos hinstellte. Neben dem hohen Lob der Poesie Brankos enthielt Ristits Buch die erste begeisterte Stellungnahme von serbischer Selte zu Njegoss "Gorski vijenac"; die Person des Verfassers und die starke nationale Tendenz des Werkes hatten die serblschen literaten jahrelang vor elner Äußerung zurückscheuen lassen.

1 Jovan Pačlt übersetzte bls 1842 zahlrelche Gedichte Goethes, die $1 \mathrm{~m}$ "LFTOPIS" und $1 \mathrm{~m}$ "SERBSKIJ NARONNI.I LIST" erschienen. Vasilife Subotit und Borde Maletit begannen mit SchillerUbersetzungen. 
Ristils Buch stieb auf negative Kritiki er sah elch daher zu einer Entgegnung in den "Novine srpske" (1852) veranlaBt ( Odgovor na pretresivanje moga dela "Die neuere literatur

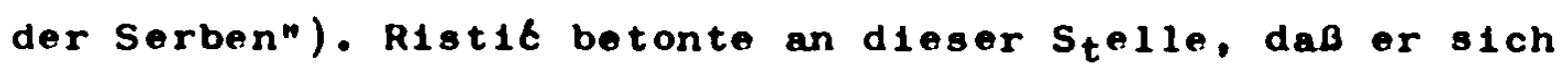
in seinem Buch bemuiht habe, "nach den Gesetzen der historischen Betrachtungswelse den inneren ablauf und den inneren Wert der serbischen Literatur zu entwlckeln"(128,s.317); der Verlauf dieser Entwicklung seit Dositej zeige elne zunehmende Annaherung der literatur an die Bedurfnisse des volkes, an den Gelst des Volkes, und das Wertvollste hierbel sel lhre allmăliche Verselbstand 1 gune.

Ferner arbeltete Ristit in dieser Entgegnung den krassen Gegensatz zwischen dem echten Dichter Branko und dem gelehrten Poete: vorde Maletil heraus: In Brankos Gedichten lebe die Begeisterun der Höhenflug des Dichters, in Ihnen zelgter elch die Schönheit und der Relchtum der serbischen Sprache, wăhend Maletits Poesi nichts als Nachahmung fremder Vorbllder darstelle; er schrieb:

Wenn Kenntnisse den Poeten ausmachten, ware Herr Maletit kein schlechter Poet, aber zum Poeten befahigen den Menschen jene Tugenden, die Branko auszelchnen, der, ohne naci dem Ruhm gelehrten wisens zu streben, die Eigenschaften des schöpferischen Geistes besitzt...er hat, was Schiller Insbesondere vom Poeten fordert: er hat Geist."

(zitiert nach 128, S. 318).

In dieser Entgegnung fabte Ristit u.a. die Richtilnien einer neuen serbischen $L_{1}$ teratur zusammen: sie sollte eine vom echten dichterischen Gelste beselte Literatur sein, weder den formalen kegeln anderer $L_{1}$ teraturen folgen noch nach Art der alteren Poesie auf die klassische Mythologie zurickereifen, sondern die serbische Vergangenhelt, das Volksleben, die helmatliche Landschaft, die serbische Hesensart und die alten slavischen Mythen dem Leser nahe bringen.

Immerhin billigte Ristit der jungen Literatur gewisse Ubernahmen zu, so sehr er sich gegen den "Fremdgelst" wandte, wenn er von der "nicht immer schadlichen Assimilation fremder Anlethen und threr Anpassung an die Richtilnien der Volkepoeste in jener schlichten Größe. Nalvität und eplsch-plastischen Vollkommenheit" sprach(128,S.319). 
Infolge seines Auslandsstudiums hat te Ristit einen weiteren geistigen Horizont als viele seiner Zeitgenossen; so intensiv er auch den Standpunkt der nationalen Richtung in der Literatur vertrat, so fabte er den Begriff "national" doch nicht so eng auf wie z.B. noch subotit und vor allem eine Reihe der spateren Anhänger Karadžlts,die inn buchstablich verstanden. Zivković vertritt die Ansicht, daB kistlt ohne Zweifel die neueren Theorien der Dichtkunst nicht nur kannte, sondern auch für sich selbst ubernommen hatte, da er ausdrucklich vom dichterischen Gelst als Voraussetzung der Poesie sprach und damit der modernen Aufassune unbedingt naher stand als seine serbischen Zeitgenossen.

ŽIVKOVIĆ betrachtet das Jahr 1852, in welchem Ristits Buch erschien und in dem Branko und Njegot inre volle Wirdigung als national-serbische Ilchter erfuhren, als das Jahr der endgultigen Hinwendung zur nationalen kichtung in der neueren serbischen Literatur. Die veränderte situation spiegein u.a. die schon erwähnten wohlwollenden Äulserunpen elnes Mannes wie Maletit uher Karadžit wider.

Auch in den folgenden Jahren setzte sich Ristit aktiv fiir die Iurchsetzung der nationalen Tendenz in der Literatur ein, indem er Neuerschelnunpen in den "Novine srpske" kommentierte. Anlalslich der zwelten Ausgabe von Karadžits "Srpski rječnik" wies Ristit auf die grole Bedeutung dieses works fiir die Entwicklung der serbischen Kultur hin; andere völker häten derartig umfassende Wörterbiicher der Volkssprache erst nach Jahrhunderten literarischer Aktivitat erhalten, wahrend die serbische Literatur bereits von Anfang an uber elne solche reiche Quelle nicht nur der sprache, sondern auch des Volksgeistes verfuge.

Wahrend in den $40 e r$ Jahren die Gegner elner nationalen itieratur, die im Sinne Vuks von der Volksdichtung ausgehen solite, noch zahlreich waren, setzte sich die Uberzeugung von der Notwendigke1t dieser Richtung in den 5oer Jahren allmahlich durch, thre kichtilinien wurden auch theoretisch formuliert. In diese Jahre fallt der Beginn der literarischen Tatigkeit dreier bedeutender Dichter der serbischen Romantik: Zmajs, Jakłıts und Kostits. 
ŽIVkoví́ wendet sich gegen die Behauptung SKERLIĆs, die 50er Jahre hätten elnen Ruckschritt in der serbischen Literatur dargestellt 1 , es gebe nur Gelegenheltsgedichte und didaktisch-moralisches Schrifttum, und drel strobungen kämpten um die Vorherrschaft: der Pseudoklassiz1smus, die deutsche Romantik und die serbische Volkspoesie. Von alledem treffe nur dip Tatsache der Vorherrschaft der Volkspoesie 2u, und ein Ruckschritt sel nur in der Menge der 11terarischen Produktion, nicht aber in ihrer Qualitat zu beobachten. Der Pseudoklassizismus hußerte s1ch - nach ŽIvxović - in den 50er Jahren nur noch in den Poetik-Unterrichtsstunden der Mittelschulen, während vom Katheder des Belerader Lyzeums die neve, nationale Auffassung von der literatur durch A.Vukomanovit und Bure Daničlt verbreitet wurde. (128,5.324/ 325).

1 Jovan Skerl1t: Omladina 1 njena književnost, 5.51-64. Beograd 1906. 
II.5.1.5. Jakob I \& nja tovit (1822-1889)

Zu den Befurwortern der nationalen Richtung in der serbischen Literatur gehörte Jakob Ignjatovit, obwohl er, im Gegensatz zu anderen Serben, an den Kämpfen 1848 auf der Selte der Ungarn teilnahm und stch in späteren Jahren offen zu den "Madaroni" bekannte. Während seiner Tätipkeit als Redakteur des "LFTOPIS" - nach 1848 - nahm er in einer Reihe von Artikeln gegen die klassizistische älere literatur und insbesondere gegen den deutschen Einflub Stellung. Gepenstand der serbischen Literatur sollte, nach Ignjatovit, das serbische Volksleben in Vergangenheit und Gepenwart sein. Seine vorstellungen versuchte er in einer Reihe von historischen Romanen und Erzahlungen zu verwirklichen, die die erste Periode seines Schafiens darstellen(ca. bis 1860$)$. Diese, aus der romantisch-nationalen Begeisterung entstaidenen früheren Werke entsprachen keineswegs Ienjatovits kritischer und nuchterner Veranlagung. Selne eleentliche Begabung zeigte sich erst in seinen spateren Romanen sozialkritischer Art, die voll kihler, sachlicher Beobachtung e1ner sehr negativ gesehenen virklichkeit sind. Ihr Thema ist vor allem der Niedergane des alten, kraftrollen Serbentums in der ungarischen Heimat Ignjatovits, dem eine neue, demoralisierte Generation pepenübergestellt wird. Ifnjatovits Roman "Milan Narandžit" (1860/1863) ist in elner noch ganz vom Ge1st der Iomantik getrafenen zeit der erste realistische, tellwelse brutal naturalistische Roman der serbischen Literatur. Die negative Kritik, auf die Ienjatovits Romane stieben, richtete sich gröbtenteils gegen die person des Autors; in Bezug auf die tells direkt fehlerhafte sprache seiner Romane war sie berechtigt.

Aus der Feder dieses Autors stamm die umfangrelche Schrift "Pogled na knjižestvo" ("If.TOPIS" 1:857), die den endguiltigen Bruch mit allen klassizistischen und nicht nationalen Tendenzen und die volle Bestatigung der nationalen Richtung in der serbischen Literatur bezelchnet. In dieser Schrift stellt Ignjatovit zunachst fest, dabs sich die neue serbische literatur, unter der er die Literatur von vuk bis Branko versteht, in vielem von der alteren unterachelde. Die klassizistische Schule und die "deutsche Mode" hätten sich tn Serbien 
infolge ihres fremden Wesens nicht halten können. Jedes Volk habe ganz spezifische, nur thm elgene Wesenszüge, denen selne Poesie entsprechen müsse:

Unsere Poesie mul unserer nationalen Individualitat ahnlich sein. Den Deutschen mag ein Lenau oder Simrock gefallen, uns aber kommt es vor, als waren diese Dichter nur der Ausdruck krankhafter Fimpfindungen oder elner kranken Laune, d1e gesunden Menschen nicht ansteht.

Die diteren Poeten nennt Ignjatovit "Versemacher, aber kelne Dichter"; mit dem Auftreten Karadžlts und der herausgabe der Volkslieder habe die serblsche literatur elne neue, nationale Richtung bekommen. Obwohl sich schon fruhere Dichter an diese Richtung gehalten und gegen fremde fiemente gewehrt hatten, z.H. Sima Milutinovit, habe die serbische Literatur als Ganzes erst im letzten Jahrzehnt, also zwischen 1847 und 1857,diesen Weg eingeschlagen:

Die serbische Jugend hat wahrend des letzten Jahrzehnts ihr Interesse der volkspoesie und jenen schriftstellern zugewandt, die im Gelste des Volkes zu schrelben begannen. I) 1 glelche Jugend hat in thren Dichtungen angefangen, jene Gedanken und Fmpfindungen zu reproduzieren, die in den Volksliedern zu finden sind. Dies war ein grober Schritt vorwärts, denn damt begann bel uns der Bruch mit dem fremden Element...

Branko RadiCevit tauchte wie ein Meteor am Himmel der neuen serbischen Dichtkunst auf...

Heim Lesen selner Gedichte konnte jeder erkennen, daB sich der serbe erst mit seinem eigenen Gefuhl und seiner elgenen Form in der Poesie umso vollkommener ausdrucken kann. In thm ist der serbische Gelst wie ein Phoenix auferstanden...

("LFTOPIS" 1857,knj.96,S.141-170; zit1ert nach 128,s. $322 / 323)$.

Diese worte der Hegelsterung, zu denen sich eln Mann mit ausgesprochen sachlicher Veranlagung hinreiisen ließ, charakterisieren die Elnstellung der serbischen schriftsteller bis weit in die joer Jahre hinein. 
II.5.1.6. Svetozar Markor 1 C $(1846-1875)$

Svetozar Markovit, der zunkehst die Blldungsmöglichkelten - elner serblschen Helmat erschbpft hatte, von denen or sobr enttuscht war, studierte als stipendiat in Russland und dann in Zürch. Wuhrend seines Aufenthalts in St.Petersburg kam or mit den Ideen Cernyterskije, Dobroljubove und Pisarevs in Beruhrung, die er leldenschaftlich aufgriff und opter, nach selner Rückehr nach Serbien, unter den dortigen Verhultisisen zu realisieren versuchte. In Serbien gab es damals nur eine -1nz160 Fabrik, so dab es auch noch keln Proletariat gab; os begann slch aber berelts elne Sch1cht der Bourgeo1sie herauszubllden, und die Entwicklung zur Industrialisierung und damit zum Kapitalismus war bereits vorgezelchnet. Markovit, der die kinft1ge Industrial1sierung richt1g vorausah, wandte $81 \mathrm{ch}$ an die Schicht der klelnen Handwerker und grundete Erzeugerund Verbrauchergenosenschaften (zadruge); or glaubte, daB Serbien auf diesem Wege die Entwicklung zu den grbBeren Produktionsgemelnschaften eines industrialisierten staates voliziehen und,d1e Stufe des kapitalistischen systeme uberopringend, unmitelbar zu elner oozialstischen Gesellschaftsform ubergohen könne.

Um Svetozar Markovit sammelte sich um die Wende zu den 70er Jahren die serbische Omladina, darunter fast alle der spteren serblschen realistischen Schriftsteller. Obwohl Markovite Anliegen vor allem elne Lbsung der sozialen Probleme war, hat or durch die Verbreltung der materialistischen philosophie und durch solne wentgon, aber markanten Stellungnahmen zur L1teratur elnen sehr groBen Einflub auf die Entwicklung der serbischen Literatur gehabt.

In Slaventum sah Markovil besondere gemelnschafteblldende Krufte wirksam, uber die die anderen völker nicht verfugten; deshalb hielt er es fúr falsch, dab serbien das kapitalistioche System In elnem Augenblick zu ubernehnen beginne, da man im vesten berelts seine Fehier erkannt habe. In der altserbischen Zadruga sah Markovit ebenso wie 1a Kosakenstaat eln echt slavisches Vorbild elner sozialen Lebensform. Er vertrat die Ansicht, dab das Prinzip der serbischen zadruga, in der jeder nur so lange 
Anspruch auf den Gemelnschaftsbeoitz hatte, als er dieser Gemelnschaft selne Arbeltskraft zur Verfugung stellte, auf die gesamte Gosellschaft ubertragen werden kbnne.

Ausgehend von selner materialistiachen Konzeption, betrachtete Markovit die Literatur nicht als Selbstzweck, sondern als elnes der Mittel zur Heranblidung neuer, besserer Menschen; bie sollte nur das belnhalten, was dem Fortschritt der Gesellschaft nutzte. Trotz selner tberzeugung von vorblidlichen zusamenloben in den slavischen Gemelnschaften der Vergangenhe1t lehnte Markovit die romantische Ruckwendung zum Mittelalter ab. Die Literatur solite sich nach selner Ansicht mit der Erorterung aktueller Fragen vom standpunkt der modernen wissenschaft aus befassen, sie solite ze1tgembs sein und das loben des Volkes realistisch darstellen.

In den belden Aufsktzen "Pevanje 1 mirljenje"(1868) und "Realnost u poez1j1"(1870) wandte sich Markovit energisch gegen die romantische Sentimentalitat und die Phrasenhaftigkelt der Literatur. In den anonymen schöpfern der volkedichtung sah er ebenso wie In Petar Petrovit Njegos echte Dichter:

Jene Persönlichkelten im Volk, die alle leiden, die das ganze Volk bedrucken, tiefer und starker emprinden und fuhig sind, diese Gefüle in küstlerischer Form auszusagen - das sind die wahren Dichter.

$(74,5.204)$.

In der Verbundenhe1t mit dem Volk und dem unmittelbaren Bezug zur Realitut sah Markovit elne unbedingte voraussetzung der Dichtung:

Das 1st es, was fur den Dichter notwendig 1st: dab er ein mitbetroffener Tell des Volkes lst, d.h. daB or jenes Leben gelebt hat, welches das Volk lebt, daB er jene Leiden erlitten hat, oder dab sie ihm wenlgatens nahe sind, die das volk erleldet...

...Wo sind diese Dichter bel uns? Kennen sie das Volk, selne Nöte und Lelden? Fuhlen s1e, was das Volk fült und was sie ausdrucken vissen? wie kann jemand uber das Leiden der Raja in Bosnien oder in der Boka dichten, wenn er weder Bosnien noch die Boka kennt, nicht elnmal au Ze1tungsartikeln? Das 1st es, weshalb unsere Poesie leer lot, dab sie 1 mmerzu um Blattwerk und Schmetteringe herumstrelcht oder mit der "Liebsten" girrt und s $1 \mathrm{ch}$ abschmatzt, und wenn sie sich manchmal in eine 
"patriotische Positur" wirf, dann lst das etwas so Armsel16es, Leeres, Muhsames, ohne jedes Gerunl nur der Parade wegen... Das Leben des Volkes, das lot Inhalt - das lot die Realitut in der Poesie.

("Realnost u poezij1"; 74.S.204).

D1e Bedeutung der Poosie Fabte Markovit in Folgender Formulierung zusamen, d1e glelcherwelse rur alle Gattungen der Literatur galt:

Wenn man d1e Poesie so aurfaßt: daß se elne Erscheinung des gesellschaftlichen oder des rolkischen Lobens 1 st, und daB se dies immer 1st, In welcher Form 1mer o 10 auftritt, in den Produkten elnzelner Menschen oder des ganzen Volkes, In eplscher, lyrischer, dramatischer Poosie, usw. - nur dann kann man 1hre wirkliche Bedeutung erfasson und solche Erschelnungen orklkren wie z.B. Ihren Verfall in westichen Europa.

$(74,5.206 / 207)$.

Fur Markovit war jedoch der Sinn aller Literatur damit erschöpft, das Volk auf selne situation aufmerksam zu machen und in thi den kumperischen Gelst, den Entschlub sur Verunderung der sozialen Lage zu wecken:

D1. Völker haben erkannt, daB dichterische Begelsterung nicht genugt, um das $\mathrm{z} 101$ zu erreichen, nach dem sie sich sehnen; sie habon die Erfahrung gemacht, dab kein elnziger Dichter, so genial or auch sein mag, die violfHltige soziale Frage zu lbsen 1mstande 1st; um diese Frage zu loben, von der die Freihelt des Volkes abhkngt, bedarf es der gesamten geistigen Kraft der Masse des Volkes.

-....

Darum glbt os kelne "Poesie" lm houtigen Westen. Der Inhalt der Dichtkunst, das Loben des Volkes, hat sich so we1t entwickelt, dab man jetzt jene Ideale zu rerwirklichen beginnt, die elnst nur die Dichter aufgebaut und erfaBt haben und die se in lichten Farbon ror das Volk hingteliten. Die Dichter haben grbitentells ihre Aurgabe erfuilt. Die ze1t der praktischen Arbelt 1 st angebrochen.

$$
\text { (74, s.207/208). }
$$

Diese utilitaristische Auffassung von der literatur veranlabte - inigo Anhanger Markovits, In ihr nur noch einen uberfiussigen bourgeolsen Luxus zu sehen.

Von dor revolutiontren Erschelnung Svetozar Markovite gingen jedenfal 1. wicht1ge DenkanstbBe aus; zur Verbreitung der Ideen von elner nouen Gesellschaft trug neben den Schriften Markorits d1e Tutigke1t Ljuben Karavelove bel, der neben kritiochen Artikeln zur zeitgenbseischen Literatur den Roman "Je 11 krira sudbina" (1868/69) verdfrentlichte, elne bertragung ron Cerny- 
bevok1 Je Roman "Cto delat'p" In das serbische M1110u. In eelnen Artikeln wandte sch Karavelov gegen die 1dealistische Ästhet1k und d1e zeltgenössische romant1sche L1teratur; w1e Markovit forderte or elne realistioche Darotellung der sozlalen Vorhyltn1s80, seln Standpunkt war aber gendBigter und onteprach etwa dea Šenoas.

Das Engagement Svetozar Markovito fur das Volk war nicht frel von Anklangen an die nationale Begelsterung, deren romantische und phrasenhafte Auswichse or ablehnte, nur bezog or auforund des erlernten klasendenkens in selnen volksbegriff jene dunne, wohlhabendere Schicht nicht alt e1n, die elch gerade erat herauszubliden begann und deren selbstrerstandnis auseoprochen serblech-national war, weswegen sie stch ebenso wie die Reglerung gegen die Bewegung Markovits otellte.

Durch Markovit wurde die endgult1ge Hinwendung der serblechen Literatur zun Real1smus ausgelbst unter selnem Elnflub begannen Gliø̌lt, Lazarevit und Veselinovit zu schreiben, und Dure Jaksıt wandte sich der sozialen Poesie zu. 
II. 5.2. Kroaten

\section{II.5.2.1. Ljudevit G a $\mathcal{H}(1809-1872)$}

Die nationale Selbstbesinnung der Völker der habsburfischen Monarchie, die gepen Ende des $18 . J$ ahrhunderts einsetzt und im 19.Jahrhundert zum Durchbruch gelangt, kennzeichnet die entstehenden jungen Literaturen. Politische und kulturelle Bestrebungen sind in dieser Perinde untrennbar miteinander verflochten.

Die zunehmende Tendenz zur Madjarisierung und zur Finschräkung, der alten Rechte Kroatiens, der sich ein grober Teil des kroatischen Adels aus Grunden persönlichen Vortells nicht widersetzte, veranlalste 1830 Josip Kuševit zur Abfassunfe seiner Broschiire "De municipalibus iuribus et statutis refnorum Dalmatiae, Croatiae et Slavoniae", in der er die Geschichte der Kroaten und ihres staatsrechtichen Verhilinisses zu Ungarn von den Anfäneen an darlegte. Kuševit erhrachte den Heweis, dals Kroatien seit dein Vertraf init Koloman ( 1102 ) einen besnnderen, unabhingigen status innegehabt habe. liese cchrift im Verein mit der "Disertacija 11 iti llazpovor darovan pospodi poklisarom..." des Graten Janko Draškovit (1832) rief die kroatische Intelligenz aut den plan.

Dieser, der lefahr der Madjarisierung wie der des liermanisierunf. Eleicherwelse ausfesetzten Schicht gehörte l.judevit $G$ a $j$ an. der sich ab 1832 um die (ienehmigune zur Herausgabe einer kroatischen politischen Zeitung bemiihte, die er schlieislich im Juni 1834 erhie1t. 1835 erschienen erstmalie die "NOVINF. HORVATZKF." und die BeIlate"IANICZA HORVATZKA, SIAVINZKA Y DAIMATINZKA", die 1830 in "MirskF. NUVINF" und "DANICA Il.MiSkA" unbenannt wurden, um zum Ausdruck zu brineen, dals hiermit nicht nur die Kroaten, sondern alle suidslaven aneesprochen werden sollten. Mit dieser Zeitung, die zweimal, und der liellage, die einmal wichentlich erschien, schuf Gaj die plattform fü die kinftige politische und literarische Arbelt der 11 lyrischen Bewegung. Der Aufruf zur Mitarbeit regte die literarische Produktion In der bisher von den Gebildeten vernachlassieten kroatischen Sprache an; auch Gaj selbst hat te ja zunachst deutsch geschrieben ("Die Schlösser bei Krapina", Karlstadt 1826).

Nach der Auffassunf Gajs und vieler seiner Gleichgesinnten hatte die Literatur der Aufklärung und Belehrung der Bevölkerung 
und der Erweckung des Nationalgefuhle su dienen. S1e sollte daruber hinaus dazu beltragen, die Gemelnschaft der vilker "Grob-Illyriens", d.h. aller sudslaven, su restigen.

Daß Gaj sich die kunftige "1llyrische" literatur von vornherein als eine national bestimite literatur ait aufkiarerischer Tendenz vorstellte, geht aus den Ankindigungen der Zeltung bzw. Ihrer Bellage hervor, die er 1834, 1835 und 1842 veröffentl1chte. So helit es z.B. Im "Proglas" von 1835,

DIP DANICA ILIRSKA...wird Im Slavo-illyrischen Geiste vielerlei verschledenartige, sowohl zur leichten Unterhaltung und Frheiterung, als auch zur entsprechenden Blldung und zur angenehmen und nutzlichen Belehrung gehörlge Dinge enthalten...

. Da zur Ausblidung der Sprache und des Geistes am me1sten.... Volksileder und patriotische Gedichte beitragen. wird die DANICA wie bisher auch weiterhin durch ausgewalt, Dichtkunst...verschönert und geschmilckt se1n...

$(94, \mathrm{~s} \cdot 306 / 307)$

Auf die Volkslledersammlung Karadžlts war Gaj schon als Schüler der "filozofija" in Graz gestolen; die reformatorische Tatigke1t Vuks habe inn entscheldend beeinflubt, berichtet GaJ in seiner Autoblographle $(127, \mathrm{~s} .237)$. Bere1ts 1835 sprach Gaj in seinem Aufsatz in der"DANICA" (Nr.43) 1m Zusammenhang m1t der Volksliedersammlung Herders vom Typ des "naravskonarodn1 pjesnik" (natülich-volkstuml1chen Dichtere), der ohne fremde vorbilder, nach den Gesetzen der selnem Volk eingeborenen Ästhet1k schafft (5, S.136).

In selner programmat1schen Erklärung von 1835 vertrat Gaj auch den von Kollar ubernommenen Gedanken oer Zusammengehörigke1t aller slaven, die er "das gröbte Volk furopas" nannte. Er forderte die Uberwindung aller gegenseltigen vorurtelle zwischen Kroaten, Serben, Dalmatinern etc., die alle den "groben Illyrien" ancehörten:

Derartige Vorurteile mögen Egoisten verteldigen, In denen der wahre Funke der Helmatliebe nicht gliht. $(94,5.308)$.

Die fur die westeuropalsche Romantik charakteristische Ruckwendung zum Mittelalter erhielt in Kroatien ebenso wie in Serbien eine ausgesprochen nationale Bedeutung. Die Beschaftgung mit der Vergangenheit des elgenen volkes (und der anderer slavischer vblker), die Gaj als eine weitere Aufgabe der Lite- 
ratur bezeichnete, sollte dem leser den elfenen Wert bewulst machen. Aus dieser binstellung resultierte die zunehmende nationaligtische Tendenz der historischen "Novelien", die im ubrigen weiterhin den Typ der erelenisreichen romantischen firzahl une. verkörperten.

Mit der Ubernahme des Śtokavischen als schriftsprache, dessen "Uniberschätzbarkeit" (neprecjenost) Gaj bereits bei der ersten Tektiire der Volkslieder emilinden hatte 1 , war ab 1836 eine weitere voraussetzung fiir die betonunp des volkstimlichen filementes in der neuen literatur pereben, da in diesem Dialekt die eplschen lieder verfalst waren, an denen olch die urspriinglich kajkaviscli sprechenden schrittsteller orientierten.

Die porderung nach elner volksnalien literatur bestand mithin bereits seit den Antingen der lliyrischen Bewefunpe Bald schon entziindete sich hieran die liskussion libes "umjetnost" und "narodnost", d.h. iiber die Frapt, ob in der literatur das kilistlejische oder das volkstimliche liferent vorherrschen solle. ler durch die politischen Verhiltinise ledingte prafmatsche Charakter der l.iteratur bewirkte noch fils eiue länfere Zeit ein Hiutanstellen asthetischer Anspriche.

1 Velimir Gaj: Knjižnica Gajeva, Zapreb 1875, (s.XrIV). 
II.5.2.2. Stanko Vra $=(1810-1851)$ und

Dimitrije Demeter $(1811-1872)$

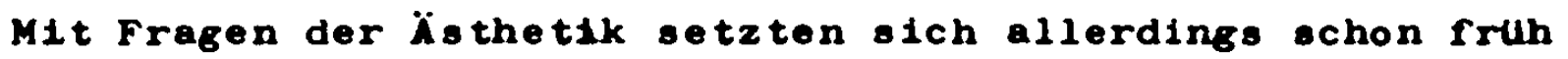
Stanko Vraz und Dimitrije Demeter auselnander.

Die Gröbere Verbreltung des Štokavischen und seine im Vergleich zum Kaj- und zun Cakavischen entwickelteren Ausdruckamblichkelten gaben den Ausschlag bel der Wahl dieses Dialektes als Schriftoprache. Hier boten sich als literarische Vorbilder nicht nur die schopfungen der mundlichen tberlieforung, sondern auch die Werke der Dubrovniker Dichter an. In der Frage nach der Gultigkeit dieser Vorbilder gelangten Vraz und Demeter zu unterschiedlichen Aufrassungen.

Der slovene Vraz, das ausgepräteste lyrische Talent unter den Illyrern, der zugleich der europlischen Romantik an ntichsten stand, hatte ich der kroat1schen Bewegung aus der tberzeugung heraus angeschlossen, daß erst der zusemenschlus der vielen kleinen Sprachgruppen auf der Grundlage des Stokavischen die Voraussetzungen für die Entwicklung einer suidslavischen Literatur schaffen kbnne. Vraz, dessen kroatische Gedichte sich trotz der nie ganz uberwundenen sprachlichen Schwierigkeiten durch Unmittelbarke1t und individuelle Empfindung auszeichnen, war nie der weltfremde Träumer, als der er gelegentlich hingestellt worden ist; er war ein kritisch beobachtender Geist, dem seine ungewöhnliche Bildung zu unso schärferer Urtellskraft verhalf. vraz war uberzeugt, daß eine volksnahe Literatur nicht lediglich die äußeren Merkmale der Volksliteratur ubernehmen, sondern von ihrem Gelst durchdrungen sein musse. Mehr als irgendein anderer der lllyrischen Dichter lieb er sich von der Volksdichtung inspirieren; er versuchte, ihre Vorstellungswelt und die Atmospäre der Volkslyrik in seine Gedichte einzubeziehen, die in verschiedenen slavischen, aber auch klassischen Metren gehalten waren; u.a. schrieb Vraz auch in der orientalischen Versform des Ghasel. Allein der Anfang der nach den Vorbild des Krakowiak geschriebenen "Dulabije I"(1836) ist ein Beispiel dafur, wie Vraz sich eine volksnahe Poesie vorstellte. whihrend Vraz die Volksdichtung, auch die anderer slavischer v8lker, als Vorbild für die neue Literatur anerkannte, stand 
er der Dubrovniker Dichtung we1t skeptischer gegenuber als die meisten kroatischen Literaten selner zeit, da er sie als Ausdruck 1 talienischen Geistes emprand. In seinem Aursatz "O Dubrovčan1ma"(1847; 121,s.161-165), In dem er sich wiederholt auf Karadžlt bezieht, kommen selne berelts früher vertretenen Ansichten deutlich zum Ausdruck:

Ebenso, wie die Ritter und Ritterfrauen im "Osman" nur dem Namen nach slavisch, thr Herz und thre Seele aber romanisch sind, ebenso wird Jeder unpartelische Forscher zugeben, daB unsere Dubrovniker mehr der sprachlichen Form nach als hinsichtlich des stofres (des Geistes) und seiner Gestaltung Slaven sind.

$(121,5 \cdot 161 / 162)$.

Mit diesem Urteil, das BARAC als zu scharf bezelchnet hat (121,S.28), wandte sich Vraz gegen die Imitatoren der Dubrovniker Dichtung unter den Illyrern, die aus dieser den 1talienischen Endecasyllabo und die Elision ubernahmen, nicht aber

die Klarheit und Leichtigkeit des Ausdrucks, die Kraft und dif Gewandtheit des Relmes -

wie sich Vraz in elnem Brief an Celakovsk' bereits 1841 beklagte (121,3.27). Dennoch hat auch Vraz selbst gelegent11ch auf den Wortschatz und auch auf die Tropen der Dubrovniker nichtung zurückgegriffen, die allerdings oft mit denen der volksdichtung identisch oder zumindest verwandt sind.

Als einer der ersten wies Vraz auf das Beispiel der groben russlochen Dichter, vor allem auf Puśkin und Gogol' hín, die bereits jenes 2101 erreicht hatten, dem die kroatische literatur zustreben misses elne literatur, die aus dem Gelste der eigenen Sprache Werke schuf, die dem Wesen deselgenen volkes entsprachen.

Somit gelangte auch Vraz, der nicht von pol1tischen oder ut111taristischen Erwägungen, ondern von kunstler1schen Gesichtspunkten ausging, zu der Forderung nach einer national bestimmen Literatur. In seiner AuBerung zu der Frage, wie die Samier von Volksliedern diese Texte zu notieren hatten, klingt noch die romant 18 che Auffassung von der "Natursprache" der Volksdichtung, In der die kinstlerischen Mittel fertig vorlkgen, nach:

Bel den Volksliedern darf man nichte uberarbelten, verkndern oder verbessern, sondern man mub 10 so aufreichnen, wie sie aus dem Munde des Volkes entepringen. Ihre Schonhelten und thre Pehler - all das lot das hell1ge Erbo un- 
serer Vorvater. In thnen erkennen wir wie in einen altertialichen Splegel thre Art des Denkens und des Fuhlens...

("Narodne pjesme u Slavon1j1", "KoLO" 1842; 121.5.156).

Deutlicher noch kommt die romantische Auffaseung rom Volk als Urquell der Kunst in den Schlubsatzen des Aufsatses "O Dubrovčanima" zum Ausdruck. Hier bezelchnet Vraz den "romant 1schen Klassiz1smus der Dubrovnlker" und thre Vernachlassigung elnheimischer Vorbilder als Mode der danaligen zeit, um dann fortzufahren:

Und erst $1 \mathrm{~m}$ gegenwart1gen Jahrhundert hat der l1terarische Gelst des Volkes einen anderen Weg elngeschlagen, Indem er zu selnem wahren, reinen Urquell zurlickkehrt, der unter der lebendigen helmischen Vurzel entspringt, unter dem Herzen des Volkes selbst...

$(121,5,165)$.

D1e ablehnende Haltung Vraz' gegenüber den Dubrovniker Dichtern kritisierte Dimitrije Demeter in seinem artikel "Misil o našem knj1ževnom jez1ku" ("DANICA", 1843). Demeter war der Melnung, daB Im Hinblick auf die Schwierigkelten, mit denen alle kroatischen Dichter in lhren Anfungen zu kumpren hatten, ein so kostbares Erbe nicht unbeachtet bleiben durfe. Er vertrat die Uberzeugung, dal die Sprache des elnfachen Volkes der literatur nicht genugend Ausdrucksmöglichkelten bletes

Der entwickelte Mensch hat elne Fulle von Gedanken, von denen sein zurickfebliebener Bruder nicht elnmal traumt. Da jedoch die Sprache die Reallsierung von Gedanken durch das Mittel des Klanges lst, muls die Sprache des entwickelten Menschen (die Literatursprache) um soviel mehr Worte besitzen als die Im Umgang mit einfachen Menschen erlernte Sprache, als der eeblldete Mensch mehr Gedanken hat als der ungebildete...

(z1tiert nach 5,S.107).

Demeter gelangte zu dem SchluB, daB man auch die Muttersprache erlernen und kultivieren musse; hierfür blete die Dubrovniker Literatursprache mit lhrer Welchhelt und Klangfulle, 1hren groBen Wortschatz und lhrem Formenrelchtum elne ausgezelchnete Mögl1chke1t.

W1e Demeter dachten auch viele andere der 111yrischen Schriftsteller; dies zelgen z.B. die Bemühungen Ivan Mažuranits um die Sprache Gundulits. Neben der Dubrovniker Dichtung erkannte jedoch auch Demeter den Nert der miindlichen Uberlieferungen 
an; hierin, wie in seinen Bemuhungen um die Reform der Sprache. war er ein Anhänger Karadžıls, wie ŽrvaNČ́vić berichtet( h27, $5.247 \mathrm{fr}$.$) Mt seiner Forderung, ausgehend von der sprache$ der Ragusaner Dichter unter Elnbeziehung der Elemente der Volksdichtung eine neue Literatur zu schaffen, stellte Demeter elnen derart hohen Anspruch, daß the nur ein Kinstler vom Rang Ivan Mazuranils zu elnem so frihen Zeltpunkt erfulien konnte.

II.5.2.3. Mirko Hobović (1816-1893)

Mirko Bogovil ist elner der charakteristischsten Vertreter jener Generation von Intellektuelien, die sich durch die 111yrische Bewegung. durch Gajs "Proglasin zur aktiven Te1lnahme am politischen und literarlochen Leben aurgerufen rilhlten. Obwohl er zeltiebens Gedichte schrieb - Liebesgedichte, patriotisch-didaktische, zuletzt pessimistisch-resignierende Gedichte - und, vor allem während selner Tátigkelt als Redakteur des "NEVEN", elne Reihe von Novelien, sah er, entsprechend der althergebrachten Auffassung, Im nrama die höchste literarische Gattung; um sie hat er sich am meisten bemuiht, und hierzu hat er sich auch theoretisch geasuert ("o ubemljenju narodnog kazal18̈ta", 1845; "Naše narodno kazalište".1852). Seine drel Dramen werden als das wertvoliste seiner literarischen Produktion angesehen, doch auch fur sie pilt, was BARAC uber Bogovit gesapt hat: er sel keine schöpferische Personilchkelt gewesen, fur die das küstlerische Schaffen eine naturliche Funktion bedeute, sondern ein literarischer nilettant, der recht geschickt eine fabel ersinnen konnte, dem aber die Kraft zu lhrer Gestaltung fehlte (8, S.136,5.134).

Bogovit war jedoch ein guter Organisator und Redakteur, ein begelsterter Patriot, der im öffentilchen leben die neuen, freiheitlichen Ideen zu vertreten wubte. Sein plan einer neuen nationalen Zeltung ("DOMOBRAN") wurde 185 y von Minister Bach abgelehnt; 1853-54 mubte er als Redakteur des "NEVEN" wegen des Abdrucks eines nim aufreizenden sinne gegen die Regierung" $(85, \mathrm{~S} .344 / 345)$ geschriebenen Gedichtes eine Gefing- 
nisstrafe abbuben (Ivan F1l1povits Gedicht "Donorodna utjeha", "NEVEN" 1853,Nr.38).

In der Ankund1gung der geplanten zeltung "DOMnBRAN" von 1851 wird deutlich, wie sehr es Bogovit vor allem um politische Z1ele ging:

Darum entfalten wir das Banner des nationalen Fortschrittes, un unter lhm all jene Patrioten su sammeln, die Im Loben des Volkes ihr Leben, in seinem Tod Ihren elgenen Tod erblicken. Unter dem Fortschritt des Volkes jedoch verstehen wir selne politische, gelstige und materielie Entwicklung.

$(85,5 \cdot 592)$.

Im gleichen rext heibt es einige Satze weiter:

Wo sind, fragen wir, unsere besonderen, felerlich garantierten Institutionen? - wo die so sehr gepriesene Gleichberechtigung des Volkes und der sprache? - wo die Land tage und alles andere, so felerllch Versprochene...

Am Schlub des Aufrufes werden die "Patrloten und Slaven des Sudens" zur M1tarbe1t aufgefordert:

...tretet in unseren Kreis...Patrioten und Slaven des Sildens, und unterstutzt mit Wort und Tat unser Unternehmen, zelgt der Welt: dals Sudslavien noch treue sobne hesitzt, die bereit sind, lhrem armen Vaterland allselts zu Hilfe zu ellen...

$$
(85,5 \cdot 592 / 593) \text {. }
$$

Diese Sätze kennzelchnen die Grundelnstellung Bogovils zur Aufgabe der literatur, deren nationale Funktion er gerade whrend der zelt des Absolutismus verstandlicherwe1se uber alle anderen stellte. Ljerka SEKULIĆ vermerkt, daB Bogovit selne Novellen wohl "eher aus Pflichtgefühl als aus besonderer Neigung" geschrieben habe (101,S.137). Nach der absolutistischen Perlode hat Bogovit keine elnzige Novelle mehr geschrieben, auch keln Drama, sondern sich nur mit welteren Gedichtsammlungen und Artikeln zu aktuelien Problemen zu Nort gemeldet, z.B. zur bosnischen Frage (1880). In der Pol1tik blieb er welter, b1s 1875, akt1v, obwohl er als Unionist den Angriffen der Volkspartel ausgesetzt war. 
II.5.2.4. Bogoslav S u 1 e k $(1816-1895)$

Der glelche kämpferische Gelst, der aus den ïuberungen Gajs und Bogovits spricht, erfülte auch Bogosiav Śulek, der selt 1841 Mitarbelter, von 1843-1849 Redakteur der "DANICA" war. Sulek, der sich als Historiker mit der Verfassungsgeschichte Kroatiens beschaftigte, der sich mit der Thenrie Darwins und mit materialistischen Konzeptionen auseinandersetzte und der auf lexikalischem Gebiet Bedeutendes gelelstet hat, vertrat auch die Idee der Zusammengehörlgkelt der südslavischen völker auf der Basis gegenseitiger Achtung. Deshalb polemisierte er 1856 u.a. gegen den Artikel vuks "Srbi svi 1 svuda"("Kovčežrín, 1849) in seiner erst 1861 in "VInOVDAN" veróffentlichten Entgegnung bemilhte sich Karadžlt um elne Bellegung dieser Differenz.

Hinslchtlich der Literatur hatte Šulek fortschrittliche Ansichten; er forderte in seinem Artikel "Pogled na ljetołnje proizvode nałe književnost1" ("I)ANICA" 1846) eine konstruktive Kritik an den Werken der Jungen Schriftsteller und begrüiste die Ausgewopenheit zwischen kiinstlerischen und volkstülichen filementen in Mažuranits "Smrt Sma1l-age Cenpita"(95,S.212).

In seiner Schrift "క̌ta namjeravaju Il1rcip" (B1ograd 1844) nahm Šulek ausführlich zu aktuellen Fragen stellung; Indem er hier zunachst die alten Munizipalrechte Krotiens historisch ableitete. wandte er sich sodann dem Problem der Amts- und Unterrichtssprache in Kroatien zu, die auf keinen Fall ungarisch sein dürfe:

Fs ist die heilige pflicht jedes Kroaten und Slavonen, selne so schöne, relche und berühinte Sprache, die $1 \mathrm{hm}$ seine Mutter sozusagen ins Herz gepflanzt hat, auf die einst seine mutigen Vorfahren mit Recht stolz waren... und die jetzt andere gern ausrotten möchten, dab er diese seine Sprache wie elnen helligen Schatz bewahre, ehre. verteldige und liebe. - Besondere jedoch sind unsere helmatliebenden kroatischen und slavonischen schönen Frauen verpflichtet, die liebe zur Helmat und zum Volkstum den Herzen ihrer zarten Kinder tief elnzuprägen...

$(95.5 \cdot 197)$. 
In dem berelts erwhinten Art1kel von 1846 gibt Sulek zu, vor welchen Schwierigkelten elne so junge Literatur stehe: die Schriftsteller mülsten "Historiker, Archiologen, Ethnographen, Grammat1ker, Volksschullehrer und Gott weli was noch alles" in einer Person sein. $(95,5.212)$. Es gebe noch keinen Schriftsteller, der das wirkliche Loben des Volkes, selne Brauche usw. schlldern könne; die jetzigen Literaten muBten olch mit skizzen begnugen, deren storf aus den volksliedern geschöpft sel. Dennoch durfe man die Literatur nicht "aut elnen spáteren 2 eltpunkt" verschieben, well sonst welterhin mit fremder literatur auch fremer Gelst elndringe. Sulek welst auf den Zusammenhang zwischen der Literatur und der Geschichte hin, womit er einen Gedanken Manzonis aufgreift: neben der nationalen Literatur kön auch die Verbreltung historischer Kenntnisse zur Erweckung des Nationalgefunls, des Nationalstolzes beltragen (95,5.212).

Auch Šlek, der Im wesentlichen von wissenschaftlichen und historischen Gesichtspunkten ausgine, stellte also die nationale Funktion der Literatur in den Mittelpunkt seiner theoretischen Forderungen.

II.5.2.5. AdoLf Veber-T $k$ a 1 c $v 1 t(1825-1889)$

Tkalkevit, der nach einem Theologiestudium 1850 Gymnasiallehrer in Zagreb wurde und als Verfasser von Schulgrammatiken Pionterarbelt lelstete, trat wărend der Jahre des Absolutismus gegen dip zunehmende Germanisierung auf; selne Bestrafung durch Zwangsversetzung unterblieb nur infolge des politischen Umschwunges. Nachdem er von 1861 - 1867 Leiter des Zagreber Gymnaslums war, wurde er von Baron Rauch einer anderen Tutigkelt Im Dienste der Reglerung zugetellt, un seine politischen Wirkungsmöglichkelten elnzuschränken. Selne Grundhaltung charakterisieren sitze wie diese:

Politische Frelheit besteht darin, daB das Volk selbst selne Fuhrung und verwaltung ausibt... -.eln freles Volk zahlt Steuern, aber es erlegt ole sich selbst auf, und nicht der König.

$(95,5.341)$. 
Ein Mann wie Tkalčevit, der als Gelstlicher die Demokratisierung der Orden forderte und von der "Sklaverei der Gelstlichen" sprach, beurtelite selbstrerstandlich auch die literatur nach inrer bedeutung fur die nationale Freiheit. Fr verófentlichte 1852 die erste umfangrelchere literarische Kritik in "NFVEN". die allpemein als wichtiges Ereignis begribt wurde; sie betraf das Drama "Mejrima" von Matija Ban( 1849 geschrieben). Die positive Hewertung des Dramas brachte Tkalčevit u.a. mit folgenden Worten zum Ausdruck:

Unser Dichter hat bewiesen, dals er nicht nur viele Bestandteile so zu elnem Ganzen zu verschmelzen vermaf, als wären sie aus einem GuB, sondern dab er sie auch mit dem frommen Gelste der Tugend und der nationalen lesensart zu beseelen weib, wodurch sein Werk zu einem wertvolien Besitz unseres gianzen Volkes wird, welches thm in umso frößerer Dankbarke1t verpflichtet ist.

(A.Veber-Tkalčevit, DJela IX,S.728; zitiert nach 3,S.13)

Als Fehler wertete Tkaltevit den nicht eindeutif heldenhaften Charakter einer der zentralen christlichen Gestalten des Dramas (Živan), während er die Technik der Schwarz-WeiB-Malerei der ihrigen charaktere als Vorzug hervorhob:

Seine(d.h.Matija Bans) Helden bleiben sich, von einifen Fehlern abgesehen, immer glelch, sie sind immer konsequent entweder den Tupenden oder den lastern treu, der sieg aber ist der reinen Tugend bestimint. Dadurch wird das Werk sehr lehrreich und ermutigend, obgleich es ihm nicht an schönster Romantik fehlt....

(A.Veber-Tkalcevit, DJela IX,S.667; z1tiert nach 3.S.13). Veber-Tkalčevit, der sich mit verschiedenen problemen der Literatur auseinandersetzte 1 , behielt hinsichtlich der Bewertung eines Werkes immer die gleichen Malsatabe bei, wie Bapac feststellt:

Schön 1st nur das, was zuglelch moralisch 1st; der Dichter darf die Natur nicht kopieren, sondern muls sie idealisieren. ... Be 1 uns solite man keinen Helden schildern, der nichts zur Verwirklichung der nationalen Freiheit beigetragen hat; ein Madchen sollte man nur dann im Gedicht preisen, wenn Heimatliebe sie auszeichnet.

(Aus: "Najnoviji pojavi našega pjesniłtva", 1865; zitiert nach $3,5.15)$.

1 o slogu hrvatskom (1869); Metrika hrvatska (1869);

o hrvatskom heksametru" (1864); Ukus (1882) etc. 
Veber-Tkalčevits moralistischer standpunkt kam u.a. In der Ablehnunf erotischer Gedichte zum Ausdruck, z.B. In der Kritik an der Lyrik Bura Kovačevits und J.E.Tomits.

Den grolien kulturellen Wert der Volksdichtung erkannte TkalCevit unbedingt an, forderte jedoch von den Dichtern der zeit anstelle sklavischer Nachahmung elne Welterentwicklung zu neuen küstlerischen Formen. Deshalb lobte er die Gedichte Kazalis, In denen er den Ansatz zu einer neuen Dichtkunst sah:

Ehren wir unsere Volkslieder als das allerteuerste prand des Geistes unseres Volkes; aber lch bin nicht der Ansicht, dals die Dichter nichts anderes als Helden besingen, kein anderes Versmall als das volkstumliche, keine anderen Fifuren als die der Volkslieder anwenden durfen. Diese Lieder sollen das Fundament sein, auf dem der Dichter und Künster selbständie ein neues Gebăude errichtet...

(Narodne novine" 1858,Nr.188; zitiert nach 3,5.14)

In Utješinovits "Nedjeljko" ("Narodna pjesma Junačka", 186n) sah Tkalčevil diese Art der Dichtung berelts errelcht:

Selne Poesie ist absolut volksnah, ihre Gedanken, Tropen und Flguren und Ausdrücke beruhen auf den Anschauunfen des Volkes, die jedoch mit felnem Geschmack zur Hohe und zur geschliffenen Form kinstlerischer Dichtung emporgehoben sind.

("Naśe gore 118t" 1861,Nr.66, zitiert nach $3,5.16$ )

Obwohl sich Veber-Tkalčrit ebenso wente wie seine zeitgenossen systematisch mit ästhetischen problemen auseinandersetzte, hat er dennoch nächst Vraz mit der literaturkritik begonnen und durch seline Äuserungen vieltach die kichtung der literatur bestimm. Dif zitate zeleen, wie sehr selne Auffassungen von moraI ischen und nationalen Grundsäten bestimmt waren.

1 z.H.: Ut ješlnovit-ostrožinski: M1sli o krasnijeh umjetnostih, uvod za nabe krasoslovje*, In "Vila 0stroźnska", 1845 ;

E.Sladovit: Uputa u pjesmenu umjetnost, Zagreb 1852 ;

Ivan Macun: Kratko krasoslovje, in "NEVEN" 1852. 
II. 5.2.6. Janko J u r k o v I t (1827-1889)

Jurkovit, dem die 1855 in "NEVEN" erschienene Erzählung

"Pavao Cuturif" den Ruhm des ersten kroatischen Humoristen einbrachte - nicht ganz zu Recht, da schon der 1849 verstorbene Nemlit den humoristischen stil pflegte - hat te bereits zu Beginn selner literarischen Tatigkeit klare Vorstellungen von den zielen der kroatischen Literatur. Dies zeigen seine fruhen Artikel ("Moja o kazalistu" und "Misl1 o jeziku", 1855; "Nas1 kalendar1" und "Plsmo nekome mladome prijatelju o spisateljskom zvanju", 1862); nach Nikola Andrit hat es vor Jurkovit keinen kroatischen Schriftsteller gegeben, der mit einer derartigen theoretischen Vorbereltung an die verwirklichung se1ner Ideen von den Aufgaben des Volksschriftstellers herangegangen wăre '

Im Laufe seines erfolgrelchen Lebens war Jurkovit vorwiegend auf pädapogischem, daneben auch auf politischem Geblet tätigi im Schulwesen nahm er länfere Zelt hervorrapende Positionen ein. Selne allemeine Tendenz zum Belehrenden melet sich z.B. In seinen Äulserungen zu Artikeln eines bestimmten Autors in "NF. VFN" : -..hier zeift sich der lobenswerte fifer des rechtschaffenen J,ehrers und Freundes der Volksblidung... ...und daher habe $1 \mathrm{ch}$ diese Artikel mit besonderer Aufmerksamkelt gelesen... und lch habeaus der letzten Nummer des "NF.VFN" jenen Gedanken von der Nutzlichkelt und Zweckmäligke1t des lesens helterer Texte mit moralischem firundgedanken als Mittel der Belehrung für die lesende Jugend aufgegriffen...

$(57,5.201)$

In dem eleichen Aufsatz ("Moja o kazalištu") wendet sich Jurkovit gepen die Sentimentalitä und die psychologische Unglaubwirdigkelt der damals aufgefunrten Tragödien und fordert die Schaflung elner volkstülichen Dramatik (57,5.205), fur die Demeter mit seinem Werk"Teuta"(1844) ein Belspiel gegeben habe. Von der Komödie fordert Jurkovit eine belehrende Wirkung durch das negative Belspiel; gerade für ste böten die elnhelmischen Verhältnisse Stoff in Hülle und Fülle, und sie sol die für Kroatien angemessenste literarische Gattung.

II Nikola Andrit: Pod apsolutizmom, Zagreb $1906,5.34$. 
Die Bedeutung der Pflege der Muttersprache hob Jurkovit in dem Aufsatz "Misli o jeziku" hervor, in dem er diese Aufgabe der schule, vor allem aber den kroatischen Frauen ans Herz zu legen versuchte. In dem Artikel uber den Beruf des Schriftstellere kommt er erneut auf die wichtige voraussetzung der Kenntnis der eigenen Sprache zurück und weist auf den Wert des Flelbes und der ständigen Ubung hin; hier tritt u.a. berelts der Gedanke vom Dichter, der ein besonderer Mensch sein muls und aus innerem Antrieb schafft, auf:

Der Künstler muls zuallererst in sich die stimme des Herzens vernehmen, Jenen inneren Impuls, der thn zwingt, dem Ideal nachzujagen... (57.5.225)

Du slehst, dal der Dichter kein gewöhnlicher Mensch ist, dals es nicht jedem gegeben 1st, ein Dichter zu sein; daß er ein Liebling der Götter sein muls; dals er dazu geboren sein muls, und dals es sehr muihsam, um nicht zu sagen einfach unmöglich ist, eln Dichter zu werden. (57.5.229)

Wo alle dichten, ist dies ein sicheres Zeichen, dals das Volk den Ernst des Lebens noch nicht erfalit hat. ...Dieser Frnst des 1ebens wird in Prosa ausgedruckt. $(57,5.230)$

In seinen Forderungen unterscheidet Jurkovit also 2 wischen dem "seltenen" Dichter, dem Musensohn der Romantik, und dem Schriftsteller, der durch Ubung, durch Schulung an klassischen Vorbildern und durch häufiges Uberarbeiten seiner Texte zu einer guten Leistung gelangen kann:

..verlali dich niemals auf die erste Niederschrift... ...so musa auch aus einer schlechteren Arbelt schliels$11 \mathrm{ch}$ ein ausgezelchnetes Werk entstehen.

$(57.5 .233)$

Nachdem Jurkovit Mitglied der Jugoslavischen Akademie geworden war, veroffentlichte er elne Heihe von Arhelten uher hathetische Probleme ("O narodnom komusu"; "Ob estetskih pojmovif uzviłena"; (1874). "O ženskih karakterih u nasılh narodnih pjesmah"1874; "o metaforı našega jez1ka" 1875). In diesen Schriften, in denen er, wie BARAC berichtet, zwar einige der damals neueren auslandischen Werke erwahnt, im wesent$11 \mathrm{chen}$ Jedoch auf dem Standpunkt der formalen Ästhet1k verharrt, wies Jurkovit u.a. auf die Anregungen hin, die die kroatische iteratur, insbesondere die Dramatik, aus den epi- 
schen Liedern und aus typischen Erschelnungen des eigenen Volkslebens gewinnen könne (3, S.21/22).

Henngleich Jurkovit, wie übripens auch Demeter - die Idee des deutschen "Sturm und Drang" vom küstlerischen Genie aufgegriffen hat, das aus der Tiefe selner Empfindungen heraus schafft, uberwlegt bel inm doch die vorstellung vom Schriftsteller als Lehrer des Volkes und "Priester der Aufklarung, der Bildung und der Kultur" (all diese Begriffe etwa unfaBt das Wort "prosvjeta", zumindest im Kontext des 19.Jahrhunderts; vgl. 51,S.33). Unter "Nutzlichke1t" ist bel Jurkovit, wie das zitat liber den Wert heiterer Lekture zelgt, vor allem moralische Belehrung zu verstehen. In seinem Aufsatz "Našl kalendari" z.H. helist es:

Unser einfaches Volk liebt die wissenschaft, Insbesondere wenn man es versteht, sie thm in einer Art nahezubringen, die selnem Verstand und seinem Gelst zuganglich 1st. Deshalb muiste der Inhalt unserer Volkskalender wenigstens zum uberwlegenden Tell belehrend sein, etwa gute und hubsch geschriebene historlsche Artikel, durch die das Nationalbewulstsein, der Nationalstolz geweckt wird... $(57,5.22 n)$.

In Jurkovits forderungen an die Literatur verbinden $\mathrm{sich}$, wie bel den melsten zeltgenossen. Auffassungen, die noch aus der Epoche der Aufklarung des 18.Jahrhunderts stamen, mit dem Volksbegriff der Romantik:

Unsere Aufgabe mul vor allem die allseltige Entwicklung unserer nationalen Individualitat sein. $(57.5 .221)$

Wenn es Jurkovit selbst nicht gelang, selne so prazise formulierten Vorstellungen in selnen elgenen frzahlungen zu verwirklichen, obwohl er als stokavisch sprechender slavone wentger sprachliche schwierigkelten hatte als die "kajkavci", lag dies am Fehlen eben jener schöpferischen spontaneitat, fur die er selbst gelegentilch elngetreten ist. 
IT.5.2.7. August $S$.

Durch die Porsönlichkelt Šnoas lst in der kroatischen Literatur d1e Ubergangsperiode zwischen Romantik und Realismus gokennzelchnet. Šenoa, dessen vielseltige literarische Tatigkeit sich über den Zeitraum von ca.1860 b1s 1881 erstreckt, veröffentlichete 1865 in der Ze1tschrift "GLASONOŠs" selnen fast programmatisch zu nennenden Artikel "Naśa knjizernost"; FLAKER setzt daher bel der Perlodisierung der neueren kroatischen Literatur dieses Jahr als die Grenze zwlschen der "nationalen Pseudoromant1k" (1850-65) und dem kroat1schen Vorrealismus und Real 1smus $(1865-92)$ an $(33,5 \cdot 34)$.

In d1esem Artikel (109,S.1B7-146) umr1B Šenoa die Krise der kroatischen Literatur und deutete die Hauptrichtungen selnes Programms an, an welches or selbst stch whinrend der folgenden Perlode konsequent hielt. Tendenzen zum Realismus, zur Poychologislerung waren zwar schon vorher sowohl in den Artikeln veber-Tkaltevits und Jurkovits als auch in einigen kunstlerlschen Ansatzen vorhanden; bel Senoa jedoch tritt die Forderung nach Realismus in voller Deutlichkelt auf, und die Bezugnahwe auf das "Volk" erschelnt in welt konkreterer Form:

Ich bin der Ansicht, daß gerade das soziale Moment in unserer gesamten Entwicklung und Bewegung das allorwichtigste $18 \mathrm{t}$.

Solange be 1 uns der Bauer nicht geblldeter 1st, solange der nationale Gelst nicht nur in jeder stadt, in jedom Amt und in jeder Schule, sondern geradezu in jeder Fami11. verwurzelt $18 t$, die das elgentliche Fundament sowohl des Volks-wie des staatlichen Lebens $18 t$, solange glbt es keln starkes, vielfultiges nationales Leben! Dieses nationale Leben zu starken und zu festigen, 1st oben d1e Aufgabe des populiren, belehrenden und unterhaltenden $\mathrm{Zwe} 1 \mathrm{ges}$ der Literatur.

(109,5.139)

Von ganz besonderer Bedeutung sind diese zwelge der Literatur bel jenen volkern, die entschlossen sind, eine selbstind 1 ge $21 v i l i s a t i o n$ zu shaffen, un thre Individua11tit gegenüber fremden Elnflibsen zu bowahren. Be1 solchen völkern wuB die Literatur tendenziös seln. $(109,5.140)$

Als Vorbild elner solchen Literatur nannte Šnoa die polnische Literatur. Fs habe aber wenig Sinn, auslundische bücher, wie z.B."Bablika" von der tschechischen Autorin Nemcovh zu uber- 
setzen, da das Milleu der einfachen Leser fremd oel; das Volk, dor auBer der "Gospodarsk1 l1st" und elnigen Almanachen und Kalendern nichts geboten werde, emarte von seiner lekture, dab s1. eIn Spiegel seines eigenen Lebens se1.

Besonders vernichtend war Senoas Urtell über die kroatische Novellistik, In der es selt Bogovits letzter Novelle (1859) nichts Nennenswertes mehr gebe. Als beste Autoren bezelchnete or Jurkovit und Kurelac, den er den besten Prosalsten nannte. Šenoa, der alt der Ubernahme der Redaktion des "VIJENAC" zuglelch der produktivete Autor der Ze1tschrift wurde, hat bis zu seinem Tod durch Zeltungokritiken, Artikel, Feullletons ("Zagrebul je", 1866/67;1877;1879;1880) Elnflub auf d1e Entwicklung der literatur und die Auffassung von ihren Aufgaben genomen. In selnen Romanen behandelte er stoffe aus der Vergangenhe1t Kroatiens, weil auch or das Wisen um die Geschlchte des elgenen Volkes fur elne Stutze des Nat1onalbewubtselne hielt; in selnen Novellen beriuhte er sich un fosselnde, lebenonahe Gestaltung zeltgenossischer Probleme.

In Natur und Kunst sah Šnoa kelne Gegenstze: d1e Kunst se1 d1e vollkomenste Stufe der Natur, und was nicht naturlich sel, könne nicht in eigentlichen Sinne künetlerisch sein. Mit Anschauungen dieser Art war Šenoa der erste und zahes te Vorkámper des Realismus in Kroatien.

Zur Ablehnung des deutschen Elnflusses veranlabte Šenoa nicht allein die politische Lage, sondern auch die Uberzeugung, daB der Charakter der "Nordlander" (severnjac1) der Lebhaftigke1t der Kroaten welt wenloer entspriche als z.B. der der Franzosen oder Italiener. Durch selnen Hinwels auf die anderen 1 lavischen Literaturen, elt dem or elnen Gedanken Vraz' aufgriff, gab Senoa den AnstoB su der sunehmenden Beschaftigung in den russischen Schriftstellern, deren ElnfluB, vor allea der Turgeners, auch in selnes elgenen literarischen Werk spurbar 1st. Auf die Notwendigkelt zur literarischen Gestaltung der oozialen Verhultnisse w1es Senoa z.B. In Zusammenhang mit Gogol's "Toten Seelen" hin:

Der soziale Roman funrt uns durch die unerbittliche Selbstanalyse zur Erkenntn1s. ("VIJENAC" 1874,S.443) 
Šnoa verfolgte auch die zeltgenössioche serbische Literatur und nahm kritisch zu lhr Stellung. In Jovan Jovanovit zaaj an or einen

von himmlischem Feuer Insplrierten Dichter, der, aus dem Volk hervorgegangen, aus der Tlefe der Volksseele dichterlsches Gold schöpfe und dieses, durch die Flamme selnes Genies gereinigt, dem volke in wundervolien Gedichten zuruckgebe ("VIJENAC" 1878,s.776).

̈̈hnliche Worte der Begelsterung enthalt seln Nekrolog fur Dure Jakšll ("VIJENAC" 11878,5.88). LJubiša nennt er olnen fourlgen, klugen Menschen mit lebhafter Phantasie und Rednergabe und einen ausgezelchneten Kenner der Volkssprache der Hercegovina; Šapčanin verglelcht or mit Jurkovit.

Mit dem Auftreten Senoas und dem fast gleichzeitigen Ruckzug Bogovils von der Novelistik war die Perlodedes patriotischen Dilettantismus in der kroatischen literatur beendet; dies yuber sich in der ernsten Auffassung Senoas vom Beruf des Schriftetellers:

Nach meiner Erfahrung scheint es mir, daB die melsten Leute, die sich mit dem Schrelben von Novelien beschiftigen, diese Arbe1t nicht ernst nehmen...

-..wenn du beim Schreiben nicht jede Landschaft, jeden Gegenstand, jede Person vor dir slehet... wenn du nicht jeden Schmerz und jede Freude mit deinen erdachten Peronen mitfihlst...dann taugt deine Arbelt nichts, denn du hast kelne Kraft in dir, dann wirf die Feder weg... ...jeder Mensch auf der strabe trägt in sich eine kleinere oder grölere Geschichte, manchmal kann man sie geradezu auf selnem Gesicht lesen, aber wer ...nicht lesen kann, der soll nicht schrelben....

("VIJENAC" 1879: Knj1ževna p1sma. 21t1ert nach $111, \mathrm{~s}$. 273-275)

Šnoa lehnte es strikt ab, dem Schriftsteller seln Thema vorzuschrelben; dieses musse selner Nelgung, selner veranlagung und seinen Fahigkeiten uberlassen bleiben. In der Literatur sah er kelnen Zeitvertreib fur mülge stunden, ebenso wentg durfe ste selbstzweck Im Sinne des "l'art pour l'art" seins

wir wollen das Volk erheben und zur selbstbesinnung bringen die Fohler der Vergangenhelt wieder gutmachen und in $1 \mathrm{hm}$ den Sinn für alles Schöne, Gute und Edle wecken. ("VIJENAC" 1879, S.57).

In Satzen wie diesem liegt der Schluseel zu dem "milden" Realismus (blagl realizam), den man allgemeln als Charakteristikum Senoas bezelchnets er forderte elnen Realismus, der den leser nicht schockierte, sondern inm Elnsichten vermittelte und platz 
fur Hoffnung und Versobnlichkelt 110B. DaB or damit den richtigen Ton traf, zelgt die Tatsache, dab eigentilch erst durch thn oin breiteres kroat1sches Leserpublikum gewonnen wurde. Hierzu trug wesentlich der Erzahlotil Senoas bel, in welchem - ich ochrifteprachliche und umgangesprachliche Elemente so verbanden, dab der Text fluselg und $108 \mathrm{bar}$ blieb und an den Ton der Volkserzahlung nur in eben jenem Maße anklang, daB or vertraut, aber nicht imitierend oder archalsierend wirkte.

D1. Vorausetzungen fur Senoas auberordentliche literarische Aktivitut lagen sowohl in selner grindlichen Kenntnis anderer europalocher Literaturen als auch in oelnem ungewbhnlichen crzanltalent und oelnem Gespur fur die Notwendigkelten der 2e1t. Immer noch war der nationale Gedanke die zentrale Idee der Literatur, lmmer noch ging es um die verteldigung der Integritut des kroatiochen Volkes:

Freihelt und Volkstur sind zwel untrennbare Begriffe. (1n "P0zOR" 1861; z1t1ert nach 111,S.18).

Deshalb setzte or sich fur elne Literatur ein, die nicht nur d1e elgene sprache reprusentierte, sondern auch den elgenetundigen, unverwechselbaren nationalen Gelot; deshalb ging es thm um die Ausschaltung fremder Einflusso und um die Forderung elnheimischer Talente, die or, wie die optere Kritik foetgestellt hat, oft zu mild beurte1lte, und nicht un die schaffung eines Systems der Ästhetik, ondern vielmehr um praktische Anwendungen. Um wieviel welter Senoas Horlzont war als der oelner vorgungor, ze1gt eln vergle1ch zwischen der Kritik Vober-Tkalčvils an Bans Drama "Mejrima" aus den fruhen 50er Jahren und Senoas Besprechung der "Marta Posadnica" rom glelchen Autor. wuhrend Veber-Tkalčevil elne schablonenhafte schwarz-We1B-zelchnung der Charaktere und die absolut positive Darstellung der Chrioten gegenuber den "Turken" verlangte, kritisierte Senoa an Bans Drama d1e mangelhafte Herausarbeltung des Konfliktes zw1schen zwel Ideen, w1e er 1m historlschen Thema - dem ZusamenotoB zwichen dem aufstrobenden Moskauer staat und dem frolen alten Novgorod - angelegt war, d1e fehlende Konsequenz der Charaktere, den Mangel an dramatischer ste1gerung $(3,5 \cdot 38)$. In -1ner zelt, die den nationalen akzent in der Literatur unurgunglich brauchte, wiol somit Šnoa glelchzeltib auf jene Qualituten hin, die elnem verk uber die momentane Aktualitut hinaus Gultigke1t verle1hen. 
IT.5.2.8. Franjo Markor $\operatorname{ll}(1845-1914)$

Franjo Markoril gilt als der erste kroatische ïsthetiker, der den limpressionistischen $S_{t} \cdot 1$ lungnahmen nach Art Šenoas eine wisenschaftlich fundierte Theorle gegenuberstelite, die auf den Ideen des deutschen Philosophen Herbart basierte.

Der dem kroatiochen Adel entstamende Franjo Markovil, der whrend selner Schulzelt die Perlode der Intensivoten Gormanisiorung durchmachte, lernte whrend selnes Studiuss in wien - wo Senoa und Ivan Dežman zu selnem Froundeskrels gehorten - die anderen savischen Literaturen, insbesondere die polnische, kennen. Zeugnis selner slavischen Begelsterung ist das unter dem Eindruck Micklewiczs und Byrons beschriebene Epos "Kochan 1 vlasta"(1868). Sein Fruhwerk "Dow 1 svijet"(1865) behandelt in romantischer Form die Innerkroatischen Verhaltnisse zur $\mathrm{Z}$ it des Absolutismus. Be1de Epen zeigen eine starke antideutsche Tendenz, die fur den zeltraum lhrer Entstehung bexelchnend $18 t$. Bere1ts m1t selnem 1869 in "VIJENAC" verbffentlichten Aufsatz "O baladah 1 romancah" wandte olch Markovil dem Geblet selner kinftigen Interessen zu - der ïsthetik und der auf ihr fundierten Kritik. SeIn Gesamtwerk setzt slch aus wisenschaftilchen Abhandlungen uber Probleme der Kunst und der Literatur, aus Stellungnahmen zu aktuelien Fragen und zu Nouerschelnungen und aus Artikeln uber bltere Autoren zusammen; seln erst 1902 orschienenes Hauptwerk "Razvoj 1 sastar optene estetike" enthalt -1ne Kompilation seiner bereits friher gekuBerten Ansichten. Markovils ïthetik erschöpft sich nach BARAC mehr oder weniger In Darstellungen der formalen selten der Kunet; d1e grundlegende Frage nach dem Wesen des Schönen beantwortete er wie VeberTkalčevit schon in den 50er Jahren mit dem Hinwele auf die "Elnheit in der Vielfalt", die zur E1nheit gestaltete vielfalt $(3,5.41)$. Unter dem zentralen Begriff "oblik" (Form/Geatalt) verstand Markovil nicht nur die duBeren, sondern auch die Inneren Elemente des Kunstwerke:

Der Wert der dichterischen Schöpfung liegt nicht 1E Gegenstand, sondern in lhrer Gestalt. Allerdings darf nan unter Gestalt nicht nur die wetrische und opachliche rorm der Dichtung rerstehen, sondern die Idee, die Komposition, die Charaktere, die psychologische konsequenz. ("VIJENAC" 1873,s.225; zit1ert nach 3,5.41/42). 
Proportionalitut in Sinne des goldenen Schnittes, Symetrie, dre1- bsw. funfte111ger Aurbau waren fur Markorif wicht160 kinetlerische Prinziplen, deren Anwendung thn manchnal zu allsu formal 1st1scher Beurteliung von Kunstwerken fuhrte. ReaI1smus und Natural1smus waren fü 1 hn blinde Nachahaung der Naturs Aufgabe der Kunst oel os, d10 Natur su 1deal1e1eren. Äs thet 1sche Qualitut tollte or uber Aktualitut.

Der Grundsutzlichste Unterschied zwischen Markovif und Senoa 128 in threr Auffaseung vom Wesen der Kunst und von threr Boziohung zu anderen Lobenoberelchen. Wuhrend der Pragaatiker Šenoa elne tendenzibse Literatur 1a Dienst der allgeweinen Aufkikrung verlangte, oagte z.B. Markovit in oeinen Vortrugen uber das Theater:

No 1 mmer die drawat1sche Kunet als Mittel und nicht un lhrer oelbet willen gepflegt wurde, entwickelte 10 elch nicht in lhrer naturlichen, ursprüglichen velse, ondern war nur elne echwache Kople fremder Vorbllder.

...das Drama, w1e uberhaupt jede Kunst, taugt nichts, wonn es nur als Mittel fur politische zwecke gepflegt wird, Inebesondere dann, wenn diese der $s_{t} 1 \mathrm{mme} d e r$ Geschichte und der Menschhelt widersprechen.

("VIJENAC" 1870,S.356)

Jede Tendenz ochadet zunkchst der formalen Vollkomenhe1t, wenn sie in der Literatur auftaucht, und erst alt

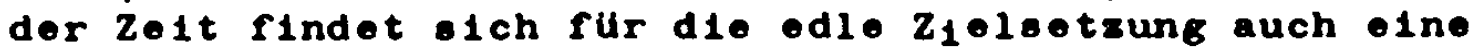
schöne Hethet1eche Form.

("VIJENAC" 1873,s.237).

Gerade das letzte 21 tat ze1ct, dab Markovit nicht den reinen "l'art pour 1 'art"-Standpunkt vertrat, dab or aber d1e Gefahr der Uberechktzung auberliterarischer W1rkeamkelt erkannte.

In selnen Kritiken Jener Werke, die an die mundliche Tradition anknupften, betonte Markoril das Verdienst der Autoren, aus dew rohen ungeschliffenen Vorblld der Volkedichtung literarieche schopfungen entwickelt zu haben (z.B. In Vorwort au Luka Botite "Pjesme" , 1885 ).

BARAC stellt fest, daB die kritischen Methoden Markorito berelts veraltet waren, alo or 1 e anzuwenden begann; da aber Markorit - In perebnliches Gespur rur d1e Kunst, elne besondere Untereche1dungefuhl gke1t zw1schen Konstruktion and Kunstwerk besessen habe, seien elne Urte1le doch oft sutreffend, nur druckte elch Markorif melet so unstundlich aus, dab eelne Artikel s.B. heute rast unlesbar sind. $(3,5 \cdot 59 / 60)$. 
Dennoch etellt das Werk Markovibs einen Großen Fortachritt in Richtung auf die Orientierung an allgoneingultigen rriterien dar, die uber d1e aktuelle, wenn auch noch oo dringende Notwend1gke1t hinaus gehen. D10 Wl rkeanke1t der kursen krit1echen Stellungnahmen Šenoas war unglelch größer; doch alluhl1ch golangte Markovit zu oo allgobelner Anerkennung, das or den luf elner Autoritut erlangte, die das letzte Vort uber die kroatiochen Schrifteteller su eprechen hatte, vor allem nach Senoas Tod. BARAC echreibt:

Markovils bethet1eche Anechauungen calten in Kroation fast drel Jahrzehnte lang alo etwas, was auberhalb joder Diskussion oteht.

Markovite weitgefabter Begriff "oblik" 1ot olcher nicht lamer in seinem Sinne interpretiert worden, was z.B. dazu fuhrte, daB manche Iritiker, welche die küntlerischen Ausdruckenttel an Hand von Markorils formaler Hethetik untereuchten, den Wert dos "Smrt Smail-ago Cenglta" haupteuchlich darin orblickten, dab hier offenbar der "rolletundigste Kodex der (oogenannten) kroat1schen Poet1k" vorliege(38,5.15). Der wesent11chete Mangel bolner Kritiken liegt jedoch nach BARAC darin, daB 10 in kelner we1se d1e Atmoephure berickelchtigen, In der e1n Kunetwerk ontetanden ist, obwohl or auf diese Notwendigke1t ellbet hingewiesen hatte $(3,5.60)$. Solner bereits in den Vortrugen uber das Theater formulierten Forderung, daB die $L_{1}$ teratur jene Aufgaben erfullen musee, die lhr das Volk und solne situation eteliten, konnte er oelbst alt selnen dramatischen vereuchen nicht cenugen ("Iarlo Dračk1", "Benko Bot", 1872; "Zronimir", 1877, von Šnoa cehr wohlwollend bourtellt). Wenn er diese Forderung gegen Ende des Jahrhunderte erneut an d1e Junge Generation richtete, oo lag hierin ein gewiseer widerspruch su eeiner auf absolute Mabetube fixierten Einstellung.

Da ich Markovil in ounehmendem MaBe aus dor aktuelien Literaturbetrlob herauehielt, war oeln E1nfluB auf die weltere Entwicklung relativ gering. Sein Verdienet liegt haupteuchlich darin, daß or durch d1e Betonung der usthetiechen Qualituten des Iunetwerks den Geolchtekreis der kroatiechen Literaten weitete und einer fundierten Xritik den wes ebnete. 
III. Die Volksdichtung als elner der Ausgangspunkte

der jungen Literaturen

\section{1. Funktionen der mündlichen Literatur}

Vido LATKOVIC stellt in selnem Buch "Narodna knjizievnost" rest, daß für die Entwicklung der serbischen Heldenepik die allgemelnen Bedingungen miindlicher literatur nicht genugt hatten, sondern dals es hierzu daruber hinaus eines langdauernden Kampfes gegen einen Felnd bedurfte, der die Thematik und die ldeelle orientierung der Dichtung bestimute $(62,5.20)$.

Aus dieser Feststellung labt sich die Antwort auf die Frage nach der Funktion der Heldenepik unmittelbar ablelten: ihre wesentlichste Aufgabe lag demach in der starkung des Kampfeelstes und des Nationalstolzes. In glelcher weise, wie stch hier die Funktion elner literarischen Gattung aus ihrem historischen Hintergrund erklaren laist, macht z.B. der Zusammenhang anderer Lieder mit Ritus und Hrauchtum deren Funktion als Erfullung religibser und sozialer Bedurfnisse deutlich.

Die Funktion der muindlichen Literatur innerhalb ihrer ursprunglichen Umgebung wurde von Ihren "Entdeckern" in der 2.Halfte des 18.Jahrhunderts im wesentlichen als eine nationale gesehen. Diese Komponente trat bereits bel August Burger in seinem "Herzensergul uber Volks-poesien(1776) in den Vordergrund, wie BAUSINGER feststelit(9,S.13). Herder ging es um eine belebende Funktion der Volkspoesie innerhalb der zeltgenössischen Literatur. Die von MacPhersons "0ssian"(176n) ausgelöste Begeisterungs welle in den gebildeten Schichten Europas bewirkte ein schwarmerisches Ruckbesinnen auf das "Volk" und die "Volkspoesien und damit eine Idealisierung dieser Begriffe. die sie in den Bereich des Mythos entruckte. Hinter den Worten Jakob Grimms vom "Schlei des Gehelmnisses". der uber der Entstehung der Volkspoesie liege, und von Ihrer "tiefsinnigen Unschuld"' steht die Vorstellume elner helien welt, die es nife gegeben hat, aus deren pflanzenhaftem Dasein die Poesie wie elne Blute hervorspriebt und die Frage nach threr Funktion gewissermaben durch thre blobe Existenz beantwortet.

Jakob Grimm: Uber den alten Me1stergesang, Göttingen 1811, $\mathrm{S} .5$ und $\mathrm{S} .170 \mathrm{Anm}$. 
In den glelchen Vnrstellungsberelch gehören die Herderschen Begrif. fe von der "Natursprache" und der "Naturpoesie" oder Hananns berihmter Satz: "Die Poesie lst die Muttersprache des Menschengeschlechts" 1 .

We1t konkreter war demgegenuber die Funktion der neuerschlosenen Volksdichtung in der Gegenwart als belebender Urquell der Kunst uni als moralisches Vorbild umissen. Durch die Glelchsetzung der BeGriffe "Volkspoesie Naturpoes10 = Nationalpoesie" (9, S.20), die sich aus der Yerwendung dieser Bezelchnungen durch die Romantiker ablesen labt, erfolgte jene vendung zur Uberbetonung der nationaIen Funktion - sowohl Im Hinblick auf die Vergangenheit als auch auf die Gegenwart - die fü das 19.Jahrhundert charakteristisch $18 t$.

Die von den Bridern Grimm angeregte Sammlertatigke1t, die im serbokroatischen Raum Vuk Karadžit und seine vielen Nachfolger aufnah men, stand in zunehmendem Mabe in Zeichen des nationalen Gedankens an dem sich in paralleler Entwicklung zum Kampf um die politische Selbstandigkelt die jungen Literaturen orientierten. Da für sie das Kernproblem darin lab, uberhaupt erst elne adaquate sprache zu finden, bedeutete in diesem Raum die volksilteratur weit mehr als elnen wlederentdeckten kunstlerischen Wert und elne Möglichkelt zur Erneuerung der Poesie; sle war einfach die wichtigste Quelle, aus der die zu formende Literatursprache geschöpft werden konnte.

Wahrend sich die Sammler bemihten, so viel als möglich zusammenzutragen, begannen die Erforscher der Volksilteratur mit der Klassifizierung des Materials, der Untersuchung von Motiven und Symbolen sie befabten sich mit der Frage nach Entstehung und verfassern und mit der zuordnung zu bestimmten volksgruppen oder völkern. Das letztere Problem erwles sich in elnem Geblet, welches jahrhunderte lang durch Bevölkerungsverschiebungen gekennzelchnet war, als besonders schwierig. Das úbergewicht der Idee von der volksuberlieferung als nationalem Érbe, als elnem aus glorrelcher vergangenhelt herubergerettetem Schatz bewirkte, dals Erwagngen uber sonstige Funktionen der mündlichen Literatur in den Hintergrund traten. Worln diese nationale Funktion im einzelnen bestehen kann und welche Aufgaben der volksdichtung daruber hinaus zufalien, wrd nachstehend skizziert.

1 Joh. Gg. Hamann: Kreuzzüge elnes Philologen, 1762. zitiert nach : Aeethetica in nuce, otto Mann, Le1pzig 1937, S.381. 
Dort, wo man entweder uberhaupt noch keine schrift kennt oder wo das geschriebene Wort erst im Begriff 1st, seine dominante Position zu erobern, fallen der muindlichen Literatur zahlretche Aufgaben $z u$, die auf einer fortgeschritteneren stufe dem Schrifttum vorbehalten sind oder, aufgrund veranderter bebensformen, uberhaupt nicht mehr gestellt werden. Dieser Aufgabenbereich erstreckt sich von der einfachen Mittellung einerseits bis zum feierlichen Kultwort, der oft "dunklen" rituelien Formel andererselts; er unfalst alle zwischen diesen Polen liegenden Schattierungen sprachlicher Gestaltung, d.h. das weite Feld der "Erbaung und Helehrung", welches die Individuelle Gefülstuberung elnschlielst, und die Fulle der an das Brauchtum und an die wichtigen stationen des lebens gebunden Texte, die entsprechend ihrer Bedeutsamke1t für die Erhaltung von Tradition und Gemeinschaft zwischen der "Belehrung" und dew Ritus stehen. Es soll versucht werden, In diesen, jede beliebige Volksliteratur umfassenden Kahmen die im serbokroatischen Raum bestehenden Arten elnzufigen.

Mit der Einteilung der serbokroatischen Volksilteratur in seiner drelbandigen Auswahl von 1952 hat Trrtko CubEl.IC deren wichtigste Gruppen bezelchnet, von denen 1ch hier ausgehen will: epische Lieder, Erzahlungen, lyrische Lieder. Erganzend mussen noch die literarischen kleinformen bericksichtigt werden, wie sie in anderen Sammlungen enthalten sind.

Kein Gebiet der serbokroatischen Volksdichtung ist selt dem Erwachen des Interesses fur d1e "naturnahe" Poesie so eingehend behandelt worden wie die Heldeneplk. Auf ihre ursprungliche Bedeutung im Herrscherkult, der an den Grtterkult anschlob und den Firsten in den Strom der Uberlieferung elnbezog, schlob man in Analogie zur Stellung der klassischen Epen. Inre spatere ethische Funktion, das Bewubtseln völkischer Eigenstandigkeit in elner Zeit der Freadherrschaft wachzuhalten, lag für jeden Sammler, Forscher oder Leser des 19.Jahrhunderts auf der hand, da dieses genau der Zeitraum war. in dem die Idee der nationalen Fretheit Allgemelngut wurde und in den jungen, durch sprachliche bzw. ethnische Elnhelt bestimmten staaten reale'Gestalt annahm. 
Dab gerade bel den Serben diese nationale Funktion vielleicht noch intensiver von der autokephalen serbischen Kirche ubernommen wurde, sel hier nur am Rande vermerkt. Die Bedeutung des epischen Heldenliedes als Bastion serbischen Nationalgefuhls nach dem Untergang des Großeerbischen Relches oteht jedenfalls auber Frage. Will man diese nationale Funktion durch Entsprechungen aus einew uns vertrauteren sozialen Milieu prazisieren, so könnte man sagen: das Heldenlied war politisches Programn und Bekenn1 nis, es war Mittel der Agitation wie Flugblatt oder Pamphlet, und es war der rituelle Text fur die symblische Handlung der Selbstbesinnung.

Daneben jedoch erfullte die Epik auch die verglelchswelse vorder. grundigen Aufgaben der Mittellung historischer oder aktueller Er. elgnisse und der Unterhaltung, ungeachtet ihrer oft hohen künstlerischen Qualitut, etwa im Verhaltnis zu einer heutigen Tageszeltung. Auch die von Kacit so schmerzlich empfundene historische Unzuverlassigkelt des Heldenliedes steht nicht im Widerspruch zu dieser Parallele.

Mittellung und Unterhalting sind auch wichtige Funktionen der Volkserzahlungen, ob es stch um Marchen, Legenden, Safen, realistische, sat1rische oder schreckenerregende Geschichten, Anekdoten, sog. Volksnovellen (narodne novele). Fabeln oder Tiergeschic ten handelt, wobel naturlich einmal die elne, einmal die andere Funktion liberwiegt. Wenn auch fast jede Erabhlung einen belehren. den Kern enthalt, so geht es doch durchaus auch un die Mitteiluni einer "unerhörten Begebenheit" im Sinne der zur Definition erhobenen Bemerkung Goethes uber das wesen der Novelle. In ganz ande. rem Maße als dem Schriftsteller $18 t$ es ja dem múndlichen Erzáhler bewubt, dab er selne Zuhörer fesseln und eine eventuell beabsichtigte "Moral" geschickt verpacken muB, da er selne Erzählung ohne Publikum uberhaupt nicht realisieren kann. Selbst ein noch so sehr auf die Wirkung bedachter Schriftstelier legt sein Werk erst in fertigem zustand vor, whrend beim miindlichen Schar. fensvorgang der Zuhörer unmittelbar an der Entstehung betelligt 1st. Hierin gleicht der Erzahler dem Schauspieler mit all seinen Abhangigkelten von elnem schlechten oder jenem "guten" Publikum, das thn durch selne Antelinahme zu besonderen schöpferischen Leistungen emportragen kann. Der Erzahler erfullt aber nicht nur den Wunsch der Zuhörer nach Unterhaltung, indem er aufregende Erelenisse schildert oder durch das stichwort der 
bloßen Nennung eines interessanten Milieus, etwas Königshof, Schatzkammer, Drachenhöhle, ihrer Phantasie Nahrung gibti er befriedigt zugleich ihr elementares Bedurfnis nach Gluck und stutzt ihren Glauben an die Gerechtigkelt - oder an das Wunder: der Schafhirt kann zum König aufsteigen, der ausdauernde Held uberwindet al le Hindernisse und besiegt das Bose. I Selbst gelegentliches Unterliegen bedeutet, In etwas weniger direkten Varianten, einen Sieg in höherem Sinne). Schlieblich aber bestitigt der Erzahler auch ausdricklich die Lebensauffassung der Gemeinschaft, der er ebenso angehort wie seine zuhorrer, ob es sich nun um religiöse oder soziale Vorstellungen und Vorurtelle oder um die Wertschátzung bestimnter Elgenschaften handelt.

Damit bietet der münliche Erzähler genau das, was spliter die Trivialiteratur bietet: die Illusion und Hoffnung eines besseren, intensiveren Lebens, die Möglichkeit zur Identifikation mit den positiven Figuren und, nicht zuletzt, die erneute Uberzeugung von der Richtigkeit der eigenen Anschaunngen - mit anderen Worten: das, was das Publikum hören will. DaB er das tut, is t fur den mündlichen Erzahler eine Lebensnotwendigkeit, denn in der Folklore besteht, wie JAKOBSON/BOGATYREV es formuliert haben, die "absolute Herrschaft der Präventivzensur" $(46,5.7)$.

Selbstrerstindlich haben viele serbokroatische Volkserzthlungen auch eine ausgesprochen nationale Funktion, die der der Heldenepik entspricht, nur auf einer anderen stilebene. Hierfur finden sich unter den montenegrinischen Erzählungen besonders viele Beispiele, die oft durch die Knappheit des Ausdrucks und den ausgeprägten Realismus zur Kurzgeschichte tendieren.

Die Existenz der Volkssatire, mit der ein geschickter Erzáhler seine Zuhörer zum Nachdenken, zum "Zu-Ende-Denken" anregen kann, läßt ihre Funktion als Waffe der Unterdruckten erkennen; sie zeigt übrigens das Erreichen einer hoberen geistigen stufe durch die gesamte Gemeinschaft an, da sie sich andernfalls nicht hitte halten können.

Das epische Lied und die Erzailung sind Formen der Volksliteratu: die von einem Einzelnen vorgetragen werden; der Begriff des lyri. schen Liedes umfaßt sowohl individuell gestimmte Liedarten, die den Elnzelvortrag erlauben oder verlangen, als auch Gemeinschafts. lieder, die thn ausschlieben. In einer Gesellschaft, in der die 
Isolierung der Kleinfamilie aus dem Verband der S1ppe, des Dorfes des stammes noch nicht eingesetzt hat, ergibt sich eine weitgespannte Skala von Gruppenzusammenkunften und damt von Anlassen zur Entstehung von Liedern, aber auch von anspruchslosen 11 terariechen Kleinformen. BAUSINGER deutet die vielschichtige Problematik des Volksliedes an (9,S.247 ff.) und beruhrt dabel auch die Frage nach seiner Funktion; diese kann die elnes "zeichens" Innerhalb der Gemeinschaft seln(9,S.256), d.h., das Lied lst Ausdruck lhrer Zusamengehörlgkeit, ungeachtet seines Gehalts. Weiterhin wird die Bedeutung des Liedgutes im Brauchtumszusamenhang genannt $(9,5.257)$ und der Hinwels von MERSMANN zitiert, dals das Volksilied ja auch als LebenstuBerung des Einzelnen verstanden werden könne $1(y, 5.256)$.

Ausgehend von ČUBEI.Í́s Elnte1lung (24, I,s.XXVIII) kann man mehrere Arten der unter der Bezelchnung "Gelegenheitslieder" (prigodne pjesme) zusammengesteliten Lieder sowohl als verbindendes Element zwischen Mitgliedern elner Gruppe als auch als Realisierung der Tradition auffassen, namlich jene, die mit Volksbrauchen. gemeinsamen Arbeiten, mit der Werbung und mit der Hochzeit Im Zusamenhang stehen, ferner die sog. mythologischen cieder. Hierbei haben gerade die "Arbeltslieder" auch eine unterhaltende Funktion, whrend die von religibsen vorstellungen verschiedenster Herkunft durchsetzten Brauchtumslieder und mytholofischen Lieder elne in ihrer Intensitbt abgestufte kultische Bedeutung haben. Wlegen- und Klagelieder, wenn man von diesen die professic nellen "Blindenlieder" ausnimmt, wird man wohl als persönliche cebensauserung verstehen durfen, die aber beim klagelied ( $t u-$ żaljka, narlcaljka) untrennbar ist vom vollzug elner rituelien Hand lung.

Unter der Bezelchnung "Llebeslieder" fabt CuBELrĆ Liebeslieder Im elgentlichen Sinne, Romanzen und Balladen zusammen. Obwohl es nahe liegt, dab viele Lieder der ersten Gruppe zunachst als Ausdruck persönlicher Empfindung erdacht wurden, ist hier vielleicht ein Vergleich mit der Kunstdichtung angebracht, in der die Liebe oft nur ein thematischer Vorwand 1st, um konventionelle Topol in neuer Kombination zusamenzufugen. Insofern sind Volkslieder dieser Art trotz des Anklangs persönlicher Gefunle ihrer Funktion nach - etwa wie der Tanz - der Gesel11gkeit und

1 Hans Mersmann: Volkslied und Gegenwart, Potsdam 1937.5.74. 
Unterhaltung zuzuordnen, ebenso wie die handlungsrelchen Balladen und die Romanzen. Zuglelch bietet sich dem Einzelnen lm bereits gestalteten Text elne Möglichkeit zu persónlicher Gefuhlsbuberung, etwa in einem unter dem Fenster der Geliebten gesungenen Lied, damit wurde in einer analphabetischen Gesellschaft die Brieffunktion erfullt.

Zu den geselligen Kleinformen der Volksliteratur gehören K1nderund Abzahlreime, Lernverse, sog. Zungenbrecher, Begrülsungssprüche, Trinkspriche (zdravice), Scherzfragen (pitalice), Spottund Neckverse (podbodačlce/podrugal1ce). Sle alle dienen der Unterhaltung, aber auch dem "seel1schen Auslauf". Gegenuber den vorgefertigten Unterhaltungsarten, die heute mehr und mehr in alle Berelche des Zusammenlebens elndringen, haben sie den Vorzug der Aktivitut vor der Passivitat, des Produzierens gegenuber dem Konsumieren, denn auch hier kann, wie bel Lledern und Erzahlungen, in der wiederholung der Ansatz zu Improvisation und Innovation liegen. Gemelisam lst diesen anspruchslosen Formen die splelerische Komponente jeder kiinstlerischen Produktion, aus der das klangliche oder semantische fixperiment mit der Sprache entsteht und zur Rhythmisierung, zu den Vorformen des Reims und zum Reim selbst, zum Parallelismus, zur semantischen Reduplikation, zum Wortspiel fürt. Auch das Scherzatsel 1st hier zu erwähnen, welches die altere Ratselform parodiert. LiTHI bezelchnet das Ratsel als "elnen Akt menschlichen Selbstverständnisses; indem er Ratsel stellt und sle löst, demonstriert der Mensch, dals das Schwierige zu bewaltigen, dals das scheinbar sinnlose oder Widersinnige sinnvoll se1"( 1,S.13). Das Scherzatisel vermittelt die gleiche, befrelende Erkenntis in heiterer Form. Die Gelegenhe1t, Scharfsinn, Intuition und witz zu beweisen, bleten auch die "podrugalice", die als Pendant zum sportichen Wettspiel im scherzhaften Wortstreit zwischen Gruppen Junger Manner entstehen, mit der Moglichkelt zur Selbstrerwirklichung Im Impon 1 ergehabe.

Zwischen sog. Scherzfragen und "Witzen" lassen sich kaum exakte Grenzen ziehen, da belde Arten auf elne Pointe hin angelegt oind und es lmmer um die jahe Erhellung elnes Sachverhalts, um Kritik oder verschlusselung geht, was diese klelnformen in die Nahe der Fabel und der Satire ruckt. Wie diese sind sie "Ventil" im Sinne der deutschen Redensart, wan misse "selnem Herzen Luft machen". 
Nicht auf die Geselilgkeit, sondern auf das Zwiegespräch oder auch auf die einsame Erkenntnis des Einzelnen hin angelegt ist das Sprichwort; seine Hăufigkeit beweist seine Bedeutung. In Ihm kommt das Bedurfnis nach Formulierung einer - oft resignierenden Einsicht, einer bestimmten Lebenshaltung zun Ausdruck, von dem selbstrerstandlich auch Scherzfragen und Rätsel oft goprägt oind. In seinem Streben nach Eindringlichkeit macht sich das Sprichwort ebenfalls die formalen Mö́lichkeiten der Sprache zunutze. Wenn im Zusammenhang mit den Brauchtumsiledern von einer kultischen Bedeutung gesprochen wurde, so liegt in dieser für eine bestimmte Gruppe der "Kleinformen" die ausschlieBliche Funktion, nämlich für die Formeln der Beschwörung, des Segens und des Gebets. Gerade hier, wo Irrationales angesprochen wird,zeigt sich elne der extremen Möglichkeiten der Wirkung gestalteter Spraches durch die Anwendung sprachlicher "Kunstgriffe" entsteht - oft unter Mitwirkung entstellender mundlicher Veitergabe und archaischer Wendungen - die von der alltäglichen Rede deutlich unterschiedene, bis zur Rätselhaftigkeit verdichtete Formel, deren Funktion Suggestion, Magie ist.

Da die hier angedeuteten Funktionen der mundlichen Überlieferung ganz allgemein Funktionen der Kunst und damit auch der schriftlich fixierten Literatur sind, erhebt sich an dieser stelle die Frage nach einer Abgrenzung der Bereiche. Hierauf geht LÜTHI ein, wobei er J.GRIMMs Formulierung, daß sich in der Volksdichtung vieles "von selber mache", aufgreift. LÜTHI entmy thologisiert diese Vorstellung: ex sieht hierin das Wirksamwerden der "zielkrăfte der Sachen, Worte, Motive und Themen" (71,S.209). Es gibt menschliche Grundthemen, die Immer wieder zur Gestaltung drängen; aber schon in den Dingen selbst liegt, wie LUTHI sagt, ein Zielbedurfnis, das zu den Grundlagen nicht nur des Kunstschaffens, sondern des menschlichen Daseins uberhaupt gehört. Ein Verbot for dert seine Ubertretung heraus, ein Heldenleben "zielt" auf den Drachenkampf, das Motiv des Bruderpaars enthält den Keim zu der Alternative Treue oder Treulosigkeit. Auf der sprachlichen Ebene "zielen" bestimmte Substantiva auf die sie ergänzenden Adjektiva. Diesen Zielkräften seht die Volksliteratur in weit höherem Maße offen als die Hochliteratur; hierin liegt ein wesentlicher Unterschied. $(71,5.203-210)$.

Die Besonderheiten mündicher Literatur ergeben sich aus der

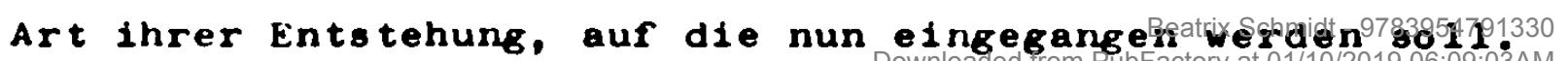


III.2. Entstehung der münll chen Literatur

Kollekt1v und Ind1viduum, Tradition und Innovation - dies sind die elnander entgegenwirkenden und dennoch sich erganzenden Faktoren, die Entstehung und Wesen der mündichen Li teratur bestimmen. Aus der fehlenden Einsicht in die Art dieser Wechselwirkung und in die sozialen Voraussetzungen für diese Form küstlerischen Schaffens resultierten, angefangen von den Romantikern, unzutreffende, zumindest elnse1t1ge Vorstellungen vom Werden der Volksdichtung.

iber die gesellschaftlichen Gegebenhelten, unter denen sich mundliche Literatur entwlckelt, schrelbt LATKOVIĆ(62,S.20):

Verallgemelnernd gesagt, entwlckelt $81 \mathrm{ch}$ die miindliche Poesie in solchen Gemelnschaften, die $81 \mathrm{ch}$ auf elner niedrigen stufe der wirtschaftichen und demgemäls der kulturelien Entwicklung befinden und keine entwlckelte Schrelbfertigkeit besitzen. Im wirtschaftilchen Berelch charakterisiert insbesondere elne ungeniigende Spezial1slerung die Primitivitat der gesellschaftlichen Entwicklung... . auf dem rebiet der geistigen Kultur jedoch die mangelnde Aufteilung in geistige und physische Arbelt, ...das Fehlen elner zahlrelcheren Gesellschaftsschlcht, die sich ausschlielslich mit intellektueller Tatigke1t befalst und die Bediufnisse der Gemelnschaft in dieser Hinsicht befriedigt.

Damit ist das Milieu der Volksdichtung umrissen, jedoch noch nichts uber den Vorgang inrer Entstehung ausgesagt. Hier stellt sich als erstes die Frage nach dem verfasser, die fü die Bruder Grimm, wie BAUSINGER(9,S.19) sagt, "von vornherein 1llegitim" war. Der romantische Begriff der Naturpoesie umfalte neben der Idee vom uralten Mythos als Quelle aller Dichtung die Vorstellung vom pflanzenhaft-unbewulten Aufkeimen der Poesie aus der Sprache und den Gedanken der Betelligung des ganzen Volkes am küstlerischen Schaffen. Damit waren bereits Ansatzpunkte fur Joli,es' Theorie von den "Elnfachen Formen" und für JAKOBSON/BOGATYREVs Darstellung des kollektiven Schaffens gegeben, die belde 1929 erschienen.

Na die Romantiker mit der Elnbeziehung national orientierter Kunstdichtung in die Volkspoesie die Grenzen zwischen beiden Gebleten verwischten, wurde die Bezlehung zwischen Volks- und Hochliteratur fü die vissenschaftler des 19.Jahrhunderts zum Forschungsobjekt; die wichtigsten theoretischen Formulierungen zu diasem Fragenkomplex entstammen bereits dem 20.Jahrhundert. 
Die Erschließung vieler in Vergessenhelt geratener, hochliterarischer Vorbllder der Schöpfungen der Volksdichtung veranlabte 190: E.Hofmann-Krayer zu der SchluBfolgerung, daßndie volksseele nichl produziere, sondern reproduzieren 1 und fürte 1922 zu H.Naumanne Formulierung vom "gesunkenen Kulturgut" als Charakteristikum der Volksuberlieferung: die Gemelnschaft "zlehe herab oder ebne mindestens ein"..."mit anderen worten, Volksgut wird in der oberschicht gemacht" 2 . Naumanns Theorie steht im Einklang mit der Beobachtung, daB literarische stoffe und Formen innerhalb des Systems der Gattungen absinken, wenn sie in threr ursprügltchen Funktion erschöpft, automatisiert sind. wahrend nun für die kulturerzeugende Oberschicht die vorstellung von elner elnzelnen schöpferischen Persönlichkeit als Urheber elner Dichtung ohne weiteres akzeptiert wurde, hielt sich hinsicht$11 \mathrm{ch}$ der Volksdichtung bis ins 20.Jahrhundert die romantische vol stellung vom Volk, das in selner Gesamthelt am Schaffensprozess betelligt 18t. Ihr traten Wisenschaftler wie Vsevolod Miller unc M.Speranskij entgegen, die auch innerhalb der Folklore ein individuelles Schaffen annahmen $(46,5.5)$. Den Begriff "kollektives

Schaffen" ersetzten einige Forscher durch den des "anonymen Schal fens", ohne damit die Vorstellung von elnem Individuelien Schöpfe zu widerlegen.

1929 gelang es Roman JAKOBSON und Petr BOGATYRFV in dem Aufsatz "Die Folklore als elne besondere Form des Schaffens", den Begrlfi des kollektiven Schaffens zu präzisieren und damit elne Abgrenzur zwischen Volksliteratur und Kunstliteratur vorzunehmen. Sie machten den Prozess der Ubernahme und der Tradierung anschaulich, Indem sie Parallelen zu de Saussure's sprachwisenschaftichen Begriffen "langue" und "parole" zogen. Mit der "langue", d.h. "der Gesamtheit von Konventionen, die von einer bestimmten Gemelnschal angenommen wurden, um das verstehen der "parole" zu sichern" (46, s.2) verglichen die verfasser die Gesamtheit der in einer Gesellschaft geltenden Normen, mit der "parole", dem einzelnen Sprechakt, das mindliche Kunstwerk; so wie die "parole" nur dank der Sanktionierung durch die "languen elne sprachliche Neuerung zu deren Bestand hinzufügen kann, so wird - nach JAKOBSON/BOGATYREV ein neues lied oder dergl. nur dann "Volksgut", wenn es die betreffende Gemeinschaft akzeptiert.

1 E.Hofmann-Krayer: Naturgesetz im Volksleben? In: Hess.Bl.f.l 2.Jg-1903,S.57-64,Neudruck b.G.Lutz: Volkskunde, Bln.1958,S.6: -72 ; .70 . 
JAKOBSON/BOGATYREV formulierten: "1nwiefern diese individuelien Neuerungen in der Sprache (bzw. In der Folklore) den Forderungen der Gemelnschaft entsprechen und die gesetzmabige frolution der langue (resp. der Folklore) antizipleren, insofern werden sie sozialisiert und bilden Tatsachen der langue (resp.elemente des Folklore-Werkes)" $(46,5.6)$. Damit hatten die Autoren das wesent11 chs te Kennzelchen der muindlich tradierten literatur herausearbeltet, die "unzertrennbare verschmelzung der zensur und des Werkes" $(46,5.7)$, die belm Werk des Schriftstellers fehlt; der geschriebene Text existiert auch ohne die Zustimmung der Gemeinschaft. Gleichze1t1g konkretisierten JAKnBSON/BOGATYREV das Wesen "kolloktiven" Schaffens in der Folklore: "Das Milieu stutzt sich. ..das geschatfene Werk zurecht, und...alles vom Milieu Zuruckgewesene existiert als Tatsache der Folklore einfach nicht, es wird auber Gebrauch gesetzt und stirbt abn $(46,5.3)$.

JAKOBSON/BOGATYREV haben sich mit der Entstehung der Volksdichtung auselnandergesetzt, aber nicht mit lhren Erscheinungsformen. Einen anderen weg wahlte Jolies' Indem or die Produkte der Voll dichtung, aicht lhren Werdegang ins Auge falte. Jolles pragte der leicht milzuverstehenden Terminus "einfache Formen", die er als in der Sprache vorgegebene Gestaltungsmöglichkelten auffabte, die sich unter dem Einflub einer bestimmten "Gelstesbeschaftiguni elner Epoche realisierten. Seine Vorstellung von der zwangsiafi, keit ihrer Entstehung aus der sprache barg die Gefahr erneuter Mystifizierung im Sinne der Romantiker in sich, obenso wie das Wort "einfach" verschiedene Auslegungen zulabt; zudem weisen die von Jolles genannten Arten elnen sehr unterschiedlichen Elafachhe1tsgrad auf (Legende/Sage/Mythe/Ratsel/Spruch/Kasus/Memorabile, Marchen/W1tz) $(9,5.51 \mathrm{ff.})$

Obwohl Jolles' Entwurf die Frage der Entstehung der volksdichtun, nur indirekt berihrte, ergab olch fur wolfgang Mohr ${ }^{2}$ hier ein Ansatzpunkt. Indem or d10 einfachen Formen auch als Darbietungsformen auffalite, wurde offensichtlich, dab die Praventivzensur der Gruppe nicht nur das Inhaltiche, sondern auch das Formale betrifft. Da für jede der einfachen Formen bele Publikun bestimete Erwartungsnormen bestehen, sind diese nicht nur als ob-

1 Andre Jolles: Einfache Formen. 1929, Halle.

2 Nolfgang Mohr: Einfache Formen. RL.1958 i Bd. ${ }^{2}$ S.321-328. 
jektive Gebilde, sondern auch als bestimmender Faktor fur die Wege und Kanlile der Uberlieferung zu verstehen $(9,5.59)$.

Zusamenfassend libt sich an Hand dieser Ausfuhrungen uber die Bedeutung von Kollektiv und Individuua fur die Entetehung der mindlichen Literatur folgendes agens im Bereich der Volksuberlieferung ist das Verhultnis der schöpferischen Persónlichke1t, die Tradiertes aufnimmt, reproduziert oder umgestaltet und in neuer Funktion einsetzt, zu der Geelinechaft gekennzelchnet durch thre absolute Abhingigkett von der zensur und durch deren Anerkennung. Die Bereitschaft hierzu bezieht der Einzelne aus dem Gefuhl der unbedingten Zugehörigkeit zu dieser normengebenden Gemelnschaft,deren psychische und intellektuelle Vordisposition er ebenso teilt wie ihre Erlebnisse,d.h. aus dem Kollektivbewubtsein. Hier steht der Verpflichtung zur Unterordnung der Gegenwert der Geborgenheit in der Gruppe gegenuber.

Das "Schaffen" des Kollektivs besteht in der Anwendung seiner Normen auf das betreffende Kunstwerk, in "zurechtstutzen" ( 46 , S.3) auf diese lormen hin oder in der Aufnahme einer Neuerung in einen bestehenden Rahmen - einem oft langwierigen Vorgang, der viele Wiederholungen beinhaltet. Auf die Bedeutung des Publikumb fur jede Form der Darbletung wurde bereits Bezug genommen, sie lst jedoch für den volkserzähler oder volksä́nger besonders ausschlaggebend. Je nach Art und Stimmung der Hörerschaft, nach der Tageszeit und der Situation kann die wiederholung eines an sich bekannten Textes in abgewandelter Form erfolgen, Korrekturen oder Ergtinzungen seltens der Hörer aússen berücksichtigt werden (71,S.203); Insofern kann gan hier tatsächlich von"Kollektivschaffen" sprechen, denn das Kollektiv leistet einen wesentlichen Beitrag zur Entwlcklung eines aúndlich tradierten Textes auf seine "2ielform" (LUTHI) hin, d.h. jene Form, auf die elne Erztiblung in allen thren varianten "zielt", da sie in ihr den sturksten Ausdruckscehalt erreicht. Mithin ist nicht nur der schöpferieche Einzelne, sondern auch das Kollektiv an der Innovation betelligt.

Die Innovation, d.h. die Aufnahme elnes neuen Stileittels in den Iormenkodex einer alten, erschöpften Form, tritt in der Hochliteratur von Werk zu Werk, in der Volksliteratur von viederholung zu wiederholung des glelchen Textes aufi das größere 
Gewicht der Tradition, der Gegenspielerin der Inuovetion, im Milieu der Volksdichtung bewirkt deren langsamere Entwicklung.

Jede Wiedergabe elnes nur mündlich überlieferten Textes kann bis zu einem gewissen Grade Neuschöpfung bedeuten. Das Ausmas der Nuschöpfung hängt einerseits von der formalen Geschlossenheit und der stufe der verfestigung des Textes, andererseits von der Wesensart des Tradierenden ab. Es gibt Formen, für die lediglich ein Handlungsplan festliegt, was bei vielen Erzählungen der Fall ist, die nur an wichtigen stelien einen ganz bestimmten Wort laut verlangen, und andere, die viel weniger spielraum bieten, z.B.Lieder, die durch Melodie und Reim nicht nur "zusammengehalten" werden, sondern auch besonders einprägsam sind.(Auf die unterschiedilche Funktion von Stilmitteln, z.B. des Reimes, in Volks- und Kunstdichtung - hier primir als Mittel der ImproviBationstechnik, dort als formales Element - haben JAKOBSON/BOGATYREV im Zusammenhang mit den Arbeiten von Jousse' hingewiesen) (46,5.12). Schlieblich gibt es Formen, deren Prägnanz nur eine einzige Art der Wiedergabe zulät und zugleich ermöglicht, z.B. das Sprichwort.

Unter den Trägern der mundlichen Uberlieferung gibt es je nach Temperament, Traditionsauffassung und Elnfallsretchtum solche, die nur reproduzieren, und andere, die inmer wieder improvisieren und so neue Nuancen in bestehende Formen einbringen. Ursache hierfür kann auch die Weitergabe eines Textes von einer ethnisch, Gruppe an die andere - mit unterschiedlichem Milieu - oder von e ner Generation an die andere - mit veränderten Ansichten - setn, wodurch Varianten von Erzbihlungen oder Liedern entstehen.

Auf dem Hintergrund der Tradition also vollzieht sich der allmáh liche Wandel der Volksdichtung durch Innovation im Rahmen standi ger Wiederholung. Diese Wechselwirkung und die danit verbundene Abhangigkeit der Tradition vom Erzahler charakterisiert M.BOSKoVIĆ-STULLI treffend mit folgenden Worten:

Bereits zu Beginn... wurde erwainnt, wie die Tradition, der der Geist des Kollektivs sein Siegel aufgeprägt hat, den Sttl und die Motivik der Volkserzahlung bestimmt. Andererseits aber wirde es ohne die schöpferische Anteilnahme begabter Individuen, die dieser Tradition jedesmal aufs Neue im konkreten Ausdruck Gestalt verleihen und zuglelch kaum merklich ihren Rahmen durchbrochen und so zu lhrer Entwicklung und thren schrittweisen veranderungen beitragen, uberhaupt keine Tradition geben, sie wirde erlöschen. $(16,5.20 / 21$

1 M.Jousse: Etudes de Psychologie Linguistique, Paris 1925. 
III.3. St1listische Merkmale der serbokroatischen

Volkserzahlung

III.3.1. Allgemeines

Die Erforschung der Volkserzahlungen hat bekanntlich zu der Erkenntisis der Gleichartigkeit vieler Motive bei den verschiedenen Volkern gefürt, die mit Hilfe der Erbtheorie(Bruder Grimm, später v.Sydow, in Verbindung mit Entlehungs theorie), der Migrationstheorie (Benfey), der Polygenese-Theorie(Waitz, Bastian), der strahlentheorie (Wesselski) und der Wellentheorie (Anderson) erklärt worden ist $(9,5.30 / 31)$.

Die sog.finntsche Schule entwickelte die historisch-geographische Methode der Márchen- und Sagenforschung; Antti AARNEs Typensystem von 1910 bildete die Grundlage für das heute gebräuchliche Typenverzeichnis von AARNE-THOMPSON ${ }^{1}$.

Die Gemeinsamkeiten beschräken sich jedoch nicht auf die Motive der Erzbihlungen, sondern betreffen teilweise auch die Art der wiedergabe. Wenn hier bei den einzelnen völkern Besonderheiten auftreten, so beziehen sie sich vor allem auf das "Lokalkolorit" und gelegentlich auch auf sprachliche Kunstgriffe, die sich aus der jeweiligen Sprache ergeben.

Unter den slavischen Volkserzählurgen zeichnen sich die russischen, ukrainischen, weibrussischen und slovakischen durch einen besonderen Reichtum an ornamentalen Formeln aus, doch findet sich diese Erscheinung in abgeschwächtem Maße auch bei anderen slavischen völkern. Auf die Unabhängigkeit einiger typisch slavischer Stilmittel von der Überlieferung benachbarter völker bel gleichzeitiger übernahme ganzer sujets hat POLÍvKa ${ }^{2}$ hingewiesen.

In der serbokroatischen Volkserzihlung finden sich, in regional abgestufter Intensitat, sowohl typisch slavische Formelemente (z.B. weitgehend ibereinstimmende Anfangs- und SchluBformeln in verschiedenen slavischen Sprachen oder die vielen, aus dem Flexionsreichtum entwickelten rhetorischen Figuren,

1 stith Thomspon: Motif-Index of Folk-Literature. 6 Bde. Kopenhagen 1959-1958. - Antti Aarne u.Stith Thompson: The Types of the Folktale (=FFC.184), Helsinki 1961 .

Jir̆i Polivka: Uvodni a zaverrečné formule slovanskych pohádek. Narodopisný véstnik Eeskoslovansky, Praha,XIX 1926, XX 1927. 
vgl. III.3.4.6.) als auch eine Anzahl allgemeiner Charakteristika mündlich überlieferter Texte. Eln besonderes Gepräge erhält sie uberall dort, wo historische oder landschaftliche Gegebenheiten als realistisches Detail in die Handlung einflieben. Was hier für den Auslander nur exotischen Reiz ausmacht, bedeutet fur den Serben oder Kroaten unmittelbaren Bezug zur bewegten nationalen Vergangenheit und war fur thn teilweise noch im 19.Jahrhundert ein Hinweis auf das gegenwärtige Schicksal seines Volkes. Dieser Umstand ruckt einen Teil der serbokroatischen Volkserztihlungen - ungeachtet evtl. enthaltener marchenhafter Elemente In die Nahe des Tatsachenberichtes; hierin liegt eine der Ursachen fur den verhaltnismaßig hohen Anteil ungangssprachlicher Wendungen in einer Reihe von Texten. Einen wesentlicheren Faktor jedoch stellt in dieser Hinsicht das intimere, gleichsam private Milieu der Volkserzahlung dar, verglichen mit der erhabenen, distanzschaffenden Sphäre des Heldenliedes. Eine parallele Feststellung trifft Roman JAKOBSON in seinem Aufsatz "O sootnošenil meždu pesennoj 1 razgovornoj narodnoj rě' ju" $(46,5.530)$ in Bezug auf die Sprache der Volkslyrik und die der Bylinen, wobel er für die Lyrik das auch für die Volkserzbilung wichtige Moment der Selbstidentifikation mit dem Text nennt.

Da die nachfolgend einzeln behandelten stilistischen Erscheinungen in den Volkserzăhlungen aller serbischen und kroatischen Regionen auftreten, wenn auch in unterschiedlicher Häufung, ist es in dem hier vorgegebenen engen Rahmen möglich, ganz allgemein von Merkmalen der serbokroatischen Volkserztilungen zu sprechen. Ebenso wenig braucht hier die Art und der Zeitpunkt der Aufzeichnungen berucksichtigt zu werden (auch wenn gelegentlich darauf hingewiesen wird); denn wenn auch schriftliche fixierung mundlicl tradierter Texte durch die Transponierung in ein anderes Medium (bzw. In eine andere Kategorie, wie JAKOBSON/BOGATYREV formulieren, 46,S.12) Immer bis zu einem gewissen Grade Entstellung, Ver. fälschung bedeutet, und wenn auch alle blteren Aufzelchnungen durch die Auffassung, die Absicht und den persönlichen stil des Sammlers verformt sind, whihrend andererselts die modernen Magnetophonbandaufnahmen bel allen Vorzugen der Authentizitit in naturalistischer Manier auch Uberflussiges getreu notieren, so 1 as. sen sich die auffäligen stilistichen Eigenheiten dennoch durch. gehend uberall verfolgen. 
III. 3.2. Loka1kolor1t

Obwohl riele Mot1re in den Erzkhlungen rerschiedener vilker 1 mer wiederkehren, erfahron ele doch hauflg eine unterechied11che Behandlung. Man hat versucht, diese Erschelnung aus dea Charakter der jewell1gen Volkegruppe zu erkluren, doch bletbt d1ese Art der Doutung stets oohr problematioch.

Zur Frage der nationalen Elgenart der Volkserzkhlungen niant M.BoŚKović-STULII in three Aufeatz "Reglonalne razlike medu narodni a pripovijetkama" (19) Stellung und lehnt die Annahme - iner peychischen Pradispostion elnes Volkes als Uraache hierfur ab. Sie vertritt die These, daB die Abwandlung einer Erzuhlung nicht auf den Volkscharakter, ondern auf bestimnte Lebeneformen zuruckzufuhren oe1. Diese These wird eindruckevoll gestitzt durch das Belopiel der alpenlandischen Erzbhlertradition, die bel ethnisch und eprachlich verschiedenen Gruppen sohr viele comeinsamkelten aufweite (19,5.9).

Faktoren, denen viele eerbokroatieche volkserzkhlungen besondere Elgenhelten verdanken, inds die historischen Erelgnises auf der Balkanhalbineel, welche Kontakte at anderen volkern bew1rkten; der reglonale Landechaftecharakter; Lebene- und Wirtechafteformen; religiobe Gegenettze.

Das M1l1eu also - raumlich und zeltlich verstanden - gibt bel der Tradierung elner Fabel AnlaB zur Einkleidung in ein neues Gewand. Eln bestimmtes Milieu bringt aber dariber hinaus auch neue, typleche Erzahlungen und Flguren hervor. D1e serbokroatischen Volkeerzihlungen bieten zahlreiche Belspiele belder Art. In dem zitierten Aufsatz fürt M.BoŠovrĆ-STULLI das bekannte Marchen vom "Teufel mit den drel goldenen Haren" an, das in e1nigen Varianten konsequent in das historioche M1lieu der ehema11gen beterrelchiochen M111turgrenze ubertragen wirds an die Stelle der"abetrakten"Murchengestalten des Konige und ceines Schwiegereohnes treten hier ein offizier und ein soldat, der nach 16 Jahren den Dienst quittieren aöchte, und als Puhrmenn in die "andere Welt" orecheint oin Soldat, der auf ablbaung wartet." Whrend die groben Erelentose der Geschichte weite Gegenstand der Eplk blieben, war d1e Volkserzahlung der 1deale Rahnen zur Daretellung privater Verhaltnisse. So bletet die glelche Erzahlur 
d1. Shakespeares "Kaufmann von Vened1g" zugrunde 11egt, In Ihrer bosnischen Variante eine Rethe von Hinwelsen auf die Lebensform und d1e Gerichtsbarke1t zur Türkenze1t("Dran Jez1ka",24,Bd.3, S.177-183, aufgeze1chnet 1847). Der Turke tritt oft in die Rol1. des Muchtigen, der typisierten Figur des "Königs" eln, etwa In der Erzahlung von dem Pała, der den Dubromikern Ratsel aufglbt, aber auch in die Rolle des Bösewichts schlechthin, des ungerechten Richters, andererselts in die des Dummen, des Geldglerigen oder des Dumschlauen, der selbst in die Falle geht. In Dalmation ubernimm viele dieser Rollen der Venezianer, In Montenegro sind sie auf Turken und Venezianer, die historischen Widersacher, vertellt. Gerade diesen "Schlauen" und den "Dumeschlauen" stellen oft drel weltere volker - Juden, Cincaren, 21 geuner.

In M1110u der serbokroatischen Volkserzkhlung ist elne Relhe von Figuren verschiedenster Herkunft helmisch, die sich oft durch besonderen Witz und jene Art von Schlauhelt auszelchnen, die fur das Uberleben unter schwierigen Umstinden wichtig 1st: Nasredin-Hodza, aus der Welt der orlentalischen Murchen ubernomen, der 118t1ge "Ero", der Hercegoviner, Vuk Dojtevit in Montenegro und im Primorje, Im kajkavischen Raum der "Grabancijas̆ dak". An historischen Gostalten begegnet man vor allem dom Helden der epischen Lieder, Kraljevit Marko, und dem Heiligen Sava, aus dem christichen Berelch ferner st.peter und dem Herrn, der Jungfrau Maria (z.B. Sinjaka Gospa) und selbstrerstandlich dew Teufel. Der slavischen Mythologie entstammen die vilen, die Werwölfe, die kynokephalen Dumonen (rukodlaci und pasoglavc1), viellelcht auch "Manjinjorga" In Dalmatien trotz des auf die Mittelmeerpflanze Mandragora zurlickgehenden Namens (vgl. Gogol's "vijn).

Auch Begegnungen zw1schen dem Popen und dem Hodža, wobel der Pope melst der Klugere 1st, sind eln an bestimmte Verhaltn1sse gebundener Vorwurf, ebenso wie jene, oft von kelnerlel MurchenGlauben an den sieg der Gerechtigkelt korrigierten Erzahlungen vom reichen Turken, der seine Position dem Christen gegenuber ausnutzt (z.B.123,Nr.224,S.102). Ubrigens enthalt gerade die Samiung Vuk Vrěevits von 1868 elne ganze skala von Mb̆glichke1ten, wie sich das Zusammenleben von Turken und christen gestalten konnte - von offener Felndschaft b1s zum"Arrangieren" w1telnander $(123, \mathrm{Nr} \cdot 137, \mathrm{~S} \cdot 61)$. 
Obwohl das Fohlen von Landschaftsbeschrelbungen ein oft betontes Charakteristikum der Volkserzkhlung 1st, weist sie indirekt gelegentlich auf die Landschaft ihrer Entstehung und Verbreitung hin. Ein anschauliches Belspiel hierfur ist die sage von der alten Hirtin, die den Februar seiner Warme wegen verspottet, woraufhin sich dieser rom Marz Schnee und Sturm ausborgt und sio samt Ihren Schafen zu Steln erstarren labt: der Karet, die Schafzucht als Lebensinhalt, das unsichere Fruhjahrewetter - all das gohbrt zum dinarischen Gebirgsiand, dem alle varianten dieser Sage entstammen $(19,5 \cdot 10)$.

In thnlicher We1se $198 \mathrm{sen}$ sich Abwandlungen, Ausschmuckungen und Prazisierungen Im Hinblick auf einhelmische Lebensformen beobachten, wenn z.B. Von Festen die Rede $18 t ;$ In manchen dalmatinischen Geschichten spiegelt die Schilderung besonderer rafelfreuden unmittelbar d1e karge Lebenswelse, wenn das Festmahl aus nichts welter als Brot. Wein und kHse besteht. Die 1strische Variante des weltrerbrelteten Märchens von den 3 Brudern, denen 3 winsche erfullt werden, spiegelt die fur dieses Geblet typlschen Wirtschafteformen: Getreide- und Weinbau, Schafzucht, Fischerei $(19,5,12)$.

Diese Tendenz zur Annkherung elner Fabel an das vertraute Milieu 1st bezelchnend für viele serbokroatische volkserzăhlungen; sie reicht sogar noch bis zu Karadźl, der, wie MoJAšrvić berichtet, aus der Erzahlung "Čardak n1 na nebu ni na zemljl", die thm Fürst Mihajlo 1844 aufschrieb, die Figur der Amme der Königetochter gestrichen hat - möglicherwelse um die Erzahlung dem dorflichen Mil1eu anzunähern $(81,5.308)$.

Die Nelgung, elne Erzahlung durch geradezu realistische Detalls In den elgenen Lobensberelch elnzubeziehen, auch wenn es sich um die "wunderbare" Märchen- oder Sagenwelt handelt, gibt den Erzählungen oft einen besonderen Re1z und trägt dazu bel, auch aufgezelchneten Texten die Intime Atmosphare des "Muindlichen" zu bewahren. In dem Kontrast zwischen Ubersinnlichem, Schicksalhaftem auf der elnen, Alltaglichem auf der anderen selte liegt elne elgentulliche spannung, die auf der schöpferischen Leistung des Erzähiers durch selne phantasievolie Neugestaltung aus dem elgenen Milieu heraus beruht. 
III, 3.3. Xomposition

tber die Bedeutung der standigen kritik des Kollekt1ve fur gundlich liberlieferte Texte wurde schon gesprochen. Es lst rerstynd$11 \mathrm{ch}$, dak sich tw Zueamenhang att der Orientierung auf dieses Publikum hin Kompoeitionsechemata entwickelten, die elne besondere Ubersichtlichkelt der Handlung alt guter Elnpragsamke1t und der Möglichkelt verbanden, das Interesse des Zuhörers wachzuhalten, z.B. durch Stelgerung.

Aus dem glelchen Grunde vertragt die Volkserzahlung kelne E1nle1tung, etwa in Form olner Landschafts- oder Personenbeschrelbung oder einer Vorgeschichte. Wenn einfuhrende Formeln gebraucht werden, so dienen sie nur dem "Elnstimen" der zuhörer; die serbokroatieche volkserzahlung kennt sie kaum. Selbst elne der bellebten Volkswelshelten wird oelten vorangestellt, viel eher folgt se am SchluB; In den wonlgen Fullen, In denen der Erzuhler damit beglnnt, wuB sio so knapp wie möglich seln. Elne Rahmenerzahlung im 1 igentilchen Sinne glbt es nicht, da der "Rahmen" fast lumer in elnem einzigon Satz besteht, der auf den elgentlichen Erzuhler hinwelst. Manchal wird elne kurze Bemerkung uber Ort und Zeltpunkt des Geschehens oder uber elnen bestimmten Brauch vorausgeshickt. Der weltaus gröbte Tell der serbokroat1schen Volksorzkhlungen aber beginnt sofort mit der handlung bzw. Int der fostetellung ihrer Ausgangesituation; Inwiewelt auch eIn solcher Anfang formelhaften Charakter in selner otandigen Verwendung von Erzahlung zu Erzahlung annehmen kann, ooll spter behandelt werden (III.3.4.3).

Bezelchnend für die volkserzahlung lst die Elnetranglgkelt der Handlung, d.h. es glbt kelne Neben-oder Parallelhandlung, etwa ie Sinne eines retardierenden Momente; dieses bilden die zahlrelchen Hindernisse, die der Held liberwinden muB, ohe er ans ziel gelangt, mit ihren oplschen wiederholungen.

Eine Rethe von Erzahlungen 1st oymetrisch-antithetisch aufgebaut, der glelche Vorgang wird zwelmal erzuhlt, jedoch mit umgekehrtem Vorzelchen. GroBe Bauelemente der Komposition kónnen hierbel nach dem glelchen prinzip weiter untertellt oein, oder es kann zu elner Kombination at dem "klassischen" Kompositionsschesa kommen, das auf der Drelzahl beruht und sohr vielen Erzuhlungen zugrunde $110 \mathrm{gt}$. Elne solche Verflechtung findet sich 
2.B. In den oerb1echen Murchen "Pravda 1 krivda" (Vuk Nr.16),

W1. schon $1 \mathrm{~m}$ Titel angedeutet, handelt es $01 \mathrm{ch}$ un zwel gegensutzliche Bruder. Zueret coht os den Bosen gut und den Guten schlecht, wobel der Bbse don Guten In dre1 vetten oein Erbte11 (200 Zechinen) abnimet. Danach ot $\overline{1 c h t}$ or the auch noch d1. Augon aus.

Blind unter elner Tanne an elner Quelle liegend, hort der Gute die Worte der Vilen, daB des Quellwaseor die ausatzige Kónlgatochter "In elnew Tag und elner Nacht" he1len würde, und daB os auch gogen jede andere Krankho1t helfe. Er helit zunkchst sich selbet und $111 \mathrm{t}$, wieder sohend, mit einer GefuB voll wundertutigen Wassers zum kontg und veropricht, "In einem Tac und elner Nacht" die Prinzesoin zu heilen; die Hellung gelingt the "In elnee Tak und elner Nacht", und or helratet die Prinzessin; seln Ungluck 18t In Glück umgeschlagen.

Als dies der Bbse erfuhrt, o11t or zur Quel1e, un ebenfalls unter der Tanne oeln Gluck zu finden; er echópt eln Gefab voll Quellwasser und sticht ich auch die Augen aus. D10 vilen aber, die erfahren haben, das jemand lhre Worte gehort hat, suchen nach elnew Lauscher, finden den Bbsen und reiBen $1 \mathrm{hn}$ in Stuckes wo fur den Guten das Gluck begann, beginnt für thn das Inglifk.

D1. großen Abschnitte sind hier ganz symetrisch vertellt, und d1e Eplooden an der Quelle verlaufen parallel, aber att ontgegengesetztem Ergebnis; 0 weit 18t die Komposition also paarib angelegt, analog zum Bruderpaar und zum Gegensatzpaar der Uberochrift. In dieses Zweler-Schema oind Drelfach-Motive eingeflochten: dre1 wetten, dre1 Begegnungen ait dem Toufel, 300 Zechinen, und $\operatorname{chl} 10 \mathrm{clich}$ die dreimalige viederholung des Satzes: "U dan 1 not ostala b1 zdrava"; "u dan 1 not bite zdrava"; "Kad prode dan 1 not, devojka ostade člota 1 zdrava od Gube" (54, S.88).

D10 dreifache wlederholung tellt das hafigste Konpositionsprinzip dar, d.h. e werden drel parallel gebaute Episoden berichtet, die manchmal glelchwertig, nur varilert oind, huuf1ger aber elne stelgerung bilden, z.B. Im Murchen "Bas-Celik" (54,Nr.51): der erste Drache hat ein Haupt, der zwe1te zwe1, der dritte drel Hupter. Gerade dieses Marchen 18t ubrigens - In Be1spiel fur die Zusamenkettung mehrerer Dreifach-Episoden in langeren Erzanlungen.

D1e Dreizahl der Eplooden 1ot Innerhalb der Erzahlung durch dreifache wiederholung glelchen oder ahnlichen Wortlautes gekennzelchnet, w1e 1e oblgen Belepiel; dies gilt für Schilderung und direkte Rede. Dieser Dreizahl in der Makrostruktur der Komposition entsprechen zahlrelche drelfache wiederholungen 
In der Mikrostruktur des Textes (s.III.3.4.1.).

Uber ihre formal-ordnende Funktion hinaus knupft die Dre1sahl durch thre vielfultige Verwurzelung in Mythos und Religi on - ine zusłtzliche Verbindung sum kollektiven Unterbewubtedin.

Symetrie bzw. Parallelismus und Droizahl sind die hufigsten Kompositions-Prinzipion der serbokroatischen Volkserzkhlung; -1. findon sich nicht nur in Murchen und Sagen, ondern obenso in Erzahlungen aus dem Alltag, die ron modernen Samlern ohne jede St1lisierung wiedergegeben worden. Elne weltere Gruppe verfolgt das Prinzip der Aufzuhlung, der Reihung, der Kurulation, z.B. die bellebten Lugengeschichten.

Kurze, melst scherzhafte Geschichten (śaljive priče) berichten demgepenuber ohne besondere Gllederung oder Abstufung gerad11n1g oin elnziges kleines Vorkomnis, das fast immer in oiner Art Pointe muindet. Sie stehen der Anekdote nahe, die ebenso wie Scherzfrage und witz auf elne treffende Antwort hin stilisiert 1st. D1e große Zahl solcher "pričice" we1st auf elne besondere vorliebe für die schlaglichtartige Pointierung hin, die sich b1s heute in aktuellen Neuschöpfungen dieses Genres lußert. Neben diesen, klar gebauten Kompositionsformen gibt os bel den serbokroatischen volkserzahlungen auch Belspiele unubersichtilcher Vermischung und Addierung von Motiven, die zwar für oin wentg ausgepragtes formgefuhl, dafur aber für eine erstaunliche, die unterschiedlichsten Elemente assimilierende Phantasie des betreffenden Erzahlers und seines Publikums sprechen, das diese Erzkhlform sanktioniert. Als Beisplel fur - ine solche Vermischung von Motiven nennt M.BoSKović-STULLI die In dem Band "Narodne priporijetke" (PSHK 26) enthaltene Erzahlung "Pasoglave1" (16,Nr.20;S.76).

Bayerlacho Staatablbllothak Monctien 
IIT. 3.4. Stilmittel - "Kunstgriffe"

\section{II.3.4.1. Wiederholun. - Varlation - Dre1zahl}

Wenn auch der ornamentale stil der slavischen Volkserzählung im serbokroatischen Sprachraum weniger ausgeprägt ist als z.B. im russischen, so lassen stch doch auch hier zahlretche charakteristische "Kunsteriffe" beobachten, die keineswegs auf bearbeitete Editionen beschrankt sind. Insofern kann man dem Urteil Bratoljub KLAIĆs kaum zustimen, der am Schlußs seiner uiberaus informativen Ausfihrungen uber Phonetik, Morphologie und syntax der Volkserzăhlungen feststellt, daß diese selten lrgendwelche stilistischen schönhelten haben könnten, viel eher kïme es zu Alogismen (Anakoluthen) (16,s.398). Gerade diese lieisen sich ja dort, wo sie tatsächlich stören, aus den heute üblichen Tonbandaufnahmen ausmerzen, ohne dals die Ursprüglichkeit des Textes dadurch litte. Immerhin fürt selbst Kiald einige Zelien später Beispielestilistisches Schönheit all, die auf Wiederholung, Variation, Parallelismus beruhen, also aut typischen küstlerischen verfahren der Volkse-zählung.

Die Wiederholung ist ein orcnendes Prinzip aller Künste - damit 1st ihre ästhetische Funktion angedeutet; sie ist zugleich ein wichtiges Element aller Belehrung - damit lat auf ihre didaktische Funktion hingewiesen. Wo immer es also um "Erbauunf. und Belehrung" geht, hat sie ihre Berechtigung.

Die Wiederholung paralleler Episoden dient, wie schon gesagt wurde, der Architektur der Erzählung; sie wird gestiltzt durch wörtliche oder varilerende Wiederholung von Handlungsablaufen, Dialogen und von Formeln, die bereits der Mikrostruktur des Textes zuzuordnen sind. Doch nicht allein in den groben Kompositions-oder Bauabschnitten, auch in der kleineren Einheit des Satzes gibt es immer wieder Belspiele für die wiederholung In allen ihren Spielarten, die nicht auf die direkte Rede beschräkt bleiben. In einer einzigen, beliebig herausgegriffenen Erzählune wie der von den "Neun Wolfsbrudern" (Devet brata vukova", 16,Nr.32,S.106-110) gibt es genügend Belspieles Wiederholung und Variation: Troja majka fmala devet strova paci zaklela 1 svi su otiśli y vukove u sumu, sama ti si jedna ostala... 
.. Antwort der Mutter, mit erweiternder Varlation:

...jeste... Ja sam imala devet sinova 1 nisam nide nista 1 mala, uvik prosila i njlma nosila, davala, a oni zderali, ja sam 1. zaklela, ont su u Sumu otifil, postali vukovi. (s.107)

Die gleiche Passage bietet ein Beispiel des sprachlichen Paralle113 mus (vgl.v.3.4.6.), der hier bereits bis zum Reim fürt(pros1la :nosila) und in der Erzahlung mehrfach auftritt,z.B.

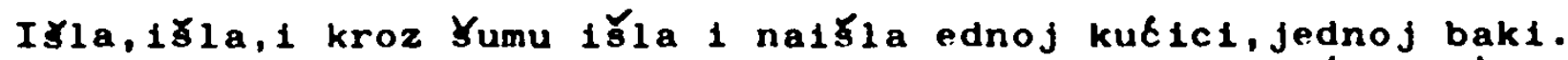
wiederholung, sogar mit dreifacher $S_{t} e i g e r u n g s$

(S.107)

(1) A stara, čim se ona porodila, joś ni bijo ni doß̌a,

(2) a ona stara. (3) njezina svekrva, baci dijete kroz pendzer u jezero (S.109).

Charakteristisch ist auch die direkte Rede der brider im entscheidenden Moment der Erzälung varilert, wobel bezelchnenderwelse wleder nur die worte der drei altesten Brider angefihrt werden:

Najstariji brat vice: Sestro, na ti dijete, govoril Danas je devet godina dana, prošlo vrijeme, slobodno govoril

Drugi vile: Govori,sestro - 1 daje joj dijete - danas je devet godina, sloboda lzasla, govori, niłta se ne boj!

Treti viče: Sestro, govorill daje joj dijete. (s.109).

Die Dre1-Zahl ist also nicht nur in den Fakten der Erzahlung ( $3 \times 3$ bridder, $3 \times 3$ Jahre des Schwelgens, 3 xinder in 3 Jahren, 3-maliges "Zum-Militar-Gehen" des jungen Ehemannes), sondern auch in der sprachlichen Niedergabe durchvarifert, bis zum Schluls, wo sich die Niederholung des wortes "brze" bis zum formelhaften Ausruf steigert:

...A carev sin brže balje po mater. Brže da mi je mat doł̌la - kaže - vamo gore da vidi kak Eemo snahu objesit1...

A stara skočl od radosti, znaš, de on sad veli da te objes1ti.

Kaze:

BrZe-bolje polet' gorel (s.110)

In dieser Fassung der Erzăhlung verbindet stch der spröde Reiz des "Mündichen" mit alten formalen Prinziplen, die belm guten Erzähler lmmer noch wirksam sind. Nach Angabe der Herausgeber ist keinerlei Art von Bearbeltung erfolgt, sondern es handelt sich um die penaue viedergabe elner Tonbandaufnahme von M.BốskovićSTULLI aus dem Jahre 1959 aus dem Dorf Donji Javoranj bel Dvor a.d.Una, handschriftliche Samiung des "Institut za narodnu umjetna in Zagreb,Nr.343,S.8-11; Frzahlerin: Zagorka Januzovit. 


\section{3.4 .2 .2 ahlon allgene in}

D1e "mag1sche" Dreizahl, die In den Mythen und Erzahlungen aller volker elne beherrschende Rolle splelt, lst nicht die elnsigo Zahl, die háf1g auftritt. D1e Bellebthelt der Zahlenangaben in der Volksdichtung deutet af elne alte zahlensymbolik hin, die für die Zahlon 1 bls 12 von A.TAYLOR ${ }^{1}$ auf ein judisches PassahRitual und noch weltergehend auf orlentalische Religionsformeln zurickgefuhrt worden 1st, die nach selner Ansicht bls su den Texten des Sanskr1t zurückgehen (9,S.89). Das Christentua, das sich wie alle Religionen der Zahlenmagle bedient, hat sur Erhaltung dieser vorstellungen wesentlich belgetragen, die bel allen christianisierten volkern von bestehenden Mythen gestutzt wurden. Fü die serbokroatische Epik hat MARETIC festgestellt, daB gegenuber unbestimmten Zahlworten wie "elnigon, "mehreren usw. prazise Angaben bevorzugt werden, und zwar neben der 3 die 7 und $9(=3 \times 3)$ sow1e die vielfachen 30,300, 70, 700, 90,900; auch die 4 ist vertreten, wenn auch seltener, wärend im Bereich zwischen 10 und low auber den genannten Zahlen 12, 15 und 20 am haufigsten sind. Nach MARFriC finden sich in den russischen Bylinen ahn11che Verhbitnisse $(73,5.91)$.

Die serbokroatische Volkserzahlung, die im glelchen Milieu überliefert und aus gleichen Quellen genkhrt wird wie die Volksepik. bedient sich z.Tl. auch der glelchen Stilmittel wie diese, zu denen die Verwendung bestimmter zahlen neben der 3 gehört. Auch hier sind os vor allem die von der 3 abgeleiteten $2 a h l e n$, 9 , 12, 30 oder die zweite "magische" Zahl, die 7, mit inren entsprechenden vielfachen, darunter auch 77 , ferner die 4 , die am häuftgsten vorkommen. Ste lassen sich in Sammiungen verschiedenster Herkunft belegen, doch scheint in den neueren, auf ronband notierten Erzahlungen die Hufigkelt der abgelelteten $2 a h i e n$ abzunehmen, whihrend die 3 offenbar so zăh elngewurzelt ist, dab sie sich selbst in relativ Inhomogenen und schwach stilisierten Texten bohauptet.

Im Ubrigen muB gerade bel elner so konkret fabbaren Erscheinung wie der Nennung von Zahlen bedacht werden, daB neben der Uber-

1 Archer Taylor: Formelmarchen, In HDM 2.Bd.,S.164-191. 
110rerung und den Weiterwirken helbverechutteter Symbolvoretellungen oot dor Drucklogung dor oreten Samiungen in sunehmen-

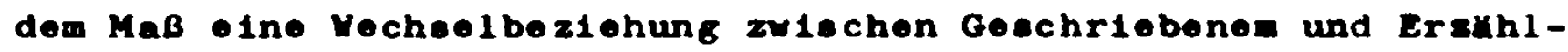
ter besteht.

Nachetehend ein1ge Be1spieles

Cajk.6,5.6:

Zapitabe 11:1ca jazarca: "Kol1ko 1mał rję̌tina, t1 Jasor" Odgovorite Jazarac: "Iman tri vjostine".

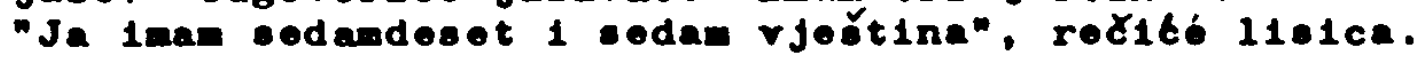

Vuk Nr.4, S.20:

dranaest podruna...

S.15,16 otc.: dovet zlatnih paunica..

sinj Nr.9,S.342:

(Das Gobet eines Kindes, das der Toufel holen vills)

Dranes' apostola, Jedanes' muXenika, deset bošjl'

sapovid1, devet korâ andoosk1', osan diva uniljoni', sodan diva radosnl'. Yoot kamenja kalandorski', pot jo rana Iousori'. Eot1r' ou andel18ta, Iran, Marko. Mat1ja, Luka, ovot1 Jol Patrljel 1 dra tajno boxja slavna, bog jodint 1 kriš slavni, ko nas Čuva vazda 1 bran1.

Cajk.60, S.158:

Ja čorke nemam, nego lmam četrdeset elnova...

Auch bol groben Mongen werden gorn exakte Zahlon angegeben:

Vuk Nr.1, S.4:

..dok se 1za brda ponoll jedan brk 1 u njenu trieta

1 bozdeset 1 pet tičijlh gnijezda.

Cajk.69,s.179:

. . car tako učini. Skupi ototinu hiljada rojnika... 
III. $3,4,3$ Anfang und SchluB.

Zu den bestinenden Elewenten jeder Ersuhlung gohoren ihre Anfango- und Schlubektzes der erste Satz gibt Gowiseoraben den Ton an, der letzte kann die Komposition abrunden, eci os mit elner Polnte, einer Schlubfolgerung oder elner Art Aueklang; or kann auch elne Frage In den Rau otellen, d1e zun Nachdenken zwingt. D10 schon erwahnten relch augeschulukten Anfange- und Schlubrormein anderer elaviecher Erzthlungen, vor allen der Murchen, sind im btokavischen Raum, dow die Samiung Vuks entetamot, wentg verbreitet, wahrend ole Im kroatioch-kajkaviochen Bereich relatir haufig sind. Belepiele hierfur onthalten die Samalugen M.Langs aus Samobor'" und Matija Valjavec' aus Varaždin ${ }^{2}$. M.Bošković-sTULLI bieht hierin kein Zelchen größerer Archalzitat der dort aufgezelchneten Varianten, zumal gerade die zwelte der gonannten Samiungen aus olner Kle1nstadt bzw. Ihrer Ungobung, d.h. elnew recht ontwickelten Geblet, otamt; s1e faBt vielmehr d10se Erscheinung als Hinwels auf den undittelbareren AnschluB dieses Landetriches an den gesamtelavischen siedlungoraun aur, verglichen mit der goographischen lage Serbiene; dadurch orgebo olch elne andere regionale Tradition $(19,5,13 / 14)$. V1ellelcht könnte wan daneben das Elnwirken von Blldungefaktoren in Betracht ziehen, wenn man an LATKovićs Bewerkung lber die Entetehung von Valjavec' Samiung denkt: Valjavec habe z.rl. die Erzuhlungen oeiner schuler bzw. Ihrer Familien notiert und sel dabei nicht immer vorsichtig genug gewesen $(62,5.61)$. Da jedoch auch andere Sammiungen aus dem kroatischen Raum onteprechende Beispielo 11efern, kann man die Häufigkelt lnsbesondere der Schlubformeln fur Erzkhlungen dieses Gebletes als gegeben annehmen.

Obwohl hier also betruchtliche Unterschlede zwischen kroatischen und serblschen Erzkhlungen bestehen, lassen sich doch auch gew18se Geneinsankelten beobachten, die sich zwar nicht in der Ausblidung von Forneln, aber lmerhin in elnem formelhaften st1l yuBern, der für Anfang und Schlub bestimete Konventionen geschaffon hat. Hierzu gehort zu Beginn das oofortigo eintreten

1 Milan Lang,Samobor: Zbornik za narodni život 1 oblčaje južnth Slavena. Zagreb knj.XDX, 1914.

2 Narodne pripovijeetı u Varaždinu 1 okolic1. Sakupio Matija Kracmanor Valjavec. II $12 d .$, Zagreb 1890. 
"In mediae res", dae nit uhnlichen, wlederkehrenden Wendungen geschloht, die entweder die Auegangestuation in knappeter Form unreiben (Typ "blo jedan car") oder eofort alt der Handlung elneetzen (TYp "Ǐ̌a puton čorik 1 Yone"). D1e zwe1te Mbgl1chke1t let die Andeutung elnes "Rahnene" in eeiner reduziertesten Forn (Typ "ǒuo can" oder "pričca se"). die dritte - Ine Orte- oder zeltangabe oder eine Festetellung, die ertl. zun Sinnepruch oder zur weleen Lehre tendiert (Typen "kad ou davol1 otpal1 od Boga" = 201t; "u selu Košut1man" = Ort; "Jadan t1 je onl ko se na ́to namuti" = Belehrung).

Diese drel Grundtypen finden sich in Samiungen aue vililg verschiedenen Gobleten, die unter ganz unterschiedlichen voraussetzungen entetanden sind. Al. Belepiele wurden fur die nachfolgende Zueamenetellung herauegegriffen:

1. D1e ereten 50 Erskhlungon aus: Vuk St.KARADžríc, Srpoke narodne pripovijetke 1 zagonetke. Blograd 1897 (entepricht der Ausgabe von 1852 ).

(L1t.verzelchn18 Nr. 54; 1. Text oft abgekurat "Vuk")

2. Divna ZEĆEvIĆ Uamena kaz1vanja u okolici Daruvara. In: "Narodna unjetnoet" knj.7, Zagreb 1970,S.33-63. 21 Texte. (Lit.verseichn18 Nr.126; abgekurzt "Daruvar" od."Dar.")

3. M.Bośković-STULLI, Narodne pripovijetke 1 predaje injeke kraj1ne. In: "Narodna unjetnoet", knj.5-6. Zagreb 1968, S.329-411, 1neges.95 Texte. (L1t.verzelchnis Nr.17; abgekirzt "Sinj").

A B

B C

\begin{tabular}{|c|c|c|c|}
\hline "b10 jedan car" & $" 1$ ba..čovik" & $\begin{array}{l}\text { "čo sam" } \\
\text { prita so" }\end{array}$ & $\begin{array}{l}\text { "kad eu davol1" } \\
" u \text { oelu } \ldots \text { ". } \\
\text { "Jadan t1 je..." }\end{array}$ \\
\hline (vuk $2,3, \bullet t c)$. & $(\operatorname{sing} 20)$ & $\begin{array}{l}(\operatorname{sinj} 50 \\
\operatorname{sinj} 46)\end{array}$ & $\begin{array}{l}\text { (Vuk 18; Sinj } 52 ; \\
\text { Sinj 20) }\end{array}$ \\
\hline
\end{tabular}

$\frac{\text { vuk }}{(50)}$

35

4

12

$\underline{1}$

$\underline{2}$

Deruvar

11

$+$

2

8

๑

(21)

13

Stn 1

28 .

$+\quad 24$

31

12

(95)

52

D1. erete Gruppe 10t, w10 man sioht, In elien drel Samalungen d1e Grobte, wobel $1 \mathrm{ch}$ der vortlaut vieler Anfangestzo nahozu 
deckt, nur tritt in den neueren Texten melst anstelle des furstlichen das dörfliche Milieu. Die Gruppe B lst bel Vuk offensichtlich deshalb so schwach vertreten, well derartige Vorbemerkungen wohl schon von den Sammlern weggelassen wurden. Dies dürfte Insbesondere auf Karaď̌lls langJahrigen M1tarbelter Vuk Vrderle zutreffen; In dessen 1868 verbffentlichter Samiung finden bich fast nur Anfungo mit unmitelbarom Elnsetzen der Handlung, die sehr oft durch das Wort "nekakav" (1rgendeln, d.h.: Irgendeln Mensch, Irgendeln Dorf..) aus jedem deutlichen brtlichen oder persónlichen Bezug gelost und dadurch jener Abstraktion angenahert wird, die den E1nzelfall zum Typischen, zun Belspiel la ursprüglichen Sinne des Murchens, der Fabel erhebt.

D10 Schlusse der Erzahlungen weichen vom slavischen Muster der ornamentalen formel weit entschiedener ab; keine der herangezogenen Sammingen entstammt ja dem westkroatischen Raum, auf dessen besondere Schlubformeln eingangs hingewiesen wurde. Be1 Karadżt sind formelhafte Wendungen haufib, die dem Grimmschen MarchenschluB "und wenn sie nicht gestorben sind, so leben sie noch heute" entsprechen; in den belden modernen Sammlungen sind sie weltaus seltener. Darin auBert sich vermutilch die Bearbeltung, obenso wle In jenen Schlubsatzen in Form einer Lehre, die auf die Bemuhung un formale Abrundung bzw. um prdagobische Wlrkung hindentet. Wenn andererselts fast oln Drittel der Erzahlungen aus dem Sinjer Geblet mit elner persönlichen Bemerkung ondet, beruht dies auf der absolut wortgetrouen Wiedergabe.

2u dem formelhaften SchluB - Typ nach Art der Bruder Grimm kann man all jene Erzkhlungen rechnen, die mit der Heirat des Helden und dem Ausblick auf ein glückliches Leben bis zum Tod schlieBen (Typ 'te ou sretno živell do svoga veka", Vuk.Nr. 14). An die breit ausgebauten slavischen Schlubformeln klingt in der Sammlung Vuks nur der SchluB dos Marchens Nr.23 an, der aber doch eher dem vorgenanten Typ entspricht. Elne kleine Gruppe endet at elnem kurzen Spruch bzw. Re1m, der formal manchmal gew ssen kajkavischen ornamentalon Formeln angenahert sein kann (" 1 laž ču, laž kazao, 1 Bog ml te vessilo", Vuk Nr.29). 
Die perabnlichen Bemerkungen reichen vom Binweis auf die tberlieferung ("to san od stari' ljudi cuja", sinj.nr.49) bis zum Wahrheltstopos ("to san ja gledao, to je istina", Sinj.Nr.39) oder seiner Umkehrung, elner angedeuteten Distanzierung vom Inhalt ("sad Jesu l' mu sretu dale vile, ja ne znan", Sinj Nr.72).

EIn Grobteil der Erzuhlungen - ob Marchen, Sage oder "realistische" Eratihlung mit evtl. Hineinspielen des Wunderbaren - endet jedoch in allen drei Samilungen analog zum unittelbaren Einsetzen der Handlung zu Beginn mit deren Beendigung bzw.Ergebnis, worin manchmal eine Art Pointe liegen kann.

Vuk Daruvar

Typ A - formelhaft

"te su sretno..."

(Vuk Nr.14)

21

6

" 1 dan-danas żividu

aku nisu unrli"

(Daruvar Nr.20)

Typ B - formelhaft

"I Bog mi te vese-

$110 "$ (Vuk Nr.19)

4

$\phi$

$\varnothing$

Typ C - Belehrung

(oder Gemeinplatz)

9

1

Typ D-Feststellung d.

Ergebnisses d.Handlg.bzw.

bzw. Inrer Beendigung

"I Camac otibo 1 bog-

zna kud je kum dospio"

(Daruvar Nr.10)

"I od tada 1 ví̧e kru-

nije tukla nikako"

(Sinj Nr.87)

Typ E - persönliche

Bemerkung

$\varnothing$

9

30

(In den Sammiungen aus der Umgebung von Daruvar und von Sinj treten Typ $D$ und Typ $E$ oft in unmittelbarer verbindung auf, weshalb eintge Erzuhlung in beiden Gruppen mitgezăhlt wurden).

Auch in der sammlung von VRCEvić von 1868 (123) schlieben die melsten Eraählungen mit dem AbschluB der Handlung oder ait einer Art Schlubpointe; gelegentlich fledet sich auch hier eine abschliebende Belehrung oder eine Art Sinnspruch. Inwiewelt die Bevorzugung einer Schlubpointe bzw. eines Schlubsatzes vom 
Typ $D$ auf den personlichen Stil des Samiers, auf die aufgrund der Aktualitit vieler seiner Motive anzunehmende relativ kurze Uberlieferungsdauer oder auf das Herkunftsgeblet (Dalmatien) Boka Kotorska/Crna Gora) zuruckzufuhren ist, läbt sich schwer beurteilen.

Zusammenfassend kann man sagen, daB Amfang und SchluB der serbokroatischen Volkserzbhlung - auBerhalb des kajkarischen Raumes - den formelhaften slavischen Erainlstil nur in abgeschwichtem MaBe reprasentieren, worin ein weiterer $\mathrm{Zug}_{\mathrm{g}}$ ihrer Neigung zum Realismus gesehen werden könnte. Wenn, wie die oblge zusammenstellung zelgt, bei absichtlich extrem gegensitzlich ausgewihlten Sammlungen wie denen aus sinj und Daruvar gegenuber der Karadits Gemeinsamkeiten zwar hinsichtlich des Anteils relativ einfacher Schluskize auftreten (Gruppe D), andererseits aber bewubt geformte Elemente bel Vuk deutlich uberwiegen (Gruppen A, B, C), so liegt dies an den vollib verschiedenen Ansatrpunkten und zielen der Herausgeber. Hierauf wird unter III.3.8. näher eingegangen. 
III.3.4.4.Direkte Rede und endere Redefermen.

In der serbokroatischen Volkserzahlung niant die direkte Rede elnen groBen Raun e1n, und zwar hauptsächlich In Fora des Dialogs, seltener des Monologs; auch die zahlreichen Befehle sind Ja letztlich als Dialog "alt aubersprachlichen Repliken ", nualich "der Erfüllung der Befehle" zu werten, wie MUKȟ̌ovskŕ sagt (82.5.113). In der haufigen verwendung der direkten Rede liegt wieder elne Parallele zum eplschen Lied, welches gelegentlich ausschlieblich daraus besteht, z.B. aus Frage und Antwort in nahezu glelchem wortlaut, so daB sie zum tragenden Element elner streng symetrischen Komposition werden kann. Die gleiche Erschelnung weisen viele lyrische Lieder aur.

Allein die Tatsache, dals die Erzahlung nicht an ein Metrum gebunden 18t, bewlrkt hier eine gröbere Variationsbrelte entsprechend der offeneren Form. Auch in der Volkserzahlung kann die direkte Rede stutzendes Element der Komposition sein, indem sie an entscheldender Stelle im gleichen Wortlaut oder in Variation auftrit, aber die Form der Prosa an sich gestattet Erweiterungen und unterschiedilche Linge solst paralleler Abschnitte, ste ermöglicht z.B. bel elner dreffachen stelgerung die Wiedergabe elner bestimmten Antwort zweimal in direkter, beim dritten Male in indirekter Rede. Inwlewelt von Fall zu Fall die eine oder andere Redeform gewahlt wird, liegt im Ermessen des Erzählers. MOJASEVIĆ (81,s.302) berichtet, daB KARADZ̃IĆ bel seiner Bearbeltung tellweise direkte in indirekte, teilwe1se Indirekte in direkte Rede umgewandelt habe, d.h. also, dab fur elnen so hervorragenden stilisten wie Vuk nicht unbedingt in jedem Fall das gleiche stilmittel als "dem Gelst der serbischen Sprache gembier" erschien.

Die direkte Rede tritt in der serbokroatischen Volkserzahlung nicht nur an besonders markanten stelien auf; sie lst oft die tragende Substanz der Handlung, die sich nach elner kurzen Darlegung der Ausgangsituation wie ein Theaterdialog alt szenischen Aneerkungen entwickelt. Diese Form ist in modernen - unbearbelteten - Sammlungen besonders häufif, wie ja auch die Umgangsprache bel der wiedergabe fremder Worte die direkte Rede der indirekten vorzieht. Dals dieser 246 nicht zwangsiaufig ein Abgleiten in Formlosigkeit bedeuten muB, beweisen viele Beisplela 
Da jede Erzahlung durch die direkte Rede an Plastialtat gewinnt, 1st e10 für den wündlchen Erauhler elnes der wichticsten Mittel, um das Interesse der Zuhörer an den handelnden Persenen wach zu

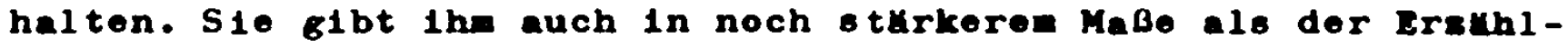
text Gelegenhe1t, typloche Wendungen der Ungangseprache, Ausrufe u.a. zu gebrauchen und so selne Geschichte den M1l1eu des Publ1kums anzunahern. In den serbekreatischen Ersahlungen wird ven dieser Möglichke1t relchllch Gebrauch genaoht, was orneut auf elne" real1st1sche"Tendenz hindeutet. Selbst in vUKe sprachlich ausgefellter stilisierung fohlt dieser Zug kelnesregs, $z . B$.

In den Marchen "Usud" (Nr.13,S.73-81):

S.75 "I t1 11 si coja sreta, Bog te ubtol"...

S.79 "Št, moj brate, ja bam Gazda

-der in "Kn manje 18̌te, viǒe mu se daje" (Nr.14,5.81-86):

5.83 sagt der König: "Sta tomo sad..."

darauf der Engel: "Znate 11 Gta? Orako da uredieo: ..."

Dieser "Umgangston" bußert sich auch in der lmer wiederkehrenden Begrubungsform, z.B. In "Aždaja 1 carev sin"(Nr.8,5.45-52):

S.45 Carev sin joj nazove Bogaz"Pomoz1 Bog, bakol" A baba mu prihrati: "Bog t1 ponogao, Binkol"

Im Marchen "Baš-Čl1k" (Nr.51,5.187-207) fragt d1e Prau Bă̌-Čel1k:

$S .206$ "Boga t1, de je to troje junaštro?"

Dieser vertrauliche Ton findet sich auch in allen anderen Sammlungen, z.B. In CAJKaNovićs Anthologie (22), die aus rerschiedenen blteren Sammlungen zusamengeetellt lst, wenn z.B. In der Erzahlung Nr.66(S.175/176) das in elnem Grab eingesperrte personifizierte Ungluck (nevolja) wieder ausgegraben wird:

S.176 Bogatega obuze zavist, te pode na greblje, otkopa greb neveljin, 1 zorne Je. "Evo me, Jedra sam Żia," edgoveri ona.

In den nicht bearbelteten Erzahlungen 1st dieser "familiken Ton noch haufiger.

Vielfach zelchnet $81 \mathrm{ch}$ die direkte Rede durch eine besondere lakonische Ausdruckewe1se aus, die sich bls zur lapidaren Fermulierung steigern kana. Dew umgangssprachlichen Berelch sind ach jene abgerissenen Dialoge zuzurechnen, in denen die Satze aufe Hetwendigste beschrunkt, gelegentlich sogar unvollstund1g sind, $z$. B. In der Erzahlung "Štngala-Mingala" (S1nj Nr.1.S.330): 
- Jesi li pita za mene?

- Kaže:

- Jesan.

- A Ta ni je reka?

- E, kad lzaden $1 z$ broda, kamat tu ti.

- Kad 1zasa la broda:

- Sta je reka?

- Nisan ni pita, zaboravijo. Kaze brodar:

- Dot 6 es t1 opet k meni.

Die letzte Replik dee hier angefuhrten Dialogs entspricht bereits jenen aufgrund ihrer Bedeutsamkeit zusammengedrángten Sătzen, die Entscheidendes verkunden:

Vuk Nr.12,S.67:

Daruvar Nr.20,5.628

Cub.Nr.14,S.105:

Troga sam oca ubio, pa tu i tebe. Niko viăe noj nego samo ti. Dat tu sve onome, ko me lzvede na pravi put.

Cajk.Ant.Nr.26,5.338 Neman je tus al1 temu je nat1. Auch dort, wo die direkte Rede aus lángeren sitzen besteht, werden die Sachverhal te in knapper Form ausgedruckt und nur durch ungangseprachliche wendungen als ̈̈uBerung einer der handelnden Personen gekennzelchnet; die direkte Rede lat Bestandte11 des Erzahl textes, d.h. sie enthält wie dieser nur dort besondere Akzentulerungen durch Lapidaritbi einerseits, durch Hhy thmisterung oder Ausschmuckung andererseits, wenn ihr Platz im Rahmen der Gesamtkonzeption dies erfordert. Auch hier, wie uberall. gibt es selbstrerstädlich Abstufungen von Erzahler zu Erzahler.

Feben der direkten Rede tritt in den serbokroatischen Volkserahlungen in geringerem Maße auch die indirekte Rede auf, $z . B$. Cub. 3.5.52:

Potom car ode naprvo, a sluga malo zaos tane, a mrar jedan najreti pita, o to bl najvolio, da mu dade zato, to je od njth vatru odgurnuo.

Čajk.Ant. 64, S. 169:

Div se nasmija 1 upita starca ta mu b1; a on odgovorl kako je preko ablane ugledao u grmu zeca, pa preskotio ablamu l uhvatio zeca za veceru.

Sinj 12,S.3458 ...all pop mu je kaza da ne more niko k njemu uti.

Beta mindlichen Eratihlen erfolgt der Ubergang vom Erabil text zur direkten Rede, von der direkten zur Indirekten Rede oft onne deutliche Cisur; das Verbum dicendi entfillt in den Tonbandaufzetchnungen besonders háufig, aber auch bel Karadżt 
glbt es Falle unnittelbarer Aneinanderfügung von verschiedenen Redeformen. Als Beispiel fur den wechsel zwischen indirekter und direkter Rede sel ein Textstück aus dem Mirchen "Opet zmija mladozenja" (Vuk Nr.10,S.57) angefuhrt:

Ona joj odgovori: "Nevolja me, majko, naterala", pa joj pripovedi kako je stradala, kako je muz prokleo 1 kako ide po svetu te ga traxi, "pa sam", veli, "dolla pitati troga sina, ne bi 11 mi mogao on za njega to kazati, nije 11 gde video, jer on preko svega svijeta prelazi."

meben direkter und indirekter Rede lassen sich in der serbokroatischen Volkserztihlung Ansitze zur Verwendung der erlebten Rede erkennen; geht man von dem russischen, weiter gefaßten Terminus "nesobstrenno-prjanaja rex"" aus, so lassen sich auch hierfür Beispiele finden. Mit dem russischen Terminus wird nicht nur die wiedergabe gesprochener oder gedachter Worte in der 3.Person bezelchnet, sondern daruber hinaus auch die eines nicht als Rede formulierten Standpunktes des Helden. L.SOKOLOVA unterscheldet, unter dem Gesichtspunkt der Wechselwirkung zwischen Autor und Feld, drei Arten der "nesobstrenno-prjamaja reci": einmal die klassische erlebte Rede, bei der der Held uberwiegt, zun anderen elne Form engerer wechselwirkung, bei der Autor und Held etwa glelchberechtigt sind und - In vielen Fillen - abwechselnd zu Worte komen, sowie schlieblich, als dritte Möglichkelt, eln völliges Uberwiegen des Autors gegenuber dem Helden, dessen subjektive Einstellung nur durch den Gebrauch gewisser, für inn typischer wendungen oder auch nur einzelner Worte zum Ausdruck kommt (105, S.24-30). Nachstehend werden einige Beisplele hierfür wiedergegeben, die den mit Sicherheit authentischen sammlungen entrommen sind:

Daruvar Nr.17., S.54:

Sta te sad, sad ga ovaj nasamario - nista nego da ga ubije, makar mu je brat, je l'. Ubi' te ga 1 gotovo. Daruvar Nr.20,5.62:

A on dode tam', pogleda, joj, pa to nije ona.

A sto te?

Sinj Nr.10,5.3438

A mater 1 kter iz jame izadu, jedva jedvice se škapulale, vala bogu kad ou izable na sitlost.

wendet man die von Sokolova vorgenommene Eintellung auf diese drei Beispiele an, so ist das erste Beispiel dem Typ I, das zweite dem Typ II und das dritte den Typ III zuzuordnen, da 
im letzten Belspiel nur das in den Erathl text eingeschobene "vala bogu" mit S1cherheit als "nesobstrenno-prjamaja ref"n zu verten 1st; allerdings könnte man den rext auch schon ab "jedva jedvice..." In diesem Sinne auffassen, und zwar bis zum SchluB; dann wäre dies ein Beispiel für Typ II.

Das Verbum dicendi entfílit nicht nur in den luber längere Strecken hin dialogisch aufgebauten Passagen, es kann auch sonst durch eine Pause oder das Wörtchen "da" ersetzt werden. M.BOSKOVIC-STULLI zitiert in ihrem Aufsatz "o rexenici usmenog priporjedaca" ein Beispiel aus einer Variante der Sage von Kaiser Trajan $\left(18,5.261^{1}\right)$ :

Brico koji ga je bricio vidio je to, pa ga je kralj htio pogubiti, a brico - da neka mu dozvoli da prije nego te ga pogubi', pojede bokun pogate sto mu je dala njegova majka.

Weltere Beispiele fü den Ausfall des Verbum dicendi:

vreevit $1868 \mathrm{Nr} \cdot 112, \mathrm{~S} .48$ :

...pocnu zeta zapitivati tast 1 punicar kako, zete, ijetina? "Ta Imao sam desetak tovara same benice." A drug mus jest vala 120.

Daruvar Mr. 16, S. 50 :

Car odma' $k$ njoj, pa joj odma' praten dao 1 viłe dalje nete od nje. Sjedi kraj nje pa sjedi. Pa otklen je, pa kak se zove?

Dieser Ausfall des Verbum dicendl bewirkt eine besondere Unmittelbarkeit der Erzahlung. MOJASEvIC hat diese Erscheinung auch in den Handschriften der Sammler Karadzits festgestellt. Zusammenfassend ist zu sagen, daB die direkte Rede ein vesentliches Stilmittel des mündlichen Erzählers ist und daß auch andere Redeformen in der serbokroatischen Volkserzbihlung, wenn auch rudimentir, bereits vorgegeben sind.

$1 \operatorname{nach} 15,5.240$ 
Je länfer elne Erzählung mindlich weltergegeben wird, umso mehr wird ihr Wortlaut festgelegt, vor allem an den wichtigen Punkten der Handlung. Ebenso, wie Kinder beim Erzählen elnes schon bekannten Märchens auf dem glelchbleibenden Wortlaut beharren, verlangt das "zensierenden Kollektiv vom Volkserzähler an bestimmten stellen seiner Geschichte jene erwartete Wendung, die Ausdruck seiner elgenen Mentalität ist bzw. die stch dank ihrer eindringlichen formulierung eingeprägt hat. Für den Erzähler wiederum sind diese stelien Gedachtnisstitzen und zugleich tragende Elemente der Komposition, da sie, wie schon gesagt wurde, in parallelen Episoden einander entsprechend auftreten, das Hauptmotiv manchmal schon im ersten Satz anklinfen lassen oder aber als einmalige pointe das $z$ iel selner Erzählung sind.

Betrachtet man diese verfestigten, im Laufe der Tradition erstarrten stellen, so fällt auf, dals sie oft durch einen stilistischen Kunstgriff aus dem ibrigen Text hervorgehoben sind; dieser kann in besonderer Prägnanz oder Rhythmisierung, in Lautmalere1, Wiederholung oder semantischer Roduplikation bzw. einem ke1m bestehen oder auch in einer sprichwortartigen oder sogar rätselhaften vendung; jedes dieser Mittel kann dem betrefienden Satz einen mehr oder wentger formelhaften charakter geben. Manchmal verdichten sich diese Formeln zu versen, die migl 1 icherweise Zeugnisse eines vergessenen Liedes sind.

Noch elne weitere Bedeutung kommt diesen erstarten stellen in der Volkserzählung zu: wie Im Märchen nur ein bestimntes Wort elife bestimmte Tiir öffnet, so legitimiert sich der Erzähler durch die "richtigen" worte als einer, der wirklich die "richtige" Geschichte kennt; mit den "richtigen" Worten beschwört er den Geist eben dieser Geschichte - so wie eine Zauberformel nur in der einen, festgelegten Form ihre magische Wirkung hat.

Die verfestigten stelien sind ein wesentliches Element zur Schaffung der Atmosphäre der Volkserzälung, glelchguitig. ob es slch um die Wunderwelt des Märchens handelt oder un die harte Realität elnes vom Kampr ums Dasein geprägten Milieus, die durch die allpemein bekannte, erwartete Pointe 
einer Kurzgeschichte oder Anekdote verdichtet wird. Ein Be1spiel hierfü lst die von PAVIČEvIĆ( 87, s.9) aufgezelchnete Geschichte vom Zinsgroschen (metelik, eine kleine türkische Müze), den ein montenegrinischer $\mathbf{s t a m m}$ den Turken als harac verwelgert. Als die Türken die Christen gefangen nehmen und den juingsten Sohn des Vojvoden vor dessen Augen töten wollen, ruft dieser:

Ah, tata, sto te ovo da čine? -

worauf der vater antwortet:

Nista, sine, to te odmah proti, a onaj metelik arača, ne bi prołao nikad.

Gerade hinsichtlich der Formeln u.a. darf der Zusammenhang zwischen den Gattungen der serbokroatischen Volksliteratur nicht ubersehen werden. Die grolse Bedeutung der Formeln für den nau eines tiedes wird bel PEUKERT ( 88,s.175-183) dargelegt. Wichtig ist peUKERTs Hinweis, dab die Formel nicht unbedingt immer archaisch sein muisse, dals vielmehr die Formel bel 1 Serben, Kroaten und Makedoniern noch elne produktive Form se1:

lie Formel lebt hier ungeschwächt, ist durchaus produkt iv, nur vorläuflges Endprodukt einer allerdings wohl in Finzeltypen bis in älteste zelten zurückreichenden Fntwicklung. (S.183)

Erscheinen die verfestigten stelien nicht, wie in dem obigen Beisplel, als cichlubpointe, so enthalten sie oft Befehle oder Hinweise auf kinftiges Geschehen, so dals sle Angelpunkte der Erzählung bilden, die die Iramatik, die Spannung erhöhen können.

In den voll KAHAIŽIĆ bearbeiteten Närclien lst dieser stilzug besonders ausgeprägt, er lälst sich aber auch in allen anderen Sammlungen unterschiedlichster Herkunft beobachten. is folgen einige Beispiele.

Besonders rhythmisierte satze:

Vuk Nr.25, S.109

Haj, volovi, pomoz1, Bože, da rodi vareni bob.

Sinj Nr.14,S.347/348

Vuk Nr.4, S. $18 / 18 / 19$

Sinj Nr.9,S.342 -stoj s miron, ne kreti, stoj s miron, ne kreti.

Ustaj, hrano! Ustaj, srcel Ustaj, dušo!

Odnit te ga, odnit te ga, Gta tu Ja, mukte rodit ga, odnit te ga daval 
Čajk. Ant $\cdot N r \cdot 82, S .220$

Prägnante Sätze

Vuk Nr.4,S.21

Cajk.Ant.Nr.31,5.61

Čajk.Ant.Nr.83,S.221, 222
Ustaj, brate, otvor mi vrata, da platim toj kut 1 sto mi je kosti 12 groba kretala.

(Ribica:)

Po Bogu da 91 mi brat! bacl me u vodu... (L1s1ca:)

Po Bogu da $31 \mathrm{ml}$ bratl pust1 me 12 ovih grozda..

(Kurjak:)

Po Bogu da $31 \mathrm{mi}$ bratl pust1 me...

Šun, ote mi lz usta! (3x)

Uzme je za ruku, pa je odvede u devetu komoru, lzvadi joj jezik, pa je objest zanj ....

Uzme je za ruku, odvede u komaru, pa je objest za jezik.

Zaubersprüche, rätselhafte Formeln:

Vuk Nr.4.5.24

Sinj Nr.88, S.405

Sinj $N r \cdot 1, S \cdot 332 / 334$

Sinj Nr.4.S.338
Dura, babina koblla! ( $3 x)$

$N_{1}$ o drvo, n1 o kamenl

I o drvo, 1 o kamen! (In dieser FormuIterung hat der Spruch keine Wirkung).

singala-mingala!

U ništa tunj! (Diese Formel wird rom Frzähler selbst nicht mehr verstanden.)

Rätselhafte Antworten, hinter denen ein Sinn verborgen 1st:

Vuk Nr.25,S.110

Careva brada valja koliko trikiłe

ljetne. (d.h.. der Bart des Kalsers

lst aulserordentilch wertvoll)

Sprichwörter, Sentenzen:

Vuk Nr.29,S.311

Ču.Nr.61, S.244

Relme, Verse:

Sinj Nr.30, S.362

Cajk.Ant.Nr.82,S.220
Nema nista gorega od pijana Vlaka 1 or Gladna Turtina.

Pop ne dava, nego uzima.

Što radił, čoviče, pał.te dlitâ, ubit te dite..

Pašte dlite, ubit te dite...

Pas'te ditte, ubit te dite.

Der tote Bräutigam sagt zu dem Mädchen (Lenore-Mot1v):

Mesečina sja, je l'te, diko, stra'?

Antwort: Kako bi me bilo stra', kod tebe sam živa jal

Der Tote: Mesecina sja, je l'te, diko, stra'?

Antwort: Kako b1 me bilo stra', kod tebeka živoga? 
Sing Nr.43,S.373

- I sve blagosilje. otoke 1 potoke

1 voǔite 1 dočite,

1 sve blagosil je -

tkalju nikad ne blagosilje.

Manchmal sind die verfestigten $S_{t} e l i e n$ auch ganz schlichte Sätze, die mehrfach wiederkehren, z.B.

Varuvar Nr.20,S.62 Molim tri kape vode.

Als Belspiel eines längeren, in lelchter Ahwandlung wiederholten Satzes, der stets mit der glelchen Drohung endet und eine wichtige Funktion im Märchen "Pepeljuga" hat, sei der Befehl der Stiefmutter zitiert:

Vuk Nr.32,S.131. Ako ovo sve proso ne pokupiŏ 1 ručak ne zgotovis dok mi 12 crkve dodemo, ubitu te.

S.132 Ako to sve proso ne pokupif 1 rutak ne zgotoviš dok mi dodemo iz crkve, ubitu te.

S.133 Ako ovo proso sve ne pokupiళ, ručak ne zgotoris 1 ostalo sve ne uredis dok mi dodemo 12 crkve, ubitu te.

Diese drel elnander entsprechenden Säze, die auch in ihrer Mikrostruktur das Prinzip des Parallelismus durch Isocola realisieren, wobel der letzte Satz durch ein zusatzilches Isocolon den Eindruck einer steigerung erweckt, machen die Funktion der verfestigten Stelien innerhalb der Komposition der Volkserzählung besonders deutlich.

III.3.4.6.Epitheton - Vergleich - Metapher - Parallel1smus semantische Reduplikation - Fipura etymologica

Die im vorigen Abschnitt behandelten "verfestigten" Stelien markieren Höhepunkte bzw. Wendepunkte der Volkserzählung; sie dienen der Komposition oder sind "Frkennungszeichen" e1ner bestimmten Erzählung. Demgegenüber gehören die nachstehend genanten Figuren zur sprachlichen Berelcherung des Textes, d.h. sle wären für die reine Fabel entbehrlich. wie in der Lyrik und in der Epik solien sie die Ausdruckskraft des Textes stelgern, und, völlig analog, können sie dieses Ziel bel einem Erzahler, der diese Akzente zu setzen weib,errelchen oder, bel einem wentger Begabten, zur bloben Manter werden; doch selbst dann noch erfillen sie den $Z$ weck, zwischen Zuhörer und Erzahler jenen Kontakt zu schaffen, der aus der beiderseitigen Vertrautheit mit diesen altbekannten 
Wendungen entsteht.

Diese Figuren sind ausnahnslos aus der Lyrik, der Epik und der volkstimlichen Rhetorik geluufig, deren sich gelstiche wie weltilche Redner bedienen. MARETIĆ $(73,5.36-108)$ glbt eine Ubersicht der st1118tischen Verfahren der serbokroat1schen Volksepik; in die Anwendung der Tropen und Figuren im balkanslavischen lyrischen Volkslied vermittelt die uberaus detalliferte Untersuchung von POLLOK (90), die sich auf das Liebeslied bezieht, elnen Elnblick. POLLoK, der dem Konzept H.LAUSBergs 1 folgt, nennt als produktivste Stilmittel der balkanslavischen Liebeslyrik die Metapher (s.21 ff.), den Vergleich(s.45 ff.), das Antitheton (S.71.ff.), die wiederholung in thren verschiedenen spielarten (s.81 ff.; Geminat1o, Anapher, Epipher, Symploke, Paronomasie, Polyptoton, Figura etymologica, synonymische wiederholung) und, als eines der wichtigsten, das Isocolon, dessen Schmuckwert auf der Parallelitat in der Gestaltung der Aussagen beruht (s.134 ff.)

Die sprachliche Gestaltung der Volkserzahlung erfolgt mit Hilfe stilistischer Kunstgriffe, die in den anderen Gattungen vorgegeben sind. Ein beliebtes stilmittel der Volksilteratur sind die stehenden Epitheta. Sie dienen nicht der Anschaulichkeit - hier können sie nur der phantasie das stichwort geben sondern sind vor allem Bestandtell des traditionsgebundenen Rituals der Volksilteratur, Formeln, die vom Zuhörer erkannt werden. Fs fallt auf, dals sie in den volkserzahlungen weit seltener sind als in Epik und Lyrik. Hierfü gibt es eine Reihe von Griinden. Kein formal betrachtet, begunstigt das Metrum das wiederaufgreifen des Epithetons an der gleichen Stelle verschiedener Verszellen, wodurch es der Architektur des liedes dient; andererselts entspricht das epitheton ornans der gehobenen Sprachschicht des epischen Liedes. In der Lyrik wiederum, deren sprachschicht dem Sanger wie dem Zuhörer năher 1st, trágt das Epitheton zur stimmung bel und dient oft - Im wörtlichen Sinne - dem "farbigeren" Ausdruck.

Der mündliche Erzähler strebt nicht nach epischer Distanz, und es geht inm auch nicht in erster Linie um Stimmungen; er w111 Geschehnisse in packender forn berichten, aus denen sich evtl. elne Lehre ablesen labt, die er manchmal auch direkt formuliert.

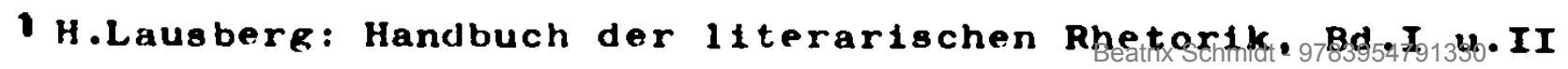


Daher eeht er recht sparsam mit den Epitheta um; wo sie auftreten - vor allem im Märchen- sind es meist die gleichen wie in den anderen Gattungen, d.h. typisierende Adjektiva, die formelhaft eebraucht werden.

MARETIC sagt über die serbokroatische Epik:

In unserer Volkspoesle besteht der erölte Tell der Epitheta aus wortern, die auch in der Umgangssprache häufig gebraucht werden $(73,5.42)$.

Er betont ferner, dab die Eptheta der russischen Bylinen "ebenso primitiv sind we in den serbischen Liedern"(73,5.43). Als Heispiele aus der serbokroatischen Epik nennt MARETIC:

bijela ruka, crna zemlja, hladna voda, ljuta guja, ravno polje, sivi soko, sitna knjiga, trrda vjera, vedro nebo, zelena gora etc. $(73,5.43)$

PEUKERT bringt entsprechende Beisplele aus der serbokroatischen (und makedontschen) Volkslyrik:

Vas Madchen lst mlada, lijepa, neprosena, nevjerena, vjerena, der Bursche mlad, nevjeren, nezenjen, der Apfel zelena, ausnahmsweise auch pitoma(Mhrv 83) und vrhom rumena (Mhrv 209) 1 , die Wiese nekosena, der Weizen bilica, die Zitrone zut, ebenso auch die Quitte, der Ring zlat, das Pferd dobar und nejahan, die Augen crne, das Gesicht belo, der Knopf zlatno, die Hosen zute, die Leinwand bjelo, das Meer sinje, die Rose rumena, die Mandel sladak, der Gurtel svilen, das Wasser studena oder ladna...(88,5.177).

Das gemeinsame Herkunftsmilieu und die Beschaftigung der Sammler mit sämtlichen Gattungen der Volksliteratur bewirken, dals stch das typische Epitheton ornans der lieder in abgeschwachtem Maße auch in Marchen und Erzahlungen findet:

pod vedrom nebom

ata vrana prijed ne Jahana

verna l Juba

suze krvave

studene vodice 1 zelene

travice

ljuta zmija

bisernu livadu

vilenu goru

krilata konja

starac bijele brade

dva siva sokola
Daruvar Nr.11,5.39

Vuk 33, S.126

Cajk.Ant.Nr.84, 5.224

Vuk Nr.35,S.145

Vuk Nr.50,S.184

Vuk Nr.28,S.117;32,S.133

Vuk Nr.30,S.125

Vuk Nr.30,S . 125;

Cajk.Ant.Nr.8,S.89

Vuk Nr.40,5.157

Vuk Nr.32,S.129

Vrčevit $1890,5.136$

\footnotetext{
$1_{\text {Mhrv }}$ = Hrvatske narodne pjesme, uredio Dr.N1kola Andrit, 1zdala Mat1ca Hrvatska, Zagreb 1929.
} 
Diese konventionelien Epltheta entsprechen nicht jenen, bestimmte Personen, Erscheinungen oder Landschaften kennzeichnenden Epitheta, wie sie bel Homer auftreten, etwa der "listenrelchen Odysseus oder die "rosenfingrige" Eos, die allein tm 1 .Buch der Illas 27 mal erwahnt wird (124,5.174). Kach MareTIC haben selbst die bedeutendsten Helden der serbokroatischen Epik, Kraljevit Marko und Miloš Obllit, keln solches, nur thnen zugehöriges Epitheton erhalten; dies lst nur bei zwel christlichen und e1nem islamischen Helden geschehen: krilati Relja, stari Jug Bogdan und gojeni Alil. Von den geographischen Namen haben nur zwel thr stehendes Epttheton: die Donau - tihi Dunav - und das Amselfe1d - ravno Kosovo $(73,5.43)$.

Zu den haufigsten Epltheta der Volkserzahlung gehören

Farbadjektiva, z.B.:

crni bik: bili bik
vran konj: bijel konj
b1jela kao snijeg 1 rumena kao krv
po bijelom svijetu
crljene kabanice
crnazemlja
crnoj zemlji
sinje more
crni sodom
čovek u zelenim haljinama(=d.Teurel)

$\operatorname{sinj} N r \cdot 93,5.410$

Vuk Nr.2,S.9

n $24,5.107$

" $28,5 \cdot 118$

Sinj Nr.18, S.352

Vuk $\mathrm{Nr} \cdot 30, \mathrm{~S} \cdot 124$

Sinj Nr.59,5.383

Vuk Nr.37,S.152

Cajk.Ant.Nr.42,S.112

Vuk Nr.6,S.37

Das Epltheton "zlatni" steht fast Immer als Zeichen für Wunderbares, für die welt des Märchens und der Sape:
zlatne skale
zlatne katrige
Zlatni grad
zlatnom żicom vezla
na zlatnoj tepsijt
zlatna jabuka, zlatne paunlce
zvijezda zlatna
Sinj Nr.11,S.344

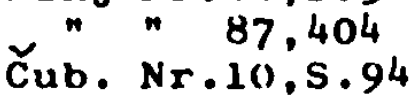
ovan sa zlatnom vunom
Vuk $N r \cdot 2,5 \cdot 9$
" $"$ "
$n \quad 4,5.15$
" $" 23,5.105$
$n$ " $12,5.66$

Hier Finden sich auch zusammengesetzte Epitheta, z.B.

rodila bih mu sina zlatnoruka 1 kter zlatnokosu

zlatokosi junak u prasetojkožl

$\underset{n \text { Cajk.Ant } . N_{n} \cdot 42,5 \cdot 110}{41,5 \cdot 104}$

In Verbindung mit "zlatni" tritt oft - wie in anderen Gattungen - das Epltheton "srebrni" auf:
zlatna 1 srebrna rosa
Nar.prip.PSkK,
grane srebrne 1 perja zlatna
$\mathrm{Nr} \cdot 117, \mathrm{~S} \cdot 268$
Vuk Nr.30,S.125 
Eine Rethe von Epitheta der Volkserzbhlung dient ledielich der schablonenhaften zuordnung von Personen oder Gegenstanden zu bestimmten gegensatzlichen Gruppens starijl i mladi, slromah : bogat, velik: malen, zla: dobra (betrifft melst die Frau, daher Femininum), lijen : vrijedan, etc., z.B.

otariji brat : mladi brat

Daruvar Nr.17.S.51 siromah, siromašan : bogat

Daruvar Nr.17,S.51

Vuk Nr.7.5.41

Cub.8r.15.s.111

m1lostiva snaha. 1 nemilost1va svekrva Vuk Nr.15,5.85

Auch wenn sie nicht als Gegensatzpare auftreten, dienen diese Adjektiva lediglich der Zuordnung zu einer Kategorie:

stara kuta

staro doba, stari l judi

u stare zemane

mlada carica

najmlada, najkrasnija

mladoj materi

zla žena

Imao zlu 1 preopaku ženu

zla makeha

Xovik bogati

pop vrlo bogat

veliki čopor svinje
velika ploca

malu djecu

mala kutica

Covik siromak (=siromah)

stromah lovac

siromah momak
Daruvar Nr.6,5.34

$" 20,5.61$

sinj Nr.49.5.365

sinj Nr.78,S.398

Vuk Nr.27,s.117

Daruvar Nr.20,5.61

Cub.Nr.21,s.138

Vuk Nr.37,s.148

Vuk $\mathrm{Nr} \cdot 33, \mathrm{~S} \cdot 134$

Vuk Nr.33,S.134

$\begin{array}{ll}\operatorname{Sinj} & N_{n} \cdot 29,5 \cdot 361 \\ & 37.5 \cdot 369\end{array}$

Čajk.Ant.Nr.41,5.104

Vuk Nr.38,5.152

Daruvar Nr.6,S.37

Sinj Nr.33,s.366

Cub.Nr.14,5.105

Cub.Nr.35, S. 190

Auch diese alltäglichen Adjektive können unter Umstanden,

etwa durch Wiederholung, die Expressivityt ste1gern, z.B. vel1ke B̆ume... vel1ke zmlje..

Daruvar Nr.19.5.59

Gelegentlich finden sich auch welter ausgebaute, volkssprach11che Topo1, z.B.

mladit posiromah, al1 pošten 1 vredan

Čajk.Ant.Nr.93,S.25

vidi prekrasnoga mladita u gospodskim hal Jinama

Vuk Nr.34,s.139

lijep momak sa zlatnom kosom

Cajk.Ant.8r.41,5.10 
Das am weitesten verbreitete Epltheton für das Madchen ist auch in den Erzählungen "11jepa". "lepa", prelepa":

11 jepa djevojčica
lijepa djevojka
lepa devojka
prelepa devojka

Daruvar Nr.18,S 57,58 ;

" $\quad 16,5.49$

Cajk.Ant .Nr. $44,5.117$

vuk $\mathrm{Nr} \cdot 13,5 \cdot 74$.

Personen, die sich in Notlagen befinden, erhalten oft das bipithet on "jadan":

jadna mater, jadna ter

jadno ždrıjebe

Sinj Nr.10, S.342,343

Vuk Nr.50,S.185

Eine kleine Gruppe von Epitheta entstamm dem kirchlichen Bereich, z.B.

sveti Petar, Veliki petak sveton vodon

kral jevstro nebesko

premudri solomun

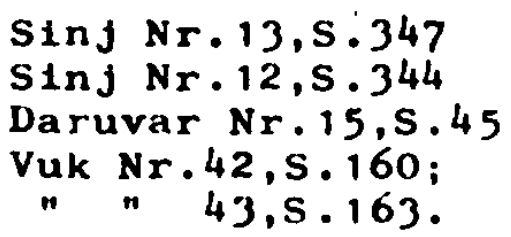

All diesen Epitheta ist gemeinsam, was zu Bepinn angedeutet wurde: sie sind Zeichen im Zeichensystem der Volksliteratur, innerhalb dessen sich die Kunst des mündlichen Erzählers entfaltet.

Karadžlt hat diese volkstimlichen Fiptheta in den Stil seiner Bearbeltungen einbezogen; er hat daruber hinaus auch andere Adjektiva verwendet, jedenfalls mehr, als man ale in anderen, vor allem unbearbeiteten Sammlungen findet, etwa:

-po dubokijem alugama 1 gust1jem grmenima-Nr.4n,s.157 Solche Adjektiva haben keinen zelchenhaften, sondern einen beschreibenden Charakter; sie kommen auch in Ćajkanovits Anthologie vor, z.B. In einer Erzahlung, die von simeon Burit stammt (Zborn.Akad.Nr.4n):

- eto doleti bura, l juta 1 namrgodena Čajk.Ant.Nr.45.S.1121

In der Sammlung aus Daruvar, die sonst sehr wenige, nur alltägliche Epitheta aufweist, finden sich als Attribute des Todes nicht nur "tanka, visoka" sondern sogar "svakojake boje" (Nr.7,Seite 35). Es handelt sich um eine von persönlicher Anteilnahme geprägte Frzăhlung. Die Vision des Todes ist hier nicht konventionell als "ble1ch", sondern "in allen Farben" - dariber hinaus noch als ständig wachsend und wachsend - von elnem blinden Erzähler geschildert, dessen Ergriffenheit ihn hier ausnahmsweise zum individuellen Ausdruck, zum charakterisierenden Fiptheton hingefiihrt hat. 
Obwohl der Verglelch in der Volksliteratur vielfach als rituelle Formel auftritt wie das Epltheton, aubert sich in thm ein starkeres Streben nach Anschaulichke1t. Er kann somit bewulst elngesetztes Stilmittel der volkstülichen Rhetorik sein, tells ubernomen aus der kirchlichen - und über diese aus der antiken - Rhetorik, tells der Sprache inhärent. WELLE/WARREN weisen Im Kapitel "Bild - Metapher - Symbol Mythus" (124,S.103-187) darauf hin, daB die Metapher das "allgegenwartige Prinzip" der Sprache se1, daB man sie jedoch von der spezifisch poetischen Metapher unterscheiden misse (124,5.173). Die Unterscheldung, die hier zwischen der Sprachmetapher und der asthetischen Metapher getroffen wird, glit auch für den vergleich. Es lst jedoch schwer, die Grenze zu ziehen, denn selbst die verblalste, von der Sprache assimilierte Metapher kann sich in elnem bestimmten Zusammenhang dem Stellenwert des Dichterischen annahern, und ebenso der Verglelch. Der mündlche Erzahler gehört zu jenen Kráften, die solche bestehende vendungen nicht nur erhalten und weitergeben, sondern auch als Novum in die Sprache "einfüren". w1e aus der Hochsprache gewlsse Ausdricke in die Umgangssprache elndringen können, so trägt auch der Erzähler durch Wiederholung und Neuprägung zur Berelcherung der Sprache bel.

WFILEK/WARREN haben Im Zusammenhang mit den geflugelten Worten Homers diese Position 1m Berelch zwischen Automatisation und Originalitat mit folgender Formulierung trefrend umrissen, die auch fü die Verglelche der serbokroatischen Volkserzahlung zutrifft:

- sie verschaffen durch thre Konventionalitat, dadurch, dals sie zur berufsmäbigen ritualen Sprache der Dichtung gehören, den Hörern Vergnugen. Ihre metaphorische Qual1tat wird weder voll erkannt noch gainzlich lenorlert. $(124,5 \cdot 174)$.

Nachstehend elnige Be1spiele von Vergleichen aus serbokroatischen Volkserzahlungen:

mlada... spava ko andel

ko prst tanka

dobar kao dobar dan u godini dva konja ko dvi bile vile uhvatilo dva vranca, ki dvi vile
Daruvar Nr.18,S.57

" 19.59

Vuk Nr.15,5.85

Sinj Nr.62,S.385

Cub.Nr.60,5.244 
stap drorogi crljen kao vatra

Vuk Nr.20,5. .8

-.pa se protegne na trav1, kao

matak na suncu

Cub.Nr.35,S. 192

Ebenso konventionell wie diese Vergletche sind die folgenden, die aus dem kirchlichen Bereich stammen:

..da se hrani ko nebeske tice

Čub.Nr.35,s. 190

Jedan Covik...ima petero dice 1

ženu. Pa bila zia ko dava.

$\operatorname{sinj} N r .21 .5 .353$

Expressiver wirken die folgenden vergletche:

čupave su 1 sorave babe kao kuke

l jeskove

Cub.Nr.20,S. 135

zdrava kao kremen

Čajk.Ant.Nr. $93,5.252$

on mu$X_{1}$ kao kamen

Vuk Nr.31,S.127

Auch für ausfihrlichere Vergleiche lassen sich Belspiele

\section{Finden:}

- glas mu meden, da bl se i ćela zasla-

dila; al se ispod brka smijutka ko pra-

vi smutipluk (=svadlj1vac) Cub.Nr.35,5.135

- . bter blago kao andio, dobru kao

kruh, a pri tom biją̧ 1 lijepa kao

vila od gore, visoka kao jela a tanka

kao sibika, a rumena kao jabuka 1 u

licu bijela kao gorski snijeg... Vuk Nr.33,5.134

..1 tamo t'mo ukrast kraljevu terku.

I to mora bit sigurno - pa uvati jrian

clavni lopov na viljusku meso - "ko

ovo meso צto držim na viljußkit, tako

sleurno mora ona danas b1t' naša." Daruvar Nr.1, 5.56

Der Vergleich kann auch in der Volkserzahlung - wie in der

Heldenepik - bis zur Hyperbolik gestelgert werden, z.H.:

- srete na putu nekakva čoeka toliko

velika koliko danałnja tetirt, sijede

brade do nite pasa, a brkove prebacio

pro ramena te mu vise niz leda.

Vrčevit 1868,

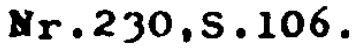

..dohvati nekakvu sviralju dugu

prevjenu i Sarenu kao najveta zmija..

Vuk Nr.40,S.1.57 
Die Metapher, der unschreibende, "uneigentliche" Ausdruck fur Personen und Dinge ohne den Hinwels "s...wie", entstanden als tabuisierende Redeweise fur Heiliges, Furchterregendes, die in der poesie oft fü das verwendet wird, was man besonders liebt, lst elne Welterentwlcklung des Vergleichs, die in der serbokroatischen Volkserzthlung in unterschiedlicher Haufung aufritt. Verblaßte Metaphern der Umgangssprache stehen hier neben den elgentlichen poetischen Metaphern, deren Erscheinen in den verschiedenen Sammlungen ganz besonders von den Fähigkelten des Erzbihlers, aber auch von der Auffassung des Aufzelchnenden abhaingt. Es ist denkbar, daß auch die Herkunftsregion einer Erzählung eine linnliche Rolle spielt wie z.B. hinsichtilch des Stils der serbischen Heldenlieder.

In Karadzits Texten gibt es schöne Belspiele von Metaphern, z.B. das folgende, das unmittelbar aus der Bibelsprache ubernommen ist:

...evo se priblizila posijednja ura moje case, 1 ja tu umrijeti pride no tret 1 kokoti zapoju.

Vuk Nr.28, S.117

Eng verwand mit der Metapher lst die Periphrase, fur die der zweite Tell des vorstehenden Satzes ein Belspiel gibt. Im gleichen Mirchen folgt eine weitere Periphrase:

-..samo ne prestupl kletve da te

ljuta zmija ne uvjede... S. 118

In einer Erzählung der von CUBELIĆ zusammengestellten Auswahl (24, S.190-197: "Momak, gajde 1 popon, Nr.35; aus elner handschriftlichen Sammlung von Balint Vujkov, Hrvatske narodne pripovijetke (bunjevacke), Subotica 1950), die sich durch einen besonders lebhaften Erzbhlotil auszeichnet, sind ebenfalls einige Metaphern und Periphrasen enthalten, $z . B$. ...vidio je, da je momak trrdi oran neg on...

... I bome je za kratko vrime salah pozlat1o

(d.h.,der vom Popen neu elngestellte Junge Knecht war so tuchtig, dab Haus und Hof des Popen binnen kurzer"in neuem Glanz erstrahlten") 
Im Märchen "Zlatumbeg"( 26,5.175-181) finden sich u.a. folgende metaphorischen Wendungen bzw. Pertphrasen:

-.a ja ne dam bez njezine volje.

jer nije krv pura.

S. 176

Zlatumbeg ret videdi b̌ to biva od njega, metne glavu u torbu, pa pode za tetom

S. $177 / 178$

- a Zlatumbegu se guje okn srce savijaju

sto te biti s njega.

S. 180

Vrévits Sammlungen enthalten sehr viele Beispiele fir

alle Arten rhetorischer Figuren; so auch der volkstiultchen Metaphorik:

Je li lstina da siti pod atarost

ubezobrazila 1 troga muža obraz hoteł

da pod noge bacts?

$(122,5.266)$

-.alt koja fajda kad mi je došlo vet

da se moja kuta 1 skopa?

$(122,5.265)$

- kuta obilata, posla dosta, a sin mu

prispio kao karamfil, a tvoja ruža

pocvala..

$(122,5 \cdot 150)$

Belspiele fiir Metonymie sind verhältnismälstg selten. So sapt der als Hirte verkleldete Königsoohn in elnem von Vuk bearbeiteten Märchen zum König:

Hotu, svet lo krunol

vuk, Nr.8,5.47

Weitere Stilverfahren, die dem mundlichen frzahler zur verrigung stehen, sind der sprachliche Parallelismus, die semantische Reduplikation und die Figura etyologica, d.h. die Kombination von wortern, die entweder formal, semantisch oder der fitymologie nach gleichartig sind - also spielarten der Wiederholung, die in ihrer einfachsten Form, der verdoppelung "Im Kontakt oder auf Abstand". wie priliok es formuliert ( 90 , 5.82 bzw.87), ebenfalls beliebt 1st. Unter dem Begriff des Parallelismus, d.h. der formalen Glelchartigkelt, wird hier sowohl die Parallelstellung einzelner worter in glelcher Flexionsform, insbes.Verben (nosila: prostla) wie die ganzer Satztelle (Isocola) zueamengerabt.

ŠkLovskIJ (115,S.55) stellt fest, dals eine solche Abfolge glelcher worter für die antike oratorische Prosa normal gewesen sei; in der Volksdichtung entspreche sie elner allgemeinen Regel. Er zitiert SPFRANSKIJ : 
Die russische vichtung liebt offenbar dieses Verfahren besonders und erreicht in dieser Hinsicht eine grobe vielfalt von Formen 1 .

Eine solche Vielfalt ist auch in der serbokroatischen Volksliteratur zu beobachten. SLAMNIG erwahnt Roman JAKOBSONB Idee elner möglichen ungeschriebenen volkstumlichen Poetik des Slavischen und sagt hierzu:

Diese seine (xJakobsons) Konzeption kann man sicher. zumindest in der Formulierung billigen, dab die sprachlichen Moglichkeiten bestimmte poetische Prinzipien hervorbringen. So zelchnen sich die flexionsrelchen slavischen Sprachen durch haufige gemeinsame etymologische Figuren aus...(104,S.20).

Das Grundprinzip dieser stilistischen Verfahren, die auch der Umgangssprache geluufig sind, ist bel vielen slavischen Schriftstellern produktiv wirksam. SkLOVSKIJ betont, daB die Verwendung von Synonymen ein bevorzugtes Stilmittel Gogol's sel (115,S.57). Flakfir hat im stil ante Kovactis nicht nur den Gorauch zahlrelcher volkstiulicher Redewendungen, Insbesondere semantischer Reduplikationen, sondern auch Neuschöptungen nach dem gletchen Prinzip nachgewiesen $(32.5 .306 / 307)$.

Fur die oben angefürten stilverfahren einige Beispiele aus serbokroatischen volkserzahlungen:

\section{Parallel1smus}

još ovake galije nije bilo nt ovake trge

Vuk Nr.12,S.71

kud te of 1 vode 1 noge nose

Vuk Nr.6,5.38

zašto sam postila, zašto sam $\operatorname{rad11a}$

$\operatorname{sinj} N r .11,5.344$

. ona te sve - kaže - potrt 1 bacit 1 odat 1 trazit te 1 vikat te

$\operatorname{sinj} N r \cdot 13,5 \cdot 347$

(zugleich polysyndeton)

meni nije terko populjat,

meni nije terko lłzerijat

morske dubine 1 nebeske visine

Sinj Nr.11, S. 344

..ele nemam očl, da vas gledam nitl

us ta, da vam zborim

Vuk Nr.43,s.164

1 M.N.Speranskij: "Rusekaja ustnaja slovesnost"n Moskau 1917, S.146. 
-. a ti, ako baš hotes da me

ubiješ, a $t 1$ me ubij 1 siject;

troj sam, pa mozes raditi sa mnome

rto god hotes 1 to ti je volja.

-.al1 nije kud kamo niti razmi-

canja...

Kad je dołao kutl, pitaju ga kon-

sije, pitaju ga sel jani:

..da 11 te to sve tako bitl kako

Uris urist 1 Sudentce dosudiše

(zugleich Fig.etymologica)

Zna da baba nije ovo iz prsta

1sisala 1 da nema dima bez vatre.

\section{Figura etymologica}

..1 nosu ta nosila. Najzad nanesu

da on ponese.

Tuguje tugu -

Car Stepan loveti lov..

\section{Paronomasie}

Joka pomaši (=rodi) ajeţita a ja djevojku, 1 što je narečeno, to biva obreceno...

Todor kad 1 kad pogleduje na Milutina krivim okom, a Stevan na $M_{i} 1$ icu krivim 1 krvavim.
Cajk.Ant.Nr.85,S.225

Vrčevit $1890, \mathrm{~S} .265$

Sinj Nr.59,S.383

Cajk.Ant.Nr.5n,S.136

Vreevit 1890 , S. 160

Sinj Nr.76, S.395

Daruvar Nr.21,5.63

Vrčevil 1868

Nr. on, S.27

Vrćevit 1890

$\mathrm{S} .266$

Vrčevit 1890

S. 163 
III.3.4.7.T.M $\mathrm{T}$.

Da die serbokroatische Volkserzahlung von der Handlung lebt, 1st im Rahmen ihres $S_{t 118}$ das Verbum von besonderer Bedeutung. Es gibt Erzahlungen, die im wesentilchen nur aus knappsten Aussagen und Dialogen bestehen und in denen von den im vorgehenden Abschnitt genannten Kunstgriffen fast nur die semantische Reduplikation und der Parallelismus aufteten jene stilverfahren also, die dem Verbur besonders gemab sind. Im Anhang der in der Reihe "Pet stoljeta hrvatske knj1zernosti" erschienenen "Narodne pripovijetke"( 16 ) Glbt B.KLAIĆ( 56A) elne ausfuhrliche Darstellung der dort auftretenden Tempora. (s.380-390, S.394-395). Die Erzahlungen sind Sammlungen aus allen Gebleten des cerbokroatischen Sprachraumes entnommen, wobel besonderer Wert auf eine unveranderte wiedergabe des miindlichen originaltextes gelegt wurde; deshalb sind auch viele dialektale Eigenhelten erhalten.

Die "normalen" Tempora der serbokroatischen volkserzahlung sind - wie in der Umgangssprache - das historische Prasens und das Perfekt, wobel bei letzterem das Hilfseitwort oft entfralt, $2 . B$.

A sestra njemu kazala... Kad došao kut1.. $\underset{n}{\operatorname{Nar}} \underset{n}{\operatorname{pr} 1 \mathrm{p} . \mathrm{PSHK}} \underset{\mathrm{Nr} \cdot 43}{\mathrm{~N} \cdot 14, \mathrm{~S} \cdot 58}$

I tak' uzeo onog konja 1 doðo na vrata..

Daruvar Nr.12,S.42

In manchen Erzahlungen wird das Zuruckliegen des Geschehens zu Beginn durch einen Satz im Perfekt signalisiert und die weltere Handlung im Prásens wiedergegeben; sehr haufig aber sind belde Tempora durch die ganze Erzahlung hin miteinander verflochten, wodurch der $T_{p} x t$ besonders lebendib wirkt. Ana$10 g$ zur Umgangssprache tritt das Prásens auch oft anstelle des Futur I:

-.ako ne pogodiš, ubijem te

Nar.prip.PSHK Nr.92,S.245

KLAIC weist auf die Seltenheit des Imperfekt in den Volkserzahlungen hin; der Aorist sel demgegenuber häufiger, doch zelge sich der allmähliche Verlust dieser Tempora u.a. In der Verwechslung der formen, wofúr er Belsplele anfuhrt: 
a 1 brkovi mu ne smetałe (statt: smetahu)

metoše statt metnuše

(Analogie zu z.B.rekore)

dodeb̆e statt dodołe

(Analogie zu z.B. pozezo)
Nar.prtp.PSHK

$N \mathbf{r} 03, \mathrm{~S} \cdot 196$

Nar.prip.PSHK

$\mathrm{Nr} .14$

Nar.prip.PSHK

Nr. 62

Dennoch stellt man belm aufmerksamen Lesen der Anthologie und anderer Sammlungen rest, dals sich der mündlche Erzahler manchmal recht souverin dieser Tempora bedient, die oft im Fluß der Erzahlung mit Perfekt und Prajsens historicum abwechseln, z.H.

Nar.prip.PSHK Nr.14,S.59:

-.To se Cudo daleko ¿ulo...Neko vjeruje, a neko ne vjesuje... Kad dodose na jedno polje, nadose jednoga čoeka de uzeo tuskiju u ruku pa je baca nebu pod oblake, a dotekuje sam seb' u leda. A oni su stall pa gledali pa su mu govorili:...

Cub. Nr.61, S.245:

A ont joj odgovore: Kad se lzvrnu čun, 1 mi svi panusmo svi jednogrlice zavikasmo:...

$I$ on mogase jasno dati, tek da hotałe, ma ne dade

1 utoliko se utopi.

Wie wirkungsvoll der Erzahler die wechselnden Tempora einsetzen kann, zelgt ein belspiel aus der Sammlung aus dem Gebiet von Sinj (Nr.89.5.405/406):

Sutıa dovecer on stâ vrebat, šta te onl radit. Kad on nije otisao u selo tamo na sijelo, on ti, moj brate, fleda fta te radit. Dode ti zena 1 mater njegova pa uzeşe niku ślpku, udariše ont starinski priklad, rastrori se priklad, lzvadiłe niki lonac masti neke, namazabe se, bogami ona skoti na stolac, ona skoti nr. neku drugu stvar, 1 s vragon, zमjašlle na panje...

In dieser Episode geht der frzähler nach einer Einleitung in ruhigem Perrekt (stâs=sao, nije otisao) zum Präsens historicum iber (gleda, dode), um dann das zentrale Geschehen, eine Reihe schneller und unerwarteter, teuflischer Handlungen zweler Hexen, in kurzen, beschleunigten Aorist-Formen aufzuzählen

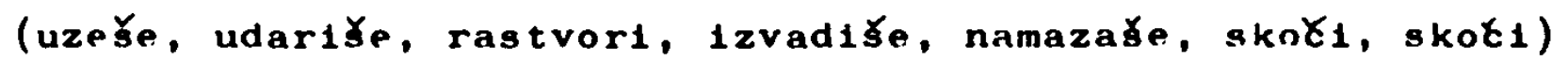
und zum Schluß zum Perfekt zuriuczukehren (zajăsıle), wodurch die Frzahlung abgerundet wird (vgl.18,5.260).

Auch bel KARADŽrć traget der Hechsel der Tempora oft zur lebendigkeit und Unmittelbarkeit seines St11s bei. Inwieweit dieser wechsel bereits in den ihm vorliegenden Handschriften bestand, ließe sich nur durch finzelanalysen feststellen, doch 
durfte dies oft der Fall gewesen sein. So welst z.B. M.BoKKoVIĆ-.STULLI in einem Aufsatz uber die von Maksim Škrlit stammende Aufzeichnung des Mărchens "Drvo nasred svijeta" aus dem Nachlaß Karadzits (die in dieser formerst 1964 veröfentlicht wurde) auf den lberaus elndrucksvolien Gebrauch der unterschiedlichen Tempora hin $(14,5.676)$.

Eine besonders expressive Wirkung entsteht in vielen serbokroatischen Volkserzahlungen durch den Gebrauch des Imperativs anstelle des Indikativs, z.B.:

- ali ne može nigdje da nade: pitaj ovoga, pitaj onoga za zlatni

Ćajk.Ant.

Rasudenac, all ne zna gdje je.

$\mathrm{Nr} \cdot 45, \mathrm{~S} \cdot 121$

Lodoše dva prasca, dohvatłłe se onoga groba, otkopaj, otkopaj, otkopaše.

sinj Nr.12, E, mater tragaj, gledaj, nikako nema 1 gotovo. S.345

Sinj Nr.11, $\mathrm{S} .343$

Kad ujutru baka ustala, ona daj Kupaj $s$ lame da lozi pet.

Nar.prip.PSHK

Nr.Y,S.47

- nade rijeku, on pokraj nje hajde,

Vuk Nr.31, hajde, dok dode na 1 zvor.

S. 127

Durch diese Verwendung des Imperativs anstelle elnes erzahlenden Tempus wird die Handlung noch stärker als durch das Präsens historicum in die unmittelbare Nahe des Zuhörers geruckt. Elne ähnlich intensivierende Funktion hat auch der Gebrauch des Futurs I als Präteritum, z.B.

Ovaj te skotit sa kreveta, gleda..

Nat.prip.PSHK $\mathrm{Nr} \cdot 42,5 \cdot 144$

Ja Imam sedamieset 1 sedam vjě̌tina, reti te $1181 \mathrm{ca}$. Cajk.Ant.Nr.6, S. 6

Der Gebrauch wechselnder Tempora ist mithin ein Stilmittel, das nicht nur in uberarbelteten Texten aufritt, sondern auch dem mündlichen Erzăler als Möglichkelt der Ausdruckssteigerung zur verfigung steht. 
In ihrem Aufsatz "o rečenicl usmenog pripovijedač" stellt M. Bošković-stulli fest:

Der Satz des mündlchen Erzahlers - wle uberhaupt der gesprochene Satz - unterscheldet $81 \mathrm{ch}$ vom geschriebenen Satz u.a. durch weltgehende Abwelchungen von der normativen Grammatik, den freten Gebrauch dialektaler Formen, einfache Satzkonstruktionen, ellipitische formulierungen und durch die Art und Weise, Affekte zum Ausdruck zu bringen (118, S.257).

Damit sind die wichtigsten Merkmale zusammengerabt.

Der miindliche Erzähler bevorzugt die Parataxe gefenüber der Hypotaxe; wo diese auftritt, handelt es sich meist um einfache Perioden. Dies ist vor allem aus den Tonbandaufzeichnungen zu ersehen, wăhrend gerade hinsichtlich des Satzbaus der Stil der einzelnen Sammler in der schriftilchen Fixierung spirbar wird. Karadit verwendet gelegentlich kompliziertere Satzkonstruktionen, die jedoch in threm streng logischen Aufbau tmmer übersichtilch bletben:

Vuk Nr.5, S. 32

Stojba se onde napije pa legne u hlad da se malo odmori pokriv̧̇ se po licu jednom od one tri marame da ga muhe ne bi klale.

...kako ugleda stojšu 1 maramu, a ona uzdahne, po tom tocetl vodu jednako je unj gledala, 1 porto natolt vodu, nikako nife mogla da se otkine odande nego je sve unj gledala.

vuk Nr.47,s.177

Kad Žna otide 1 to popu kaze, pop sa nekolika Coveka dode, te onoga nazovi-mrca metnu na nos1la, 1 odnesavł 1 fa u crkvu onako na nosilama ostave ga nasred crkve, da onde po obłčajı prenoti, pak te ga sutradan opojati i sahraniti.

Vuk Nr.12,S.66

Lovac padne na mesto mrtav, 1 drustro njegovo kad ga posle nade, ne znajuti ko ga je ubio, odnese ga kuti 1 ukopa.

Vuk Nr.22, S.103

Onako trudan sjedne ispod jednoga visokoga drveta, da takoga u svijetu nije, 1 začuje navrh njega de se drojlca u velike degaju, pa pogleda, kad 11 doleteo vilenik 1 vila, 1 vilenik hotałe da mu vila nerto sllom kaze, a vila bojeti se zakle mu se govoreti:...

Doch auch in diesen Beisplelen ist jenes einfachste Erzahlprinzip wirksam, demzufolge eine Handlung an die andere 
angereiht wird: "Es war... und dann...und dann", welches in allen münlichen Erzahlungen vorherrscht und in reinster Form in Tonbandaurzeichnungen zu finden ist:

Sint Nr.8,S.341

Ifa sveti Petar 1 Gospodín po svitu. Dorll u jednoga Covika, al1 ta čovik bija zloban, znar. Doł̆l su na konak, pusta jl na konak, al1 je bija zloban. Bome lezu, da in krevete 1 sve, ležu lipo da te notit, a ta covik lipo u jedno doba notl lati prutinu pa po sveton Petru udri...

Mit Ausnahme des kurzen Finalsatzes "da te notit" folgt in diesem Text ein Hauptsatz auf den anderen, tellweise ohne jede Konjunktion. Sind die Hauptsatze durch gleichlautende Konjunktionen wie "pa...pa...pa" oder "1...1...1" verbunden, entsteht manchmal ein feierlicher, fast blblisch anmutender "Märchenton":

Sinj $\mathrm{Nr} \cdot 11,5.343$

Inala mater jednu terku, 1 nije tila dobro slubat I mater je prida vragu. I male nestane. E, mater tragaj, gledaj, nikako nema 1 gotovo. Ona otifia u pakâ. I kad su je odnili vragovi u pakâ, tamo su je onl doveli luciperu 1 ona je kod lucipera stala. I onda hl ona njega čę̌́jala, puljala 1 rrugo niłta nije radila. I onda zaspe luciper jedanput...

Aus dem glelchmäisen Ablauf der Erzählung ist der satz "E, inater tragaj.." durch den affektiven Ausruf zu Beginn, durch die Imperative und den lapidaren Schlul geschickt hervorgehoben, so dals er elne emotionelle Farbung erhält, ohne dals es eines weiteren Hinwelses auf die Emprindungen der Mutter bedarf.

Durch kurze, parallele Hauptsätze kann der Erzähler Spannung und Erregung ausdricken, wie in der Erzahlung Nr.12,S.345, aus dem Sinjer Gebiet:

(Der Diener des Popen beobachtet nachts seltsame Vorgänge auf dem Friedhor):

.. Odołe dva prasca, evo t1 dva vola vel1ka vilaša, ont rogovi od metra 1 po, dodośe ont, udoše u groblje, nakriviše rogove, lzbacił̌ mrtvoga vani, pa ga metnif̧e kraj groba.

Ebenso können mehrere solcher sätze zu elner Art Pointe hinrühreß:

Cub.Nr.60,5.144 "Kako je na drugom sv1 jetu"

(Jemand hat Gelegenhelt, sich nach dem Wohlergehen verstorbener Verwandter im Jenseits zu erkundigen): 
- A kako kum Radovan?

- A ki ode: napravilo mu guvno, nabacalo mu trnje, uhvatilo dva vranca, $k 1$ dvi vile, pa vranci nam lete oko trnja, a on bos po onomu trnju - a dobro mu je.

Besonders interessant ist eine Erzahlwe1se, die KLAIĆ(56A,S,395) als elne Art Konjunktiv bezelchnet und mit der eine Reihe von Erzahlungen beginnt: ein Satz, der eigentlich ein normaler Hauptsatz im Indikativ sein miste, beginnt mit der Konjunktion "da", manchmal auch mit "kako...". Damit kann sich der Erzahler elnerselts vom Inhalt der folgenden Geschichte distanzieren, andererselts verstarkt er den Eindruck des Märchenhaften, lange Zurückliegenden:

Nar.prip.PSHK Nr.1139,S.285

Da je neka stara sjedala tu blizu mora ujutro rano.. Sinj Nr.59,S.383

(Es geht darum, daB man die Grabstatte des "kralj Deciklijan" nicht kennt, da die Männer, die thn begraben haben, danach sofort getötet wurden)

Stalno je tako bilo 1 zato da se ne zna, svi su izeinili na takav vinet, 1 sad da se nikako ne zna di je ukopan. Da zna se di je, ali da ne mogu se namiriti na njegov Grob.:

Sinf $\mathrm{Nr} \cdot 13, \mathrm{~S} .346$

Da je ima svoju vojsku, I da ima ter, da mu je umrla 1 da je se učinilia u vukozlaka...

Sint Nr. $5,5.338$

Kako je blo jedan momak 1 cura, pa su ašikoval1.. Diese Satzkonstruktionen weisen gewissermaben auf die tiberlieferung des Frzahlten hin, da sie durch Wendungen wie "priCa se". "kazu" oder "Zuo sam" ergänzt werden könnten. Sie stehen damit den elliptischen satzen des müdlichen Erzahlers nahe, in denen nicht nur das verbum dicendi, sondern auch andere verben entfallen können, $z$. B.

Daruvar Nr.12,5.41, (direkte Rede)

Joj moj muz sad, ajte brzo...

. oni ugriju koto vode 1 preko tih popova.

Wie in diesem Beisplel (joj!)sind die elliptischen satze oft mit cusrufen verbunden, die nicht selten lautmalerisch die Funktion des Verbs ubernehmen, $z$. B. 


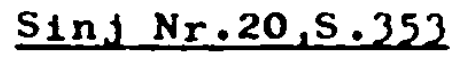

A ona huh na kaput, pa u Jamul Al Covjek, neka je nema, vratijase kut1 radostan..

Daruvar Nr.10,5.37

Kad je došla blizu rijeke, on se lzmake, a ona bup u vodu.

Durch derartige Ausrufe und durch elliptische Satze bringt der Erzähler die besondere Schnelligkeit eines Vorgangs ebenso wie emotionelle Beteiligung zum Ausdruck, wie dies auch in der Umgangssprache geschieht. Auch Karadžıt hat solche typisch "miindl1che" Ausrufe in seinen Stil ubernommen; elliptische, prädikat lose satze verwendet er ebenfalls:

vuk Nr.1,S.5

Onda se Brko zaleti, pa hopl preko vode na drugu stranu... pa poteraj za Mefedovitem.

vuk Nr.27,S.115

Pa otolen svoj put, te doma.

Die Häufigkelt elliptischer satze in Verbindung mit sehr kurzen Repliken der direkten Rede, die oft unmittelbar an den Erzähltext anschlieien, gibt manchen Erzahlungen einen ausgesprochen lakonischen charakter. In diesen stil figt sich, wie im folgenden Beispiel, auch die erlebte Rede eln; alltägliche Wendungen können ihn noch unterstrelchen, wenn sie entsprechend knapp sind:

Daruvar Nr.19,5.6n

- kvo, majko, mene živa 1 zdrava.

- lobro, dijete, dobro.

Ide se on ženıt. Sta te sad? $E$, nete on seljanku, on ote kral jevu ter. Nema tuj šta.

- Nemoj, sine - kaže - uzmi si ti u selu našu curu, sirotu.

- A ne - kaže - Idem ja - kaže - po kral jevu kter.

On se lepo obuče, bogat čovjek, vilu sagradl ze tas.

To sve, kraljevsku zgradu, nema tuj yta. Dobro. Ide on, spremi se potpuno - kraljevit, nema tuj fta. On se spremi 1 Ide. Zaprosi, ozene se, svatovi veliki...

KLAIĆ fuhrt zahlrelche Belspiele elliptischer satze an,z.B.

Nar.prip.PSHK Nr.19

..uto 1 braka, pa stanu kazivat

Nar.prip.PSHK Nr.48,S.163

I on na sluge, zašto mu crijet sahne (=I on navali na sluge 1 pita, załto mu crijet sahne? 
Als weiteres Charakteristikum der mündilchen Rede finden sich in den Volkserzahiungen Alogismen und Anakoluthe, auf die KLAIĆ besonders hinweist (564s.398).

Zur Atmosphare der Volkserzahlung tragen ferner jene Hauptsatze be1, d1e mit "kad" beginnen, z.B.

Daruvar $\mathrm{Nr} \cdot 12, \mathrm{~S} .41$

Ide ona u dutan, nakupuje svega... Kad muz gleda jel' to ona 11 , nije.

..jednu veče on1 te dot... Kad jedan zakuca, a muž se sakrije.

. sakrite se tuj u tu kacu dok on ode. Kad on skoti na ona dva.

Das Wörtchen "kad" kann auch anstelle des vorbum dicendl stehen:

\section{Daruvar Nr.16,S.50}

Kad jel Ima ona roditelje?

(=pita lma 11 ona roditelje)

Der miindliche frzahler verwendet auch die rhetorische Frage, 2. B.

Sinj Nr.59/S.382

Kad bi dołao, on bl obrija ga - unda ga pogibi.

Zašto b1 ga pogilija? Zato da ne kaže kakav je u

oh111žju svome.

Auch in Karadžits Texten gibt es rhetorische Fragen, z.B.

Vuk Nr.23,S.104

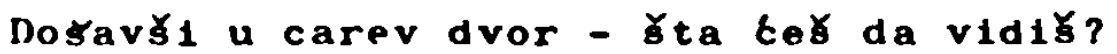

ČAJKANıVIĆ ( 22, S.VII) und MOJASEEVIĆ( $81,5.310)$ haben auf die Tendenz mancher Volkserzahlungen zum Deseterac hingewiesen (s.III.3.8). In neueren Aufzelchnungen 1 st manchmal eine expressive Rhythmisierung des Satzes zu beobachten, z.B.

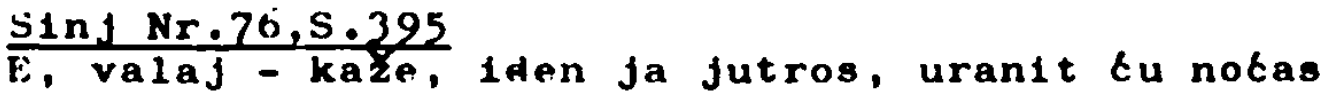

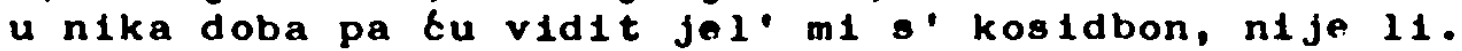

Die serbokroatischen Volkserzahlungen welchen nicht nur in Lexik und Morphologie von der normativen Grammat1k ab, sondern auch in der syntax. In den melsten Dialekten können die Enklitika auch an betonter stelle des satzes stehen, d.h. sie sind - wie KLAIĆ bemerkt - dort eben keine Fnklitika(56 A,s.398): 
Nar.prip.PSHK Nr.17,S.68

- pa tu ondar povest te kut 1

Nar.prip.PSHK Nr.43,S.145

-.1zbroji cekine nu te ode

DaB solche Abwelchungen von der literatursprachlichen Norm den Texten nicht nur den sproden Charme der Urspringlichke1t, sondern auch elne gröBere Ausdruckskraft verlethen können, hat M.BOŠKovIĆ-STULLI ausführlich in dem oben zit1erten Aufsatz dargelegt $(18,5.201)$.

\section{III.3.5. Der Erzahler}

Vergegenwartigt man sich, dals die Volkserzahlung das Produkt elner oft jahrhundertelangen Uberlieferung unter standiger Kontrolle elnes Kollektivs 1st, so wird klar, dals hier der Frzähler von vornherein in elner völlig anderen position $18 \mathrm{t}$ als in der individuell gestalteten Literatur. Die Frage nach elner Differenzierung zwischen dem fiktiven und dem tatsachlichen Erzahler entfillt, da der Volkserzahler nicht "Autor", sondern in erster Linie Vollzieher des durch die Konvention weitgehend festgelegten Erzahlaktes ist. Wer elne zeremonielle Handlung vornimmt, muls der Gemelnschaft angehören, in welcher diese Handlung eine bestimmte Bedeutung hat: der Erzahler ist kein aulsenstehender Betrachter, er gehört in das Milieu der Geschichte und nimmt Ante1l, und das umso mehr, je authent1scher der uns vorliegende Text $18 \mathrm{t}$. In alteren Aufzelchnungen sind im Bemuihen um literarische Qualitat oder um Objektivitat persönl 1che Bemerkungen auberhalb der direkten Rede weitgehend eliminiert worden; Inwlewelt sie in Karadzits Bearbeltungen aufgrund seiner streichungen oder der selner Mitarbelter fehlen, lieBe sich nur durch den Vergleich mit den - nicht veröffentlichten - Handschriften feststellen. MoJAŠEvid( 81 ) 1st auf diese Frage nicht eingegangen. Die Intensitut der persönlichen Antellnahme des windlichen Erzahlers goht jedoch in modernen Sammiungen elnwandfrel aus den vielen expressiven Ausrufen 1m Erzahltext ( 1 s vragon, zajas̆11e ou na panje Sinj Nr.89,5.406), den in Ichform gehaltenen Hinweisen auf die Quelle der Erathlung, den persónlichen Kommentaren hervor. 
Auf den Gesprächscharakter der Erzahlung deuten die vielen Hinwendungen zum Zuhörer wle "moj brate", "znašn hín, die,oft aus tatsächlichen Gegebenheiten entstanden, elne reizvolle stilistische Elpenhelt darstellen.

Daß3 die persönliche Antellnahme bls zur volikommenen selbstldentifizlerung mit elner der handelnden personen gehen kann, zeigen Belspiele der Sammlung aus dem Sinjer Geblet. Der Erzähler, hier Ante Rantit aus Brnaze, wechselt bel besonders aufregenden Geschehntssen von der 3.Person zur 1.Person uber: Sinj Nr.89,5.405/406

Sutra dovečer on 8 tâ vrebat $Y_{t a}$ te one radit... (es folgt die Szene, in der er beobachtet, wie zwel Hexen, seine Frau und seine Mutter, auf stobken davonreiten)

- Nu t1 boga, yta tu ja, e ja t1 kažen, 1den 1 ja!

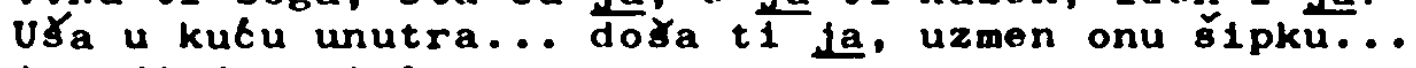
izvadi ja oni lonac....

Dese Intensität der Antellnahme am Geschehen spürt man auch in jenen krzăhluneen, in denen persónliche Bemerkungen nur sparsam oder farnicht vorkommen, einestells aus der Diktion, von der unter III 3.4. ausfihrlich die Rede war, andernteils aus der oflensichtlichen Zustimmung des frzählers zu der enthaltenen lehre, die gelegentlich durch Sprichwörter bekrätigt wird.

In Uhereinstimmung mit dieser Nahe zum Geschehen ermöglicht die Perspektive des miindlichen Erzahlers keinen Uberblick auf ein umfassendes Panorama, sondern den Finblick in bestimmte Situationen. IÄMMEKT (59,S.87) schreibt:

Szenische larstellune von Vorgängen erfordert notwendif kleinen Zeitausschnitt und nahe Erzahlperspekt1ve... so strebt sie idealiter nach Zeltcieckung, und deshalb hat auch die direkte fede an ihr allgemein grolsen Anteil.

Die serbokroatische Volkserzahlung ist relch an direkter Rede, thr Handlunesablauf ist an elnen bestimmten Zeitraum gebunden; sie lst oft typische szenische Erzählung, aber da ja eine zeitdeckung praktisch nur im Drama möglich 1st, 1st der Erzahler bel der wiedergabe der Exelonisse zwischen den szenen zur Zeitraffung gezwungen und spart bestimmte zeitriume volikommen aus. 
Seine Abhängigkeit von der Gemeinschaft zwingt den Erzähler ferner dazu, eine einheitliche Perspektive beizubehalten, und zwar eine gewissermalen "naturalistische", die thm und den Zuhörern entspricht. Die äsopische Redeweise der Fabel, in der der frzäler scheinbar hinter Tierfiguren zurucktritt, beinhaltet sinngemäb die gleiche Perspektive, da der Erzähler sich mit demjenigen Tier identifiziert, das eine bestimmte. vom Publikum und vom Erzăhlenden selbst geschätzte Filgenschaft repräsentiert, z.B. Schlauheit oder Mut. Äußerlich betrachtet, liegt hier allerdings eline verfremdung vor.

Die Erzählhaltung varifert je nach Art der Volkserzählung. Den: Inhalt des Märchens mit seinem Absolutheitsanspruch, der Sage mit ihrer Tendenz zum Tragischen, der mythologischen Erzählung und der legende, die "glitige" Erklärungen zu geben versuchen, steht der Erzahler ernsthaft gegenuber. In der scherzhaften Kurzgeschichte (Yaljiva priča) iberwiegt naturlemáb die humoristische sinstellung, die vom gutmitigen spott bis zur Ironie, sogar zum Sarkasmus und vom Malsvolien bis zur vulgären Uhertreibung der "nicht druckfähigen" Geschichten reichen kann. In den aus real möglichen situationen entwickelten kiirzeren oder lägeren Erzahlungen (letztere als narodna novela bezelchnet) varilert die Erzählhaltung je nach sujet.

III.3.6. Typisterung oder Charakterisierung?

LUTHI sagt im Kapitel "Das Hild des Menschen in der Volksliteratur:

Da das Märchen seine Gestalten nicht als Individualitäten, sondern als Figuren zeichnet, diirfen wir ohne weiteres so weit gehen, in ihnen zusammengefabt das Bild des Merschen zu sehen ( 71, s.16).

In seinen weiteren Ausfihrungen stellt er die Geborgenheit des Menschen im Weltganzen, wie sie das Märchen zum Ausdruck bringt, seiner verlorenheit angesichts der Ratselhaftigkelt des Daseins in der sage gegenuber, sieht aber hierin keinen echten Widerspruch: 
Beide Menschenbilder haben Wahrhe1t. Das Marchen visiert mehr die Gattung Mensch, die Sage mehr das Individuum. Den Kinde gibt sie, auf dem sichernden Grunde des Marchens, eine neue Perspektive.

$(71,5.19)$

Wenn LiTHI schon der Sagengestalt eine ausgepragtere Individualitat zuspricht, könnte man etwas innliches hinsichtlich jener aus dem Alltag gegriffenen Gestalten erwarten, wie sie in vielen serbokroatischen Volkserzăhlungen auftreten. Dies ist fedoch nicht der Fall; sie sind vielmehr ebenfalls typische riguren wie die des Marchens, nur in zunehmendem Mals in eine andere Umpebung transponiert - der König ist hier gegebenenfalls einfach der Relche - oder es sind aus den besonderen Verhältnissen des Landstriches hervorgegangene bzw. aus fremden Uberlieferungen ibernommene, zum Lokalkolorit Rehörende Gestalten, die etwa nach Art der commedia dell'arte Typen repräsentieren. Ebenso, wie in der Volkserzahlung nur jene Hinwelse auf die Landschaft gegeben werden, die fur die Handlung wichtig sind - eine weite Ebene, ein grober wald deuten die länge des weges an, eln hoher berg die Schwierigkeit des Aufstiegs - glbt es auch kelne schilderung des Äulseren elner Person und kelne ins Detall gehende Charakterisierung.

Der Held ist Jung, arm und mutig, aber selbst das muis nicht ausdricklich gesagt werden; Abenteuerlust ist die Motivation seines Handelns; manchmal ist er dazu noch schlau und überlistet Kinige, Wrachen oder Riesen, die Immer diimer sind als er. Bel der prinzessin entfält meist sogar das konventionelle Attribut der Schönhelt; man welis von thr nur, dals sie der Preis der Anstrengungen des Helden ist, nur manchmal gehört sie zum Typ des "klugen Mădchens", das aber hăufiger aus dem Volke stamm. In seltenen Fallen tritt die Prinzessin ein wenig aus ihrer Anonymitat heraus, z.B. Im Mărchen von "BašČelik" (Vuk Nr.51), wo sle den Helden zum Aufgeben uberreden will - aber auch das ist eine "typische" Verhaltensweise.

Auch die ibrigen weiblichen Plguren sind vom Moment ihres Auftretens an als Typen festgelegt: die böse stiefmutter mit der halilichen Tochter, die böse Ehefrau, die widerspricht oder den Mann betrugt, die dumme, die neugierige Frau, die 
Hexe, die ratselhafte Alte, die arme witwe und - als reizvollste Erscheinung - die zauberhaften vilen, die Glick oder verderben bringen können und unbezahmbar sind wie die Natur selbst.

Vielfaltiger ist die Skala der männlichen Fifuren: neben dem zentralen Helden, der lmmer der Jungste, Ärmste orer der In eine habliche Gestalt Verwandelte ist, stehen die. ălteren Bruder als die Zwelfelnden, Zögernden oder Bösen, neben dem Frommen und dem Helligen der Gottlose und der Teufel, neben dem Faulen der fleibige. Die personifizierten Naturkrafte sind hilfreich, solange ihr Gesetz nicht verletzt wird. Der Pope ist schlau, solange der Hodža sein Gegenspieler ist, dumm gegeniber dem zigeuner, habgierig und hochmiitig gegeniber dem Armen. Die Typen des Schlauen und des Dummachlauen, die in der welt der serbokroatischen volkserzählung so zahlreich sind, wurden schon im Abschnitt "Lokalkolorit" auigezahlt. Obwohl aber insgesamt - wie bel den Motiven - durch die vielfache Uberlagerung von Kulturkreisen und -schichten ein sehr abwechslungsreiches Bild entsteht, lassen sich all diese Gestalten auf einfache crundtypen mit bekanntem Verhaltensschema zurückfüren.

Auch durch die direkte Rede ist nie elne Charakterisierung des Sprechenden, sondern allenfalls die Unterstrelchung selnes "Typs" beabsichtigt. Der Held entschlielt sich zum Abenteuer "govoreti makar šta bilo od mene"1, oder die vom starken, aber dummen wolf bedrohten Tiere retten thr Leben. inciem sie dem Vorschlag, gefressen zu werden, scheinbar zustimmen, aber eline Abmachung treffen, deren"Trick" der Bösewicht nicht durchschaut - also durch die typische Redeweise des Machtlosen, aber Klueen mit dem vertreter der brutalen Gewalt (Čub.Nr.75,S.267-269:"Lakomi 1 lakomisleni vuk").

Diesen Zug, Typen und nicht Individuen darzustellen, hat die serbokroatische Volkserzählung auch dort belbehalten, wo es nicht mehr um ferne, märchenhafte Erelgnisse, sondern um real mögliche Dinge geht, und das selbst dann, wenn ausnahmswelse

1 Drro nagred soljeta, handschriftl.Aufzelchnung von Maksim Skrlit aus dem Nachlaß KarudZ1ts. $14,5.676$. 
die Personen namentlich genannt werden (z.B.Sinj Nr.62, 5.384 , Nr.82,s.399). Ganz allgemein betrachtet, hat zwar der Anteil des Wunderbaren in den Erzahlungen zugunsten des Realen abgenommen, aber diese Erscheinung betrifft nur Detalls oder den auberen Rahmen. So 1st z.B. aus der "hintska (zindijska) sultanija" alterer Fassungen die "ingleska kraljica" in der 1888 in der "BosANSKa VILA" abgedruckten Version des Märchens "Oklen ingleskoj kraljici tolike pare" geworden (vgl.Čajk.Ant.Nr.78, Anmerkung S.398; Queen Victoria!). oder, viel krasser noch, es erscheint in einer $E r-$ zahlung aus Daruvar (Nr.19,S.60) anstelle elnes rliegenden Teppichs oder dergl. ein Auto, das durch die luft fährt. In manchen Bemerkungen äubert sich lediglich die sehr konkrete Vorstellung des Erzählers von der geschilderten Situation, die dem Zuhörer dadurch besonders nahegebracht wird: cajk.Ant.Nr.82,S.220

(Der tote Geliebte holt sein Mardchen) ..on joj kaže da se odmah spremi, pa da ide s njim. (hia pokupi platno 1 svoje haljine...

Ileser llinwels aut das verhalten des Mächens, das dem Brăutifam folet und seine Aussteuer mitnimmt, gibt dem gespenstischen (isschehen etwas Alltagliches, sogar Humoristisches, da der Zuhiser ja weils, dals der Briutigam ein Toter lat; das realistische Detill dient hier also der stimmung und auch der Spamilug der lirzahlung, nicht aber einer charakteristerung der person.

Dem Fehlen individueller Charakterisierung entspricht - wie erwänt - das Fehlen von Landschaftsschilderungen. Wenn in manchen Siunmlungen ausfürlichere Beschreibungen dieser Art zu finden sind, liegt das sicher an der stilisierung durch den Sammler oder an elner Beeinflussung schon des münlichen Erzahlers von der Hoch-bzw. der Trivialliteratur her, so z.H. il der aus der Sammlung von D. Bogdanovit, Zagreb 1914 , überuommenen Erzählung "Mala vila" (Čub. Nr.9,5.91):

$U$ ponot se razidoše gosti, a kraljevit ode u gaj od starih lipa, jer je bila mjesečina ko dan, a njemu se ne spavalo. Carobno bješe pogledatl na tamne sjenke debe lofa crveta. Kroz eranje se uvlacila injesečina 1 padala po zeml 1 u cunnim sarama. Lipe su mirisale kao tamjan iz crkve. Kraljevit je polagano setao zamikljen po mekanoj tyinici.. 
In diesen, ausgesprochen schriftsprachlichen Sitzen ist nichts mehr von der Spontaneitat müdlichen Erauhlens zu spuren; sle können nicht als Beispiel für den volkstualichen Erabistil gelten.

Die typisierende Darstellungsweise ist bekanntilch nicht auf die volkserzahlung beschránkt; in der Kombdie z.B. exmöglicht sie es, bestimmte menschliche schwichen zu verdeutlichen und unso sicherer der Lächerlichkeit anheimzugeben, in ernsten Drama dagegen trägt sie dazu bel, das Geschehen aus der Einmaligkeit, Zufálligkeit und Anonymitat auf die Ebene des Allgemeingilitigen emporzuheben. Beides strebt auch die Volkserzbilung an und whilt mithin eine adäquate Daretellungsweise, die freilich mit der Schwarz-Weib-Maleret des bilteren Romans (bis weit ins 19.Jahrhundert hinein) und der Trivialiteratur viele Gemeinsamkiten hat. Fur elne charakterisierende Darstellung fehlen in Milieu der volkserzáhlung die psychologischen Voraussetzungen und die individuelien Entraltungsmöglichkeiten des Erzahlers, dem die Tradition Grenzen setzt, und die Typisierung komt den didaktischen Absichten der volkserzkhlung entgegen.

III.3.7. Weltbild und Ethik

\section{III.3.7.1. Allgemeines}

In den Erzahlungen der Völker spiegeln sich die geistigen Entwicklungsstufen, die die Menschheit durchlaufen hat. Alle Vorstellungen und Auffassungen, die elnmal gultig waren oder die es im Augenblick des Erzählens noch sind, können unmittelbar oder verschlusselt in die Uberlieferung eingehen. Hieraus ergibt sich die vielschichtigkeit, die vielfiltigkeit der Ideenwelt der Volkserzahlung, die umso ausgeprigter ist, je mehr Kulturkreise sich in einem Gebiet uberschneiden und beruhren, wie dies auf der Balkanhalbinsel seit Jahrtausenden der Fall war.

Ebenso, wie uns in den serbokroatischen Volkserzihlungen typische Gestalten verschiedensten Ursprungs begegnen, ist auch die Elnstellung zu den Grundtatsachen des Lebens unterschied1ich. Dennoch kann man sagen, dab sich all diese, einander gelegentlich widersprechenden Uberzeugungen vor dem einheitlichen Hintergrund patriarchalischer Lebenshaltung darstellen, die dem Herkunftsmilieu der Erzbilungen entspricht. 
ㅍ. 3. $7 \cdot 2$ Der He 1d

Der Verwirklichung des patriarchalischen Lebensideals, das nicht nur durch die firtschaftsform, sondern auch durch die damit verbundene grobe Bedeutung der Familien- und sippenbande bedingt war, stellten sich lmmer Hindernisse entgegen die erst Schritt um schritt begreiflich werdenden Krafte der Natur einerselts und die politische Macht in all ihren Verkörperungen andererse1ts. Deshalb 1st das Grundthema vieler Marchen die Bewaltigung der scheinbar unuberwindlichen Schwierigkeiten des Daselns, und deshalb ist unerschutterlicher Wagemut die erste ethische Forderung. Das deutsche Sprichwort "Frisch gewagt ist halb gewonnen" druckt bereits eine abgeschwachte Version dieser Lebenshaltung aus; denn der Márchenheld hat nicht halb, sondern hundertprozentig gewonnen, wenn er sich nur ohne Zögern ins Abenteuer stiuzt und - das ist die zweite Forderung - nie vom elnmal eingeschlapenen Weg abwelcht.

Damit, dals der gerechte und anstandige Mensch $1 \mathrm{~m}$ Kampf um ein besseres leben zum Schlulis siegt, kommen in der Volkserzahlung Optimismus und ein humanist 1scher Heroismus zum Ausdruck, die zugletch das Grundelement und den größten wert der volkserzáhlung darstellen -

schreibt Euhfilic (24,5.10). Indem ste die Hoffnunp auf eine bessere Zukunft nahrten, selen die Volkserzahlunpen in den verganfenen Jahrhunderten ein wesentlicher raktor im Kamif uils lasein gewesen.

In den ditesten Uberlieferungen aller Volker wird vom Helden in erster linie Mut verlangt; seine oft gerunmte Kraft ist eine Gabe, für die er nichts kann, erst der Mut ist seine persönliche leistune, ist also ein ethischer Wert. Außer seiner auberordentlichen Kraft kennzelchnen diesen Typ des Helden nicht selten Eigenschaften, die auch dem Riesen zugeschrieben werden - Gefrabigkeit, Begehrlichkeit, ein jahes, unberechenbares Temperament und eine relativ geringe Intelligenz, wie CaJkanović unter Hinweis auf den griechischen Helden Ach111 ausfuhrt (22,S.381). Neben dieses archalschste Heldenideal - dem z.ls. "Medvetovit" (Vuk Nr.1) entspricht tritt in der serbokroatischen lirzählung der kluge: auch fiir inn geht es ums Uberleben, er bedient sich aber "fortgeschrittener" Mittel, bzw. er hat keine andere wahl. Die

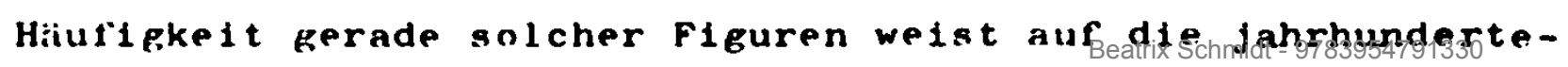

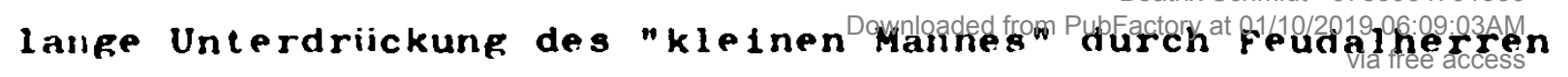


fremder oder elgener Nationalitat hin, viellelcht auch auf eine besondere Geschicklichke1t im Umgang mit den Măchtigen; der Beifall, den die zahlreichen Varianten des Uber118 tens eines starkeren offensichtlich gefunden haben, bewelst, wie hoch solche Fahigkelten olngeschäzt werden. Selbst in elner Erzuhlung, in welcher der kluge schlechter davonkommt als der starke, heibt es einschrankend:

-"Vidił ludovel da oka snage negde viłe valja nego stotina oka pametil" (Vrcevit $1868 \mathrm{Nr} .2, \mathrm{~S} .2$ ).

Auf der höchsten stufe vereint das Heldenideal nicht nur Kraft und Intelligenz, sondern daruber hinaus Opferbere1tschaft und Grolsherzigke1t, d.h. es geht um eln "zwar immer kampferisches, aber durch Christentum und Rittertum veredeltes Mannestum"( $41,5.1132)$. Aus der Ex1stenz e1nes solchen Ideals labt sich die enge geistige Verbindung des Nemanjidenrelches mit dem ubrigen Furopa ablesen. Selne reinste Verkörperung im epischen lied 1st nicht Marko Kraljevit, sondern Miloł nbilit, weshalb sich z.B. Batrit in N.jegošs "Bergkranz" auf den "Glauben Milošs"beruft (Gorsk1 vijenac V.1341). In der Prosauberlieferung tritt uns dieses Ideal am deutlichsten in den montenegrinischen Kurzeschichten bzw.kriegerischen Anekdoten entgegen, z.B. In der Sammlung des Marko Miljanov"l.

\section{3.2.3 Das mythische Weltbild in der serbokroatischen}

Volkserzăhlung

Bel der Darstellung der Naturkräte, mit denen es der Mensch aufnehmen muls, bedient sich die Volkserzählung alter mythischer Bilder, die nicht nur in den attologischen lependen und Sagen erscheinen, deren Thema sie sind, sondern ebenso in Märchen, Kurzgeschichten, Novellen und Fabeln. So treten z.B. In Vuks Märchen Nr.10 ("Opet zmija mladoßenja",s.56-61) Sonne, Mond und Wind personifiziert auf, doch fehlt ihnen die Magie des Göttlichen, die solchen Personifizierungen auf elner fruheren Bewulstseinsstufe eigen ist. In diesem Marchen haben sie selbstverständlich noch lubernaturliche Fahigkeiten, die uber das rational Erklärbare -"sie sehen alles" - hinausgehen, und

1 Marko M1ljanov: Primjerl Čojstva 1 Junaštva. Beograd 1901 (78) 
es lst, wie bel den Göttern der Vorzelt, nicht ratsam, sie herauszufordern; trotzdem ahneln sie viel eher jahzornigen, im Grunde aber gutmitigen Mánnern aus Fleisch und Blut, die nach der Arbelt des Tages heimkehren, als rátselhaften, ubernaturlichen Wesen: das alte Götterblid der personifizierten Naturkraft ist in Laufe der Uberlieferung vermenschlicht, entzaubert worden.

Als Belspiel unmitelbaren Bewahrens elnes alten mythischen Bildes sel hier die Erzăhlung "Noćna strašlla" (Sinj Nr.71, S.392) erwahnt: ein Wanderer beobachtet den nachtlichen Kampf"eines schwarzen und eines weilsen Menschen" am Himmel:

Kad gori viłe bome pojaca se crni 1 bill לovjek, te udri, te udri, te udri, mumljaj te udri, te drzi crni, drźl bili. Sad on tuda mora prot, mora. Al' to se uvik komiša, te držl jedan, držl drugl, tako se tukli jedno pola sata, a on sta ka drven, mora stat, samo mukonsali, muml jall.

Dem mafisch-mythischen Weltbild entstamen auch die Dämonen und Irachen, deren Erscheinen stets von gewaltigem Brausen und von feuer begleltet wird. ČaJkanovic weist auf die parallele zwischen den Auftritten der Könige der Drachen, der Adler und der Falken Im Märchen "Baš-Čel1k" (Vuk Nr.51) und den biblıschen Schllderungen vom "Hemiederfahren des Herrn"auf den Bere Sinat (2.Buch Mos.19,16-19) oder der AusgleBung des He1ligen Geistes (Apostelgesch.2,2-3) hin (22,S.381). Es Kann hier nicht darauf elngegangen werden, inwlewelt diese vorstellunfen lin elnzelnen urspringlich in der slavischen Mytholofie verwurzelt sind. Mit Sicherheit gilt dies jedenfalls fiur die Gestalten der Vilen, der kynokephalen Damonel (pasoplavci) und verwölfe (vukodlact) ${ }^{1}$. Die enge bezlehung zur Tierwelt sel es durch zeitwellige Verwandlung, durch Abstammung (Medvedovit ist von elnem Baren gezeugt; Miloś obilit wird von elner ctute geboren; das geflikgelte Pferd in Vuks Märchen Nr.40 ist der Sohn einer Frau, etc.), durch Freundschaft (Kraljerit Marko und sein pferd) - auch zur mythologischen Tierwelt der Drachen, das kingrelfen von Tieren als Helfer und Ratgeber

1 vel hierzu:

L.Kretzenbacher: Kynokephale Dämonen südosteuropäischer Volksdichtung, München 1968;

F. Schneewe 1s: Serbokroat1sche Volkskunde, Berlin 1961. Roman Jakobson: The cerblan Zmaj Oenjent Vuk and the Tussian Vseslav Fpos (with G.Kužltit) In: Selected Nritings IV, S.369-379. 
(Schlange, Puchs, Taube etc.) stellt lmer eln Relikt aus weit zuruckliegenden Epochen dar, in denen diese vorstellungen noch ein ganz anderes Gewicht hatten; die mundliche Uberlieferung bewahrt sie als Bllder, deren symbolgehalt kaum mehr empfunden wird.

\section{III.3.7.4. Rechtsdenken}

So wie die Uberlieferung Frafmente vergangener Weltbilder welterträgt, splegelt sie auch alte Auffassungen von Recht und Unrecht. Die Porderung nach "naturlicher" Strafe, d.h. der Vergeltung von Glelchem mit Glelchem gehört zum altorientalischen Rechtsdenken; so heilst es im 3.Huch Mos. 24, 19-20:

Und wer seinen Nächsten verletzt, dem soll man $t$ un, wie er getan hat. Schad um Schade, Auge um Auge, Zahn um Zahn; wie er hat elnen Menschen verletzt, so soll man thm wieder tun.

Dieser Forderung liegt, wie litill ausfihrt, eine im Bewulstsein des Menschen tief verwurzelte Uberzeugung zugrunde, dals der Mensch mit seinen eipenen Waffen gestraft werden misse $(71,5.105)$. Es ist daher oft nicht Grausamke1t um der Grausamkeit willen, wenn der Böse einer entsetzlichen strafe unterworfen wird, sondern Befriedigung alten Rechts-. empfindens: die Hexe verbrennt in ihrem eigenen ofen, nder der Schuldiee richtet sich sogar selbst; in Vuks Mirchen Nr.34 "Mačeha 1 pastorka" ertränkt sich die böse stiefmutter freiwillig im Brunnen. Zwar nicht mit den eigenen Waffen, doch nicht minder grausam erfolgt die Bestrafung in vielen anderen Erzahlungen, z.B. "Ovca trandafiljka" (Cajk.Ant.Nr.42, Nr.112): die zwel bösen velber des "schönen Jova", welche selne jungste, geliebte prau und deren Kinder durch Zauberel zu vernichten trachten, werden nach der Aufdeckung ihres Treibens, an Pferdeschweife gebunden, zu Tode geschleift was der Grausamkeit ihres eigenen Vorgehens entspricht. Wird die Strafe erlassen oder gemildert, so bubert sich hierin bereits eine spätere, vom Christentum gepráge Einstellung, wie sie als Ideal der den Heroismus uberragenten Humanitit von einigen wenigen Helden in Vollkommenheit verwirklicht wird fXojstro" als höchste stufe des Menschseino; . III.3.7.2; vel. Alo1s schmaUs, "Heldentum und Hybris" (99)). 
Die serbokroatischen Volkserzahlungen sind eln Samelbecken christlicher, altorlentalischer, lolamischer und naturrechtlicher Auffassungen, die manchmal in elgenartiger Kombination auftreten. LATKovic erwahnt in selnen ausfinrungen uber die Herkunft der Motive, das urspringlich christliche stoffe hier elne neue Motivation Im Sinne altheldnischer Vertvorsteliungen erhielten (etwa Blutrache, Menschenopfer), wahrend umgekehrt bereits vorhandenen Geschichten von den Geistilchen elne christliche Moral "aufgepfropft"wurde ( $62,5.51 \mathrm{ff}$.

EIn interessantes Beispiel für die Darbietung vorchristilcher Rechtsauffassung im Gewand elner christlichen Helligengeschichte ist die Erzahlung Nr.48 in Cajkanovits Anthologie (s.131-133) "Ne uzajmljujzla, jer te t1 se vratiti" (entnommen der "BOSANSKA VILA" Nr.2,S.106,1887). Es geht um d1e Uberzeugung, daß die Kinder - Im Sinne des Alten Testaments fü die Taten ihrer vater verantwortlich sind, und um die Idee der Blutrache, die im Rechtsdenken der siidslavischen Völker elne wesentliche Rolle spielt und auch $1 \mathrm{~m}$ Gesetzbuch des $2 \mathrm{a}-$ ren stefan Dušan von 1349 festgehalten ist; der Interpret dieser Ansichten ist in der Erzahlung der Hl. Sava.

Ein frommer alter Mann wüscht sich, wenlgstens ein einziges Mal vor seinem Tode Gerechtigkeit zu erleben. Der Hl.Sava erfullt inm diesen Wunsch, lrdem er inn folgende Szene beobachten labt:

ijber ein Feld reitet ein prachtroll gekleideter Mann, der an einer Quelle absteigt, um zu trinken und zu baden. Nach dem Bad verelist er seinen Geldbeutel an der vuelle und reitet davon. Nun kommt ein Hirt mit seiner Ziegenherde an den eleichen ort; eine ziege grabt den versteckten Geldbeutel aus, der Hirt nimmt inn an sich und zieht weiter. Wie nun als Dritter ein Bettler des Wegs knme und sich an die quelle setzt, um dort sein Brot zu essen, kehrt der Relter zuruck, um den vergessenen Beutel zu holen. Er fragt den Bettler danach, der jedoch nichts davon welis, und als der $R_{p}$ lche den Beutel nicht mehr findet, tötet or $1 \mathrm{~m}$ Zorn den Bettler. Ehe er sich entfernt, begräbt er den Bettler, damit inn niemand des Mordes bezichtigen kann.

Der fromme empfindet diese szene nicht als Gerechtigkeit, sondern als grobte Ungerechtipkeit; der Hellige aber erklärt lhm, dies alles sel nichts als Gerechtigkelt gewesen, denn: 
Der Vater des Re1ters sel ein Taugenichts gewesen, der durch Diebstahl an dem Vater des Hirten zu Geld gekommen sel; daher sei es gerecht, dab der Hirt, ohne es zu wissen, "se1n" Geld wieder genommen habe. Der Vater des Bettiers habe als Hajduk den Vater des Reiters getótet, und dieser Mord sel nun an seinem Sohn gerbicht worden.

- Sad recl da nije pravda to bilal - lautet der Schlubsatz.

Die glelche Einstellung kommt auch in den arabischen bzw. hebralschen Vorbildern der firzahlung zum Ausdruck (22,5.392).

Die Uberschneidung. christlicher und heldnischer Denkweisen zeigt sich in vielen Detailsder serbokroatischen Volkserzahlungen: der Bärensohn Medvetovit muls vor dem Essen beten, die Mutter der Sonne redet die Köniein als "rajska dušca" an (Vuk Nr.10,S.57), die heidnische vila betet zu Gott (Čajk.Ant.Nr.45,S.120). In den Sagen iiber die Quelle des plusses letinja treten glelchzeltig vilen und Martyrer auf, und in Varlanten ein und desselben Marchens erscheinen einmal Engel und Hellige, eln andermal vilen oder Vögel als Retter.

\section{III.3.7.5.S1ppe, Familie, Freundschaft}

Die zentrale Bedeutung von Sippe und Familie im Rahmen der patriarchalischen Lebensform ist aus vielen Erzahlungen ablesbar. Es wird absoluter Gehorsam gegeniber dem Familienoberhaupt gefordert; die Wahrung der Familienehre 1st ungemein wichtig, ebenso die Erhaltung der sippe, weshalb kinderlosigke1t als schwerer Schlcksalsschlag gilt. Von grober Bedeutung $18 \mathrm{t}$ das kinhalten gegebener Versprechungen, die Achtung der Gastfreundschaft und der Blutsbruiderschaft (pobratimstro). Felche Schande das Nichteinhalten gegebener Versprechungen darstellt, geht eindrucksvoll aus mehreren Belspielen der Sammlung VRCEvils "Narodne pripovijesti 1 presude" ( R2) hervor; der verlust der Ehre (obraz) wird mit dem Verlust des Wichtigsten 1m Leben, des Hauses, gletchgesetzt:

. al1 koj1 fajda kad mi je dołlo vet da se moja kuta 18kopa (S.265). 
Wie hoch die Freundschaft eingeschatzt wird, zeigen $z$. B. die Worte des Popen am Schluls einer Erzählung (Sinj Nr.23, S.355-358); zu dem Jungen, der bei ihm im Dienst steht, sagt er, nachdem dieser thm elne Rethe von Gemeinheiten angetan und zum Schlub auch noch seine Freunde vertrieben hat:

Ma što znaš, monče - kaže - ma smaka si mi - kaže vola pa san ti prost1jo; pa si mi smaka - kaze prasad, prost1jo, pa si mi smaka koze, prostijo san; pa si mi smaka mater, pa si mi smaka 1 Zenu, pa da mi nisi - kaze - odbijo moje prijatelje, sve bi' te kaze.

\section{II.3.7.6 die Frau}

Einander widersprechende Ansichten kommen hinsichtlich der Einschatzung der Frau zum lusdruck: es eibt zahlreiche Geschichten von "bösen" Prauen, deren Bosheit von elner von der des Mannes abwelchenden Meinung bis zur Helmtuicke und zum Ehebruch relcht, wobel sie sich lmmer der list bedienen. In einer Frzählung aus dem Geblet um Daruvar (Daruvar Nr.9, S.36) redet die Frau ihrem Mann ein, er habe einen Fisch "aus dem Boden geprlugt", und es gelingt ihr, thn auf diese Art ins Irrenhaus $z u$ bringen. In einer anderen Geschichte der fletchen Sammlung (Nr.10,S.30-38) versucht ste, ihn durch eine üpplge Ernahrung blind zu machen, damit sie thren "kum" ungestört lieben kann, In Vuks Märchen Nr.42 stellt sie sich tot, um sich von dem fellebten ausgraben zu lassen usw. In elner Erzăhlung aus dem Geblet um Sinj (Nr.22, S.354/355) wird sie als der gröbte Felnd des Mannes präsentiert. Die klasslsche Methode zur Behandlung solcher Frauen sind Prügel (Vuk Nr.3), durch die auch faule Frauen zum pletis erzogen werden (Cajk.Ant.Nr.93,S.252). Diese Geringschätzung der Frau aubert sich bekanntlich noch in Njegozs "Gorski vijenac", nach dem Zakonik Cara Dusana mulste bel der Beilefung eines Streites durch Geldbule fur elne getötete Frau nur halb so viel bezahlt werden wie für einen Mann. In der legende von der Weberin und dem Hl.Sava (Čajk.Ant. Nr.155.S.307) lautet die Schlubmoral -

I zato i nema hleba od ženskog rada.

Die euten Frauen sind vielleicht nicht in der Minderzahl, sie fallen nur wenter auf und sind, wie schon pesagt wurde, der lohn der Bemiihuneen des Mannes, solange sie jung sind, 
und später - aufopfernde Mitter. Sie fügen $81 \mathrm{ch}$ auch dummen Anordnungen des Mannes, um nur nicht ins Gerede zu kommen (Čub.Nr.34,S.184: ...samo da ne b1 svitu na glas 1zlazile.) Immerhin gibt es auch ausgesprochen positire Beispiele, z.B. die Erzahlung "Ko je čoveku najpręt" ( 224), In der die Frau sich als die Treueste erwe1st: Vater und Mutter zobgern, sle aber lst berelt, ihr Leben für ihren Mann hinzugeben (Alkestis-Motiv).

\section{III.3.7.7.51tte und Brauch}

Zur patriarchalischen Lebensform gehört auch unbedingt die Einhaltung bestehender Bräuche. All die Mărchen, in denen u.a. vom Besuch der Bruder bel den verheirateten Schwestern die Rede ist, belnhalten unausgesprochen den alten Glauben, dals ein Mädchen Innerhalb der ersten 7 Jahre nach der Helrat von thren Anpehörigen besucht werden misse, weil es sonst 1 Jenselts mit unreinen Tieren, z.B. Kröten, zu tun haben werde $(22,5.386)$. Welch ungeheuerlichen Makel die Blutschande bedeutete, zeigen Märchen wie Vuk Nr.28(S.117-120)oder Daruvar Nr.16(S.48-51), in denen die von ihren vatern begehrten Töchter unerfullbare Bedingungen stellen bzw. allerlel Mittel und Zauberel anwenden, um diese Schmach - oder Sinde zu vermelden. llier wie in der Frage vorehelicher Liebesbeziehungel oder einer lheverfehlung seitens der frau sind christliche und vorchristliche Moralbeeriffe miteinander verschmolzen (vel. "Grozna osuda na smrt", Vrtevit 1890,s.148164; ein Liebespaar wird mit Finverständnis der váter vom Volk gesteinigt, denn "Narod ne hote da s njima dijeli grijeha ni sramote", \$.162).

\section{III.3.7.8. Wert der Arbe1t}

Dab in der serbokroat 1schen Volkserzahlung Auffassungen unterschiedlicher Epochen thren Niederschlag gefunden haben, zeigen zwel weltere Belspiele. Die Einschatzung der Arbeit als ethischer wert ist jiingeren Datums; in Vuks Marchen "Usud"(Nr.13) ist das Glük nicht vom FlelB abhänglg, sondern davon, ob man in elner glucklichen Stunde geboren ist; dem Nichtstuer fält alles zu, der Fleilige plagt sich vergeblich. 
"Nichtstun, Essen und Trinken sind das Ideal des primitiven Menschen", bemerkt CaJkanović( $22, \mathrm{~S} .375)$ und bringt als treffende Beispiele die Lebensweise des Helden Utpaniftim im babylonischen Paradies und die der Im Kampf Gefallenen im germanischen Walhall. In Erzăhungen, die solche Helden zelchnen, bubert sich mithin eine alte, einer frihen Fntwicklungsstufe entsprechende Auffassung. Dagegen wird in Vuks Marchen "Sve, sve, al 1 zanat"(Nr.48) ausdrickl1ch auf die Bedeutung handwerklicher Fihigkeiten hingewiesen, wenn auch teils aus uti1 t tarlstischen Frwägungen heraus. In elner Fraählung der Anthologie von ČUHELIć (Nr.34,S.184.186) wird der Faule, der hinterm ofen sitzt und Pfeife raucht, energisch zur arbeit bekehrt.

Die zuletzt erwähnte Geschichte entstamm der Sammlung von Balint Vujkov (Hrvatske narodne pripovijetke, bunjevacke) ; sie wurde in elnem fruchtbaren Gebiet aufgezelchnet, in welchem der flelilge Ackerbauer zu beträchtlichem wohlstand gelangen kann; die Vualitat der kxistenz hing hier schon seit Generationen von der Arbeitsleistung, nicht von kämpferischen Fähigkeiten ab. Wenn demgegenuber GESEMANN ( $39,5.81)$ von der "heroischen Faulheit" spricht, die sich in Verachtung des Ackerbaus und des Gewerbes äuliert, so zeigt dies, dal nicht nur unterschied1 tche Epochen, sondern auch unterschiedliche lebensumstände die ethische finsteliung bestimen. GFSFiman schreibt:

Fin ganz auf Krieger- und Hirtentum gestelltes Volk, welchem zudem die Natur den anbaufähigen Boden karb bemessen hat, verweigert dem Ackerbauer und dem gewerbetreibenden "Banausen" die soziale Fihre. Kein schlimmeres los für elnen beriihmen Helden, als im Alter und im Schwelie seines Anpesichts den Acker bauen zu missen. $(39,5.81)$

Dieser Autfassung begegnet man immer wieder in Erzählungen aus Montenegro; sie gilt auch fü die zahlreichen verherrlichungen des Hajduken, des "edlen Räubers", in denen das nationale Moment im Vordergrund steht. Daßs sie sich speziell in Montenegro weit uber das eifentliche "heroischen Zeitalter hinaus gehalten hat, erwähnt Milovan Dj1las mehrfach ("Besudna zemlja", 1958). 
III. 2.1.9.5chicksals - und Wunderglaube

Auch der Giaube an die Vorbestimmung, wie er in dem oben erwähnten Marchen bel Vuk (Nr.13) zum Ausdruck komnt, hat Wandlungen erfahren. In den Anthologien von tajkaNovid und von CUBELIĆ sind zwei sehr ahnliche Erzahlungen enthalten, in denen es um die Vorbestimmung des lebensweges in der Geburtsstunde geht, die zu entgegengesetzten Ergebnissen fuhren. Be1 čajkanović (Nr.50, "Uris", s.135-137) wird die ditere Uberzeugung von der unumgänglichen Erfullung der Prophezelhung vertreten;

Što je kome Uris urisio I Sudenice dosudile na njegov roden dan, to te mu biti, pa ma mi radili ne znam Yta. Be1 ČUBELIĆ (Nr.20,s.135-137) dagegen erfullt sich die voraussagung nicht:

sudto je bog, a usude su varalice.

Dies ist elner jener Fälle, in denen die christliche Auffassung bewulst gegen die mythische Uberlieferung ausgespielt wird. In wentger aufdringlicher form hat das christilche Denken in viele Erzahlungen Elngang gefunden, wozu die moralisierende Tendenz Karadžits und seiner Nachfolger durch die Rückwirkune der Aufzelchnungen auf die miindlichen frzähler belgetragen haben diufte. Das elne solche gegenseltige Durchiringung christlicher und heldnischer elemente schon viel fruher erfolgt ist, wurde schon erwähnt; so 1 st die wunderbare Frrettung der Mădchen aus der Gewalt des "Mörderbräutigams" in einer Variante des bekannten Blaubart-Märchens als Belohnung der Barmherzigkelt - einer spezifisch christlichen Tugend - der jingsten Schwester motiviert, die elne Taube getrankt hat (Čajk.Ant. $\mathrm{Nr} .83,5.221,-223)$.

Die Volkserzähler unserer Tage erzahlen zwar immer noch gern von wunderbaren Geschehnissen und wesen, sind aber selbst nur noch bedingt wundergläubig wie der ldeale Märchenerzahler; dies zeigen Kommentare wie:

-Sad jesu l'mu sreku dale vile, fa ne znan. (Sinj Nr.72, S.392).

Dals das Nachlassen des Wunderglaubens bis zur Ironisierung gehen kann, zeigt eine Erzahlung der Sammlung Vrčevits 1868 (Nr.231, S.107). 
Ein einfacher(und einfultiger) Turke hbrt, wie bein Kadija lmmer wieder sagt, dab Allah jeden hundertfach belohne, der elnem Armen nur einen Para gebe. Er verteilt daraufhin 1 no Groschen und denkt, wenn Gott ihm dafür 1000 gebe, könnte er endlich helraten. Da er seinen letzten Groschen verschenkt hat, wuB or zwel Tage lang hungern. Zornig luuft er zum Kadija, um von thm selne 100 Groschen zurickzuverlangen und the jene "gottlichen" 900 Groschen, die er als Ertrag erwartet hatte, zu uberlassen.

Wie er zum Kadija kommt, sieht er dort einen Chrieten, der eerade zu diesem hineingeht, aber seine rasche vor der Tür stehen läb. In der Hoffnung, darin ein stuck Hrot zu finden, stiehlt der Türke die Tasche und lauft nach Hause, wo er tatsachlich eln Viertel eines noch warmen Brotes darin findet, dazu aber noch, in einen Lappen eingewickelt, 1000 Groschen, die jener christ dem Kadija bringen wollte, damit ihm dieser einen Dienst erwelse.

\section{III.3.7.10.Nationale Komponente}

Die Vielfalt der vorstellungen und Auffassungen, die in den serbokroatischen Volkserzahlungen zum Ausdruck kommen, lst mit diesen Beispielen nur grob umrissen. Das verbindende Element aller frzahlungen ist das streben nach der Verwirklichung der in der patriarchalischen Lebensform gültieen ethischen verte, die auferund der besonderen Verhältnisse als Symbol nationaler bigenstindigkelt und Selbstbehauptung empfunden wurden. Fine solche Umdeutung ins Nationale haben auch christliche Auffassungen bzw. bestimmte Charakteristika der orthodoxen Kirche in cebieten erfahren, in denen es zur Konfrontation mit dem Islam bzw. mit der römisch-katholischen Kirche kam. 
III.3.8.Vuks stilisierung im Verfielch zum Originaltext: geschriebenes Wort und mindliche Rede

In den vorhergehenden Abschnitten wurde bereits mehrfach auf Karadżlts Bearbeltung serblscher Volksmärchen Bezug genommen. Worin diese Bearbeitung im einzelnen bestand, hat MOJAŠEVIĆ in seinem Aufsatz "O Vukovoj stilizaciji srpskih narodnih pripovedaka" (81) an Hand von Beispielen dargelegt. Hierauf wird später eingegangen.

In MnJašrfićs artikel findet sich folgender Satz:

Wenn wir heute vom volkstumlichen Erzählstil sprechen, denken wir an den stil der volkserzahlungen Vuks.

$(81,5.313)^{1}$.

Diese Feststellung fuhrt unmittelbar auf das Problem der Wechselbeziehung zwischen der sprache Vuks und der Sprache der Volkserzahlung zu, wie sie in den Aufzelchnungen verschiedenster Herkunft in Frschelnung tritt; denn in seinem Bemiihen um die schaffung einer literaturfahigen sprache hat Karadzit versucht, in diesir den Relchtum der volkssprache mit syntaktischer und grammatikalischer Eindeutigkeit zu vereinigen. Seine melsterhaften Fassungen bekannter stoffe haben nicht nur den stil der Sammler beeinflulit, sondern diirften auch manchem mündlichen Erzähler direkt oder indirekt als Vorbild gedient haben. Man darf die Wirkung des gedruckten fortes selbst auf den, der es persönlich garnicht lesen kann, nicht unterschätzen; so hatten die gröbtentells von Katit selbst verfalsten "Heldenlieder" des "Razgovor ugodni naroda slovinskog" (Venedig 1756), volkstümlich "Pjesmarica" genannt und oft nachgedruckt, elne erstaunliche Anziehungskraft fiur viele Sänger, die sie nachzuahmen suchten, obwohl sie in ihrer kunstlerischen Qualitat bel weitem nicht an die uberlieferten Lieder der noch lebendigen epischen Tradition heranreichten, wie schon Karadžlt festgestellt hat ${ }^{2}$.

1 Im gleichen Sinne äubert sich I.FRANGeS in der zweiten(dt.) Fassung seiner Studie über die erlebte Rede bel Krleza: "Unter "Sprache des Volkes" wird hier selbstverstandlich die Volkssprache vom Typus Vuk Karadżts verstanden." (I.F.. Elne stilist.Eigenschaft von Krležas "Davni dani", Ins The Art of the World (Umjetnost rije 1 ). Selected studies 1957-1967. ed1ted by Z.Skreb, Zagreb 1969,5.255).

2. Dragoljub Pavlovit: Vuk 1 Kak1t. Vukov Zbornik, Heograd 1966, S. $451-463$. 
Umso eher konnte elne solche Wirkung von stilisierungen ausgehen, die mit vertrauten formalen Mitteln zu sprachilcher Schönheit und Einprägsamkeit gelangten.

Aus allem, was bereits Im Kapitel uber die Ausgangssituation der Literatur im 19.Jahrhundert (II, 1) gesagt worden ist, geht hervor, wodurch slch die Ansatzpunkte Karadžits grundlegend von denen der heutigen Sarmler unterschieden. In einer Epoche, in der sich die Schriftsprache erst formierte und milhsam von fremden Elementen befreite, ging es für vuk in erster Linie um Beispiele elnwandfreier volkssprache, und, was den Anstols zu seiner Ubersetzung des Neuen Testaments (1847) gab, um den Bewels der Ausdrucksmöglichkelten dieser Sprache. Selbstrerstandlich verfolgte er zugleich das ziel, die volksuberlieferung vor dem Untergang zu bewahren und das Nationalbewustsein zu starken. In der Vorankindigung der "srpske narodne pripovijetke" am schlul der erweiterten Ausgabe des "Srpski rječnik" (Wien 1852) schrieb er ausdrücklich:

Fibenso wie die Lieder Muster der Sprache unserer Volkspoesie sind, werden diese Erzählungen Muster der Volkssprache in Prosa sein.

(zitiert nach $81, S .300)$.

In der vorrede zu den 1853 erschienenen Volkserzählungen erklarte Karadzit zunächst, dab man die volksliteratur nur "getreu, rein und unverdorben" zu sammeln brauche, fugte aher sogleich hinzu:

- aber beim Schreiben der firzählungen mull man schon nachdenken und die worte umatelien (aber nicht nach dem eifenen Geschmack, sondern dem kesen der serbischen sprache gemäis). ( $54, \mathrm{~S} . \mathrm{XI})$.

Um also eine vorbildiche serbische Prosa zu schaffen, iberarbeitete Vuk die thm ibersandten Aufzeichnungen. Als ziel schwebte ihm ein volksnaher, aber zuglelch literaturfahieer Stil vor, der nicht mit seinem persönlichen Stil identisch sein sollte, bei dessen Ausformung sich aber sein individuelles, sehr ausgeprägtes Sprachgefihl auswirkte. Da inm der Stil der jeweiligen Aufzelchnung gewisse Grenzen auferlegte, ergab sich somit, wie MOJAŠEvic sagt, eine synthese aus dem Stil des miindlichen Erzählers bzw. des Sammlers, dem St1l Karadžlts und jenem Idealen Stil der volkserzählung, den er anstrebte. 
Die heutigen Sammler von Volkserzahlungen können demgegenuber von der gesicherten Position elner ausgeformten Literatursprache ausgehen. Es ist nicht mehr notwendig, aus einer Fulle von Dialekten einen zur Hochsprache zu entwickeln, ihn von Uberfremdungen, Archaismen und Provinzialismen zu befreien und mit jedem geschriebenen Satz die blobe Existenz und die leistungsfähigkit dieser Sprache unter Beweis zu stellen. Zwar haben sich die serblsche und die kroatische Literatur infolge der Wahl des Štokavischen zur schriftsprache aufgrund unterachiedlicher voraussetzungen - hier elin štokavisches "Hinterland", dort, jedenfalls anfangs, der Ausschluß der eigenen dialektalen Elemente und daher die orientierung an der Dubrovniker Literatur und der ztokavischen volksuberlieferung - nicht in dem Sinne gemeinsam entwickelt, wie es die Unterzelchner der Vereinbarung von wien (185n) erhofft hatten. Grundsatzlich aber hat die serbokroatische literatur den Vorsprung, den die "großen" europäischen Literaturen um 1850 vor ihr hatten, vollstandig aufgeholt; das Problem der Literatursprache, die heute zwel Varlanten aufweist, ist so weit uberwunden, dals man bereits auf die Dialekte zurickzugreifen beginnt, wie dies in der $2 . H a l f t e$ des 19. Jahrhunderts z.B. In Russland nach der Ausformung der Sprache durch einen Schriftsteller wie Leskov geschah. Das Auftreten eines Schriftstellers wie Mirko Bozit, der bewult Provinzialismen in seinen Stil einbezieht, ist bezelchnend für diese situation ("Kurlani", 1952; "Ne1splakani", 1955).

Dem heutigen Sammler münlich tradierter Texte geht es im Gepensatz zu Vuk um den Relz des "Mündlichen", um die Markigkelt und Expressivitat der Sprache des Volkes, die oft gerade durch das Abweichen von der schriftsprachlichen Norm, durch Archatsmen und Provinzialismen gestelgert wird. M.BoškovićSTULII stellt fest, dals

jene Volkssprache, die für gewöhnlich als Grundlage unserer (der serbokroatischen) Grammatik gilt, in thren urspriinglichen formen ziemlich weit entfernt lst von der grammatikalischen Norm, der sie als Grundlage gedient hat,

und sie fügt hinzu: 
Die Volkssprache, und zwar vorwiegend die der Volkedichtungen, war tatsachlich die Grundlage für die normative Grammatik (die serbische wie auch die kroatoserbische), aber nicht in der urspringlichen mindlichen Gestalt, sondern in jener gereinigten Form, die thr vuk Karadzit und seine Mitarbeiter und Nachfolger gegeben haben. (18,S.261).

Eine Reihe der Charakterlstika, durch die sich die stilisierungen Vuks von origlnaltexten unterscheiden, sind berelts unter III.3.4. erwähnt worden. In selner eingangs genannten Studie hat MoJAŚrvic die Arbeltsweise Vuks im einzelnen beschrieben, nachdem er insgesamt 28 Handschriften mit Vuks Fassunf verglichen hat. Demnach handelt es sich hierbei nicht nur um eine sprachliche Redaktion durch Umstelien, Hinzufugen oder Weglassen elnzelner Worte, obwohl Karadzit sich, vor allem bel den Autzelchnungen Vrcevits, gelegentlich tatsachlich darauf beschränkt hat.

Vuks Streben war grundsatzlich nicht darauf gerichtet, in den Grenzen sprachlicher Kichtigkeit die St1lisierung selnes Mitarbelters möglichst wortgetreu zu bewahren. sondern auf die Gestaltung eines möglichst schönen und zugletch volkstimlichen und somlt möplichst klaren und flissigen satzes -

schreibt M()JAŠ́vić(81,S.302). Es lat klar, daßs hierdurch viel vom kelz des Urspriinglichen verloren fing; wo er dennoch erhalten blieb, war dies dem Sprachgefuhl Karadzits und selner Inneren Verbundenhe1t mit dem Volk zu verdanken. Das Ergehnis war daher iber lange strecken hin kein Redestil, sondern der Stil eeschriebener Prosa.

Mojašfive erwähnt im einzeluen iolpende Verfahren der stilisierunf: Um einen locischeren Aurbau einer firzihlung zu errelchen, stellte Vuk ganze Abschnitte bzw. die Reihenfolge bestimmter Informationen um. Stat des Personalpronomens wurde vielfach der Name bzw. die bezelchnung der person eingesetzt, um den Ablauf der Handlung klarer darzustellen. Unmögliche Satzkonstruktionen und Germanismen wurden ausgemerzt, weniger konsequent auch Turzismen. Manchmal erfolgte eine stilistische Abrundung durch Hinzufügung und F.rklärung, manchmal wurden uberflisstge "Frgusse" oder Geschehnisse gestrichen. Unverständliche Wendungen, die heute aus folklorietischem bzw. linguistischem Interesse getreu notiert werden, wurden ebenso 
beseltigt wie unanstandige worter (ubrigens werden obszóne Erzahlungen auch heute nicht in gedruckte sammiungen aufgenommen). Anstelle farbloser Ausdrucke setzte Karadzit expressivere Nörter. MnJAŠEvić betont, daß er elne Anzahl besonders schoner Redewendungen und worter der Volkseprache in die Texte elngefügt habe. Die "verfestigten" Stelien der Marchen habe Vuk oft auf eine einheitliche Form gebracht, In der er sie dann wlederholte; manchmal aber habe er auch ursprünglich glelchlautende Formulierungen varifert. M1t der direkten Rede sel Vuk sehr frel verfahren, Indem er sie manchmal in indirekte, manchmal jedoch Indirekte in direkte Rede umgewandelt habe.

Als welteren Zug der Vukschen Bearbeltung nennt MnJASEvić das Streben nach möglichst großer Natürlichke1t in den Detalls, d.h. nach Anpassung des Milleus an die dörfliche Umgebung. Ferner welst er auf den stellenwelse spürbaren Elnflub der eplschen Lieder hin; gelegentlich ist Karadzit in den epischen Deseterac verfalien, z.B.:

In der Handschrift:

be 1 Vuk:

onda kaze

A azdaja stane kazivat1

Vuk Nr.8.5.39

- da 1zidu svi napolé

1 da 1du kud je kome drago Vuk $\mathrm{Nr} .8,5.43$

Gospodaru! Gospodarul Svetli care, sunce ogrejalol Metni ruku preko trbua moga...Baci desnu ruku preko mene.. Vuk Nr.10,S.50

Es glbt nach MOJAŚEviĆ schon in den Handschriften Belspiele des Deseterac; gelegentilch sei dieses Metrum durch die Bearbeltung zerstort worden. Auch die Pathetik des Heldenliedes hat s1ch manchmal auf die st111sierung der Erzahlungen ausgwirkt, was z.B. In dem Märchen "Stojba 1 Maden" (Vuk Nr.5) zu elnem sprachlichen Parallelismus fuhrt:

Kazi mi, kad je moj otac bio car, gde mu je oruzje fo je pasao, gde 11 mu je konj sto ga je jahao.

In der Handschrift des Sammlers heibt es:

Kaz1 t1 ment kadi $\theta$, mo1 oč bio car d1e nĕgove oružle, d111 mue kono.

(samtliche Belspieles 81,5.310). 
An einigen Stellen hat Vuk nach MnJAŠEvić auch überfiussige St1lisierungen vorgenommen (z.B. In Texten von Grujo Mehandzit). Manchmal habe er auch ubertrieben, indem er dialektale Formen einsetzte, etwa statt "ne htedne" in der Aufzeichnung - "ne stedne". Ferner habe er nicht iberall einhe1tlich das Ijekavische durchgefuhrt, sondern auch ekavische Formen stehen lassen.

MOJAŠEvIĆ pelangt zu dem Schlul, dals Karadžlt die Erzahlungen durch seine Bearbeltungen nicht verfälscht habelwie dies bel manchen seiner Nachfolger der Fall war), da er seinen Stll dem Geist und der filgenart der serbischen sprache untergeordnet habe, was thm dank seiner unmittelbaren Kenntnis des serbischen Volkslebens vollkommen gelang. Diesen stil fand er nicht berelts fertig in der muindlichen Tradition vor, sondern er mulste inn erst aus den vorhandenen Elementen formen.

Der Frage nach dem Wert der Vukschen Stllisierungen als Quelle und Beisplel der Volkssprache begegnet MnJASEvić mit der Gegenfrape, ob etwa die Texte in der wiedergabe Mehandzits etc. volksnaher seien, und verneint sie sodann: gerade durch die Bearbeitung Karadžits hätten sie den allervolkstiunlichsten Ton erhalten, der möglich sel. Es könne daher nicht die Rede davon sein, dals Vuks Märchen nur ein guter Ersatz für "echte" Volkserzählungen seien; sie könnten vielmehr auch als wissenschiftliches Material der Folkloristik dienen ( $81,5.313,314)$.

MnJAS̆̈vić bemerkt, daßs es interessant wäre, den Einfluls der Vukschen Bearbeitungen auf den Stil spterer Sammler zu untersuchen $(81,5.314)$. Dals ein solcher f/nfluls bestand, steht ebenso wenig aulser $Z$ weifel wie die fchon angedeutete Möglichkeit einer Rückwirkung auf den Stil müpdlicher Volkserzahler. Wenn daher $1 \mathrm{~m}$ Rahmen dieser Arbeit von blementen der müdlichen volksliteratur innerhalb der frihen Hochliteratur die Rede ist, so wird davon ausgegangen, daß diese Elemente aus allen erdenklichen, sich als Volksilteratur darbietenden Texten ubernommen wurden, angefangen von der selbstgehörten Originalerzahlung bis zu Vuks formvollendeten Stlilsierungen und den nicht lmmer so geglickten Bearbeltungen selner Nachfolger. 
IV.1. Vorbegerkung: D1e Begr1fre "Novelle" und "novela"

Der urepringlich auf die romanischen Literaturen beschrinkte Term1nus "Novelle" beze1chnet elne besondere Form der Erzuhlung, ale deren wicht1gete Merkmale melet elne besondere Geochlosenhe1t, strenger kompositorischer Aufbau, Daretellung elnes einzigen Konflikts und elnes, hobhetens zweler, von vornherein festgelegter Charaktere genannt werden. Die Abgrenzung dieser Prosafore von anderen Gattungen, vor allem vor Roman und von der Erzahlung, erwelet elch nicht lmmer alo elnfach; diese Schwierlekelt lot an den welsten Versuchen einer exakten Definition der Novelle abzulesen.

D1e zahlreichen Definitionen des 19.Jahrhunderte Bingen imner wieder von Bocaccios "Decameron" ale dem klaselechen Vorblid aus, deseen Erzahleituation in Novellenzyklen oft imitiert wurde und durch den fiktiven windlichen vortrag -1reste1ls d1e Knapphe1t der Auseage und das Monent der Aufrechterhaltung der spannung motivierte, anderntello opter die Entwicklung des oubjektiven stile und des skaz begunet1Bte, z.B. be1 Gogol'.

Der ocheinbare Widerspruch der letzten Festetellung zu der gegentelisen, oft rertrotenen und durch das Belopiel vieler Novelien beetatigten Behauptung, daB die Novelle gerade Subjekt1vitut nicht zulasse, orklurt sich durch oben diese fikt1ve Erzahleituation: Subjekt1vitut oder objektivitat des Erzuhlst1lo oind in der Novelle davon abhanglb, welcher gesellochaftilchen Schicht Erzahler und Zuhörer angehoren und welchen Grad der Intiultat der Autor thnen zubliligt. Das klaseloche Belepiel des "Decaneron" geht von der Voretellung elner artetokratiochen Geoellechaft aus, bel der es zum guten Ton gehórt, sich zu distanzieren, Gefuhle nur 1m Rahmen des Schicklichen zu zelgen und Erechreckendes oder AnetöBlges durch ueso kunstvollere und diskretere Daretellung salonflhig zu machen. Diese Haltung gestattet keine leldenschartiche persönliche Antelinahe des Erzuhlenden und auch kelne tiefergehende Charakterdarstellung, was ubrigens der Leser oft das Vergnugen der selbetidentifizierung at den handelnden Personen nimmt. D1ese Atmosphare der Distanz, der Objekt1vitut herrscht trad1tionsgensB b18 1ns $20 . J a h r h u n d e r t a c h$ in v1e- 
len Novellen, in denen uberhaupt keln Erzäler auftritt, etwa bel Bergengruen oder Blnding, deren Werke der allgemelneren Tendenz zur Auflockerung und zur Poychologisierung der novellistischen form widersprechen. Whit der Autor demgegenuber bewulst eln anderes Milieu, wle Gogol' In "Večera na chutore bliz Dikan'k1"(1831/32), besteht kein Grund mehr für elne solche Orientierung an den Verhaltensnormen der gebildeten Gesellschaft; der Autor kann einen subjektiven St1l entwlckeln, der gerade bel Gogol' spater nicht mehr durch die vorgeschobene Erzahlerfigur motiviert wird, so dab er stch ganz frel, ohne Bindung an irgendelne soziale Schicht, entralten kann. In glelcher Welse kann die Novelle von der "klassischen" objektiven Art der Berichterstattung abweichen, wenn sie auf der Fiktion der betont zwanglosen Unterhaltung oder eines intimen münlichen Berichts aufgebaut ist.

Die Im 19.Jahrhundert umstrittene Frage der lbjektivitat oder der Subjektivitát $18 t$ also für die Charakterisierung der Novelle nicht ausschlaggebend. Als Kriterlum zur Abgrenzung gegenuber der $\mathrm{E} z$ a $h l$ u $\mathrm{f}$. die u.a. bereits Goethe und Tieck fiir notwendig hielten, kann dagegen der kunstrolle, architektonisch strenge Autbau der Novelle gelten, jene zielbewulste Entwicklung einer fast immer elnstränglgen Fabel auf elnen Höhepunkt hin, dem die "wunderbare wendune" (Tleck) oder die Katastrophe folgt. Das setzt voraus, dals die Novelle im Sinne der oft zitierten Formulierung Goethes elne"neue, unernorte Begebenhe1t" zum Gegenstand hat, d.h., sie lst elne weiterentwickelte Form der Anekdote und strebt wie diese einer Pointe zu; diese dubert sich häufig im letzten Satz, der viele Novelien - sel es durch eine allgemelne Feststellung, durch elne lapidare Zusamenfassung des Resultats oder durch elne uberraschende Bemerkung des Autors - erst elgentich abrundet. Dem kunstrolien Aurbau entspricht die bewulste Stilisierung des Textes, die sich nach der Intention des Autors richtet, z.B. In typischen "objektiven" Novelien elne Art Chronikstil. whrend elne gelegentliche Verflechtung der Fabel durch Ruckblenden und Vorgriffe mit lhrem artistischen Charakter durchaus im Einklang steht, widersprechen Retardationen in Form 
zusatzlicher Episoden, Beschrelbungen und Abschweifungen dem Wesen der Novelle, für die das cosetz der küstlerischen ökonomie gilt. Die notwendige Beschränkung der Darstellung ruickt die Novelle in die Nahe des Dramas (Storm: "Schwester des Dramas").

Die Erzahlung stelit sich demgegenuber als die anspruchslosere Form dar, die sowohl Irgendelnen Zustand, elne Lebensform als auch elne oder mehrere Episoden in epischer Brelte schildern oder $z . B$. In der Beschrelbung elnes charakters unter Zuhilfenahme kleiner szenen bestehen kann, ohne unbedingt durch Uberhöhung und Abstrahierung bestimmte Wahrhelten sinnfallig machen zu wollen; es fehlt Ihr die bis ins Einzelne gehende Komposition, die man von der Novelle erwartet. Obwohl die Erzahlung u.U. viel mehr an "Ereignissen" enthalt als manche Novelle, können diese infolge kontrastloser aneinanderrethung monoton und unibersichtlich wirken, während die Novelle durch die Konzentration auf das Wesentliche, durch die straffe Komposition, zu der auch die Verwendung wiederkehrender symbole gehört, und durch "sprunghaftes" Interventeren des Autors (R.Petsch) das Interesse des lesers aufrecht erhält.

Die Novelie stellt im Vergleich zur Frzahlung einen höheren Grad an Abstraktion dar, sie lst eine entwickeltere Gestaltungs form.

Vom $R$ o $m$ a unterscheldet die Novelle rein auberlich der geringere Umfang, doch peniigt diese Differenzierung naturlich nicht; manche Novellen sind als "kleine Romanen, manche kleinen Romane als Novellen elngestuft worden.

Der Bezug auf das Kulturleben elner bestimmten Zeit, eines bestimmten Milieus ist im Roman durch ein umfassenderes Bild - ahnlich wie Im Epos - gegeben, whrend dies in der Novelle nur am Rande der Handlung schlagl 1chtartib möglich 1st. Das Fpos neigt bel der Gestaltung seines umfassenden Weltbildes zur Typisierung der Personen; demgegenuber strebt der Roman bekanntlich elner lmmer 
deutlicher werdenden Charakterisierung des Individuuns $z u$, dessen Elnzelschicksal im ZusammenstoB mit der Umelt deren Darstellung ermöglicht. Die Entwlcklung der Charaktere $1 \mathrm{~m}$ Verlauf der Handlung tritt belm Roman wahrend des 19.Jahrhunderts immer mehr in den vordergrund und fuhrt schlieBlich durch Erschlielsung $1 \mathrm{mmer}$ teferer Bewubteinsschichten zur völligen Verdrängung der Fabel in ulner Reihe von Romanen des 20.Jahrhunderts; In der Novelle dagegen sind die Charaktere von vornherein als gegeben anzusehen und erfahren keino Veranderung, sie sind oft gerade durch inre Unwandelbarkeit der Angelpunkt der Motivation.

Schlielsich bietet der Roman dem Autor Gelegenheit, das Ergebnis seiner Welterfahrung dem Leser sowohl durch anschauliche Belspiele als auch durch direkte, ausfuhrliche Erorterung. sei es Im Dialog oder als Autorenkomentar, zu vermitteln; die Novelle muls sich auf die Darstellung einer elnzigen Erkenntnis beschranken. Als grolse Form kann der Roman kompl1zierte Kompositionsformen mit mehrfachen und parallel verlaufenden Handlungssträgen anwenden, die grobe Zeltrăume durchziehen; die Novelle tst sowohl zeltlich wie raumlich auf Abgrenzung angewiesen.

Grundsätzlich verschieden 1st, historlsch betrachtet, die Auspangssituation beider Erzahlformen: die Novelle bezieht thre typischen Elfenschaften von lhrer Urform des miindlichen Vortrags, zu der sie immer wieder zuruckkehrt. Der Roman aber lst elne schriftliche form des Erzahlens, von der ÉJCHFNHAUM sagt:

Der Roman 1st eine gemischte und gerade von ter schriftlichen Kultur erzeugte Form. Der Roman wird geschrieben und nicht aufgezelchnet, und er wird ausdrucklich zum Lesen geschrieben. Das lebendige wort des Erzahlers geht in dieser ungeheuren Masse unter, es gibt keine stimme. Lange Dialoge, umfangrelche Beschrelbung von Fakten, die Kompliziertheit der Fabel, alle diese Tatbestande machen den Roman eben zum $B$ u $h$.

(31.5.163)

Falst man die aufgezahlten Charakteristika der Novelle zusammen, so ergibt sich, dab es sich hierbel um eine sehr anspruchsvolle Frzahlform handelt, der keineswegs alles genugte, was im laufe des $19 . J a h r h u n d e r t s$ in der gesanten europalschen Literatur unter dieser Bezelchnung erschien. Dies gilt unso 
eher fiir die entstehende serblsche und kroatische literatur, die Ihre Maßstäbe aus den fortgeschritteneren Literaturen bezog, dabel aber aufgrund politischer und sprachlicher Gegebenhelten vor weit schwierigeren Problemen stand als diese. Aus diesem Grund wird hier - zumindest für das 19.Jahrhundert unter dem Begriff "n $v$ e $l$ a " alle erzählende Prosa verstanden, die sich der kleinen Form bedient. Dieser standpunkt zelgt sich z.B. bel BAKAC, der in selner umiangreichen Darstellung "Hrvatska novela do Senoine smrti" (1952; 7) sämtliche erzählerischen Versuche bericksichtigt, die in Kroatien seit Bepinn der 111 yrischen Bewegung bis 1881 entstanden sind, obwohl Barac in der fielchen Arbelt bemerkt, das erst Šenoa die kroatische Novelle im eigentlichen Sinne begriindet habe; al le Vorgänger hätten ledielich das Material hierzu gesammelt. Mit dieser Bemerkunf setzt Barac aber andere, allgemeingiltifere Malsstäbe an als in der Gesamtknnzeption seiner Zusammenstellung, die vor allem einen historischen Uherblick vermitteln soll. In gleicher Welse verfäht Barac in seinem Buch "Hrvatska knjtževnost I; Ilirizam" (1964; 5), In welchem bereits die ersten originalen kroatischen Novellen-Versuche Vukotinovits (In kajkavischem Dlalekt). Pavao Stoos' und Ivan Mažuranits erwähnt werden (5,5.93). Unter den ersten kroatischen Novel11sten nennt Barac Vukotinovit, Kukulfevit, Demeter und Jarneviteva, von der er schreibt:

Von allen penannten Schriftstellern stand sie ihren Neleungen nach der Novelitstik am nächsten. (7, 5.6)

Die Bedeutung der Novelifstik war $1 \mathrm{~m}$ Aupenblick der Ents tehung der kroatischen wie der serbischen Literatur ungeachtet ihrer Mängel sehr groß, da sie eine der wichtigsten Gattungen darstellte, durch die ein breiteres leserpublikum angesprochen werden konnte. Aus dieser Einsicht heraus hatte $\mathrm{sich} z$. B. bei den Serben Jovan Subotit neben anderen literarischen Gattungen und dem Gebiet der Literaturtheorie auch der Erzählung zugewandt .

Uber die Terminologie zur Definierung der einzelnen literarischen Gattungen schreibt A.FLAKE, d, der in dem von PETRÉ und ŠKREB herausgegebenen Buch "Uvod u književnost" (1969,89) eine der erschöpfendsten und zugleich knappsten Charakterisierungen der Novelle gibt $(89,5.433-437)$ : 
In unserer Terminologie halten sich noch die Bezelchnungen $p r i$ c a (kurze Geschichte, Kurzgeschichte), $p r 1 p o v i j e t k a$ (Erzahlung) und $p \quad r p o-$ $v 1 j$ e $t$ (Erzahlung), aber 1mmer mehr bürgern $s 1 \mathrm{ch}$ auch bel uns die allgemelne Bezelchnung $n \circ v e l$ a (Novelle) für dle kürzere und $r \circ \mathrm{m}$ a $n$ (romen) für die langere Prosaform ein. Ohne auf die nistorische Entstehung dieser unterschiedlichen Termini und thre unterschiedliche Bedeutung in verschiedenen Epochen und bel verschledenen volkern elnzugehen, können wir s1e so auch heute anwenden. Da es manchmal schwer lst, die Novelle vom Roman zu unterschelden, könnte man für die zwischen diesen belden Gattungen stehende Form auch den allgembinen einheimischen Ausdruck "pripovijest" belbehalten. Den Begriff "prita" könnten wir dem zuordnen, was die Englander und Amerikaner "short story" nennen, d.h. der kurzen und gedrängten novellistischen Sonderform, die man "in einem Atemzug" durchliest und die fiir die zeltgenössischen Massenkommunikationsmittel charakteristisch 1st, und nach Bedarf können wir uns auch des Terminus "mall roman" (kleiner Roman) bedienen, der auch bel uns in neuerer zeit, nicht nur als Terminus, das Bügerrecht erworben hat....

(89. 5.434$)$

In diesem Zusammenhang sel darauf hingewiesen, dals die Bezelchnung "pripovijetka" hauptsachlich auf die volkserzahlung, die "narodna pripovijetka", angewandt wird, wahrend mit "pripovijest" elne Frzählung der Hochliteratur gemelnt ist. Das 2 itat von FIAKER zeigt, dals auch heute fur die Anwendung der Begriffe "pripovijest" und "novela" ein gewisser spielraum verbletbt. Hierauf weist auch die Begriffsbestimmung der "narodna novela" bel LATKnvić hin:

Als (Volks-) Novelle bezelchnen wir alle Geschichten mit entwickelterem Sujet und realistisch aufgefalstem und dargestelltem Thema aus dem werklichen studtischen oder dörflichen Leben.

$(62,5,113)$

Der Begriff "Novelilstik" wird daher auch in der vorliegenden Arbelt ganz allgemein auf alle kleinen Formen erzählender Prosa angewand $t$. 
IV.2. Zur Auswahl der Beleptele

Elne Rethe der Im vorigen Abschnitt genannten Charakterist1ka der Novelle, die auf thre Herkunft vom mundlichen Vortrag zurickgehen, labt 1hre verwandtschaftliche Bezlehung zur Volkserzkhlung erkennen; hierzu gehoren die notwendige ubersichtliche Organisation des Textes, die bel der Volkserzahlung zur Entwicklung feststehender Kompositionsechemata führt, die zeltliche, ruumliche und formale Beschrunkung, d1e Elnstranglgke1t der Fabel, die Unwandelbarkelt der Charaktere.

Whrend diese Gemelnsamkelten sich aus der urspringlich gleichen Darbletungsform ableiten lassen, beruht der wesentlichste Unterschied zwischen belden Gatungen auf dem Gegensatz des Entstehungsmilieus (wobel wieder an das "Urbild" der Novelle gedacht wird); der kunstrollen und originellen Darbletung eines einmaligen Erelgnisses In der Novelle steht die traditionsgebundene Gestaltung allgewelner, wiederholbarer, typlecher Erfahrungen in der Volkserzahlung gegenuber.

Wo sich das Entstehungsmilieu der elnen Gattung dem der anderen annkhert und, wie bel den serben und Kroaten, die Anfangsschwierigkeiten einer jungen Literatur einen allzu hohen Grad an Kunstrertigke1t zunkchst ausechlieBen, 18t diese Gegensatzlichke1t abgeschwkcht, so dab gerade bel den Bemuhungen um eine sezifisch nationale Literatur Ubernahmen aller Art aus der wuindlichen Literatur in die Novellistik umso naheliegender sind. Dem Roman al großer und "schriftl1cher" Form stehen solche Ubernahmen nur bedingt und in geringerem Ausmabe offen. Wenn daher in elner Arbelt wie der vorliegenden nach Elementen der mindlichen Literatur in der Hochliteratur gefragt wird, bletet olch die Novellistik als Gegenstand der Untersuchung an, sofern man sich auf Prosa beschranken w111. H1nzu kommt, das die Novel11.t1k fur elne solche Untersuchung besonders viel Material b1etet; d1es l10gt daran, daB d1e Novelle - bzw. d1e Erzuh- 
lung - als kle1ne Prosaform für elne am Anfang threr Entwicklung stehende Literatur lelchter zu bewltigen lot als der Roman und daB zudem die Mbglichke1t, elne breitere Leserschaft durch küzere, in Zeltungen und zeltschriften abgedruckte Texte zu errelchen, unter den im vorigen Jahrhundert Im sudslavischen Raum gegebenen Umstanden einfach weitaus gröber war als durch den als elnzelnes Buch veróffentlichten Roman.

Die zur Untersuchung herangezogenen Novelien wurden unter dem Gesichtspunkt der grobtmöglichen Anschaulichkelt ausgewahlt, d.h. es wurden Belspiele herausegriffen, bel denen die Elnbeziehung von Elementen der mindlichen Literatur in einen Erzähltext besonder deutlich zu erkennen 1st; mehr oder wenlger ausgepragt finden sich solche Elemente noch in vielen anderen Novelien der vorrealistischen Epoche.

Selbstrerstandlich sind die im elnzelnen herausgearbelteten Stilverfahren kelneswegs auf die volksliteratur beschrănkt, da es sich un Stilmittel handelt, die von jeher zur Intensivierung des Ausdrucks angewandt wurden; sie finden sich ebenso In der westeuropäischen Romantik, von der einige Novellen deutlich gepragt sind, wie in dem seit sterne gepflegten, feuilletonistischen St1l, den neben typischen "miindlichen" Wendungen z.B. die Hiufigkeit der wortsplele mit der volkserzählung verbindet. Obwohl es daher nicht immer möglich ist, die Herkunft des einen oder anderen Kunstgriffs eindeutig zu bestimmen, labt sich elne Beziehung der hier zusammengestellten Novelien zur mündlchen Literatur elnmal an Hand der Texte selbst abletten, in denen die Kumulation solcher Verfahren auf die gleiche Erscheinung in der Volksliteratur hindeutet, zum anderen ergibt sich der Zusammenhang aus der Situation oder Disposition des Autors (I,jubiša, Korajac, Bo$t 16)$, aus der Notwendigke1t, den angestrebten st1l fremdsprachiger Vorbilder mit den Mitteln der elgenen sprache zu realisieren, die in der mindlichen tberlieferung vorlagen, (Nemčlt) oder aus dem bewulbten Bemuihen um elne volkstinllche, aber zugletch poetische sprache(Šenoa). Die Nahe zur volksdichtung ist schlielilch nicht allein aus der Anwendung ihrer stilistischen Kunstgriffe, sondern auch aus der zum Ausdruck gebrachten Lebenshaltung ablesbar, die der der Volksilteratur entspricht. 
Nachstehend wird zunachst durch zwel kurz skizzierte Gegenbelspiele elne Abgrenzung geschaffen, die all jene Texte von vornherein ausschliebt, In denen "Volkhaftigkeit" - narodnost - rein additiverscheint. Da es bel den ausfuhrlich behandelten Novelien darum ging, die Integration volkstumlicher Elemente in elnen kilnstlerlschen Text 1melnzelnen nachzuwelsen, mubte die Auswahl unter den besten Novelien der Epoche getroffen werden. Hierbel wurde versucht, möglichst viele Aspekte elner solchen Einbezlehung darzustellen; deshalb wurde z.B. kelne Novelle von Jurkovit behandelt, da in diesem Falle wiederholungen des bel Newčlt elnerselts, bel Korajac andererselts Gesagten unvermeldlich gewesen wären. Durch das Kapltel uber "štepan Mali" von Ljubiša eribrigte sich eln Heranziehen anderer serbischer Autoren der "Vukova fkola", da die zu zelgenden Stilzüge bel Ljubiša In besonders elndringlicher Welse zum Ausdruck kommen. Botits Novelle "Dilber-Hasan" gab Gelegenhe1t, einen ausgesprochen Individuelien Weg der Anknüprung an die mind 11 che vichtung aufzudecken. Das Kapitel uber Senoas Novelle "Barun Ivica" soll zeleen, daß auch der oft als "stadtisch" und "journalist1sch" etikettierte Stil Senoas Flemente der müdlichen, ländlch-patriarchalischen Erzahlkunst enthält, so daß auch Śnoa dank selner nachhaltigen virkung auf die nachfolgenden Schriftstellergenerationen e1nen Beltrag zur Anrelcherung der literarischen Sprache mit volkstumlichen Elementen gelelstet hat.

Ausschlaggebend für die Auswahl war schlieblich die ganz unterschiedliche Beziehung der elnzelnen Autoren zur müdlichen Literatur, aus der sich die 1ndividuell geprägte Art der Anwendung lhrer stilistischen verfahren ergibt. 
IV.2. Imitation und Addition: "narodnost" als äulser-

liches Dekor

Die Ausfühungen unter III. sollten eln möglichst detallliertes Bild jener volksliterarischen Gatung geben, die den fruhen serbischen und kroatischen Schriftstellern als vorbild oder zumindest als Richtlinie vorschwebte. In den unter IV.4. zusammengesteliten Belspielen von Nemcit, Botit, Korajac, Ljubiša und Šenoa werden die stilverfahren der serbokroatischen Volkserzihlung - bzw. der Volksdichtung ganz allgemein - Im einzelnen verfolgt und herausgearbeitet, um oft pauschal ausgesprochene Urteile zu konkretisieren.

In diesem Zusammenhang ist zu erwähnen, dals die oft wiederholte Forderung nach elner nationalen, einer volksnahen Literatur nicht selten Ursache für die Entstehung von direkten Nachahmungen der Volksdichtung oder von rein additiver Ausschmückung der Texte mit Volksliedern, Beschreibungen von Volksbräuchen etc. oder mit patriotischen Reden und Bezugnahmen auf die nationalen Werte war.

Die nationale Begeisterung, die in der Zeit des Illyrismus in Kroatien zur bintstehung unzähliger patriotischer Gedichte - z.B. der in den 50er Jahren verbotenen "budnice" - fuhrte, während sie in Serbien die friuhen Anhäner Karadzics zur Im1tation der volksepen anregte, machte es auch den prosaschrittstellern zur Pflicht, das figene Volk, seine Tugenden, seine Vergangenheit zu verherrlichen. Während die Novelistik lhre ersten Gehversuche machte und zunächst auf fremde vorbilder angewiesen war, da kein uberragendes frzählertalent auftrat, welches die kiuftige Richtung bestimmt hätte, bemuihten sich die Schriftsteller, den meist von innen selbst aufgestellten Forderungen nach Durchdrinfung der literatur mit nationalem Geist gerecht zu werden, indem sie stoffe aus der vergangenheit des Volkes wählten und in Schwarz-Weils-Manier der vollkommenen Minderwertigkeit aller Fremden den wert der Serben hzw. Kroaten gepenubersteliten. Eln typisches Beispiel hierfür sind die Frzählungen Dragojla Jarnevitevas, in denen die fehlende Innere Bezlehung zu den Ausdrucksmöglichkeiten der 
eleenen Sprache zu elnew seltsamen Kontrast zwischen den tendenziös-nationalistischen Inhalt und einer deutlich von der Struktur elner fremden Sprache beeinflubten Ausdrucksweise rithrt.

Wie viele Zeitgenossen, war Dragojla Jarneviteva im deutschen Gelst erzogen worden und hatte nach lhrem eigenen zeugnis in 1hrer Autobiographie "Žlvot jedne žene"(erst 1958 vollstăndig veröfentlicht) erst als Erwachsene richtig Kroatisch sprechen und auch schrelben gelernt, nachdem sie mit der 1llyrischen Bewe gung bekannt geworden war. Im Vorwort zu lhren "Domorodne poviest1" von 1843 hatte sie zwar darauf hingewiesen, dab ihre Erzăhlungen nach der Uberlieferung des volkes geschrieben selen, dies war aber, wie HAKAC sagt, sicher nur eine Ausrede( $7,5.10)$. Diese Virahlungen haben formal nicht die geringste Verbindung zur Volkserzahlung, von der doch wentgstens einige Elemente in den Text hatten eindringen missen, falls irgendeine Beziehung zur mindlichen Uberlieferung bestiunde. Betrachtet man $z \cdot B$. die Erzăhlung "Žrtve 12 ljubavi 1 vjernost 1 za domovinu"( 95,S.15-38), so stellt man fest, dals ihr stil viel mehr Gemeinsames wit zeitgenössischen theoretischen Abhandlungen hat als mit dem St1l der Volkserzälung. Die satze sind lang und umständlich, voll abhinglger Konstruktionen, nicht selten steht das Verb nach deutschem Muster am SchluB, und ganze Passagen sind offensichtlick Wort fiir Wort aus dem Deutschen ubertragen, wofur auch zahlre1che lehnibersetzungen sprechen, wie z.B.

-.1 pusti in u svoj šator dot1 (5.23)

und labt sie in sein zelt kommen

..oružje pružiti (die Waffen strecken) (S.24)

Fis geht hier nicht um die bekannte Tatsache der lehnubersetzungen $1 \mathrm{~m}$ Serbokroatischen, die es ja lmmer noch in betrachtlicher Menge glbt, was Im Zuge der Entwlcklung der Sprache unverme1d$11 \mathrm{ch}$ war; es geht darum, daB im Text Jarnevitevas keine Spur des "lebendigen Wortes" existiert, wie dies z.B. bel dem keineswegs von deutschem EinfluB freien Antun Nemtit der Fall ist. Bel Jarneviteva spricht der einfache Bauer z.B. Folgende Satze:

"Duśe m1l ovime se netu nikadai kako bl t1, paśo, ovo zaht1jevat1 mogo? Ovo kroza to bl ja propast moje domovine uskorio i nju joft vetemu haranju izvrgo? Moj Cako me naut 1 jubiti domorinu, 1 kada b1 bilo za njezinu korist, 1 isti zivot joj Krtvovati, a ne veljaše m1 nikada da leem pa da ju lzdaj 1 duśmana joj u srce rod1.. (S.25) 
Die Worte der todesmutigen kroatischen Bhuerin lauten dementsprechend:

Prijeti, pašo, kako ti drago, t1 ga neteš nestalna praviti; 1 jubav 1 vjernost $2 a$ donovinu au je prevaznija, 1 toga radi te eve muke lasnije podnaśati. Duinost mu je Zivot supruge 1 djeteta rtedit1, nu jorte veta domovinu cijeniti, 1 za njezinu korist svaku thu odsloniti....etc. $(47,5.27)$

Der Patriotismus, der die Movelle Jarnevitevas vom ersten bis zum letzten Satz prägt, kommt in einer form zun Ausdruck, die weder zur mündlichen Rede noch zum Erzkhl ton der Volksuberlieferung irgendeine verbindung aufelst. Die einzigen Anklinge an die gesprochene Sprache sind in dieser Novelle einigo Ausrufe wie "Lh dobrol" oder Anreden wie "brajne" sowie Hinwelse auf den 181 amischen Glauben des Sprechenden durch Bemerkungen w1e "Dina mi, kaure..."; "T1, krăčane..." etc.

Das Pathos Jarnevitevas erscheint direkt aus drittklassigen deutschen Erzahlungen der zeit bezogen und lot weit entfernt von der groben Geste und der lepidaren Formulierung, wie sie traglsche Höhepunkte der Volkserzthlung, z.B. In der sammlung Marko Miljanovs (78), kennzeichnet (vgl, auch die Beispiele von PAVICEVIC und VRČEVIĆ unter III.3.4.5. bxw.III.3.4.6., "Metapher", In der vorliegenden Arbeit).

Angesichts eines solchen Erztihlstils, der einesteils von der Struktur einer fremden Sprache bestimmt ist, andernteils dem Wesen der Erzahlkunst des elgenen Volkes zuwlderläuft, erschetnt die nationalistische Tendenz der Movelle wie aufgepfropft. Die Lovelie, die auber einigen Ortanamen nichts spezifısch Kroatisches enthält, könnte ebensogut, wie Senoa es formuliert hat, "irgendwo tn Tungusien" spielen, wenn wan ein paar Namen auswechselt. Es handelt sich also um einen versuch, mit uberaus vordergrundigen Mitteln eine "nationalen literatur zu schaffen, was im übrigen fur den größten Tell der sogenannten "Turkenliteratur" zutrifft. 
Als weiteres Belspiel rein additiver Kombination nationaler Ideen mit dem Stoff elner Novelle sel Bogovits nfilo za ognj110" (1856) genannt, die als elne seiner besten No velienglit. Sie stellt elnen vollkommen anderen Typ dar als die erwăhnte Novelle Jarnevitevas und hat bereits ein weit höheres literarisches Niveau. Es handelt $\mathrm{Blch}$ um eine Geschichte aus dem Leben der Kleinstadt Krizevci; im Mittelpunkt steht die Liebesgeschichte elnes jungen Grafen und elnes Bürgermädchens, die das unzahlige Male behandelte Thema des standesunterschiedes aufgrelft; parallel hierzu wird vom "Konkurrenzkampf" zwischen einer stadtischen Klatschbase - elner spitzziinglgen, aber noch schönen vitwe - und Inrem minnlichen Pendant, elnem gelstrelchen jungen Advokaten, berlchtet. Helde Affären enden nach allerlel Hindernisien mit der glucklichen Heirat.

In diese anspruchs lose Erzählung, die an die deutsche Unterhaltungs literatur des $19 . J a h r h u n d e r t s$ erinnert (vel. Wilhelm Hauffs Clauren-Parodie "ler Mann im Mond"!) urd die in einem munter platschernden Stil berichtet wird, der an Bogovits Freund Nemčlt anklingt, sind elne Relhe von Hinwelsen auf die altkroatische, schlichte Lebensart, auf das aufrechte kroatische Wesen elngeflochten, die in einer solchen, im leichten plauderton gehaltenen Novelle recht unmotiviert erscheinen und übrigens für den Gang der Handlung keineswegs notwendig sind. Es 1st, als häte Bogovit, der sich als Schriftsteller als "Lehrer des Volkes" im Sinne der Aufklärung verstand, elne Art Legltimation für diese etwas oberflächliche, westlichen Vorblldern folgende Novelle gebraucht. Bogovit war gewiB ein uberzeugter kroatischer Idealist, und in seinen Aufrufen, Artikeln usw., die geradezu den Charakter agitatorischer prosa haben, wirkt sein Nationalismus echt und überzeugend; in selnen Novellen, die er nach den herrschenden Klischees der Romantik verfabte, erscheint dieser Nationalismus entweder überbetont, wie Ljerka SEKULIC In bezug auf die Novelle "Slava 1 jubar" (1,854) nachweist (101,S.142), oder, wie in "Šs1lo za ognj110", addit1v, aufgesetzt. Man hat das $G_{p}$ fuhl, der gewissenhafte Schriftstelier erinnere sich von zeit zu zeit seiner Pfilcht, "narodno", also im Gelst des Volkes, zu schreiben; in den mit 
leichter Hand hingeworfenen Dialogen gelingt ihm dies teilwelse, wahrend die Bezugnahmen auf die alte kroatische Lebensart in ihrer Ernsthaftigkeit im Widerspruch zu dem ubrigen Stil stehen, vgl. 2.B. die Hăufung solcher Hinwelse in der szene, in welcher der junge Graf im Hause der Geliebten selne Aufwartung macht:

"Oprost1te, gospodine grofe", reze Mladenovit, primiv prijazno Ljudevita za ruku, "što vas zaustavljam... Ja sam starl Hrvat, pa ne hajem mogo za kojekakve et1kete, vet se držım iskrena 1 srdaCna običja preda svoJih, koji mile goste pridrzavahu na svaki moguti natin. .....

"Ali gospodin grof morat te oprostiti," primjeti gospoda Mladenovicka prijazno, "te se zadovoljtil obilnim hrvatskim objedom."

"Mol1m, milostiva gospodo", reCe l,judevit, nakloniv se, "Ja sam pravi hrvat, te isto tako, kao ni vas gospodin suprug, ne gledam na kojekakve oblitnosti, koje nam samo domat 1 nas $z_{1}$ ot truju 1 otegotuju.... $\cdots$

"Tako valjal" reče domatın.......Hvala Bogul evo vidim, da još Ima u vǐ̌ı našlh kragovih pravih Hrvata." $(85,5.460 / 461)$.

Ventger aufdringlich wirken demgegenüber die als Abschwe1fungen eingeschobenen Schilderungen der Lage eines nichtadeligen Advokaten vor dem Jahre 1847 oder der glorreichen Vergangenhelt der Klelnstadt Križevci, da sle den leichten Konversationst on selbst bel der Frwahnung unerfreulicher Tatsachen wahren, oder die Bezugnahme auf den slavischen Liebesgott I.eljo - anstatt auf Amor, wie sie in Westeuropa, aber auch be1 Nemte 1t, üblich war. (S.439; S.447; S.444).

Bogovis Novelle "Šilo za ognj1lo" stellt gewiB einen groben Fortschritt im Vergleich zu der oben besprochenen Novelle Dragojla Jarnevitevas dar; die Hinweise auf Kroatien, auf kroatische Wesensart etc. erscheinen hier aber ebenso gewaltsam wie der dick aufgetragene Patriotismus der Novelle "Žrtve $1 z$ ljubavi 1 vjernost1 za domovinu" von 1843. Die "narodnost" 1st in belden fallen nicht unmittelbar, nicht original, nicht Bestandtell der eigentlichen Substanz der Erzählung; sie bleibt daher auberliches, zeitbedingtes Dekor.

In den unter IV.4. behandelten Beispielen ist es demgegenüber den Schriftstellern gelungen, nationale Elemente tatsächlich in die Substanz ihrer Novellen einzubeziehen. 
IV.4. Einbeziehung von Stilelementen der Volksilteratur

In die innere struktur des Frzahlwerks

IV.4.1. Antun $N$ e m $t 1 t$ : "Udes 1.Judski" (1854)

IV.4.1.1. Gesamtwerk und Vorbllder

Antun Nemčit ist der erste kroatische Schriftsteller, der den feuilietonistisch-humoristischen stil prlegt, wie er sich seit Sterne in der westeuropäischen literatur entwlckelt hatte. Dieser St1l, der Nemeits scharfem Intellekt, selner Beobachtungsgabe und seinem sprihenden Witzentsprach, zeigt sich in seinem gesamten Deurre - der Keisebeschrelbung "Putositnice" (1845), der Komödie "Kvas bez kruha" (1847, gedruckt 1854, der ersten kroatischen Komödie nach Ubernahme des štokavischen als Literatursprache), dem unvollendeten Roman "Udes 1 judski" (1854 posthum veröffentlicht) und in seinen Artikeln und Feullletons.

Unter den damaligen Gegebenheiten in Kroatien stellt die Realisation elnes solchen stils elne beachtliche leistung dar, auch wenn Nemcit als hochgebildeter Mann viele westeuropäische Vorbllder hatte, wie DUKAT und SREPEL Im elnzelnen nachgewiesen haben. Diese Vorbilder waren hauptsachlich in deutscher Sprache geschrieben (Seume, Nicolal, Helne, evtle auch Sterne in deutscher Ubersetzung), tells französisch(stendhal) oder tschechisch (Kollar).

Es liegt nahe, auf der Suche nach Vorbildern Nemčlts an Gogol' zu denken, dessen Erzählungen zu Beginn der joer Jahre erschienen, also während der Anfangszelt der 1llyrischen Bewegung,die nicht nur die suidslavische, sondern auch die gesamtslavlsche Idee verfocht. BARAC berichtet, dab im Zuge der slavischen Begelsterung vorwiegend slavische schriftsteller ibersetzt wurden (5,S.124-125). An russischen Autoren, die in der "DANICA" vertreten waren, nennt er Pußkin, Pogodin, Bulgarin, Karamzin; Vraz hat u.a.Jazykov, Lermontov, Karamzin ins Kroatische ubersetzt. Sicher waren die Illyrer uber eine so hervorragende literarische Erscheinung wie Gogol' Informiert; im Erscheinungsjahr der "Mertvye duši", 1842, wird in Vraz" "Konn" darauf Bezug genommen, aber erst 1865 wird dieses Werk ins Kroatische Ubersetzt. Von Gogol's Firzählungen wurde erst 1848 "Nos" $1 \mathrm{~m}$ "Opt1 zagrebački koledar" kroatisch abgedruckt, 1856 "Starosvetskie pomešlk1" und "Taras Bul'ba" In "NFVEN". Die "Zaplski sumaşedß̌ego" wurden ab 1853 in der "DANICA Il,IRSKA" verörfent 1 1 cht, je- 
doch nicht vollständig; "Šinel'" erschien 1864 in "DOMOBRAN"'. Obwohl Gogol's "Mertvye duś1" und "Taras Bul'ba" bere1ts 1846 Ins Deutsche ibertragen wurden(von Löbenstein baw von Bode, beide Leipzig 1846), also noch zu Neme16s Lebzelten, findet sich bel den Kommentatoren, die, angefangen von Bogovit, die thw bekannten Schriftsteller sehr genau anfuhren, kein Hinweis darauf, dab er sich mit dem Werk Gogol's bzw. mit der russischen Literatur grindlich beschaftigt habe, wie z.B.Vraz; dagegen hat Nemčlt selbst oft auf die deutsche literatur und, In den "Putositnice", auf Kollár Bezug genommen (nach DUKaT ca.20mal; 28,5.143).

In der kroatischen Literatur gab es fur Nemelt so gut wie gar kein Vorbild, auch nicht für elnen ernsthaften Prosastil. D1e Erzahlungen Demeters (1844-1846 in "ISKRA" erschienen). Vukotinovits ("Pjesme 1 pripovijetken, 1838) und Kukuljevits ("Razlicita djela", 1842-47) waren ebenso wie die 1843 von Dragojla Jarneviteva veröfentilchten "Domorodne poviesti" sprachlich schwerfallig und folgten inhaltilch dem Schema der romantischen Ritter- und Liebesnovelle; vor der Kritik eines Schriftsteliers, dessen literarische Tatigkelt bezelchnenderweise mit satirischen Gedichten begann(nach Vraz uibrigens den ersten Versuchen "leichter" Poesie in kroatischer Sprache) durften diese novellistischen Versuche kaum Bestand gehabt haben, auch wenn er sicher die patriotische Tendenz dieser Autoren anerkannte und teilte.

\section{IV.4.1.2. Das Sprachproblem}

Eine weitere Schwierigkeit ergab sich für Nembit aus der Tatsache, dab er - Im Gegensatz zu Jurkovit und Korajac - aus elnem kajkavisch sprechenden Geblet stammte, aber śtokavisch schrelben mulste, nachdem die Illyrer diesen Dialekt 1836 als Schriftsprache ubernommen hatten. Damit war - wie FLAKER schrelbt - "die kroatische Literatur von der an volkstumlichen

'nach A.FLAKER: Prijevodi s ruskoga 1 hrvatska književnost 1836-1892, in: 32, S.262-263. 
Elementen reichen kajkavischen Literatur losgelöst. aber auch vom ZurluB volkssprachlicher Elemente aus jenen Gebieten, um die sich die kroatische Nation im ersten Drittel des 19. Jahrhunderts gesammelt hatten( $34,5.69)$. Zwar empranden die dem engeren Kroatien entstammenden Schriftsteller das \$tokavische nicht als etwas Fremdes - es war Ja die Sprache der Dubrovniker Dichter; dennoch war es fur sie nicht leicht, sich darin auszudrucken, wie DuKat betont: vielen Satzen Nemcits merke man an, dab sie zunachst deutsch gedacht und dann müsam ins Kroatische ubertragen worden seien; Nemčlt, der "tvrdi kajkavac", hatte Schwierigkeiten bel der Formulierung \$tokavischer Sätze gehabt (28,5.253).

Der hochgebildete Nemcit stand seinen eigenen literarischen Versuchen sehr kritisch gegenuber. Im Vorwort zu der Reisebeschreibung "Putositnice" sagt er selbat, er veröfrentliche ste nur deshalb, weil

ein Volk, das gerade erst mit seiner geistifen Bildung begonnen habe, nicht sofort in die Tiefen ernsten Wiesens hinabtauchen wolle, sonderri nach Art eines Schmetterlings auf die bunte Blute (d.h. die lelchte lekture) fliege.. ( $84,5.33)$.

IV.4.1.3. Kommentare

Das besondere Verdienst Nemčlts liegt darin, zu einem Zeitpunkt, da sich die elgene Schriftsprache uberhaupt erst formiert, einen persönlichen Stll zu finden, der nach BARAC dem westeuropaischen Stil des ersten Ixittels des $19 . J a h r h u n d e r t s$ entspricht ( $5, \mathrm{~S} .255$ fr.) BARAC zählt Nemtit nächst Mazuranit, Vraz und Preradovit zu den besten Schriftstellern des Illyrismus und sieht in Ihm - Im Hinblick auf die Hilfiosigkeit der meisten anderen "Illyrer" - einen der Begrinder der kroatischen Prosa. Auch DUNAT ( 27, S.10) nennt inn einen Kunstler. der sich uber das sehr durchschnittilche Niveau selner zeitgenossen erhoben habe, und stellt Kukuljevit als Gegenbelspiel hin; Nemčlt habe in seiner Prosa einen eigenartigen narrativen St11 gerunden ( $27, \mathrm{~S} .11)$. Ebenso wie JEŹLC(48.S.17) betont DONAT die literarische Qualitat der Relsebeschreibunpen Nemð̌lts und Matija Mažuraniles (Pogled u Bosnu, 1842). 
IV. 4.1..4. "Udes 1judskin: Gattung - Kompos1t1on -

Erzahltechnik - Milieu

Das Fragment "Udes ljudski" aus dem Nachlaß Nemtits, erst 1854 von Bogovit in "NEVEN" veröffentlicht, ist eln unvolldeter Roman; hätte der Autor ihn beenden können, wäre er ca. 20 Jahre vor Šenoas "Zlatarevo zlato" - der erste Roman der neueren kroatischen Literatur. Kommentatoren wie ŠREPEL, DUKAT, JEŽr síc sich darin einig, daß die ersten beiden Abschnitte zusammen mit einem Tell des dritten Abschnittes eine in sich geschlossene Einheit, eine abgerundete Novelle darstelien. Im Rahmen einer Betrachtung der frihen kroat1schen Novellistik kann deshalb auch dieses Frapment herangezogen werden, wobel allerdings auch auf die weiteren Kapitel eingegangen werden soll.

Aus dem vorliegenden Text geht nicht hervor, in welchen Zusammenhang der Verfasser die "Vorgeschichte" mit der Haupthandlung zu bringen beabsichtigte. Interessant ist aber, daB diese Vorgeschichte das gleiche (altbekannte) Motiv behandelt wie die elgentliche Fabel: in beiden Fallen geht es um den Widerstand der Eltern bzw. des vormunds gegen die Vereinigung eines liebespares. In der heiteren Vorgeschichte fihrt die Intrige zur Hochzeit der liebenden, in der ernsthaften Haupthandlung dagegen nach Art vieler Ritterroinane - zunächst - zur Trennung und zur Hochzelt mit einem ungeliebten Mann. Dennoch scheint das Vorspiel auf ein gluckliches Ende des Komans hinzudeuten; es liegt nahe, dab Nemkit an einer solchen ironisierenden Parallele in der Komposition ein intellektuelles Vergnügen gehabt haben könnte.

In der Erzaihlung vom "budala" Bolto Petrinil, seiner Liebe, seiner Heirat und seinem späteren Leben spielt Nemčll das Thema "Hosen" in allen Variationen durch - sie sind offenbar das $I_{n}$ teressanteste an Petrinit; sowohl seine Charakterisierung als auch die innere Komposition der kleinen Novelle entfalten sich $1 \mathrm{~m}$ Zusammenhang mit Hosen, die damit dem Humoristen Nemčlt als "Falken im Sinne der Theorie Heyses dienen. petrinils "tako napete starohrvatske hlače da bl mučno bilo šivaticu provuti" (S.274) sind Symbol seiner Heimatliebe, seines Traditionsbewubtseins und seiner Mainnlichkelt. Dals er 
sich auf GeheiB seiner Frau von ihnen trennen muls, beweist sein Pantoffelheldentum. Noch ehe er Valpurga heiratet. zerreibt er sie sich symbolisch beim letzten Rendezvous an einem spitzen $\mathrm{Zwe}$ - und zwei seiten vorher schon wird Valpurga mit einem "Dorn in seiner Ferse" (s.273) verglichen. Der Abschied von diesen Hosen erfolgt denn auch "rascriljenim srcem" :

Jedva da je ikoji aga pod obnoviteljem Mahmudom onako tužno svoje dimlije o klin obesio kao Petrinit -

denn

ove čakšire bile su nijemi svjedoci mladanih njegovih pobjeda; kajasom ovih hlata opasao je nekot svoju valpureu,... (s.273/274).

Selbst das Alter der geliebten Valpurga umschrelbt deren Mutter, indem sie sich an einen Vorfall im Zusammenhang. mit Hosen erinnert:

Toliko znadem...da za vrijeme kad su Mafari pantalore pal11i. joł ni bcossatse dobro igrala nije..(S.274)

In all diesen scherzhaften Vergleichen und Umschreibungen stecken zupieich Hinweise aut aktuelle verhältnisse und t..tsachliche Vorkommisse, die Nemtit so in den heiteren Flub seiner Erzahlung mit einbeziett; er ironisiert, wo andere Zeitgenossen pathetisch werden.

Die Erzähltechnik Nemčits entspricht dem stand seiner aulserkroatischen Vorbilder. Rückwendungen und Vorausdeutungen werlen geschickt einfesetzt, szenische Darstellungen wechseln mit lirzahlerberichten und betrachtungen ab, alle frscheinungen sind durch das Prisma der Subjektivitä des Autors gebrochen, dessen Allwissenheit ausdrücklich betont wird,z.B. in der Beantwortung der typisch romantischen rhetorischen Frage :

Tko te proučti sve tajne jednog zatravljena srca? Tko? - Cudno pitanjel Tko drugi do sveznajuteg Boga, zatim onoga koji trpi, 1 nas kofim su svekolike tajne otkrite! (S.281)

Inwieweit es Nemčit hinsichtlich des Mllieus der Romanhandlung bewulst um die - erstmalige - Darstellung des zeitgenössischen bürgerlichen Lebens in Kroatien ging, wie ŠRFFL und DUKAT erklärt haben, wăhrend DONAT diese Auslegung für "allzu 
frei" hält(27,S.21), ist schwer zu beurtellen, da das Fragment Im wesentlichen durch Handlung, Charakterschilderungen, Dialoge und Betrachtungen, wentger durch die detallilerte Darstellung der Verhaltnisse gekennzeichnet ist. Die Absicht, von der romantischen Schwarz-Weib-Malerei loszukommen und gleichzeitig den leser zu fesseln, wirde jedenfalls mit der Wahl eines vertrauten Milieus durchaus im Einklang stehen.

\section{IV.4.1..5. Romant1sche Stilelemente}

Es wurde schon gesagt, dab Nembil in der kroatischen Literatur keine Vorbilder fur den von thm angestrebten leichten St1l hatte; seine Art zu schreiben folgte herrschenden europäischen Tendenzen.

Eine Reihe stilistischer Verfahren des Sentimentalismus und der Homantik hat Nemčlt ubernommen, z.B. die häufigen Hinwendungen zum Leser, die bis zur fiktiven Diskussion mit thm fihren, die persönlichen Kommentare des Autors oder den komischen Vergleich, wie thn besonders Heine gepflegt hat. Nem $X_{1}$ erzahlt - wie Karamzin - im Stil der Konversation, aber diese Konversation lst weit weniger durch gefuhlvolle Ausrufe und Ergisse gekennzelchnet als vielmehr durch witzige Metaphern, Wortspiele und Flguren sowie durch Ironisierung des sentimentalen Stils.

\section{4.1.6. Elemente der Volksliteratur im St1l Nemčlts}

IV. 4.1.6.a. NemXits Beziehung zur Stokavischen und zur Volks literatur.

DONAT hat mit Recht auf den engen Zusammenhang des von Nemčlt gepflegten Stils mit der mundlichen Rede und threr auf der Improvisation beruhenden Leichtigkeit hingewiesen (27.5.17); "zum erstenmal", schreibt er, "begegnen wir in der kroatischen Literatur des $1.9 . J a h r h u n d e r t s$ der lebend1gen Sprache des Erzählers". Obwohl diese Sprache durch syntaktische Konstruktionen nach lateinischem und deutschem Muster belastet ist (z.B. häufige Stellung des Verbs am Satzende). Ist sie aufgrund vieler, bewust "müdlicher" Stilver- 
fahren ein frihes Beispiel des "Skaz" der kroatischen Erzählkunst, wie er später durch Schriftsteller wie Senoa oder Ante Kovatit in vollkommenerer Weise verwirklicht wurde. Wie sehr ein solcher Stil Nembit lag, beweisen seine an ahnlichen Wendungen relchan Briefe.

DUKAT, der beste Kenner Nemčlts, schreibt:

Das wesentlichste Anliegen des humoristischen Schriftstellers ist es, unterhaltend, interessant und scherzhaft zu sein $(28,5.159)$.

Zu unterhalten, zu fesseln $13 t$ auch eines der Hauptanliegen des Volkserzählers, auch wenn er zudem noch eine moralisierende Absicht hat, wie ja auch die meisten Schriftsteller dea 19.Jahrhunderts. Der Plauderer Nemcit bedient sich hierzu nicht selten der gletchen Mittel wie der Volkserzahler. we1l os jene stilistischen Möglichkeiten sind, welche ihm die elgene Sprache bietet.

In diesem Zusammenhang sel erwähnt, dals Nemčlt nicht nur ein guter Kenner der lateinischen, deutschen und französischen Literatur war, wie Bogovit berichtet 1 sndern auch der Dubrovniker Dichter, von denen er Gundulit und Bordic besonders schätzte, und der Schriften Dositej obradovits. Wärend seiner Zagreber Jahre (1829-1836), In denen er sich der 111yrischen Bewefung anschloß und mit romo Blažek, einem verehrer Voltaires, eng befreundete, hatte er sich diese Kenntnisge in relativ kurzer zeit angeeignet.

Doch nicht nur uber die lubrovniker Literatur, sondern auch durch die von den Illyrern hochgeschäzten Volkslieder. die in der "DANICA" immer wieder abgedruckt wurden 2 , konnte Nemčl mit dem štokavischen Dlalekt vertraut werden. Dals er sich damit beschäftigt hat, berichtet z.B.JEžIĆ Im vorwort zu den Werken Bogovits ( 48,5.342). Übrigens hat Nemčit die den Kapiteln von "Udes ljudski" vorangesteliten Motti Volksliedern entnommen.

1 Pjesme Antuna Nemlita. Izdao Mirko Bogovit. U Zagrebu, 1851. (Uvod: "Životopis Antuna Nemčlta".)

2 Die "DANICA" hat eplsche Lieder aus Vuks Sammlung abgedruckt, die aus stokavischen Gebieten stammten. Kukul jevit veröfientlichte im 4.Band der "pjesmen(1847) kroat 1 sche volkslieder aus stokavischen, takavischen und kajkavischen Landstrichen (vgl."Narodne pjesme puka hrvatskoga, predgovor" von Ivan Kukuljevit Sakcinski.

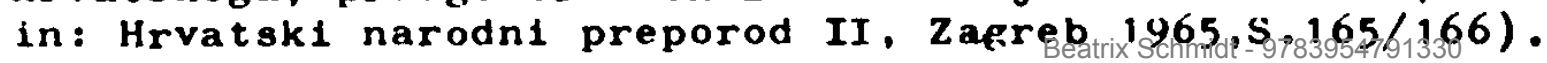


Iy. 4. 11.6.b. "Mündliche" Rede in "Udes ljudski".

In Nemétts Romanfragment lassen $1 \mathrm{ch}$ verschiedene Elgentulalichkelten verfolgen, die auf die muindliche Rede hinwelsen, und zwar in erster Linie auf die zwanglose Unterhaltung. Hierzu gehört jener"famlibe" Ton, den die Romantiker mit dem Volkserzähler gemelnsam haben und der nicht etwa in den langeren, fiktiven Diskussionen mit dem Leser, sondern in kurzen Hinwendungen anklingt:

Nu mi netemo čitatelja roditı stranputtcami, vet holemo da mu kažemo to je 1 kako je. (S.281)

To t1 je, dragi čıtatelju, jedna živa nakaza...(S.278) Immer wieder läßt Nemlit Wendungen der Umgangssprache in den Erzahltext elnfliebens

.. nu tako nam vjere.. (s.279)

- ako bog da - (S.280)

Nu treba $i$ to znatis da je Petrinit jur imao svoj krułac, t.j. da je jur javnu službu obavilo.. (s.276)

- zato su takovom prilikom obično malko kroz prste gledali... (s.276)

Das letzte Beispiel ist eine charakteristische uingangssprachliche Periphrase. Zu der Atmosphäre des privaten Gesprächs tragen auch eingeflochtene Gemeinplätze bzw. Sprichwörter bei, durch die sich der Leser in seiner vermutilch kleinburperlichen Mentalität angesprochen fuhlen mulste:

Slika vazda nade priliku (S.288)

Kratki su Kivota nagega dani (S.280)

.. ljubar bo je domiłıjata (s.286; Lehnubersetzung aus dem Deutschen?)

In den Dialogen sind Nemčtć einige bewulst umgangssprachliche und damit ziemlich realistische Passagen gelungen, z.B.labt er den sich betont bieder gebenden Bösewicht Grbovit sagen:

Da,da...sjajan je, kako mogol kažu, taj vojniłki stalez, ali što se mene tite, lpak mislim da sve $z l a t o$ nije $\zeta_{0} \mathrm{sja}$, a volim da mi je uvijek sigurna na ramenih glava nego da je nosim svaki čas u torb1.. (S.287)

In diesen wentgen zellen sind bereits zwel typische rolkstiumliche Umschreibungen und ein Sprichwort enthalten, wie 
sie auch der Volkserzähler gern verwendet. In diesem Ton

ist auch der schlubsatz des Fragments gehalten:

...mnogobrojni puk...zavapi: "Mili bož, ala je

sretnal" Nu mi znamo da bał nije uvijek sveto

pismo što puk govori. (S.290).

Diesen Beispielen gegenuber wirkt z.B. die Diskussion mit dem leser uber die Tugend streckenwelse allzu gesucht und maniriert.

An die Improvisationen einer geistreichen Konversation erinnern auch jene, nach dem Muster bestehender Wortfiigungen gebildeten, scherzhaften Neologismen wie "jezikoćlstitelji" (S.273), "franceski sjednatitelji" (S.274) etc. Ein Ironischer Seltenhieb auf die Puristen ist es librigens auch, wenn Nemtit das wort "grozdoteg" mit der in Klammern folfenden Erklarung "magnet" ergänzt (S.283). Die Mode, lateinische Zitate ins Gespräch einflieben zu lassen, lronisiert Nemtit durch witzige Uhersetzungen, z. B.

"virtus in medio" to jest: krepost se u torbi nalaz1. (S.278),

die wie ein momentaner Einfall in der Unterhaltung wirken.

Manchmal năhert sich Nemčlts stil der spontaneität münd11chen Erzählens an, z.B. In dem folgenden Bericht, der noch ein wenig umständlich beginnt, dann aber mit immer kürzer werdenden Satzen die lebhafte Antellnahme elnes Sprechenden an der aufregenden Geschichte wiedergibt:

U taj se par usvrne nesretni ljubovnik 1 videti prijetetu smrt, hote da joj se ukloni, - nu tim se niz stablo spuYtati pote, - zadjene se za ostru granu...neko praskanje se zacuje, napete se hlace od kuka do sare razderu, vruta krva oblije stegno nesretnika, a u isti mah 1 pułka puðe...l1̧će załušti... Bolto se srułı pod jabuku, - a Valpurga onesviještena pade pod tri rijive...(s.275).

Allrin diese kurze Szene bestätigt die Bemerkung BaRAC', dals Nemčlt "um die Kraft des Satzes und den Wert des Rhythmus gewubt habe" ( 7, S.13). 
IV 4.1.6.a. Stilmittel der Volksliteratur in "Udes ljudsk1"

Dem Humoristen Nemčit, dessen Stil eln frühes Beisplel des komischen Skaz in der kroatischen Literatur darstellt, boten sich nicht nur die Moblichkelten der Umgangssprache, sondern auch die Stllverfahren der mündlichen Dichtungen und Volkserzahlungen an, die ja oft von den ersteren kaum zu trennen sind, wie einige der bisher angefunrten Beispiele zeigen.

Der komische Vergleich und die komische Metapher, jene so wesentlichen Elemente des feuilletonistischen St1ls, durften sich nicht auf klassische Anspielungen beschrilaken (z.B. auf Amor,S.284; "iz pandža kletog cerbera",S.286;"Argovim očima", S.289); sie muBten auf bekannte, volkssprachliche Bilder zurückgreifen, um elnerseits den ungebildeten weser anzusprechen, andererseits dem gebildeten, westeuropäsch orientierten Leser die Ausdrucksmöglichkeiten der eigenen Sprache bewuBt zu machen.

Bel Nemঠit finden sich volkssprachliche Vergleiche und Metaphern sowohl in ernsthafter wie in tronisierender Absicht, wobel dies nicht immer klar zu unterschelden lst; selne elgenen Prägungen dieser Art fugen sich sowohl semantisch wie formal in diesen Rahmen.

An volkstumlichen Vergleichen finden sich z.B.

- te tako osta sama kao ribica u osuśenoj struzi (s.282)

- kano ptitica u zelenoj dubravi (282)

oder die Periphrase

...kao bl najbolje ovo janje ostriti mogao ( $\$ .283)$.

Die als Rückwendung erzählte Liebesgeschichte Lucijas und Davorits verwendet - wie bereits die Vorgeschichte - die Terminologie des Heldenlebens im Zusammenhane mit der Eroberung des "sogenannten" schönen Geschlechts:

. svaku feudalnu tvrdu jurišem preoteti (5.274)

. mladahna 1 ponosita njegova duša nije hleptjela za toli jeftinom slavom (S.282)

und geht dann in elne weit ausgebaute Metapher uber, die eine solche Fulle volkstülicher Tropen beinhaltet, daß sie ironieierend wirkts 
Pravi lovac kome za okom 1 tane leti, slabo haje za polupitomu zvjerad u zvjerinjaku, vet on nastojl da ulovi plahu kơ̆uticu u gori zelenoj. Lucija dakle postade cilj smiona lovca Davorita....

...A smioni lovac bał dobro nanib̆ani, jer ranjena koß̌uta pade u krilo goranskom sokolu, nu mrki 12 gorlce vute ugrabi mu - kako temo vidjeti - skoro Zeljno osvojent plijen. (s.282)

Der komische Verglelch, der die Verhelratung elner nicht mehr sehr jungen Adligen umschreibt ("nježno djevojče 1zmedu 1.5135 godina", $\mathrm{S.274)}$ wird analog zu vielen volkssprachlichen Vergleichen $1 \mathrm{~m}$ vertrauten Lebensbereich der Landwirtschaft durchgefuhrt:

Valpurga bijaše posljednje neposijano zrno plemenite 1 plodom blagoslovljene obitelj1 Pozvanovita. Ziłk1 malo łto nisu vet izjeli jezgru ovog zrna, - kad se eto 1 za njega bostandźlja nade. (S.274).

Beispiele metaphorischer Redewelse nach Art volkstimlicher Redner - und Prediger - sind im Text sehr häufig, z.B.

.. da te po svoj prilici mnogo krajišnilkih kapa pustih 1 lubovca u crno zavitih ostati (S.287)

(womit gefallene soldaten der Krajina und lhre trauernden Mädchen und Frauen gemeint sind).

Auch der lapidare Stil der volkstumlichen Rede hat be 1 Nemčit seinen Niederschlag gefunden, hier mit deutichem Parallelismus und markantem SchluB:

Jedan žıvalj, kao znamo, unı̧̌tuje drugı;

jedna strast takoder unistuje 111 barem slabi drugl.

To je vazda bilo tako, pa te biti tako u napredak

dok bude svijeta 1 vijeka. (S.286; keine direkte Rede.)

Was iber die Vergleiche und Metaphern gesagt wurde, gilt auch fiir elne Reihe anderer Figuren, die zu der bizarren Wirkung seines Stils beitragen. So sehr der Schriftsteller auch dem gebildeten Europa verhaftet ist und $\mathrm{s} 1 \mathrm{ch}$ von bestimmten Klischees nicht freimachen kann, spürt man doch 1 mmer wieder das lebendige Wort eines echten Erzahlers, der die Mittel seiner Muttersprache einzusetzen und auszubausn sucht. Zu diesen Mitteln gehören, wie unter III.3.4. dargelegt worden 1st, der Parallelismus, die dreifache Stelgerung, die semantische Reduplikation, die Figura etymologica, das wortspiel, die Kumulation, das Sprichwort. Nachstehend werden hierfir einige Belspiele herausgegriffen. 
Paralle 118 mus

I tako osta obitelj Pozvanovil bez jedne velike brige, a gospodin zupnik bez stole. $(\mathrm{s} .277)$

-.njega tješimo time da temo pripovijest, కto ju s ovom budalom zapotesmo, sa gursuzom nastavit1. (s.278)

Dreifache Ste1- Kod prve rigure kotiljone otadose jedan drugerung gome figure razlagati, kod druge figure se k njima tiho prikrade poznati mali djezarac - lukom 1 strijelom, pa on nanibani - "zape strijelu za zlatnu tetivul"...strijela poleti 1 obrant u jedan par dva srdašca mlada; 1 to b1 vrlo zanimiva figura; a kod trebe flgure razgovarahu se jur o dvjema cudnovatim figurama, 1 to je bio gospodin tutor 1 njegova punica. To su bili vragovi prijeteti raju mladahne l jubavi njthove. (s.283-284).

semantische RePetrintt......kad malko ponarastoše mnogoduplikation und Vergleich

Figura etymo$\log 1 \mathrm{ca}$ brojna djeca......nao bi se 8 nj1ma javno šetatı pa se je tad kočlo 1 prťlo kao kapun kad tude pilike rodi. (S.277)

Wortspie 1

(Paronomasie)

..zvjerad u zvjerinjaku (S.282)

- Jedna živa nakaza medu živutimi (278)

..što jedanput izumi 1 naumi ...(\$.287)

Ali pustimo razmatranja koja bi u predgovor došla blla, da mi umjesto predgovora ne volimo prigovore pisat1...(s.278)

Ovaj bezbożnt brak dohvatio se usprkos vicl 1 kricl lpak boZjeg blagoslova..(s.277)

Kumulation

..koliko ih lzdahnu pod bremenom teškog siromaštva, sramote, nuzde, nevolje 1 tuge 1 - $(5.279)$

sprichwort, Sentenz

Ruki ruku pere, a obje lice (S.290)

ojentca u kasno jesensko doba 1 na pljevu sjedne $(5.274)$

Die Aufzählung solcher Beispiele könnte beliebig fortgesetzt werden. Schlieblich sei noch darauf hingewiesen, dals Nemčlt auch auf Gestalten der Volksuberlieferung Bezug nimmt. In der Beschrelbung des Vormunds Grbovit verglelcht er diesen mit elnem "pasoglavac" und"vukodlak" (S.279), wăhrend die drel Klatschbasen "tri usude" genant werden (S.284). 


\section{IV.4.1.7. Zusammenfassung}

Mit all diesen Beispielen sollte gezeigt werden, daB Nemcit nicht nur, wie oft gesagt worden ist, den in Westeuropa bzw. in Ruseland ausgebildeten humoristischen Stil nach Kroatien ibertragen, sondern darüber hinaus auch elemente der müdlichen Tradition in seinen stil einbezogen und weiter entwickelt hat, indem er sie in neuer weise wirksam machte. Die in der Volksliteratur vorgegebenen ornamentalen Figuren und stilistischen verfahren konnten humoristisch eingesetzt werden; der intime Charakter des feuilletonistischen Stils gestattete das Aufgreifen von Wendungen des verbreiteten muindlichen Erzählstils.

Mit seinem Versuch, auf dem Weg uber die lelchte Form das Leserpublikum zu erreichen, hat Nemtit sicher einen gangbaren Weg eingeschlagen, auch wenn seinen eigenen werken kein allzu großer Erfolg zuteil wurde. Fur das Fragment "Udes l judski" ist dies wohl in erster Linie auf die Unvollständgkeit des geplanten Romans, gewils aber auch auf den vom Sentimentalismus geprägten, nicht immer an den besten deutschen Vorbildern orientierten Geschmack der ieser zurückzurühren. Ljerka SEKULIĆ (1n1, S.141) nennt in diesem Zusammenhang die Idyllen S.Gessners und die Erzăhlungen Zschokkes, die ubersetzt und z.Tl, auch in der "DANICA" abgedruckt wurden; diese Autoren waren, ebenso wie Chr.v.Schnid oder Auerbach, dem gebildeten Publikum auch in der originalsprache zugänglich, wenn nicht sogar lieber, und es konnte zu seiner Unterhaltung auch auf die deutsche Trivialiteratur zurickgreifen. Mirko Bogovit hat sich daruber beklagt, dab die deutsche literatur "po nesreti" in kroatien am bekanntesten sei(101,S.140). Die gute Aufnahme der Novelien Bogovits $(101,5.137)^{1}$ beruhte vielleicht daraur, daB sie dem gewohnten stil eher entsprachen und zugleich die aktuelle Forderung nach Volkstümlichkeit mit sehr vordergrundigen Mitteln - historischem Thema, Einflechten pathetischer Hinweise auf

1."Slava 1 ljubar" und "Vidov-dan na Lobor-gradu" erschienen ebenfal 1s 1854 in "NEVEN", "Krvarl most u Zagrebu" 1856; "Șilo za ognjilo" erschien 1856 in"NARODNE NOVINE". 
die ethischen Werte der eigenen Nation - befriedigte. Auch hat Bogovit die erhabene nationale Idee nie ironisiert wie Nemtit, der bestimmten pseudo-patriotischen Erschelnungen kritischer gegenüberstand und sogar das Heldentum, dieses In Zeiten völkischer selbstbesinnung so empfindliche Tabu, von seinen Seltenhieben nicht ausnahm; so schreibt er uber den - mit dem sprechenden Namen Davorit gekennzelchneten Helden von "Udes l judski", als dieser den Befehl zum Aufbruch in den Kampf gegen die Tüken erhält:

To je bila njegova sreta jer je ovaj slučaj probudilo u njega opet onu ponełto barbarsku nu svakako muzevnu strast koja sp amo na polju slave ljudskom krviju napaja. $(\mathrm{s} .286)$.

Auch in diesem Punkte lieBen stch ubrigens Parallelen zu Heine verfolgen. -

Auch Nemčits "Putositnicen von 1845 scheinen nicht viel Anklang gefunden zu haben - sbwohl sich z.B.Stanko Vraz begeistert dazu geäuBert hat. JEZrí berichtet 1957, daB Dukat (dessen Artikel über Nemčlt 1913 und 1942 erschtenen) eln unaufgeschnittenes Exemplar zum Geschenk erhalten und er selbst ein solches Buchlein in einem Aatiquarlat gefunden habe $(85,5 \cdot 18 / 19)$.

Der frühe Tod Nemćlts und die bedeutende Rolle Bogovits im 11terarischen und politischen Leben der folgenden Jahrzehnte Bogovit starb erst 1893 - haben bew1rkt, daß letzterer lange Zeit als der Bedeutendere galt; in neuerer zeit hat sich diese Einschätzung geandert ( $85, \mathrm{~S} .341)$ - die küstlerische Qualität der Werke Nemčlts wird heute uber die der Novelien, Dramen und Gedichte Bogovits gestellt. Auch dem damaligen Ideal einer volksnahen $L_{1}$ teratur ist Nemtit näher gekommen als sein Freund, indem er nicht die nationale Geschichte glorifizierte, sondern zeitgemäße, alltägliche Geschehnisse in einem St1l

1 Dals "barbarski" für Nemcit in einer ze1t, die sich um die Hebung des geistigen Niveaus des Volkes bemuiht, elne pejorative Bedeutung hat, ist selbstrerständlich und kommt $2 . B$. In den "Putositnice" zum Ausdruck: der Reisende $N$. ist beleidigt, weil elne venezianische Schöne die Slaven elne barbarische Nation nennt, und lst erst versöhnt, als sie hinzufügt - Barbara, ma molto erolcan(nazione) - und damit ebenfalls die verbindung zwischen Barbarentum und Heldentum knupft. ("Putositnicen, .232 ): 
berichtete, der vertraute Stilmittel humoristisch nutzte. Der Anschlul der jungen kroatischen literatur an die gesamteuropalschen Strömungen der zeit einerseits und die Elnbezlehung volkssprachilcher Ausdrucksmöglichkelten andererselts zu einem so frühen zeitpunkt lassen es berechtigt erscheinen, wenn Branimir DONAT von einem "kleinen, aber kostbaren Pförtchen, welches nach der zukunft der kroatischen Prosa hin geöfnet ist",spricht, allerdings in Bezug auf die "Putositnice", doch gilt dies in glelcher Welse auch für das Fragment "Udes ljudski" ( $27, \mathrm{~S} \cdot 17)$. Zu diesen zukunftsweisenden Elementen der Prosa Nemčlts sind auch die Anklänge an den Realismus zu zählen, die stch in der Charakteristerung der Personen andeuten. 
IV.4.2. Luka B o t 1 t: "DIIber-Hasen" (1854)

IV.4.2.1. Gesantwerk - ge1st1ger Hintergrund -

Elnfiusse - Korrentare

Das 11terar1sche Werk Luka Bot1ts (1830-1863) besteht aus dre1 Verserzkhlungen ("Pobrat1eetro", 1854; "B1 Jedna Mara". 1861 ;"Petar BaX1t", 1862), der Norelle "D11ber-Hasan"(1854), - Inigen Gedichten sowle unvoliendeten Eraahlungen und tbersetsungen; die erste Gesamtaugabe selner Werke (Zagreb 1949) enthalt auberdem noch den Text seiner kede 1m kroat1schen Landtag von 1861 . Botil gehört su der Gruppe dalmatinischer Schriftstelier und Dichter, die den Gedanken der kroatischen wiedergeburt - infolgo der besonderen verhaltnisse in ihrer Helmat mit einiger verspatung - aufgriffen und zu verwirklichen suchten; neben selnem Freund Mihovil Pavilnovit(1831-1887) gilt or als olner der besten dalmatinischen Dichter selner Epoche. Nach dem Urtell BARAC' 1st "Dilber-Hasan" die beste kroatische Novelle der 50er Jahre (7.5.22); $1 \mathrm{~m}$ gleichen Sinne uulert olch RAVLIĆ, der Herausgeber der Gesamtausgabe ron $1949(96,5.257)$.

Dem aus Split geburtigen, bescheldensten Verhaltnissen entstammenden Botil war die Besserung der sozialen und po11tischen Situation seiner Helmat ein leidenschaftiches Anliegen. Die dinne besitzende Schicht Dalmatiens gehörte damals dem ltalienischen Kulturkreis an und genob seltens der österrelchischen verwaltung viele Vorrechte; In den Ämtern und Schulen war Italienisch die vorherrschende Sprache; d1e slavische Landbevölkerung konnte gröbtentells weder lesen noch schreiben und lebte in biterer Armut.

wahrend seinee Theologiestudiums in Zadar begelsterte elch Botit fur den Gedanken der Zusammengehörlgkelt aller Slaven, den die lilyrische Bewegung verbreitete, und für die Idee der politischen und kulturelien Freiheit, wie ole den Dalmatinern 1m kleinen eerbischen staat durch die weitgehende Autonomie elnerse1ts, die Tatigkelt Karadzits andererseits verwirklicht zu sein schien. RAVLIC nimot an, dab zu dieser Begelsterung auch das Vorbild der europalschen revolutiongren Bewegungen und die Verbreltung der grobaer- 
bischen Idee durch die Agenten Garašanins' belgetragen haben(97.5.8/9). In Zadar, dem österre1ch1schen Verwaltungszentrum Dalmatiens, wurden derartige Tendenzen streng uberwacht; elne Gruppe der Jungen Theologen, darunter Botit, wurde 1851 aus dem theologischen Seminar ausgeschlossen.

Nach diesem Ausschlub relste Botit uber die Hercegovina und Bosnien nach Belgrad, wobel er sich einige Monate in Sarajero aufhielt; die Faszination, die fur thn von dieser stadt ausging, hat sich in der Novelle "Dilber-Hasan" niedergeschlagen. Nach elnem kurzen Aufenthalt bel dem Schriftsteller Matija Ban in Belerad begab sich Botit nach Zaereb, wo er in der Druckerel Ljudevit Gajs arbe1tete, bis thm die Brider Brilt in Bakovo elne Anstellung als schrelber besorgten. Von Pakovo aus hat Botit seine herke veroffentlicht; hier wurde er 1861 in den Landtag gewahlt, und hier starb er im Alter von 33 Jahren.

Dieser Lebenslauf wird hier nur skizziert, um das auf unmitcelbarer elgener Erfahrung beruhende Engagement Botits fiir die nationalen Belange deutlich zu machen. Wie ernst es 1hm damit war, zeigt die Tatsache, daB er 1860 als e1nziger Beamter der blschoflichen Bombine Bakovo den Treueeld auf den Kalser verwelgerte - wohl wissend, dab ihm dies die Entlassung und damit neues elend eintragen würde. Zu dieser, allen zeitgenössischen kroatischen und serblochen Schriftstellern gemelnsamen, nationalen Komponente selnes literarischen Schaffens trat bel Botit eine zwe1te, weitaus seltenere - ein ausgesprochen lyrisches Talent und, wie BARAC sagt, elne Innere Notwendigkelt zu schreiben:

Von allen kroatischen Novellisten der 5oer Jahre war er am melsten Kunstler und am ehesten ein Schriftsteller, der aus elnem inneren Bedurfnis heraus schuf, mit dem geringsten MaB an trocken-1ntellektual istischer Anstrengung, aber dem grobten MaB an Gefuhl, Phantasle und dem Wissen um Not und Elend... (7,5.22).

Botits Werke weisen viele Merkmale und damit auch Mangel der zeltgenössischen Lfteratur auf, auch lst es thm nicht

'Il1 ja Garałanin, serb.Innenminister 1843-52,1857-58, Min1sterprasident 1862-67; "Načrtante"(1844). 
lmmer gelungen, seinen Grundgedanken klar genug herauszuarbelten; dank selnes urspringlichen dichterischen ralentes wirken seine Texte dennoch in der Flut der standardisierten patriotischen Poesie der lllyrischen und nachillyrischen Periode"wle elne Erholung"(113,5.56).

Botit, der vor selnem Theologiestudium von 1841-1849 Schuler des Erzbischöflichen Seminars in Split war, besal jene italienisch orientierte Blidung, die fur die wenigen Intellektuelien des damaligen Dalmatien charakteristisch war. Von den zeltgenössischen Schriftstellern schatzte er besonders den aus Sibenik gebürtigen Niccolo Tommaseo; In selnem Nachlab fanden sich Ubersetzungsfragmente aus den Schriften dieses Autors ("Dell'educazionen und aus "Stud1 critic1"). Es liegt nahe anzunehmen, daB Botit auch seine Romane und Manzon1s "I promess1 sposi"(1828) gekannt hat. Bogdanovic erwahnt, dals Botit von Tommaseo den Gedanken ubernommen habe, dals die Gechichte die Grundlage aller Dichtkunst sel; dies sel die Auffassung Manzonts gewesen $\left(13^{I}, \mathrm{~S} .543\right)$. Botit hat seinen historischen Verserzinlungen tatsachlich ein Quellenstudium vorausgehen lassen. Es lot jedoch nicht schwer, als wichtigstes Vorbild fir das Schaffen Botits die Volksdichtung zu erkennen, sowhl in Form der Sammlungen Karadzits als auch aus unmitelbarem persónlichem Erleben, worauf Botit selbst hingewiesen hat.

Die umfangreichen Verserzahlungen Botits gehen uber jene, von uberlieferter volksdlchtung manchmal schwer $z u$ unterscheidenden ibergangsformen hinaus, die Latxović "pevanje na narodnu" nennt $(62, \mathrm{~S} .42)$; sie bedienen sich zwar des Zehnsilbers und der Flguren der Volksdichtung, die Botit souveran anwendet, welchen aber im Aufbau von der otrengen Architektur ab, die selbst sehr lange epische Lieder "zusammenhalt": Uberflussige Nebenepisoden zerstoren die Ubersichtlichkelt des Handlungsablaufes; die der Volksliteratur fromde Psychologisierung und die lyrischen Schilderungen deuten zwar auf elne velterentwicklung hin, otehen aber vor allem durch ihre Weitschweifigke1t nicht im Einklang mit der Form und wirken in diesem Rahmen nicht als Berel- 
cherung, sondern als Langen. Hierin liegt die Ursache, warum die Verserzahlungen Botits trotz sprachlicher Schönhelt heute kaum mehr lesbar sind, wahrend Mažuranits "Smrt Smail-age Čengita" In selner Gedrungtheit und Lapidaritat immer noch als Meisterwerk empfunden wird.

Gattungambig stellen Botits Versepen keine Einzelerscheinung dar'; als Belspiel kunstlerisch angewandter Volkssprache bilden sie in einer zelt, die durch das Ringen um die Literatursprache gekennzelchnet lst, einen positiven Beitrag und ein Gegengewicht zur Dubrovniker Tradition, vop der die Gefahr allzu grober "Literaturhaftigke1t" (11teraturnost) ausging ${ }^{2}$. Dennoch mus man FlakFr zustimmen, der durch die Entstehung solcher werke eine Verzögerung der tintwicklung künstlerischer stile gegeben sleht $(33, \mathrm{~s} \cdot 31)$ ). Solche Ruckgriffe auf überkommene Formen liegen selbstrerstandlich in einer Epoche nahe, In der es gilt, sich auf die elgenen nationalen werte zu besinnen und Bestehendes zu verteidigen; hier wird die "Ästhetik der Identitat" (LmMaN; ${ }^{3}$ ), wie sie die Volksdichtung allgemein bestimmt, Uber deren Rahmen hinaus wirksam. Die außerliterarischen Funktionen der serbokroatischen Literatur in der Periode der "wiedergeburt" und der "nationalen Pseudoromantik" motivieren diese Erscheinung.

Demgegeniiber erscheint das einzige Prosawerk Botits, die Novelle "nilber-Hasan", als eln Vorgriff auf zukúnftige

1 Preradovit: "Kral jevit Marko", 1852 ; Pavlinovit:"Ognj1bar", 1864; Franjo Markovit: "Dom 1 svijet", geschrieben 1865; Ljub16a: "Boj na V1su", 1866; Fra Grga Mart16: "Osvetnic1"1861-1883, "Posvetnic1", 1895; Jakb1t: "Bratoubica", "Nevesta Pivijanina Baja" u.a.

2 A.Flaker betont die Bedeutung der Dubrovniker Tradition für die ausesprochene "literaturnost" der entstehenden kroatischen im Vergleich zur serbischen Literatur, die stch obenfalls auf der Grundlage des neustokavischen Dialekts, aber gestutzt auf ein neuštokavisch sprechendes "Hinterland", ausbildete. (34,5.60).

3 Lotman stellt die isthetik der Identitut der isthetik der Opposition gegenuber $(70,5.439)$. "Das ksthetische Denken bestimmter Epochen... IleB die ïsthetik der Identitat zu - für schin wurde nicht die Schaffung von etwas Neuem gehalten, sondern die exakte Reproduktion von zuvor Geschaffenem". $(70,5 \cdot 196)$. 
Entwicklungen, etwa auf die Novelien Šnoas, well hier Elemente der Volkeliteratur in einen neuen, in diesed Palle lyrischen, Stil eingeschmolzen, nicht etwa ihn "appliziert" sind, whrend glelchzeltig elne Rethe grundsutzlicher Forderungen erfullt lst, die an diese Prosarorm gestellt werden. IV.4.2.2. Themat1k, HuBerer Aufbau und Togposition der Novel 1e "D1lber-Hasan"

Botits Novelle behandelt, wie viele zeltgenbsalsche Ersuhlungen (Typ der "hajdučko-turska novela") das Turken-Thema, jedoch unter einem neuen Aspekt - dem Aspekt der Liebe zw1schen einew Tüken (Hasan) und einer Christin (Sofa) und der Freundschaft zwischen Hasan und dem Christen Pavao. Unter "Turken" werden wie ubltch Mohammedaner ohne Bezugnahme auf thre ethnische Zugehörlgke1t rerstanden, unter "Serben "Christen. Die Uberwindung religibser Schranken 1st ubrigens ein Thema, das auch in anderen werken Botits erscheint; der Gedanke der religiösen Toleranz deutet möglicherwelse auf d1e Lektüre Tommaseos hin. Berelto d1e Thematik der Novelle macht die gewohnte schablonenhafte Darstellung des Türken - jedes Türken - als brutalen Unterdrucker unmöglich und fordert oine individuelle Charakterisierung; das Milieu, die turkische Lebensart werden nicht von auben her, wit der vorgefabten Ablehnung seltens des Christen, geschildert, sondern von innen her, tells sachlich objektiv, tells mit der lyrisch uberhöhenden begelsterung des Autors, den die Fremdartigkeit der stadt Sarajevo bezauberte.

Das "klassische" Turken-Thema, d1e Unterdrückung der Christen, erscheint erst im zweiten Handlungsetrang und als Begleitmotix der Haupthandlung. Im ubrigen greift die Novelle das Sujet der mit dem Einverstandnis der Geliebten geplenten Entfuhrung auf, bei deren verwirklichung ein anderer Mann in die Rolle des Liebhabers elntritt, w1e In Puškins "Metel'" und in Demeters Nachdichtung "V1javica" (1845). ÄuBerifch lot die Novelle in 6 Kapitel gegliedert, die In Fortsetzungen in "NEVEN" erschienen. In der Fabel sind zwe 1 Handlungen mitelnander verflochten, wobel die elne, die Liebesgechichte, gegenuber der anderen, dem serbischen Aufstand, deutlich iberwlegt; dieser Frelheltskampf wird 
dem leser in den ersten 3 Kapitel nur durch die Reflexionen Paraoe bewubt gemacht. Mit dem Auftauchen einer turkischen Kriegerschar unter Avdaga Selandžit, dem vidersacher Hasans, In Kap.V, und, schlieblich,mit dem allgemeinen Aurbruch der bosnischen Tüken gegen die Serben (Kap.vi) nehmen diese Vorgänge konkrete Gestalt an, um dann, nach dem tragischen AbschluB der Haupthandlung, ganz in den Vordergrund zu treten; dies geschieht im vorletzten Absatz, der die kriegerischen Ereifnisse, an denen Pavao teilnimmt, In starker Raffung berichtet. Kurz zuvor falst Botit in den Worten elnes Serben, der dem Freund und der Geliebten des toten Hasan Obdach gewahrt, noch elnmal die Sorgen und Note der Unterdrückten zusammen:

"Ja ne znam", rece, "sve vałe nesrece, all tko je danas od nas sretan ovijem prokletijem Turcima? Tko nema da zaplaxe 111 za bratom, 111 za prijate1 jem, 111 za ocem, 111 za sinom? Mozda su vam Turci popalili selo, a vi morali bjezat1! Ne temo 11 tome jedanput kraja utiniti1..." (5.402)

Nach der Schilderung der Kampfe berichtet Botit in einem aus wenigen Zellen bestehenden Epllog, daB Pavao unversehrt helwkehrt und die Braut des toten Freundes helratet, womit be ide Handlungen zusammengefihrt und abgerundet sind.

Die Haupthandlung setzt $1 \mathrm{~m}$ ersten Satz berelts mit einer schwungvollen Exposition uber den ort der Handlung und vor allem uber die zentrale Gestalt, den schönen Hasan, ein. in dessen "kahvana" sich die Türken treffen. Auch die Problematik der Erzahlung wird im l.Kapitel dargelegt: Hasan ist mit einem Christen befreundet; und hasan soll, aufgrund einer Wette, mit einem Lied einer Christin - Sofa - einen Blick, ein Lacheln entlocken, wenn sie an der kahvana voribergeht.

Das 2.Kapitel schildert in einer Ruckwendung die Entstehung der ungewöhnlichen Freundschaft; Pavao hat Hasan, der in der Nahe des "latinluk", des Christenviertels, gesungen hat te, unter elgener Lebensgefahr vor den Tutlichkelten anderer Christen gerettet. 
Kapitel 3 belnhaltet die Liebesgeschichte Hasens und Sofas: es beginnt mlt der Schllderung der Schbnhelt Sofas, dann erfolgt die erste Begegnung, bel der Hasan selne wette verliert, da die sitsame Serbin ihn keines Blickes wurdigt; Hasan verilebt $81 \mathrm{ch}$ in sie, und durch selne allabendlichen Serenaden und die Vermittiung Pavaos kommt er Sofa schrittwelse naher, bis sie sich endlich unattelbar kennenlernen und in Hasan angesichts der religibsen Schranken der plan zur gemelnsamen Flucht nach Dalmatien relft, wo er als Christ ein paradiesisches Laben mit Sofa fuhren w111.

Das 4.Kapitel bringt den ersten Höhepunkt bzw. die Schürzung des Knotens: die sorgfultig vorbereitete Flucht miBlingt, da der Turke Avdaga den Freunden zuvorkommt und Sofa auf sein Landgut entfuhrt; or selbst kehrt nach Sarajevo zuruck und laBt Pavao und Hasan durch den Kadija verhaften. Als Gegenspleler des Bösewichts Ardaga tritt der sehr menschlich gezelchnete Mula auf, der fur die sicherhelt der Freunde sorgt und sich bemuiht, das Rankesplel Avdagas aufzuklaren.

Das 5.Kapitel beginnt mit der Einberufung des Rats der Turken durch den Mula, der diese Angelegenhelt berelts durchschaut; die Zusamenkunft wird durch das jahe Auftauchen Ardagas abgebrochen, der mit elner kleinen Kriegerschar von elnem Blitzangriff gegen die Serben zuruckkehrt. Whinend der Mula noch erwagt, ob er angesichts der feindlichen Haltung Avdagas und der Famille der Entfuhrten riskleren solle, die belden Freunde aus der Haft zu entlassen, uberbringt ein ratselhafter alter diesen eine Botschaft von elnem "jungen Freund" Im Tükenlager an der Drina - der niemand anders als die entflohene sofa $18 \mathrm{t}$.

In elner erneuten Rückwendung wird über Sofas aufregende Flucht aus dem Gutshaus Avdagas berichtet, die sie - als Jügling verkleldet - auf dem folgsamen Pferd des Mula (mit dem dessen Diener zu dem Landhaus geritten war) ins Tükenlager an der Drina gefihrt hat. Botit ist bemiht, diese Flucht möglichst glaubwürdg, sozusagen sich aus den Umstanden ergebend, darzustellen, um keinen Bruch in 
der Charakteristik der sanften, zaghaften sofa entstehen zu lassen.

Das 6. Kap1tel, Uberreich an Geschehnissen, bringt den Aufbruch der Türken aus Sarajevo, dem $81 \mathrm{ch}$ Pavao und Hasan anschlieisen: Pavao, um zu den serbischen Bridern zu stoben, Hasan, um die Geliebte zu suchen. Es folgt die zwelte Klimax der Handlung: die Begegnung Hasans und Avdagas Im Túrkenlager bel der Suche nach Sofa; Hasan tötet den Widersacher und wird selbst schwer verletzt; Sofa wird gefunden, nach der letzten Umarmung schildert Botit Hasans Siechtum und Tod. Damit $18 \mathrm{t}$ der "Knoten" gelöst; nachdem für elne kurze strecke des Textes der serbische Preiheitskampf ins zentrum des Interesses tritt, miinden belde Handlungen in dem schon erwahnten, knappen Ep1 108 .

\section{IV.4.2.3. Raum und Ze1t - Erzähltechnik}

Betrachtet man die Gegebenhelten von Raum und 2 elt in der Erzählung, so stellt man fest, dab der Raum ich von der "kahvana" Hasans auf die Stadt Sarajevo, dann auf deren engere Umgebung und schlieblich bis jenselts der Drina erweitert; die Gedanken Pavaos frellich beziehen vom l.Kapitel an den ganzen Bereich mit ein.

Der Zeitraum erfaBt einige Monate des Jahres 1806; das Verhälinis von Erzälze1t zu erzahlter Zeit varilert entsprechend dem Wechsel zwischen szentschen Darstellungen, in denen es, wie bel den Reflexionen, fast zur zeltdeckung kommt, und stark gerafften Erzählerberichten. Die lyrischen Schilderungen stellen Ruhepunkte oder, wenn man so will, Retardationen dar, zu denen Jedenfalls die belden Rúckwendungen zu rechnen sind. Hierbel lot die erste Ruckwendung elgentlich eine Vorgeschichte, also. elne aufbauende Ruckwendung zum Verstundnis des gegenwartigen Geschehens, die zwelte elne auflósende Ruckwendung im Sinne einer nachtraglichen Erklarung (rgl.59,5.103). Es wird also nicht,wie In der Volkserzahlung, In chronologischer Reihenfolge, sondern in zeitlicher Verflechtung berichtet, nach Art klassischer Novelien, z.B.Klelsts; dadurch wird, im Verein ait den auf kinftiges Geschehen hinweisenden Vorausdeutungen, 


\section{- 196 -}

d1e Spannune aufrecht erhalten.

D1e Erzahlperspektive 1st, mit Ausnahme elnes kurzen, dramatischen Abschnitts, die des allwissenden Autors, der nicht nur in alle Vorgange, sondern auch in alle Gemutsbewegungen der handelnden Personen Elnblick hat; er ist aber kein "objekt1ver" Berlchterstatter, sondern nimmt spürbar Ante11 am Geschehen.

Die elnzelnen Bauelemente der Novelle sind szenen, melst mit Dialogen oder Reflexionen, oft unter wötlicher wiedergabe von Liedern; Erzahlerberlchte; lyrische Schilderungen von Landschaften, von Personen und Ihren Empfindungen; einige kurze Betrachtungen und Bemerkungen des Autors.

IV.4.2.4. Romant18che Ellemente

Charakteristika, welche diese Novelle der Romantik zuordnen, sind neben der handlungsrelchen Fabel die Uberzeugung von der uberwatigenden Kraft der Liebe, die sich in emprindsamen, von Ausrufen durchsetzten Passagen dusert, und die Begelsterung fü alles Nationale, wozu auch die eingestreuten Lieder gehören, die tells echte Volkslieder, welst jedoch fut nachempfundene Dichtungen Botits sind. Ebenfalls als romantische Elemente zu werten sind die Natur- und Stiminungsschilderungen, die manchmal in wortrelcher Weitschwelfigke1t zerflieben, die Schwarz-Weis-Malerei in der Charakterisierung Avdagas und Sofas und, nicht zuletzt, die relativ unaurdringliche, doch spurbare Anwesenhelt des Autors:

Ove moje riječi...(S.361); kano što je sočetka reEeno....(s.363); Sve je, Eovjek b1 rekao, služ110 zgodno.. (S.377)

Am SchluB des l.Kapitels erfolgt die Uberleitung zu der Ruckwendung des 2 .Kapitels mit dem direkten Hinweis auf den Kontakt zwischen Erzahler und Leser:

Nego prije svega ostaloga da kaxemo kako se je utvrd110 to prijateljstvo 1 amedu jednog Turéina 1 jednog hriztanina, fto te možda biti drago znati. 1 osim Mule, kome od Eitalaca. (S.356)

Auch durch Ausrufe oder rhetorlsche Fragen wird die Anwesenhelt und Antellnahme des Autors deutlich:

Čudnl 11 su pojari 1 jubarl! (S.381) 
Neopisiva 11 su titranja mladanog srca....(s.370) Oh, gdje je sada njoj prvał̌nji djevičanski blaženi $=1 \mathrm{r} \ldots(\mathrm{s} .377)$

Der letztgenannte Satz kann allerdings auch als erlebte Rede aufgefabt werden; hierauf wird spater eingegangen. Auch die zwelte Ruckwendung leitet der Autor durch ein kurzes Hervortreten seiner am Geschehen interessierten Person ein:

Al1 kako da je ona dospjela usluzbu mostarskog bega Adžalita 12 straśnog Avdaglnog titluka? (S.388)

Der Autor 1st es auch, der Vorausdeutungen ausspricht: Ne b1 li ona jača bila, da nije Cula žalosni dogadaj nesretne Fatime 1 Abdule? (s.375)

S kakvijem on znatizeljnim 1 zlobnijem okom nije pogledao trojlcu, koja su se razgovarall, kad je mimo nje probao! (S.375)

Vurch diese standlge Anwesenhelt elnes allwissenden und, wenn auch sparsam, kommentierenden Autors ist die Novelle besonders stark der romantischen Erzahltradition verhaftet; lediglich ein einzifes Mal gibt Botit diese Position auf bel der Flucht Sofas mit dem Fremden (vgl.Iv.4.2.7).

Als auffalliger stilzug, der uber die Romantik hinaus auf den Sentimentalismus zurückweist, ist die häufige Erwannung von Träen, Weinen und Seufzen zu nennen (suze, plač, uzdisaj, uzdisati etc.).

IV.4.2.5. Elemente der Volksdichtung als lyrische Stilmittel

In den Mittelpunkt seiner Novelle stellt Botit eine Ballade, die der vielbegehrte Hasan singt und deren sujet dem der Erzählung entspricht: in gedrangter form handelt sie von elner "verbotenen" Llebe, dem Plan zur gemeinsamen Flucht der Liebenden und der fint führung des Madchens durch einen Fremden, die tragisch endet (Kap.II, S.357-359). Dieses Leitmotiv-Lied, welches alle Merkmale der Volksballade aufwelst, wird lmmer wleder erwahnt oder tellweise wiederholt; es fuhrt die Liebenden zusammen. Der lyrische Gesamtion, der damit angeschlagen 1st, bleibt nicht auf dieses Lied und die welteren - insgesamt 7 - Lieder beschrankt; er klingt immer wieder im Prosatext an. Botit 
lot eln Dichter der Emprindung, der spontane1tat; er ist bepelotert von der liebe, von der Schönhelt, von der rdee der Frelhe1t; deshalb entspricht ind der lyrische Ausdruck, der stch auch in selner prosa und in den epischen Gedichten lmmer wieder durchsetzt ${ }^{\prime}$.

Die Lieder Hasans stehen deshalb nicht 1soliert im Prosatext wie bel manchen anderen Schriftsteliern, die damit nur den Tribut an die geforderte Volkstimlichkelt in der Literatur erbringen. Botit lehnt sich nicht nur in diesen Gedichten an die Volkslyrik an, ondern or ubernimet deren stilverfahren auch in seine Prosa, d1e damt elne Synthese aus romantischen und volkstumlichen Elementen darstellt. Diese Ubernahme geschieht umso zwangloser, als Botits sprache nicht durch elne deutsch-orientierte Blldung vorbelastet lot (wle dies bel der Mehrzahl der Illyrer der Fall war); volkslieder und ihre typlschen wendungen sind thm aus der Kindhelt geluufig, und durch die Beschaftigung mit den Sammlungen Karadžits und durch selne Aufenthalte in ytokavisch-sprechenden Gebleten hat or selnen ursprunglichen Heimat-Dialekt (čakavisch) zu jener farbigen, relchen Sprache entwickelt, d1e inn vor anderen zeltgenossen auszelchnet. BARAC spicht nicht nur vom lelchten, flussigen Erzahlstil Botits, sondern betont daruber hinaus die "Uppigke1t" selner volkstumlichen sprache(bujnt narodn1 jezik). dif weder otilistisch noch syntaktisch vom Deutschen her angekrankt se1 $(7,5.22)$.

Tatsachlich ist Botit elner der ersten kroatiochen und serbischen Schriftstelier, der die Volkseprache im Sinne Karadzits auf der Ebene literarischer Prosa konsequent anwendet. D1es 611 ticht nur filr lexik, syntax und st11; auch hinsichtilch der Morphologie folgt or den Richtilinien Vuks. Mit ganz wentgen Ausnahmen $z$. B. verwendet er die neugtokavischen Pluralformen des Dativ, Instrumental und Lokatir (Auenahmen: u zlatnijem zarfam,s.345; po brego-

1 Bogdanovit erwahnt: "Ub1la ga prerano: pjesma, kolo 1 pfelo', vell njegor pobratim i blograf Pavilinovit". $\left(13^{\mathrm{IP}}, \mathrm{S} \cdot 541\right)$ 
vima 1 po podol1cam, S.357). Se1n urspriugltches Id1om schimert noch durch, wenn er die Praposition "g" vor dea Personalpronomen palatal 1elert (o nj1ma,s.362, 363; šnjega, s.383; z njome,s.377). Wahrend er alle aus dem Italienischen entlehnten worter vermeldet, verwendet Botit in der Novelle "Dilber-Hasan" zahlrelche Turzismen, die wesent 1 ch zum Lokalkolorit beltragen.

Dieses ortentalische Kolorit des alten Sarajevo mit selnen vielen Kaffeestuben, in denen sich vornehme Tüken treffen, um neben ernsten Gesprachon auch den Klatsch effrig zu prlegen, diese Atmosphare voll verborgener leidenschaften und Liebessehnsucht hat Botit schon mit dem ersten Absatz der Erzahlung beschworen, dessen satze in allmahlicher stelgerung die Anziehungskraft hasans spübar machen, nicht beschreiben - dazu lst der Autor selbst zu hingerissen. Dieses Hingerissensein aber bubert sich gerade in diesem Anfang nicht in schablonenhaften vendungen, sondern in eigenwillig gestalteten Satzen, die nach den Stilprinzipien der volksdichtung gebaut sind und immer wieder das zentrale wort "mam" (Köder, Lockspeise) ansteuern.

Der Absatz beginnt ant1thetisch:

$(t 1=1) a t \cdot e \operatorname{th} 1 \mathrm{cus})$

(Vergletch)

(wiederholung)

Steigerung durch

4 Isocola,denen der Schlubsatz ant1 thet $18 \mathrm{ch} \mathrm{ge}^{-}$ genubers teht:
Kol1ko je kahvana u Sarajevu, neima ti druge kahvani DIlber-HasanavoJ na Bał-čarł́ 1 j.

Tude jutro vece odličnl ja turska gospoda kupe se kano u kakv1 mam.

A 1 ima mama:

no ne u 1zvrentjem fildžanima, ni u zlatnijem zarfam, u srebrnijem lbricima, nit1 u svilenijem inderima:

mam je sam Dilber-Hasan.

Diese Satze bilden mit der SchluBpolnte elne Art stroph1scher Einheit.

Fs folgt elne etwas anders rhythmisierte Passage, d1e wie eln 2 wischenspiel in anderer Tonart bel manchen Liedern anmutet und zugleich dae Thema varifert? 
(Me tapher)

3 parallele sätze, die den Eindruck der Steigerung erwecken und in das Lob der Lieder Hasans minden :

Vergleich, dabel Wiederholung im Sinne der Paronomasie: zatin: natinit1, des Po-

lyptoton : bugarija : bugariju .

Nun wird das erste Wort "koliko" wieder aufgegriffen - ebenso, wie in Liedern durch die Anapher die strophische Gliederung betont wird, wobel diese fifur jetzt zwel parallel angelegte satzpare verbindet: snu : sanja
A kako ne bi, kad je njegova dosjetna sala zacin svakom razgovoru, njegove pjesme hitro izvedene svakom dogadaju,

a stna bugarija 1 lijep glas svakoj pjesmi!

Nijedan odźa ni derviš ne zna nă̌initi amajliju, koja bi mogla na orce djelovat1, kano to pjesma hasanova uz njegovu bugariju.
Koliko su puta bijele kadune molitvu o jaciji prekinule za slusati gdje sokaknm l) 1 ber-Hasan probire po karaduzenul

Koliko mladijeh djevojaka u snu ne sanja o krasnome Hasanul

Koliko jih ne uzdahne, kad se njega sjetel Kol1ko jih ne požli petka 111 drugog sveca za moti prołetati se 1 moźda sretnut 1 Hasanal

Nach diesen Ausrufen folgt die Ankiindigung des letzten "Trumpfes" in der Aufzählung der Vorzüge Hasans:

Anagramm :

- Pa ni ta sva slava nije sav mam Hasanov. sva:s lava:sav

Lautmalerei: Wiederho-

lung des "a"

Uber diesen dritten Vorzug hasans - dals er uiber alles und jedes in Sarajevo zu erzahlen weib - wird wieder in zwei parallelen Sätzen berichtet, die jeweils dreifach gegliedertsind:

(kol1ko-kad-kad)

3 Isocola; Polyptoton: kakve-kakvi-kakvo (Periphrase für: niemals das haus verlassen)
Sam Hasan zna priporijedati, koliko ima zaljubljenika u Sarajevu, kad se tko u koga zaljublo, kad 11 se, zasto 11 sa svojom milosnicom dragi koji posvadio. Sam Hasan može odati kakve su oćl, kakvi II glas, kakvo 11 je 11 ce u koje djevojke, ma ne vidjela nikad sunca ni mjeseca.

Die abschliebende, auspesprochen volkssprachliche Wendung bildet den Ausklang der dritten "Strophe" und zugleich der gansen, liedartigen Lobrede iber Hasan, die, In drei Teile gegliedert, seine drel bemerkenswerten Fahigkeiten - zu singen, die Frauen zu bezaubern und jede neue Geschichte zu kennen - preist. 
Diese Analyse von Aufbau und Stilverfahren der Einleitung der Novelle füht zu dem überraschenden Ergebnis, dals hier der Eindruck der Uberschwenglichkeit, wie sie den Sentimentaliamus kennzeichnet, mit den Mitteln der Volksilteratur errelcht wird; will man diesen Zusammenhang noch präzisieren, so mul man Botits Text zwischen Volkserzbhlung und Volkslyrik stelien, da ihn mit der ersteren die Prosaform und typische Kunstgriffe, mit der letzteren liedhafter Aufbau, Häufigkeit der Figuren und Stimmungsgehalt verbinden.

Gewils lst dieses, an so wichtiger stelle stehende Textstück mit besonderer Intensitat konzipiert; dennoch finden sich Entsprechungen, z.B. In der Schilderung der Schönhelt Sofas am Anfang des 3.Kapitels (S.366/367), die lapidar beginnt: Sofa Radosavijevita.

Auf den entzuickten

Ausruf -

Oh, kako je krasno to dijetel

folgt elne Haufung des

in der Volksdichtung

so beliebten Epithetons "crn":

Crne ovelike oti pod stidnijem crnim treparicama, crne obrve, crna sjajna kosa....

Auf die - mit vielen Figuren ausgeschmückte - Beschreibung ihrer "ernsten" Schönheit folgt nach dem zweiten, den ersten variferenden Ausruf - Krasno li je to nevino dijetel die dem ersten Teil antithetisch gegenuberstehende Schilderung der unreinen Gedanken der Männer uber dieses sittsame Mädchen und schließlich die Erwähnung der "unverschämten" Wette.

Auch die lyrische Schilderung Sarajevos zu Beginn des 2.Kapitels (S.356) ist reich an Parallelismen, sie enthalt antithetisc Teilsktze

- kada mjesec míñno nad tobom sjaje. a pod tobom vodà bụ̂́ (S.357)

hyperbolische Wendungen und Periphrasen -

. sa svojom stotinom vitkijeh bijelijeh munara posadenijeh po bregovima 1 po prodolicam (S.350/357);

hier aber iberwiegt die romantische Komponante.

In der Naturbeschreibung vor und whingend der Flucht sofas mit Ardaga, den sie für Hasan hält (s.377/378), erscheint das verhaltnis zwischen romantischem Gesamttenor, den die häufige Erwahnung des Veinens und die Apposition "jedinog prijatelja 1 tajnika njihovi l jubavi" (=Pavao) verstarken, und den schmucken- 
den Figuren der Volksliterntur ausgeglichen. Die Projektion des menschlichen Schicksals in die Natur (kalter Wind, Hundegeheul = Ungluick) wirkt romantisch, doch sind dies viel ältere. von der Romantik aufgegriffene Metaphern; wenn dreimal vom Geheul der Hunde die Rede ist, entspricht das dem Verfahren des Mărchens oder z.B. dem dreimaligen Krăhen des Hahns im Neuen Testament.

In thnlicher Weise verfärt Botit auch in anderen lyrischen Schilderungen, denen insbesondere die Reflexionen Sofas zuzuordnen sind. Ein grober Tell der im Kapitel uber die Kunstgriffe der serbokroatischen Volkserzählung genannten Mittel labt sich in Hotits Prosa nachweisen (s.III.3.4.1 und 6). Die Funktion, welche cort die verfestigten stellen im Rahmen der Komposition erfullen (s.rIT.3.4.5), ubernimut in der Noveller"Dilber-Hasan" wenigstens andeutungsweise das Lied ron Abdul und Fatima. Verfolgt man an Hand von POl,oks "Studien zur Komposition und poetik des balkanslawischen lyrischen Volksliedes"( 90$)$ die dort als besonders produktiv hervorgehobenen Stilmittel im Text Hotiks, so wird deutlich, daB die lyrische Intensivierung des Ausdrucks oft auf der Anwendung jener figuren beruht, die vorzugsweise zum ornatus des südslawischen Liebesliedes gehören. Obwohl diese Figuren auch in der erzälenden Volksliteratur und in der Kunstlyrik erschelnen, rücken ihre besondere Häufigkeit und ihre Auswahl den prosastil botits in die unmittelbare Nahe der serbokroatischen Volkslyrik, wie die nachstehenden Beispiele zeigen, die nur eine kleine Auslese darstelien.

Metapher

-.. kad je njegova dosjetna šala začin svakom razgovoru $(5.345)$

...eto vidimo kakva je to bijesna zvijer ( $\mathrm{S} \cdot 346,=$ die aufständischen serben)

Ništa nije znala tada misliti,niti je šta moela curstrovati: strah bjeśe zrak njezin. (s.389)

neriphrase

... a evo progrušala se brada (s.349 = der Bart ist ergraut = er ist zualt)

...kad bi ti sjedio nuz koljeno novog pare ( $\mathrm{S} .348$ = wenn du Vertrauter d.neuen Paba wärest) Da nije to prijateljstro cifuta koji novce uzajmljuje? (S.352) 
Vergleich

\section{Antitheton}

Wiederholung:

"ohne Abstand" Epanalepse:

"auf Abstand"

anaphorische Wiederholung:

\section{Paronomas 10}

pseudoetymologisches Kortspiel Paronomasie per immutationem) ...krene tamo amo kano uplašena srna (s.390)

-. da je l jubar tijelu lijek kano śto dušu raj $(5.4 n n)$

.. ovaj se ne makne ko ni stanac kainen $(\mathrm{S} \cdot 380)$

3-malige Gegeniberstellung Herz: Geist: Niti viłe place, niti, o cemu vise promislja. vet sve misli i sva curstra nekako joj pretiskala sa svojijem teretom 1 srce $i$ pamet $(\mathrm{s} .378)$

Trauer: Heiterknit:

zato je na Casove bio sada tužno zamišljen. sada opet Łalivdžija, sada u gorkom plaču, sada $u$ grohotom smijanju .. (\$.382)

Zaplač nješto od radosti, što je tako sretno izmakla smrtnom svojemu jadu, njesto od nevesele nekakve zalosti slitne grizodusju, sto neima kuda da svojijem putem krene (s.390)

Dugo, dugo je tako hodala (S.392)

lirate, brate, gdje je ment nesretnoj mojeg Hasana? ( $\mathrm{S} .398)$

- .kroz citav dan svakojake misli i drmale i umirivale onu dusu, a drmale osobtio otkad se ona...slika pokaza...(5.389)

Niederholung der Worte žalost - u najvetoj žalost1 - žalosnu Sofu - gorku źalost in 4 aufeinanderfolgenden sätzen, die der verwundung Hasans folgen (S.398)

-. dakle utaman sva naša ljubavl utaman sto si jadna pretrpjela za trojeg Hasana 1 utaman suze śto si za njega lila... dakle utaman ostavili $i$ dom 1 sve sto nam je na svijetu milije 1 dražel (S.399)

Dva tri put je putem nakanjivao zvati

Pavla, pa se sveder okanto (5.368)

uzdahne duboko 1 izdahne (S.401)

-. no od mrtvog arapa 1 od polumrtve bake ne mogav nista ǒuti...(S.385)

-. pa niti znam koine bin se svetio, sta 11 bì sa sofom na ovom svijetu (S.381)

njeno lice $i$ njeno, ne znam je 11 čednife 111 čudniłe ponašanje..( $(5.393)$

Grahorova kahva razfrohott omijehom Turke $(\$ .367)$ 


\section{$-204-$}

Polyptoton

Figura etymologica

semantische Re-

duplikation

Haufung:

Asyndeton

rolysyndet on

typische Epitheta der Volksdichtung: ...svoj glas 1 glas svoje tambure složit1

sa elasovima tako skladne prirode..(s.357)

veče za veterom (s.375)

Kako tu vete, tako redom svake u Boga vecer1 ( 5.372$)$

- kano umorna, kanda bolesna, a to umornija

i bolesnija (S.370; zugleich Parallelismus)

..u obzorju najuzoritije prirode(s.391)

-kad se srce borilo borbom 1 jubavi 1

zel je (S.3911)

- jedra nadrladala sroje uzdisaje da

ne uzdise (S.394)

..da kad se kajao budes, da ti na vrijeme bude pokajanje (S.366)

- bditi kod groba moje drage 1 buditi je (s.350; Gleiche Wortart l)

.. 1 \ njome rajski živovao, ma kakvi im żivot providnost odredila (s.375)

mučna 1 tužna $(\because .377)$

osim placa 1 uzdisanja (s.377)

sve je to djevojka..prospala 111 prosnila (S. 342 )

..baba..se zaludu kune 1 preklinje.. (5.364)

a što pijetil prije zapjevaju 1

zora svite prije (s.374)

Sama kahvana, privikli taj njegov stan, postala mu usijjed toga tijesna, dosadna, nesnosna. ( 5.354$)$

-.te te drukćije nruziti, ncrniti,mrziti $(5.354)$

- pa je njena pamet sve to je god prije

čula sakupljala, promis̆ljala, ispitkivala

(s.370)

..svog jednoga 1 prijatelja 1 brata 1

roda (S.355)

Ovo mi je 1 brat 1 otac 1 rod 1 prijatelj (s.305)

crni nesretnik (s.381)

grpkinja trrda postenja (5.364)

živa dǔ̧a (s.384 u.a.)

luda Ženska glava (s.387.379)

medenijem riječima (S.38i)

oružje sve u samom srebru i zlatu(s.347) 
Isocolon

als Parallelismus

bili su prejasili hiljadu staza, kroz svakovrsne brežuljke, pokraj bogzna koliko česama

i preko koliko potoka..(s.378)

-.njekako ohladni vjetar

njihao je drveća po baśćama 1

tresao je drvene krovove..(s.377/378)

..spusti se u avliju,

utrknr u konjušicu,

odveze konja s jasala.. (s.390)

antithetisch:

Vrijedno je, da te upitam,

$i$ ti, da me odgovoris (s.374)

Niti ja lmam šta bih ti rekla,

ni ti, što bi mi pomoti mogao (s.374)

zur Erreichung dreioder mehrfacher steigerung:

Lautmalerei,

Ti bi, apo,

za pogled Sofijin dao po dućana,

za poljubac $i$ dutan $i$ Citluk,

a za ljubav djevojke ne bi ni glave svoje požalio (s.350)

:Jčingi mu se u toj l jubavi

njesto uzoritoga,

njesto ugodnoga,

nješto najvrednijeg čovječjeg žrtvovanja (S.353)

Ama neka me krste,

neka rade nd mene łta im volja,

neka me ubiju,

ali neka mi ne uduzmu nadu sofije(s.372)

1 und 3 : Isocola,

1, 2, 3 - Steigerung,

4 : Antithese zu $1,2,3$.

Alliteration:

Mrsko se zabrinu Mula, neka mu misao muČno glavu grije $(/ \mathrm{m} /-/ \mathrm{u} / \mathrm{o} /) \mathrm{s.381}$

Zatijem se Turci počeli rastrkavati po polju, pokraj potoka, da avdes uzimaju...(s.392)

Pa ni ta sva slava nije sav mam Hasanov(/a. $/ v /) s \cdot 345$

Abschliebend sei ein satz angefuhrt, der fast ein concetto darste1lt:

Putovati bez nade kraja, źalosno li je putovati! a put sirotice bio je gore nego put bez nade kraja, jer je taj kraj inorala žel jeti sa Žljom strastrene ljubavi (S.39

(putovat1-putovat $i$-put-put;

nade kraja-nade kraja-kraj; željeti-žel 1 jom)

Hier vie bei einigen anderen Beispielen liegt die Frage nach Bot Verhältnis zur Dubrovniker Dichtung und zur italienischen Lyrik nahe;dennoch weist die allgemeine Linie seines Schaffens eindeut 
auf die intensivere Rinding an die Volksdichtung hin.

IV.4.2.6. Elemente der Volksdichtung als realistische

Stilmittel

Neben diesen schmickenden Figuren, die in ihrer Gesamtheit als lyrisch-volkstumlicher stilzug zusammengefalst werden können, lassen sich in der Novelle weitere volkssprachliche Elemente verfolgen, die nicht Poetisierung, sondern Anschaulichkeit oder Lapidaritat bewirken. Hierzu gehören Redewendungen, Sprichwörter oder sprichwortartige sentenzen, aber auch metaphorische Umschreibungen der volkstülichen Rede. Sie bleiben nicht auf die direkte Rede beschrankt und stellen ein realistisches Moment dar, dem auch ungangssprachlich formulierte Sätze zuzuordnen sind. Auch hierfür einige Beispiele:

alltagliche Wendungen, einfathe Vergleiche

Sentenzen, Sprichwörter:

Metaphern, Periphrasen:

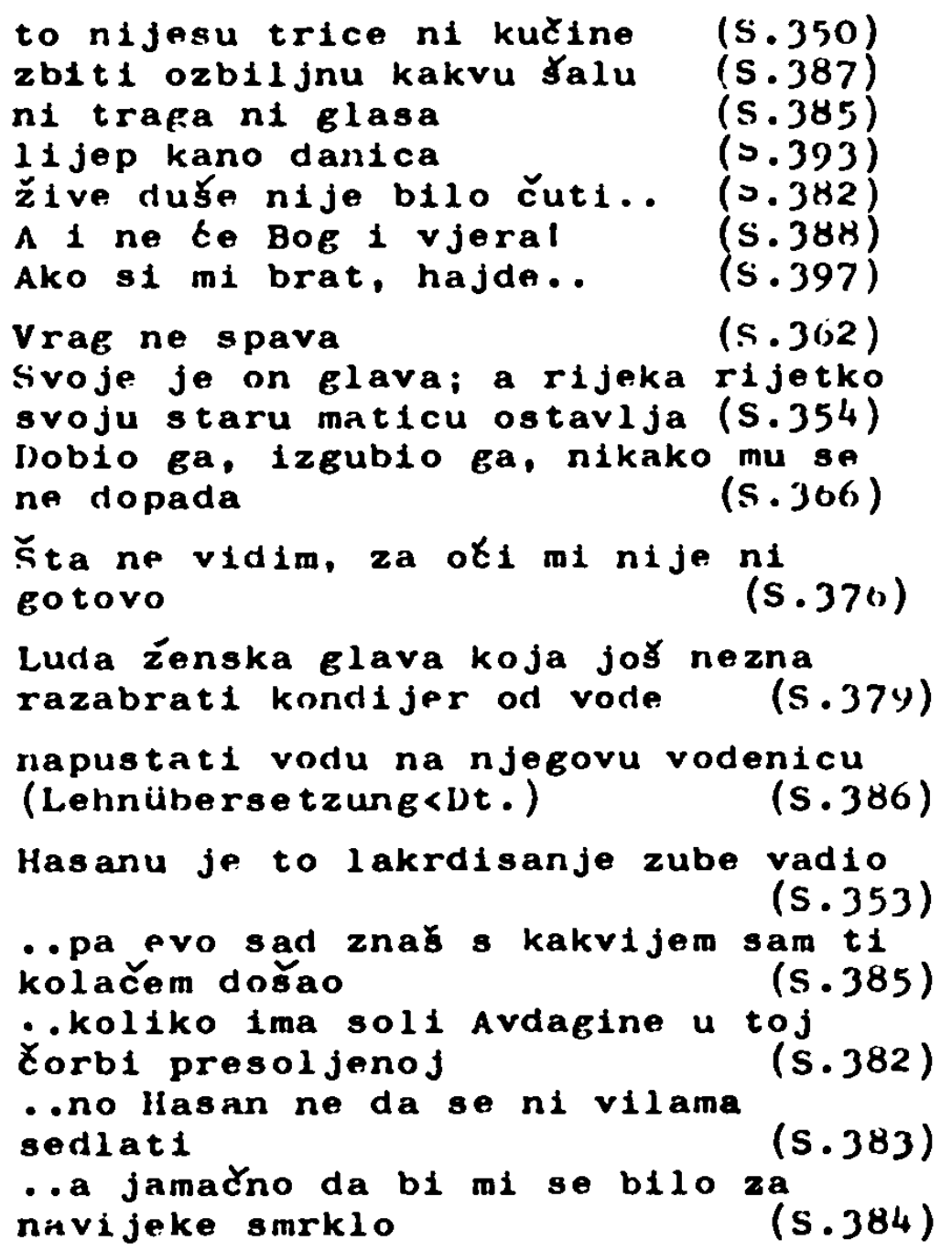

Luda źenska glava koja joł nezna razabrati kondijer od vode

napustati vodu na njegovu vodenicu (Lehnübersetzung<Dt.)

Hasanu je to lakrdisanje zube radio

- pa evo sad znas s kakrijem sam ti

kolačem došao

.koliko ima soli Avdagine u toj

Corbi presoljenoj

- no llasan ne da se ni vilama sediati

- a jamaďno da bi mi se bilo za

nivijeke smrklo

Sätze, die Elgenschaften der müdlichen Rede aufweisen, wie z.B. Ausfall des Verbums, des Hilfszeltworts. "ono" stat "on, onaj" etc Njih sroje na sokak, a Pavao jaukne, ...1 momci utekli (s.361)

Sofijin otac $i$ brata vet ot 1311 u

crkvu, a ona se sprema.d(5.367) 
Pavao na svoja kutna vrata, a hrištand blizu Turcina sa psovkama 1 prijetnja$\operatorname{ma}(\mathrm{s} .360)$

.. kad nema Hasana u kahvani, a ono je kod Pavla (S.362)

Pa kad bi složili oni dva šargiju sa bugarijom 1 njihova dva glasa, neka se kupi oko njih Sarajevo pa nek slušal (s.362)

-..tko je ono sve medu njima 1 bto ti s ve znam (S.386)

Einige Male verwendet Botit nach Art des Volkserzählers das Futurum in der Bedeutung des Präteritums (vgl.III.3.4.7.): Kad te napokon otiki u svoju kahvanu... nije se okanio, dok nije natjerao Pavla da dode z njime: ....(S.363)

Ostaviše tude u sobi samu da leži, pa te Avdaga pun ponosne radost1... nalozit1 svojemu robu, da đuva na djevojku...(s.378/379)

IV.4.2.7. Realistische Elemente

In der Zusammenstellung der vorgenannten Belspiole ist der Hinwels auf jene züge der Novelle enthalten, in denen sich der beginnende Realismus andeutet. Hier lst zunáchst die Charakterisierung einiger Personen zu erwänen. Die zentrale Gestalt wird nicht als absoluter Held dargestellt; es heist an elner stelle ausdricklich:

... no Hasana, kojl lpak, kao Yto znamo, nije bio nikakvi junačina... (s.383)

Hasan hat keine lust, in den Krieg zu ziehen, er erbietet sich vielmehr, die allein zurückbleibenden Frauen und Mädchen zu trösten; er lst leichtsinnig, und sein Lebensinhalt sind Lieder und Liebe. Auch diesen Zug kritisiert der Autor: - . a on, jadan, osim srca 1 pjesama nije imao drupijeh naćla za Zivot..(s.375)

Dem trotz seiner Fehler so liebenswerten Hasan wird als das eigentliche Ideal der ernsthafte Pavao gegenubergestellt, dessen Gedanken unablässig un die Befrelung des serbischen Volkes kreisen, der auch in relifiösen Frapen seinen festen standpunkt bewahrt, wahrend Hasan ohne weiteres bereit wäre, sich um seiner liebe willen taufen zu lassen. Der Gogensatz der beiden Charaktere kommt mehrmals antithetisch zum Ausdruck, z.B. In den Gedanken sofas (erlebte Redel): 
Besonders differenziert ist die Charakterisierung des Mula. der zwar als echter Muslim zunachst Hasans Freundschaft mit einem Christen verurteilt, dann aber Verständnis dafür zeigt. Als Pavao seinen vorschlag, der sicherheit und der Freundschaft zuliebe zum Islam uberzutreten, ablehnt, spricht er zwar den bezeichnenden Satz - "vlah je vlah"(S.365), als aber die Freunde in Not Eeraten, hilft er ihnen, obwohl ihn Hasan helogen hat. Auch andere Türen werden als Menschen mit normalen Regungen gezeichnet, nur der fintfihrer Avdaga vertritt den schablonisierten Typ der "Türkennovelle". Auf die Bemilhungen Hotits, das Verhalten Sofas bei ihrer flucht möglichst realistisch zu motivieren, wurde schon hingewiesen; da sie dem althergebrachten. sehr passiven Madchenideal entspricht, muls thre iberraschende Aktivitat aus typischen Eigenschaften, z.B. Hingstlichkeit, erklärt werden.

Wie Charakterisierung erfolet durch die direkte Rede und mit Hilfe von Mitteilungen seitens des Autors, daneben aber auch schon durch Psychologisierung. Zustände des Zweifels, der Unbehaglichkeit, des Abwägens vor einer Entscheidung werden durch botits Schilderung von Gemitsbewegungen verständich und nachvollziehbar. Hei der wiedergabe der Gedanken seiner Akteure bedient sich Botit häufie eines recht modernen Mittels der erlebten Rede.

Dies bilt besonders für die Gedanken Sofas; schon auf die erste Begegnung folgt eine Beschreibung ihrer Erregung, in die Satze in erlebter Rede eingeflochten sinds

. Nego sve to nije joj ni najmanje izjasnivalo smiješne dopataje ovoga... dana.- Sta moZe to bit1? A lpak, da je to druei tko od poznatijeh prijatelja njene kuce, no Jedan Turein! (S.370)

s ţjem promišljanjem skoro je dotle došla bila, da pođ̌me misliti, nije li mogute da svega toga nije moźa ništa bilo? Nije li mogute da je sve to sanjala? (S.371)

In die Schilderunf: inrer abenteuerlichen flucht sind zahlreiche sitze in erlebter Rede elngefügt, von denen hier nur einige wiedergegeben werden:

nh, kad je sada takn nenadno 1 sretno izmakla najerdnijoj svojoj opasnosti, od koje, pravo je imao Pavao kad joj je kazao da se čra, sada kad je od svega sigurna, da joj je kako sastati se sa Hasanoml Bogrna ̌́ta je sad s njimel No, je 11 mogute, da dok je ona stradala, njemu se nifta dogodilo nije? ....(s.391) 
In der Erzahlung von der Entfürung sofas durch Avdaga erreicht Botit durch den Wechsel der Erzählperspektive einen Uberraschungseffekt: die vorher geplante flucht wird aus der Sicht Sofas beschrieben, der Entfuhrer wird "Hasan" genannt, (sein Begleiter "Pavao") - bis er sich nach einem langen Ritt mit seinen ersten Worten als ein anderer zu erkennen $g$ ibt. Auch mit diesem Wechsel der Perspektive weicht Botit vom iblichen brzählschema ab.

Realistisch könnte man endlich auch die auf grindlicher Beobachtung beruhende Erwähnung von Gegenständen nennen, die für die tiirkische Lebensform charakteristisch sind (fildžani,zarfe, lbrik, minder, mušebak, karaduzen, Jargija etc.); hier ist aber whil kaum die Grenze zu ziehen zwischen dem streben nach konkreter "W1rklichke1t" und dem entgegenwirkenden Wunsch nach Poetisierung einer exotischen Umgebung; die letztere Tendénz dirfte bel Botit wohl uberwiegen. Ebenso dienen $2 e 1 t-$ angaben wie "istom poslije itindije"(s.382) oder "jaciju su vet davno učili mujezini" (s.377) der Gesamtstimmung, nicht naturalistischer Genauigkeit im Ablauf der Handlung; aus den vielen bezugnahmen auf die Lebensart des gröbtenteils mohammedanischen Sarajevo entsteht im Verein mit den schon erwänten Turzismen jenes Lokalkolorit, das, durch das Prisma des Autors gesehen, lyrisch wirkt. Deshalb ist hierauf bereits bei der Aufschlisselung der speziflsch lyrischen Elemente elngegangen worden.

\section{4.2.8. Zusammenfassunf}

Botit hat in seiner Novelle "Dilber-Hasan" seinen zentralen Gedanken, den der Freiheit im weitesten Sinne - Freiheit der Nation, aber auch Freiheit des Einzelnen von sozialen oder religiösen Schranken - im Rahmen einer, für die damalige zelt ungewöhnlichen, Llebesgeschichte dargestellt, die er vor dem hintergrund des serbischen Freiheitskampfes entwickelt. Dieser historische Hintergrund gibt ihm Gelegenheit, den Gedanken der nationalen Freiheit immer wieder anklingen zu lassen; das Motiv der Freundschaft, die ebenso wie die Liebe religlöse Schranken uberwindet, bietet $1 \mathrm{hm}$ willkommenen Anlab, die ethischen Verte des eigenen Volkes im Vergleich zum verdorbenen Westen su betonen (vgl.s.362). Es gelingt Botit, den kompositorischen Forderungen an den Aufbau elner Novelle waltgehend gerech th $3 \mu_{30}$ werden. 
Obwohl sein stil in den gerafften brabhlerberichten durch allzuviel hypotaktische Knnstruktionen und Haufung von Partizipien manchmal ums tandlich wirkt, wird dieser Mangel durch den Keichtum der lexik und der ornamentalen Figuren, welche den Text rhythmisieren, ausgeglichen. Die Zwanglosigkeit, mit der Botit die fifuren der Volksdichtung in seinen Prosastil einschmilzt, verhindert den Eindruck des Manierismus; ole erzeugt im Vialog den Ton der volkstünlichen Rede, in den Schilderungen die Atmosphäre des lyrischen Liedes; deshalb wirken die eingeflochtenen Lieder nicht als Fremdkörper im Prosatext, zumal sie eine Funktion im Aufbau der Novelle und als Mittel der Charakteristik der zentralen Gestalt haben. Wenngleich die Novelle bereits deutliche realistische Ansatze zeigt, uberwiegt doch die romantisch-lyrische Komponente; einen wesentlichen Anteil an der verwirklichung der lyrischen Grundstimmung haben jene stilverfahren, die Botit aus der volksilteratur ubernommen hat. 


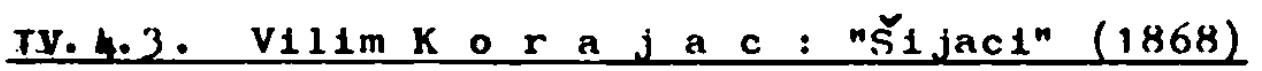

IY. 4.3.1. Orientierung - Vorbilder - Gesamtwerk

Die frühen kroatischen Humoristen Nemčlt, Jurkovit und Korajac werden in der Literaturgeschichte als "Sternianer" (sternijanci) bezelchnet, d.h. als Vertreter jenes feullietonistisch-humoristischen Stils, wie er selt sterne in der europäischen Literatur Schule femacht hatte. Wärend bel Jurkovit die Betonung aluf dem hort "humoristisch" liegen muilste, überwiegt bel Nemcit, noch melir aber bel Korajac das feullletonistische Element. Was bedeutet, dals sich seine Erzähluneen auf Kosten der Komposition und einer konsequenten Fortfühung der Fabel aus einer Reihe von Anekctoten, abschweifenden Betrachtungen, fiktiven Leserdiskussionen, rhetorischen Kunsteriffen und witzigen Formulierungen zusammensetzen, welche die ständiee Hinwendung eines sehr subjektiv erzählenden Autors an den leser dokumentieren.

Die literarische Tatigkelt Korajac', dessen erste Veröffentliching, eine politische satire, kurz nach $A b l a u f$ der periode des Bach'schen Absolutismus erschien("Dvie čudne promenade 111

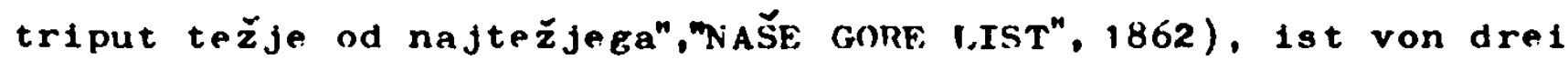
wesentlichen Komponenten bestimm: von der politischen Situation, die kein allzu offenes wort erlaubte, als auberem Faktor, der unmitelbar zur Ironie, zur satire hinfuhrt, und von den zwel Quelien, aus denen slch selne Erzăhlkunst nährt - dem vorhild der westlichen Humoristen und dem der kurzen, scherzhaften Volkserzählung (šaljiva priča), zu der er durch seine Mutter eine viel engere Beziehung hatte als z.B. Nemčlt; von riuhester Kindheit an hatte sie ihn mit solchen Geschichten unterhalten, und ihr verdankte er sein Talent. Vergegenwätigt man sich dariiber hinaus, dals er als stokavisch sprechender slavone nicht vor den sprachlichen schwierigkeiten etwa Nemčlts stand, so wird die Selbotverstänllchkeit einer Anknüprung an den $\mathrm{St} 1 \mathrm{l}$ der muindlichen $L 1$ teratur unso elnleuchtender.

Wle eriindlich sich Korajac mit der Volksilteratur befalit hat, zeigt die Tatsache, dals er 1876 seine "Filozofija hrvatskosrbskih narodnih poslovica" in nsijek herausgab, die noch durch 2 weitere, als Handschrift erhaltene Bande erganzt werden solite. 
Als europalsche Vorb1lder Korajac' eelten nach DUKAT ( $28,5.252)$ W1eland, Heine, Mnritz Saphir, Sterne, möglicherwelse auch D1derot, Karamz1n, Pušk1n, Gogol'(nach DONAT, $27,5.246$ ). DUKaT betont jedoch, dal Korajac wohl auch ohne Kenntnis dieser Schriftsteller zu einem bhnlichen stil gelangt ware:

... In allem bemerkt man elnen starken fremden Einflus. Korajac hat viel pelesen, insbesondere die deutschen Humorlsten... und or hat lhre Manier grindlich studiert; aber da er selbst eine Nelgung zu allen Launen deg subJekt1ven Erzahlers besab, ist es ke1n Wunder, dab das, was bel $1 \mathrm{hm}$ orlginal war, sich ong mit dem verband, was er von anderen ubernommen hat, oo dals selne natilrilchen Eigenhe1ten mit den fremden Elomenten zu einem..Ganzen ...verschmolzen( 28, S.252/253).

Von den elnhelmischen Schriftstellern düfte vor allem Nemčlt den St1l Korajac' beeinflubt haben, was zahlrelche unmittelbare Parallelen bestutigen; z.B. bezelchnet sich Korajac gelegentlich selbst als "putositnitar" mit offensichtilcher Bezugnahme auf den Buchtitel Nemcits. Im Untertitel der Novelle "Auvergnangki senatori" ereift er direkt ein Wortspiel aus Nemčits "Udes l judski" auf (predgovor-odgovor-prigovor,57,5.289; hel Nemcit $84,5.278$ ). Auch die Manier der komischen thersetzung lateinischer Zitate ( 57.5 .258$)$ könnte auf das Vorbild Nemčls zurickgehen.

Korajac' literarisches Gesaintwerk umfaBt neben der erwänten politischen Satire und seinen In"POZOR" in den Jahren $1865 / 66$ erschienenen, melst polemischen Feullietons vier Novellen bzw. Humoresken (Lov na sedetken, "DRAGULJUB" 1867 i"Śl jacin, "DRAGOLJUB" 1868 ;" Auvergnanski senator1", "VIJFNAC" 1.877;"Posl jednj1 Varažd1nac","SAVREMENIK"1912, posthum veröffentlicht), ferner eine kethe von Artikeln und Ubersetzunpen (Trrdica" - l'avare).

Auf die Parallelen zu Wieland, Helne und Saphir ist viadoje DUKAT in seinen studien ausfuhrlich elngegangen; in der vorlieenden Arbelt sollen anhand der Novelle "šljaci" speziell die Elemente der Volksilteratur verfolgt werden.

IV. 4.3.2. "Šstac1": GattunB - Kompns1t1on

D1e vorliegende Erzihlung 1st kelne Novelle lm strengen Sinne der klassischen Definition dieser Gattung, da sie keine einzelne Begebenhe1t in konsequenter Entwicklung auf elnen Hohepunkt hin schildert, dem eln Umschwung, eine Perlpetie-oder elne Katastrophe als Lösung folgen; hier wird kein knoten geschürzt und dann ge- 
löst; es handelt sich vielmehr um eine Reihe von Episoden ahnlichen Inhalts und Aurbaus, die den Charakter der "Šijaci", elner Art slavonischer Schildbüger, beleuchten, in die elne recht spannungs lose tiebesgeschichte eingeflochten ist. Die Erzăhlung erweckt eher den Eindruck eines statischen Porträts als den eines Handlunesablaufs, denn die in den einzelnen Episoden enthaltene Handlung dient lediglich der Illustration der besonderen Wesensart dieser leute, wobei der Autor landläufige Anekdoten üher die "S̀̀jacl", die Bewohner eines Talkessels in der Gegend des städtchens Požega, zu kleinen szenen ausgebaut hat.

Von elner Komposition kann deshalb kaum die Rede sein, obwohl die ersten beiden Kapitel elnen knnventionelien Plan vermuten lassen. Das erste Kapitel finrt den leser durch eine Hetrachtunge iber die landschaft und iber das Naturell dieser leute in die Atmosphäre, das Milieu ein, im zweiten Kapitel macht inn der Autor mit den handelnden Personen hekannt; die restlichen 7 Kapitel berichten jedoch voneinander unahhänfige, in ihrem Ausdruckswert gleichwertipe Eptsoden, die nur durch die stets fleichbleibenden Akteure zusammeneehalten verden. las eifentliche Thema ist die harmlose Beschränktheit der "Šijaci", die thre Lehensweise, ihre Ansichten, thr nalves "Geschättsgebaren" bestimmt. Nie Hauptakteure, der lorfachulze Miśo und sein Freund Jozo, verzanken sich wegen Geringfügigkeiten und vertrapen $s i c h$ wiecter, was repelmillif dazu füht, dals sich ihre kincler, Jelica uncl Milkn, die einander versprochen sind, entweder liehen dirfen oder nicht. Nichdem Jelica nach dein letzten streit soliar einem alireren Hewerher versprochen wird, wăhlt Korajac die gewaltsame Lösung, diesen Konkurrenten im richtifen Aupenblick vom Schlag treiten zu lassen, so daß elnem glicklichen Abschluß nichts mehr im rege steht. Die Hochzeit der liebenden wird ganz kurz beschrieben, um nur ehen das Interesse des Lesers am Ausgang diese Geschichte zufriedenzustelien, auf die es dem Autor selbst wenig ankomm t.

Im Hinblick auf diesen Mangel an kompositionelier straffung lief es nahe, Korajac" "S̆ijaci", die sich andererseits durch ldyllisc Stimmune und versöhnlichen Humor auszelchnen, der Gattung der Hu moreske, evtl. auch des peuilletons oder der skizze zuzuordnen. 
IV.4.3.4. Erztihl techn1k

Der Zeitraum, In dem sich die Reihe der Eplsoden abspielt, wird vom Autor recht vage umrissen; er beginnt (Kap.III) mit der herbstlichen Fahrt zum Kaetanienverkauf auf dem Markt von Bakovo, In Kap.IV wird das nahe Fest der H1.Katharina (25.XI.) erwahnt; der Anfang des VI.Kapitels falst auf etner halben Se1te den Zeitraum von "vor Weihnachten" bis zum Fruhling und zum Tap des H1.Phllipp (25.V.) zusamen; uber den Zeitpunkt der letzten Eplsode und der Hochzelt wird ketre weltere Angabe gemacht.

Das Verhältnis zwischen der Erzăhlzelt und der erzăhlten zelt 1st sehr unterschiedlich - in den szenischen Vialogen kommt es, wie im nrama, fast zur Zeitdeckung, die wenigen Erzählerberichte sind stark gerafft; oft ist der Zeitraum zwischen den Eplsoden vollkommen auspespart; die Betrachtungen und allgemeinen Informationen seitens des Autors, die fast ebenso viel Raum beanspruchen wie die Szenen, erscheinen als absolute Ruhepunkte, als Pausen, in denen die Zeit fileichsam stillsteht. Als reltere bauelemente des Textes sind neben szenen und Hetrachtungen eine ausfihrliche landschaftsbeschreibung zu Heginn des 1.Karitels, eine kurze zu beginn des 2.Kanitels und elnipe kurze Mtlieuschilderungen zu nennen, ferner zwet einfeschobene Anekdoten (Kap.V und VIII) als zusatzliche Abschweifungen, die aber den Gesamttennr der Erzählung verstärken, und eine grolse Zahl von direkten Hinwendungen an den Leser, sofar an die betroffenen Personen, und von Hezugnahmen auf den Autor.

ler lirzihler, der auf diese art ständif den Kontakt mit dem leser aufrecht erhält, deklariert sich selbst ausdricklich als "šifac" (\$.256), womit aller spott, den er ubir diesen merkwïrdien Menschenschlag ausglelst, auch inn selbst trifft, wenn er z.B. saft -

- jér valja ti, draei ל́itatelju, znati da sam ja 1 sám i. Sijak, a 2 . kao takav dobar čankoliz, al1 slab jezikoslovac! (S.250)

Daß diese Einbeziehung der eigenen Person in die Welt der"šljacl" trotz Korajac' tatsächlicher Herkunft aus der engeren Umgebung nur elne fiktive ist, zeigt der krzahlstil, in dem mehr als einmal auf bildungstatsachen Bezug genomien wird, die völlig auberhalb dieser lielt liegen (z.B. auf die priech.philosoph.schule 
der Elplstiker, S.282; auf Athen, S.258; auf die Lingulsten, S.256/257 etc.). D1ese D1stanzierung des Goblldeten - KoraJac hatte Theologle studiert und selne Kenntnisse der europalschen Literatur spater durch elne sehr umfangreiche loktiure vertieft - auBert sich in der ganzen art seiner tells huworistischen, te1ls lronisierenden Schllderung, deren erhelternde Wirkung oft genug gerade durch die Unterschiedlichke1t der Verglelchoebenen errelcht wird(Athen: Golo Brdo). Der Abstand zwischen dem Niveau des Erzahlers und dea seiner Akteure wird z.B. deutlich, wenn er eln primitives Gesprach zweler elnfaltiger Bauern als "kombinativ-hochintellektuelin bezelchnet:

-..pa zasnovali ovaj prevaźnt 1 kombinativnoveleumnt razgovor: ... (S.277)

Die Verbindung zwischen den einzelnen Bauelementen der Erzăhlung erfolgt hăufig durch elne persönliche Bemerkung des Autors, die auf selne Anwesenheit bzw. auf das Erzahler-leserVerhaltnis hindeutet. Gelegentlich wendet sich der autor auch an handelnde Personen, 2.B. am SchluB der Kapltel vI und vIII:

Uboga Jellce 1 kukavni Milkol Gdje su vam oda 11 jepe nade vare? Gdje je sada prosta 1 naravna, a svakomu covjeku urodena elpistićna f1lozofija?...(5.286)

Lediglich 4 Kapitelanfange sind frel von Hinweisen auf den Autor oder den Leser (VI, VII, IX, III). Kapitel I beginnt und endet mit Hinwendungen zum Leser, der Anfang von VIII und der SchluB von VI, VII und VIII bestehen aus Betrachtungen des Autors; die gemeinsame Antellnahme von Autor und Leser kommt durch Wendungen wie "našl putnici" (S.270) oder "..Mi temo ostati u Golom Brdu kod Jelice 1 kod M11ka" (SchluB von III,S.266) zum Ausdruck. Gewiss bedienen sich auch andere Autoren dieses Stliverfahrens'; die RegelmaBigke1t jedoch, mit der Korajac gerade am Anfang und am Schlub der Kapitel darauf zurickgre1ft, um elne Uberleltung zu schaffen, labt auf elne gewlsse Hilflosigkelt hinsichtlich der Korposition und der Fuhrung des Erzahlfadens schl1essen - elnen Mangel, den die Kownentatoren zu Recht krit1-

TBel Nemćlt z.B. tritt dieses, fur die mindliche Erzuhlwelse charakteristigche Stilmittel haufig auf, in geringerea Malie auch bel Botit, doch spielt es fur die Komposition inrer Novelien kelne so grobe Rolle wie bel Korajac. 
elert haben. Hiervon zeugen auch die letzten Satze der Eratahlung:

. Tako b1lo 1 ovaj put kod djeda M18̌e: čitar tjedan trajala gozba a onda - onda je 1 konac ovoj priporijetk1. (S.288).

Dieses unveraittelte, viellelcht als eine Art Pointe gemelnte Aufhóren des Textes erinnert an die Wendung "gotova priza" (z.B. Daruvar Nr.13.5.43). m1t der manche Volkserzuhler ihre Geschichten enden lassen - ebenfalls aus elnem gewlssen Unvermögen, elnen passenden Schlub zu finden.

IV.4.3.4. Korajac' Erzahlot11

rV.4.3.4.a. Romant1sche st11verfahren

Das Verfahren der standigen Hinwendung zu Leser is der auffalligate St1lzug, der 1m Werk Korajac' auf dif Romantik zuruickwelot. DONAT sieht hierin den Versuch einer Neubelobung der Beziehung zwischen Autor und Auditorium, die den neueren kroatischen Schriftstellern gefehlt habe:

vie "Sternianer" versuchen alle ohne Unterschied, diese Kluft zwischen dem Erzahler und dem Leser durch die Il lusion des Skaz zu uberbrucken. (27,5.244).

Damit bezieht sich DONAT unmittelbar auf EJCHENBAUM. Inwiewelt sich Korajac bel der Anwendung dieses Kunstgriffes bewulst um die Uberwindung elner solchen Kluft bemilht bzw. eInfach eine noch aktuelle literarische Mode ubernommen hat, d1e dazu noch selnem elgenen, kontaktfreudigen wesen entsprach, ist wohl kaum zu entschelden; das auch der volkserzahler den Zuhörer durch persónliches Ansprechen zu fesseln bestrebt ist, wurde schon frither augefuhrt.

Die standige Anwesenhelt des Autors lst bel Korajac deutlicher als bel manchen ausgesprochen romantischen Schriftstellern, obwohl der Erzahler nicht zu den handelnden Personen gehört. Mit der hauflgen Wendung "valja znat1.." tritt er gewlssermaken vor den leser hin, um thn uber etwas zu belehren, mit Äußerungen wie "1zraz moje čudne hiperkritiene naravi" (S.238) sondert er s1ch - w1e schon erwahnt - von den natven "Šıjaci" ab, obwohl or slch kurz zuvor als einer der ihren bezelchnet hat, und skizziert so die Umrisse elnes uber den Erelgnissen stehenden Berlchterstatters. 
Dem Tenor der romantischen Erzahlung entoprechen auch die vielen rhetorischen Fragen; Anklunge an den Sentimentalisnus finden sich in den gefuhlrolien Hinwendungen an das ebenfalls nach Art der romantischen Erzahlung - nur durch einige schablonenhafte Tugenden gekennzelchnete Liebespars

Kukarna Jelica 1 ubogl Milko - na vas se urijek kola slomel (S.278)

Die Realisierung des feuilietonistischen stils erfolgt im ubrigen weitgehend mit Mitteln, die Korajac aus der mundlichen Erzahlwe1se bezieht.

\section{IV.4.3.4.b. St1lmittel des wündlichen Erzahlers}

Die Stilmittel des mündlichen Erzahlers wurden unter III.3. ausfuhrlich behandelt. Bel Korajac, der olch in uberrelchem Maße dieser Möglichkelten bedient, tritt elne interessante Erscheinung auf: er bleibt nicht ausschliessilch in den Grenzen der Volkserzahlung befangen, sondern setzt deren verfahren neben direkter, wortwortlicher Anwendung auch zur Ironisierung eben dieser stilformen und der Welt lhrer Herkunft ein.

DUKaT hat den Erzahlstil Korajac' uberaus trefrend charakterisiert :

Korajac erzahlt, we er in einer lustigen slavonischen Gesellschaft bel elnem Glaschen Wein erzahlen wurde, damit sich selne Zuhörer unterhalten und von Herzen lachen. Und so we in einer heiteren Geselischaft die Geschichten nicht lang sein dürfen, damit die spannung nicht nachlabt, sondern kurz und gedrängt, und dabel mit elner hubschen, scharf herausgesteliten Pointe enden müssen, um die verenügten Zuhörer leicht zum lachen zu reizen, so bemulht sich Korajac auch als Schriftsteller, das Interesse des Lesers standig wach zu halten: selne Erzahlungen sind fast nichts anderes als elne Sammlung kurzweiliger Eplsoden...... Funken verstreut or mit volien Handen Scherze und Einfalle, spielt uit Worten, bildet komische Metaphern und Verglelche, flicht in olne Rede volkstiuliche Wendungen und Sprichworter ein, die, wenn sie nicht witzig sind, durch den $K_{n}$ trast zum Lachen anregen.... $(28,5.251)$

Für Korajac g11t mithin, was fJCHENBAUM uber Gogol's "Šinel" gesagt hat: 
Völlig anders wird die Komposition, wenn das Sujet an sich, verstanden als Verflechtung von Motiven mit Hilfe Ihrer Motivation, aufhört, eine organisierende Rolle zu splelen, d.h. wenn der Erzkhler stch auf irgendeline Welse in den vordergrund schiebt, wobel er das Sujet elgentlich nur zur verflechtung einzelner stilistischer Verfahren verwendet. Der Schwerpunkt wird vom Sujet (das sich in diesem Falle auf eln Minimum reduziert) auf die Verfahren des $k$ a $z$ ubertragen, die komische Hauptrolle fallt den Sprachwitzen, den "calembours" $z u$, die sich bald auf ein blobes Wortspiel beschranken, bald zu kleinen Anekdoten entwickeln. Die komischen Effekte werden durch die $M$ a 1 e des $s$ a $z$ errelcht. Aus diesem Grunde erwelsen sich gerade diese "K 1 e 1 $n 1 g k e 1 t e n^{n}$, m1t denen die Darstellung uberschuttet ist, als fur die Erforschung elner so gearteten Komposition wichtig - entfernt man sie, so bricht der Bau der Novelle in sich zusammen.

$$
\text { (30. S.122/23). }
$$

In der Humoreske "Šjac1", wt der Korajac kelne polemischen Ziele verfolgt wie in seinen feullietons oder in der satire "Dvie čudne promenade..", ist der Skaz im Sinne des oben angefuhrten Zitats das tragende Element; auf die Komposition, die ohnehin nicht selne Starke 1st, kommt es dem Autor kaum an, aber umso mehr bemilht er $81 \mathrm{ch}$ um den Skaz, dessen Bestandtelle er aus dem Fond der Umgangssprache und der Volksilteratur schöpft.

Der augenfalligote stllzug, der in der Erzahlung auf die mundliche tberlieferung hinwe1st, ist die Anhäufung von Sprichwörtern, Volkswelshelten und Redewendungen, die sowohl als Mottl als auch in Erzkhltext und direkter Rede vorkommen; sie werden tells direkt, tells lronisierend eingesetzt, oft aber dariber hinaus ins Gegentell verkehrt.

Helspiele direkter Verwendung:

Tko nos1, ne prosi. (S.261)

Teško sušı s vukom ratujutı. (s.274)

Dok se jednome ne smrkne, ne može drugome svanut1. (S.278) S' kim se ne možez počupati, ne možes̆ mu ni drag bit1.

Dok je glava, bit te kapa. (s.288)

Ont ou u svadi pravi Cigani. (S.271)

Dals die Welt, In der solche Ausspruche entstanden sind und uberliefert werden, Korajac zwar vertraut und lieb tot, dab er sie aber nicht mehr als die elnzig gultige form der Existenz anerkennt - wie dies $z$.B. bel vielen der serbischen "vukovci" der 
Fall ist - deutet z.B. bereits die Vorbemerkung an, die er einer ganzen Reihe solcher Sprichwörter vorausschickt:

Kao u svem, tako se 1 ovdje Šljak drži onth filozofiënih al' ujedno 1 rlegmati $\ell_{n i h}$ narodnih posinvica:

"Hitar odvise sretu preskate" - Dvaput mjeri, treti kroj"-

- "Ako 1 kasno, bit te Casno" 1 td.

Deutlicher noch wird Korajac' Ironische Haltune, wenn das Sprichwort als Motto eines Kapitels das Gefenteil von dem besagt, was der Text berichtet:

(Motto des l.Kapitels,S.255)

Mušterija koze pase, - wörtlich: der Kunde weidet die Ziegen, d.h., der tiichtige Händler bzw. Handwerker hat sichere kunden, die seinen Wohlstand fewhihrleisten.

In dem so lberschriebenen Kapitel nimmt die Schilderung der recht mangelhaften kaufminnischen und haudrerklichen päipketten der"śljaci"einen besonders grolien laum ein.

Murch die Umkehruip von Sprichwörtern sc' lipisilch gelinft Korajac mehrfach ein iberraschender, komischer liffekt:

Ston se danas može učinit, ne ostavljaj to za sutra. Narnina poslovica.

Sto se sutra može uciniti, cemu da to danas ciniš. కıjačka poslovica.

(Mntto des ITI.Kapitels, s.262)

Nekomu 1 pluto tone a nekome 1 olovo pluta.

Sijaku 1 pluto 1 olovo tone. Narodna poslovica.

(Motto des VIII.Kapitels,S.282)

Śjak je 1 gostoljubiv, ali samo jeseni 1 zimi; jer do proljeta $\zeta_{1 j a k}$ sve što Imade 1 pojede 1 popijel Narodna boslovica veli: najprije dobijmo, pa popijmo. Sijak

veli naopako: naiprije popijmo, onda dobijmo! (S.257)

im letztgenannten Beispiel wird nicht elnmal die vielgepriesene Volkstugend der Gastfreundschaft von der Ironie des Schriftstellers verschont.

Die Abwandlung elner gelaufieen Wendung stellt auch das Mot to des VI.Kapitels dar:

Bjě̌l kan vrag od krsta.

Bježi kao Šljak od malte. Narodna poslovica.

Bakovačka poslovica. (S.274)

Auch charakteristische Epitheta der Volksdichtung geben Korajac Anlab zu ironischen Randbemerkungen, welche die Giiltigkeit sol- 
cher Klischees in Frage stellen:

Jelica otide u svojkiljer, ojedne na jedan kovčp 1 stane - ja ne znam je il gorke 111 kisele, jer ja th jołte nikad nisam kứao - suze lijevat1. (S.280)

Dennoch geht Korajac in seiner Ironisierung nie so weit, dab or den Gelst, die Stilverfahren und die Atmosphare der Volksdichtung insgesamt negiert. Sein Spott bleibt immer gutmutig. er will nicht vernichten und richtet sich nicht gegen das Volkstumliche an stch, das thm ans Herz gewachsen lst, sondern gepen Jene beschrankte Mentalitut, aus der manche ogenannte Volksweisheiten entspringen; denn immerhin sind in unmittelbarer Nachbarschaft mancher volkswelohelt jene Aufrassungen angesiedelt, die die Grundhaltung des Splebburgers ausmachen. Korajac' Verfahren der "Umkehrung" orscheint durch das Thema der Erzahlung, die slavonischen Schildburger, deren Denkwelse ja auch eine Umkehrung der normalen logik darstelit. motiviert und angemessen, ahnlich, wie In der Novelle "Auvergnanskl senatori". In der unter dem Decknamen "Auverene" die slavonische Klelnstadt požega, für den einhelmischen Leser lelcht orkennbar, mit ihren Schwachen und threr Fngetirnigkelt geschildert wird. Da in belden Frzählunpen das 2101 aller bis zur froteske reichenden Ironisierung die polntierung. die Uberraschung, das Amusement sind, geht Korajac' Kritik nie bis zum Sarkasmus. Elne solche Haltung gegenuber der beschriebenen welt lst thm letzten findes auch nicht möplich. da er einige lhrer wesentlichsten Merkmale guthelit - ihre Unverdorbenhe1t, thre Urspriinglichkeit: man lese nur Korajac' Betrachtung uber die Vorzuge des elnfachen lebens $1 \mathrm{~m}$ Dorf, uber die strenge Elnhaltung der sitte (junge leute dirfen sich nie allein trefren usw..S.269) oder uber den altpatriarchalischen Brauch der brautwahl durch den vater(5.257.5.261). Obwohl diese Betrachtunpen voll aupenzwinkernden Humors sind, gelangt Korajac - nach elnem Seltenhieb auf die deutschen Novelisten als Vertreter des gebildeten, aber verdorbenen Auslands zu elner Art bekenntnis ( $\$ .209 / 270)$ :

Neke Nijemci noveliste trrde da je ovakova mimika pretpotopno stanje, znak slabe naobraženosti; nu ja bih Kel10 svome narodu da se nikad ne popne na stupanjone visoke naobrazenost koja zahtjeva da se ugladen mladit donle oko djevojke oavija 1 previja, donle laže i maže, dok je ubogu ne zamamil - 
In seinem Bestreben, immer unterhaltend zu sein, verwendet Korajac eine groise Zahl typischer Verfahren der Volksilteratur, die the muhelos zur verfügung stehen, da er in threm Milieu aufgewachsen ist. Dabei handelt es sich aber nur selten um den pathetischen Stil der volksepik oder die ornamentalen Formeln des lyrischen Liedes, sondern meist um den vertraulichen Fraahlton der heiteren Kurzgeschichte mit den hier vorkommenden rhetorischen Figuren. Gelegentlich flieben sogar typische Formeln des Murchens in den Dialog eins

Ej, bože, vet se veselim kako tu p1t1 1 vesel b1t1 $\cdot(5.268)$ Sehr zahlreich sind Periphrasen und Vergleiche, die, nicht immer sehr gewălt, hăufig dem ländlichen Lebensberelch entstammen und sowohl in der Volkserzahlung wie in der Umgangssprache geläufig sind:

Periphrase:

.. all kakva je sila? Ne gorl krov nad glavom! (S.268) ...morade logiku uhvatiti za cupe pa sofisticnim razlozima u Sijakovu lubanju pokucati. (S.273)

...t1 s1 stari Jarac, t1 1 vuka znao (S.279;zugi.Metapher)

Vergle1ch:

...pa sto se onda uplićes ko jazavac u tud kukuruz?(s.268) Srca je ko rovito jaje meka. (S.260)

...te se 1 ğ njim pazl kao hljeb sa solju. (S.262)

... oni se dva paze kao nokat 1 meso. (S.261)

...rastepst ce se imovina Kuburdžitera kao pljeva na vijanju! (S.261)

Eine der wentgen Metaphern ubernimmt Korajac ausnahmsweise aus der welt des epischen Liedes:

Jer kad je otac takav, zar može bitl bolje sin? Zar mote lzati soko iz vranjega gnijezda? (S.279)

Als Ironische Apposition des armseligen Dorfes Golo Brdn, die ebenfalls in die Richtung des Heldenliedes deutet, erscheint an anderer Stelle:

...u Golo Brdo, to gnijezdo lzumlj1vih sokolova.. (5.259)

Auf den Tenor des volkstimlichen Vergleichs abgestimnt sind die von Korajac gewkhlten komischen verglelche, insbesondere in den Personenbeschrelbungen des II.Kapitels: 
(iiber ajed Mišo)

lice crno, a nos uvijek - kao kakva zrela paprika crven! Glava mu je kao zrela misiraca: glatka 1 telava..(s.26n)

Bara je malena 1 uzeojna stasa, okrugle 1 plosnate,ko pokljuka, elave, a ljuta jezika, ko paprika..(s.200)

Nli si lijen ko klada, a tup ko kustura! (5.264)

Als komische Periphrase findet sich im lialog folgender satz:

Pa valjda nemaš tilita na zubih, da ne možeš ręł

sto si opazio? (S.207)

Zum bizarren Stil Knrajac' pehört auch das Wortspiel in seinen verschiedenen Aharten:

Podt.....k slobodnomu 1 odrpanomu kr. pradu Požegl, pa kreni lz ovoga varoskoga sela 111 seoskoga varosa - jer to ti je Požepa i ništa više - prema sjeveru ..(S.255)

nieser kleine Textabachnitt illustriert zueleich Korajac' Manier der komischen Antithese (slobodnomu : odrpanomu) und dor ungargssprachlichen Abschweifung unter Verwendiuf des Lativus ethicus (- jer to ti je..etc.)

Vortspiele, die der Einfältipkeit der Sprecher anpepalit sind, machen den Dialog lehensecht (hier ein primitiver Kalauer):

-Jesi li ti pri sehi, hopa ti?

- Bogati čohu nose, a ju hlato gazim. (S.270)

-Fto sad - zavrisi djed Miśn - sudi sama kakav je to

čovjek, taj Joza liogovitl

-Nije on Bopovit nepo Vragovic. (s..27(')

An weiteren Wortspielen dienen dem Autor paronnmasie und rifura etymolofica zur lusachmickune des Textes:

Fir.etymologica:

..huducepa si zeta prizetiti (S.2t)1)

(nnt snuju, a na kakvu zapreku ni ne sanjaju (s.283)

Napokon S̆ijak si u abadžije samo gunjac kupuje, t $j$. ne kupuje nego kupi; jer to je jedan - prvi 1 posijedinji put! (S.250)

Paronomasie:

- onfovarati i prieovarati (s.263)

- savija 1 previja (S.270)

life Doppelbedeutung des Verbs "presti" macht sich Korajac in folpendem wortspiel zunutze:

U drugom kutu sjedi baba Bara pa prede, do nje sjedi veliki domati macak - 1 on prede. (S.2117)

Auch einfache Reime, die teils geläufie, teils fesucht sind, dienen dem gleichen Zweck wie die Wortspiele:

Hrata bila, brata mila $(i .242)$ :

..ako dakle sunce kadàto ....srnja 1 glavrnja...(s.266)

..uzdisuti za ljubljenim al' izpuhl.jenim Milkoml (S.281)

..1 eto oad umjesto radost1, crne žalost1 (0.281) 
Weitere beliebte Kunstgriffe Korajac', die er analog zur Volkserzählung gebraucht, sind die semantische Reduplikation, die Kumulation, das Isocolon, die Antithese:

Semant.Reduplikation:

..razmislivs̆i i promozgavs̆i...(5.263)

..zdravo 1 čitavo... (s.263)

.. kad te se kao mladenci gritti, kao golubovi cijelivati moti (S.283)

Zar moz̀e izațl soko $1 z$ vranjega fnijezda?

-Il1 janje iz kurjačjega dupljal (S.279)

Kumulation:

..završe vikom, kavgom, panvkom 1 klevetom (S.276)

..kako je Milko odsele svagdje nujan, sjetan, neveseo..

(S.286)

- ćestit orać, dobar konač, marljiv berač, a కto je

još najvažnije: on je najvję̧tiji u selu knsac...(s.268)

Isocolon:

U zajednici putuje, u zajednici treuje (S.262)

..111 lanac kojim te tolkove zapinjati,

111 sjekiru kojom ke, ako sto ustreha,popravljati,

ili uzice kojimi te obode, ako popucaju, nadovezivati.. (S.265)

(Ina se kini i Zalosti u svorn srcu,

ma crili i plate,

nit sta jede nit sta pije,

vet gladuje 1 jaduje... (s.281)

Ant 1 these:

-.jer valja znati da se Šjijaci brzo zavade, ali brzo 1

pomire..... danas se, Cupaju, a sutra se grle 1 ljube(s.271)

..premda niti sunce pece niti kisa pada (S.266)

Vašl se roditelji zavadiše, a vi morate najuiłe trpjeti, oni poludiśe, a vi morate tomu krivei bit1 (S.271)

..śto su Golobraci u čitavoj Šijačkoj prvi trgovci 1 najveti ohrtnici, all ujedno prvi slijepci 1 najueti bokeil (s.259)

Ja, kao sto vet napomenuh, imam kao 1 svi druei Šijaci dobar źeludac, ali slab jezikoslovni um..(S.257)

Eine erößere, antithetisch aufgebaute Passage enthält der Text fleich zu Befinn der Erzahlung: auf die rhetorische Frage an den reser antwortet der Autor mit einer dreimalifen verneinung, um dann endlich auf den Gegenstand zu kommen, von dem er berichten will - ein Verfahren, dals der sog. slavischen Antithese des epischen Liedes entspricht:

Jesi 11, dragi ¿̇tatelju, bio lkada u svom životu u kotlu?Ne mislim u kakovu parokotlu gdje bi se čitav za nekoliko trenutaka, kao kakva instalacionalna pečenka, isprźıol

- Ne mislim ni Belzebubor kotao u kojem se davli vare!Ali ne mislimni onaj bakreni kotao u kojem se o jeseni 
rakija peče; nego mislim onaj rukom Stvoriteljevom istegani kotaokoji je tako iljep, krasan $i$ velitanstren, kao sto je sve u bozjoj prirodi lijepo, krasno 1 vel1Eanstvenol - (\$.255)

Das Verfahren des Parallelismus, ebenfalla charakteristisch fir die Volkserzählung, wendet $k$ rajac auch haufig an, $z . B$. zu Heginn des VI.Kapitels, wo der Verfasser das absterhen der Natur im Spatherbst und ihr wiederaufleben im Frihjahr mit dem Verhalten des "Šljak" vergleicht und dies auch formal durch einander entsprechende, aus Isocola gebaute Sătze zum Nusdruck bringt und so eine komische rirkung erzlelt:

Sad je nastao ndmor u naravi: crijete usnulo, raste zadrijemalo, Eitava priroda zaspala - pa 1 sijak.(\$.274) ....

.. Vet je nastupilo proljete...Gora blista,cvijete cvate, łeve crrkutu, a ṗele po crijetu optrkivaju: sva se nriroda od sna prenula 1 svi strorovi otivjeli - pa 1 Xijakl (s.275)

Was einfangs liber die Verwendung von Snrichwirtern gesagt wurde, gilt fir alle diese Stilmittel: Korajac dienen sie zwar oft nur zur Nusschmickung seines rextes, oft aber erreicht er peracte mit ihnen einen besonderen humoristischen fiffekt. IV.4.3.4.c. Realistische Elemente.

len Ahsichten des "callseura", we inn DUKAT nennt (20,5.251). sind fuch die realistischen flemente in stil Korajac' untergeordnet. lies filt vor allem fiir die llialope, In denen die lentalitat des reschildejten Menschenschlares sich spiefelt. Gelepentlich sind sie von einer knappheit, die an die volkserzahlungerinmert (vel. das Heispiel in III.3.4.4. und den lialor ant ceite 270 oder 281 der "šijaci"); dageren muten ausfiihrlichere (iespräche, in denen das "Irumherumreden" um den eifentlichen Gefenstand vorziglich fezeigt ist, geradezu wie naturalistische wiedergaben an, ile spiiren lassen, wie gut der Schriftstelier diese Art leute kennt und wie frindlich er ihre Nusdrucksweise stidiert hat bzw. einfach durch den Umpang beherrscht. Für den ieser entsteht fast immer eine erheiternde wirkung, die entweder im vergniigten wiedererkennen oder in der Uberraschung anfestchts dieser Denk- und Redeweise besteht.

Während Korajac sich in der Charakteristik seiner Personen im wesentlichen aufs Äußere beschränkt und ihre psychischen Eigenschaften eher pauschal beschreibt - sip sind sämtlich einfältig, 
gutwitig und letzten Endes, trotz aller Dickkbprigkeit, rertraglich und von einer "Peoudo-Bauernschlkue", die thnen nur schadet und nicht nutzt, - gelingt os inm, durch kleine Hinwe1se auf ortliche Gegebenhelten und Lebensgewohnheiten ein spezfisches Lokalkolorit zunindest anzudeuten (Markttage an den Tagen bestianter Helilger, Fischessen In Osijek, Art der Beleuchtung, Form des Reisens u.a.).

Pealiotische Detalls Finden sich auch in den Anmerkungen zwischen den Repliken der Dialoge, z.B.:

-Ama znas - tu odloź Grga ovoju bradru, izvadi iz usta kamil, okrene se $k$ zidu 1 pljucne mašt glavom znař, ment oe ove činl kao da sam ja nerto opazto. oder: $(\mathrm{s} .267)$

-.. Je 11 oada razumijeă?

bjed tresne nekoliko puta glavom u znak da pocinje raxabirati...(S.287)

Besonders plastisch lot z.B. die Schilderung der Entturochung der Frau des Dorfochulzen, als dieser lhr nichts vom Markt mitbringt:

Al1 kako se u čudu snade, kako se smrknu 1 namrgod1, kako usne zursto otionu, a nos $k$ zemlju osmolj1, kad joj Miło rexe da ne samo da niłta nijo kupio ni prodao, nego porrh toga puno tetovao. (s.278/279)

Als realistioche Elemente oind auch die Bezugnahren auf aktue11e Neuerungen ("teregraf", S.277) oder auf tatsachliche Verhaltniseo - die zu zahlende Maut an der "ochwarzgelben", d.h. österrelchisch-otaatlichen Schranke (Zutocrna derma, S.277) und die schon orwahnten Anepielungen auf die Linguisten zu betrachten. (Die Verballhornung des Fremdwortes "Telegrar" zu "teregraf" in der direkten Rede gehört zu den zahlreichen Kunstgriffen des Knrajac'schen Skaz.)

\section{IV.4.3.5. Zusammenfaseun:}

Im Erzahlotil Korajac' verbinden elch Stilverfahren der Volksliteratur, fur die nur eln geringer Tell der vorhandenen Belop1ele zit1ert wurde, alt romantischen, foullletonistischen und realistischen Elementen zu einew von Ironie durchsetzten, orlginelien Skax, der in mancher Hinsicht an Nemtit anknuprt, ohne jedoch durch die oprachlichen Schwierigkelten dieses Autors belastet zu seln. Was Korajac vor Nencil auszelchnet, lot der Umstand, daB er oelne Sprache weitgehend frel von 
deutschem EInfluB gehalten hat, obwohl gerade die deutschen Humoristen seine wichtigsten Vorbilder waren. Hierauf weist auch DUKaT hin:

Wahrend wir bel vielen Satzen Nemcits spüren, daB sie deutsch gedacht und dann erst mit Mine in kroatische Rede ubertragon worden sind, schreibt Korajac eine relnere Sprache, die bel allen Fremdelnfluesen das volkstumliche Kolorit bewahrt hat. $(28,5.253)$

Diese fast unverfalschte Volkssprache in die Literatur eingebracht zu haben, ist das allgemein anerkannte verdienst des slavonischen Schriftstellers. Die von der Mehrzahl der Theoretiker aufgestellte Forderung nach elner volksnahen Literatur ist von ihw weltgehend erfillt worden, wobel er aber nicht bel der Imitation der mundlichen Erzahlung sehen geblieben 1st, sondern unter Elnbeziehung threr formalen Möglichketten und Ihrer spezifischen Atmosphrre seinen humoristischen stil entwickelt hat, der eine Rethe der herkömmlichen Mittel ironisierend in Frage stellt.

Von der Ausgangsposition der Pomantik, alles Volkstumliche kritiklos als den Ursprung des Reinen, des Edlen und der Kunst selbst anzusehen, hat sich Korajac spurbar entfernt; dennoch kann man bel ihm nicht von elner Ironie im sinne der romantischen Ironie sprechen; er weckt nicht, wie etwa He1ne, Empfindungen, um sie dann wleder zu zerstören. Die Interpretation Korajac' bewirkt Helterke1t, ohne den Gegenstand der Darsteliung durch Lacherilchkelt zu vernichten; vielmehr libertragt der Autor seine sympathie für diese Menschen, die schlielilch an ihrer Bornierthelt nicht schuld sind, auf den leser - wobel in dem Wort "Sympathien seine wörtliche, ursprüngliche Bedeutung "Mitleid" mitklingt.

Der organisierende Faktor des Textes ist nicht das Sujet, sondern die Erzahlmanier, die Elemente unterschiedlicher Herkunft miteinander verbindet; mithin ist dieser Erzahlstil auf keinen bestimnten Personenkreis festgelegt - wie die Belspiele gezeigt haben -, so dab man von einem frihen Versuch des freten skaz in der kroatischen $L_{i}$ teratur sprechen kann . 
IV.4.4. Stjepan Mitrov LJub18̆a: "Štepan Mal1"(1868)

IV. 4.4.1. "Vukora Ekola"

In der serbischen Literatur setzten sich die Ideen Karadžlts erst in der nachstfolgenden Generation allgemein durch; nach Skerlit beginnt die Periode der Romantik Vuk'scher Prägung mit dem Jahre 1848, also bald nach dem Erscheinen der "Pesme" Branko Radilevits (1847), die nicht nur dte Volkasprache im Sinne des Groben Reformators realisierten, sondern gleichaelt16 einen neuen Gelst, die Frische jugendlicher Empfindung in die serbische Poesie hinelntrugen. In der Dichtkunst war damit der AnstoB zu elner Neuorientlerung an der Volkslyrik und -epik gegeben. wie sie fur elnige Anhänger Karadžlts schon zu einem fruheren Ze1tpunkt charakteristisch 1st, z.B. Joksim Novit otočanin, dessen melstgelesenes Werk "Lazarica" auoh schon 1847 erschien und erfolgreicher war als Njegošs "Gorski vijenac" (ebenfalls 1847). Fs handelt sich hierbel, wie auch $2 . B$. bel Sundečlt oder Jovan Ilit, um Ubergangsformen zwischen Volksund Hochliteratur, um Nachahmungen, die z.T1. den Ton der mund11 chen Uberlieferung so gut treffen, daB sie von dieser ubernommen wurden.

In der serbischen Romantik steht die Poesie an erster stelle, doch scton $1845 / 46$ veröffentlichte der Freund Brankos, Bogoboj Atanackovit, 2 Novellenbande unter dem Titel "Darakz Srbkinbu", mit denen er $81 \mathrm{ch}$ an die welbliche leserschaft wandte und die den Anfang der serbischen romantischen Erzahlung darstellen. Obwohl sich diese Novelien volikommen dem Schema der sentimentalen Erzählung einfugten, zeichneten sie $81 \mathrm{ch}$ nach dem Urtell der Zeitgenossen durch die Reinheit der Sprache aus (103. S.286) Atanackovit wurde in der folgezelt uberschatzt, da er der erste "vukovac" unter den Erzahlern war;. Ihm folgte elne Relhe von Schriftstellern, deren Werke $1 \mathrm{ch}$ durch Idealisierung und Poet1slerung der nationalen vergangenhelt elnerselts, durch Anhaufung folkloristischen Materials andererselts auseichnen und deren 11terarischer Wert allgemeln gering einzuschatzen iot, da sie zwar mit echter Begelsterung für ihr volk und mit den besten didaktischen Absichted, doch oft genug ohne genugendes kinstlerisches Vermögen verfaßt wurden (z.B.die Erzanlungen Čdomily Mijatovits oder Milan Miličrits). Als positiver Zug dieser, mit allen Mängeln der romantischen Erzahlung behafteten Werke 
gelten die volkssprachlichen Elemente dieser Texte und, wo es sich um zeitgenössische Stoffe handelt, die ErschlieBung der dörflichen Thematik.

EIn Grobtell der Kommentatoren, darunter Gligorit und Nedit, ist sich darin eintg, dals Stjepan Mitrov Ljubiba in seiner küstlerischen Qualitat aus der Masse dieser Schriftsteller der "Vukova škola" herausragt; lediglich skerlit vertritt die Ansicht, daß Ljubiša seine stoffe nicht zu bewăligen gewußt, thnen kein persónliches siegel aufgeprägt habe und dab seine Erzahlungen in erster Linte folkloristische bzw. etnographische Bedeutung hatten (103,S.324). Eln Vergleich mit anderen Vertretern der "Vukova škola" zeigt, daß sich diese Behauptung nicht halten laBt, vor allem, was Ljubisas gedrängte Erzahlweise und seine etgenwillige sprache, In den späteren Novellen auch, mit wenigen Ausnahmen, die Komposition betrifft.

Da die Bemuihungen der "vukovci" um eine nationale, vom Ge1st des Volkes bestimmte Literatur durch Ljubiša in besonders eindringlicher Weise verwirklicht wurden, ist als Beispiei eine seiner Novelien herausgepriffen worden, und zwar sein erstes als orteinal zu bezeichnendes Prosawerk; Ljubiłas Aufsatz iber die Pastroviti (1845) gilt als rein volkskundlicher Bericht ohne Bezug zur Belletristik. Die 1868 erschienene Novelle "Štepan Mali" welst zwar Im Vergleich zu Ljubiłas Meisterwerk "Kanjos Macedonovit" (1874) verschiedene Mängel auf, doch enthält auch dieser Text all jene flemente der Volksliteratur, die für seinen stil tynisch sind, so dass er im vorliegenden Falle als Beispiel dienen kann.

IV.4.4.2. Vorb1lder - Gesamtwerk

Der 1824 geborene Stjepan Mitrov Ljubisa, der erst im Alter von 14 Jahren schreiben lernte, gehörte einer angesehenen Familie des Stammes der Paštrovitł im Primorje an. NEDIC bemerkt, daß es Gebiete gebe, die die Charakteristika des nationalen Lebensstiles besser bewahrt häten als andere und dals Ljubiła einem solchen Landstrich mit altpartriarchalischer Lebensform entstamme ( 83,5.277). Die Beziehung zur lebendigen mündlichen Tradition ist daher bel Ljubiša bel weitem unmittelbarer als bel vielen seiner zeitgenossen, die erst durch die Sammlungen Vuks an diese 
herangefürt wurden. Den elgentlichen AnstoB zur Niederschrift der Erzahlungen erhielt aber auch Ljubisa aus dieser Richtung durch den Kontakt mit Karadzits Mitarbe1ter Vuk Vreevit.

Ljubiša, dessen belletristisches werk fast ausschlieblich auf der Volksuberlieferung beruht, verstand sich selbst urspringlich eher als Sammler denn als orlginaler Autor, the ging es un die Bewahrung des tradierten gelstigen Relchtums des Valkes und der Reinheit seiner Sprache. Selbst nach seiner Anerkennung als Schriftsteller gab er noch in seiner im Todesjahr 1878 veröffentlichten Autoblographie ("Žlvotopis", In der Zeltschrift "SRPSKA Z(RRA") zu, dab er mit Mühe zur Originalitut gelangt set $(09.5 .94)$.

Als welteres Vorbild diente Ljubifa die zeltgenösische ttalienische Prosa, vor allem die Werke Manzonis und de Anicis'; se1ne engere Helmat gehörte dem italienischen Kulturkrels an,doch gerade die Abwehr gegen diesen Einflub, die sich aus der damaligen Situation Dalmatiens erklart, bewirkte, dals die serbischnationale Komponente im Verk Ljubiłas viel starker in den Vordergrund tritt. Ljubisa, der in seiner politischen Aktivitut in spateren Jahren der österrelchischen Verwaltung gegenuber eine opportunistische Haltung einnahm, verfolgte als Schriftsteller konsequent die nationale linie; auf der verbindung dieser Tendenz mit den unverfalschten stilistischen verfahren der Volksilteratur beruhte sein Erfolg.

Nach dem bere1ts erwahnten Berlcht über den stamm der Partroviti hat te Ljubisa 1851 einen Nekrolog für Njegor verfabt. In den folgenden Jahren ubertrug er Texte von Dante, Ariost und Horaz in den Deseterac der serblschen Ep1k, und 1866 veróffentlichte er die epische Dichtung "Boj na visu".

Die eigentliche, originale literarische Tatigkeit ljubifas erstreckt sich über elnen Zeltraum von 10 Jahren - von 1868 b1s zu seinem Tode 1878. 1668 erschien 1m"ZABAVNIK DUBRovaCKI" se1ne erste Novelle "Lažnl car Štepan Mal1",der In den nuchsten Jahren elne Relhe anderer folgte: "Kanjos Macedonovit". "Pop Androvit novi Ob1l1e", "Prodaja patrijare Brk1ta"."Krada 1 prekrada zvona". In "OTADŽBINA" erschien "Prokletl kam", in "KOLEDAR DALMATINSKI" "Skočidjevojka", in "ORAO" "Gorde 111 kako crnogorka ljub1". 1875 wurden seine Novelien in Dubrovnik unter dem Titel "Pripovijesti crnogorske 1 primorske"als Sammelband 
verbffentlicht und eln Jahr später in Belgrad in kyrillischer Schrift herausgebracht. $1877 / 78$ erschienen in der "SRPSKA 20RA" die "Pricanja Vuka Dojtevita", 37 kurze Geschichten, In deren Mittelpunkt elne Figur aus der Volksiberlieferung steht, die als eine Art Hofnarr Ivan-begs, d.h. Ivan Crnojevits, Mutterwitz und Volkswelsheit vereinigt. Ebenfalls in der 'SRPSKA ZORA" veróffentlichte Ljubisa 1878 selne Autoblographie, die eine Verteldigungsschrift gegen die Vorwurfe darstellt, welche von literarischer und politischer seite gegen the erhoben worden waren.

IV.4.4.2. "Štepan Mal1": Fabel - Komposit1 on

In der Novelle"Štepan Mal1" hat Ljubisa noch nicht jene Knappheit, Jene Beschránkinf auf das Wesentliche erreicht, die elnige seiner späteren Erzahlungen kennzelchnet. Wie lmmer geht es ihm auch hier um die Bewahrung der Volksüberlieferung; nach selnen elgenen Angaben hat er sich weitgehend an den Bericht von Vuk Markov Bran gehalten. Fis handelt sich um die Geschichte des montenegrinischen "Lügenzaren" Stepan Mal1, vermutlich elnes kroatischen Abenteurers, or 1760 in der Gegend der Srednje Mahine im Primorje auftauchte, sich fur den in Wahrheit ermordeten russischen Zaren peter III. ausgab und, einige Jahre lang von den montenegrinischen Stameshäuptlingen anerkannt und gestüzt, 1771 durch den Dolch elnes gedungenen Mörders ums Leben kam.

Die Frzahlung ist in 4 Kapitel gegliedert, In denen die Ereignisse kontinuierlich berichtet werden: Im l.Kapitel - das Aurtauchen des Fremden, seine Tutigkeit als Arzt, der Beginn des falschen Splels und die Vorausdeutung des bösen Endes; $1 \mathrm{~m} 2$. Kapitel - der zunehmende Ruhm Stepans, das Für und vider um seine Anerkennune als Zar, die schlieblich durcheesetzt wird; Im 3.Kapitel - der Bericht über den noch gröberen Zulaur Stepans und die ausfuhrliche schilderung des in den vorhergehenden Kapiteln angelegten Konflikts mit Turken und Venezianern, die Ermordung von Stammeshauptlingen durch den venezianischen General Bustinian, die Verhandlungen der geistigen Fuhrer Montenegros mit den Türken um den Kopf Stepans, der Uberfall Gajo Gavrilovits und der Ruckzug der Feinde; Im 4.Kapitel - das Auftreten des russichen Fursten bolgoruki, der Aufruf Katharinas II. zum erneuten Tükenkrieg, die Gefangennahme und die Freilassung Ste-

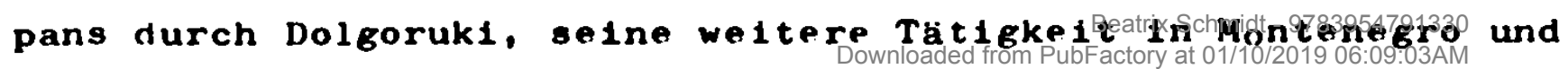


selne Ermordung durch elnen bestochenen Griechen.

Der Ablauf dieser Geschehnisse wird nur durch elne Rückblende uber den Abfall dreler Geweinden von Montenegro infolge elner venezianischen L1st - und durch eine Nebeneplsode - vor begehrlichen Providur und der stolzen Stana, der ihre Ehre mehr wert 1st als das Leben von Ehemann und Sohn - im 3.Kapitel unterbrochen; belde Abschwelfungen dienen nicht elner beabsichtigten Retardation, sondern der Illustration der verhaltisise und der Charaktere.

Trotz des sehr dramatischen Geschehens gelingt es Ljubis̆a in dieser Novelle nicht, die Spannung ständig aufrecht zu erhalten. In dem Bestreben, samtliche ihm bekannten Tatsachen zu erwbihnen, wirkt sein Bericht, insbesondere im 3.Kapitel, gelegentlich weitschwelfig und erwidend. Dramatik errelcht or nur in den szenischen Dialogen, die an einigen Wendepunkten der Handlung stehen; sobald er die Vorkommisse ohne Dialog schildert, entsteht elne Art Chronikstil, der trotz der stellungnahmen des Autors distanziert wirkt und in seiner Sachlichkelt an historlsche Abhandlungen erinnert.

\section{4.4.4. Erathltechn1k}

Die wesentlichsten bauelemente der Erzählung sind: Szenen bzw. szentsche Dialoge; Reflextonen, z.B. die als direkte Rede wiedergegebenen Erwägungen Štepans Im 1.Kapitel(S.11/12); Erzáhlerberlchte; allgemelne Feststellungen und Belehrungen durch den Autor; daneben nehmen Landschafts- und Personenbeschreibungen sowie Hinweise auf Bräuche einen geringeren Haum ein. Der Charakteristik štepans sind als elnziger der handelnden Figuren längere Abschnitte gewidmet.

In den Erzáhlerberichten, die einen großen Teil des 3.Kapitelo ausfullen, erfolgt elne zeltilche Raffung, whrend der Autor bel den wichtigen szenen langer verwellt, wobel die Uastande nur kurz skizzlert, die Dlaloge dagegen ausuhrlich wiedergegeben werden. Die Dialoge sind Musterbelspiele des gewahlten volkstumlichen Redest1ls, den Ljubiša besonders gut beherrschte; das gleiche gilt für etnige stellungnahmen des Autors. 
Der Erzahler, dessen Anwesenhe1t aus Wendungen in der $1 . P e r s o n$ sg. bzw. pl.(z.B. .. rekosmo...A sad je red da kałea...;S.34), aus Hinwelsen auf persönliche Erlebnisse im Znsammenhang at seiner Geschichte (Ja sam u ovoje mlade godine zatekao jedmog starca koji je za vremena Stepanova pưku nos1o, S.9) und aus seinen retardierenden Kommentaren erkennbar lst, ist kein küler Beobachter, sondern ein persönlich Betroffener, obwohl er zurückliegende Erelgnisse berlchteti selne Zugehörlgkelt zu dem geschilderten Milieu wird u.a. durch selne genaue Kenntnis der Verhaltnisse und örtlichkelten betont:

-.paša skadarski Mahmut Buðat11ja, poturica, starinoa Crnojevit...(S.31)

..Todosije Mrkovit, kaluder, rodom Mahina, a starinoa Baranin.. (S.18)

- pod sobow pamio tihu morsku pučinu, koja se onako strazno rastrara od rata Ortre pod Novijea Cak do starijeh gradova srpskijeh Haja 1 Nehaja...(5.12)

Elnige Erzahlerkommentare, die in lhrer epischen Brelte rou gedrangten Stil der Volkserzahlung zwar abwelchen, deuten dennoch durch haufige "miindliche" Wendungen, durch die vage Berichterstattung uber Vorkommisse in fernen LAndern und In der Formulierung der Meinung des Autors, die das Einverstandnis des Zuhörers bzw.lesers voraussetzt, auf den milndl1chen Erzäler hin; z.B. zu Beginn des 2.Kapitele:

Teško bi 1 preteśko bilo vjerovati da nije znao śtepan, kako se po smrti Petra III oglasio carem u njegovo 1 me nekl Pugačev u dnu Rusıje, pak 1 drugi 1 trell uzvil1 narod ovom varkom, dok su jedan po jedan ovi ziljem obră111. A ko zna da nije 1 ono pri Canje ranovita o Klimenu-dne otkrilo ovu stvar Stepanu prvi put? Kako je. da je, nama sad ne treba gonetat1 kad smo se vet za-

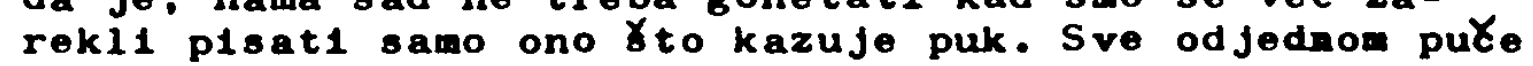
glas po primorju da se objavio car ruski u Mahinama. Kao Jto biva vazda u sli Čijem prigodama, tako se zbilo 1 onda; svako kaziva strar ne kako je Cuo, nego kako au je milije; mogi dodaju snitve, preskazivanja, čudesa, a ko hote da druge nadaudri, kate kako se on darna jetio... (S.16/17).

Dieser Erzahler lot nicht der fiktive romantische Erabler, der sich an den "genelgten Leser" wendet; er lst ganz konkret der Autor Ljubiša selbst.

Wahrend die Erzahlerberlchte durch den Chronikst1l fulhlbar in die Vergangenhelt geruckt werden, erscheinen die szenen als Gegenwart, da sie durch die plastizitat des Dialogs und durch die kurzen, oft als sehr treffende Apposition gecebenen Charakteristiken der Sprecher die Illusion unmittelbograr uAn $^{-}$ 
tellnahme am Geschehen charfen. Die elnselnen Sprecher ind nicht durch besondere Eigenhe1ten unterechieden eo bedienen olch die veneziner und Turken der glelchen Ausdruckeweleo wie die Serben, was die realistische Qualitut der Dialoge in gewiser Hinsicht aindert.

IV.4.4.5. Lox 1k, Morpholog1e, Syntax

Selbst SKERLIĆ, der Ljubiła als Kenner des Volkslebens uber den Kunstler stelit, orkennt den auBerordentlichen Reichtur und die Reinhelt seiner Sprache an. Auf eeine Erfolge suruckblickend, schrelbt Ljublěa selbst ln selner Autoblographie:

Diese Erzuhlungen haben thre Bellebthelt wegen der Reinhelt der Sprache und wegen der volkstiulichen Formen erlangt, und deshalb, we11 sie ein Splegel unseres Volkes sind. $(69,5.95)$.

In elner Epoche, in der viele Schrifteteller lumer noch un den sprachlichen Ausdruck kumpren muBten, konnte der in Budva geborene Ljubila, dessen Famile die enge Verbindung zum stamm der Pabtroviti nie hatte abreiben lassen, nicht nur uber den Vortschatz des IJekavisch-štokavischen verfügen, das der Sprache Vuks und Danıčıts zugrunde lag, sondern daruber hinaus uber elne Fulle von Provinzialismen oelner engeren Helmat - uber Archatsmen und Sonderformen, spezelle Turzismen, Rusilemen, Graezismen. Dieser Umstand bewlrkt eInen ganz besonderen 1exikal1schen Relchtum seiner Texte, or macht es aber auch notwendig, daß selbst der Muttereprachler sich bela Lesen eines Glosears bedient, das ta allgemelnen jeder Neuausabe belgerugt wird.

Ljubı̌̌a, der olch dieser E1genschaft selner sprache durchaus bewubt war, hat in selner Autoblocraphie daraur hingewiesen, daB or die serblsche sprache nicht aus Rhetorikbuchern, sondexn

aus dem Munde unseres Volkes in Suden gelernt hat, wo Ureprung und Pragestatte der Volkedichtungen sind. (69, S.96).

Da zum Ze1tpunkt des Erschelnens selner Erakhlungen ph1lologische Kriterien in der Beurteliunc der Literatur vorherrechten, mubten sie rast zwangsiufig aur elne begeloterte Aurnahme otoßen, da man In thnen olne rast ldeale Realieierung der Prinzipien Karadžles erbl1ckte. D10 Zeltechrift der Anhunger sretozar Markovite, "STRAŽa", ochrieb in threm Nokrolog rur Ljubiła 


\section{$-234-$}

1878, der woser glaube beim Lesen der Texte Ljubiłas, dae Volk selbst erzahien zu hören (42,S.82) - elne ̈̈ußerung, die sich nicht nur auf die sprache, sondern auch auf die Denkwe1se des Volkes bezog. die hier zum Ausdruck kan.

A1s Beispiele archaischer Formen im Text der Novelle iśćepan Ma11" seien angefiurt:

$$
\begin{aligned}
& \text { Dat1v zu "mi" und "vi" } \\
& \text { "ni" bzw."vi" statt "nam, vam" (enk11tisch) } \\
& \text { (< aks1. neben nawb, vamb auch nu, vai 64,5.110) }
\end{aligned}
$$

. blte 1 vama redovnicima ljepłe 1 lakǧ, jer smo v1 dosta potege daval1 1 dodijal1.(5.24)

-.pak podimo kod Dolgoruka 1 pomolimo ga da ni daruje Stepana; (s.42)

"sun (<aksl.sz) statt "sa" = mit:

..1ažac, kojl se uortačlo 1 nogovorio su tri cetiri

1zjełe...(5.19/20)

"rat" (aks1. ratb) als Femininums

Na ovo oditovanje rati...(s.27);

...omotali Turtina u ovu rat...(s.35)

Die Syntax Ljubišas ist eln wesentlicher stilistischer Faktor; whrend die chronikartigen Erzahlerberichte aufgrund seines Bestrebens, möglichst viele Tatsachen In einem Satz zusammenzudrangen, durch zusammengesetzte Perioden den Eindruck epischer Breite erwecken, bevorzugt Ljubisa in der direkten Rede einfache Perioden und parataktische satze, wie dies z.B. In den expressiven Reden der Sammlungen Vrčevits zu beobachten 1st. In diese Richtunf weist auch die Lapidaritat mancher elliptischer Formul terungen:

A on daleko, sastati se nikad. (S.11)

Der szenenartige Charakter der Dialoge wird durch die Küre der verbindenden satze unterstrichen, in denen - wie in der Volkserzahlung - oft dew Verbum dicendi ausfill:

Uz to jedan drugi gost, pošto ocijedi po bardaka vina: "Da ga hote Bog propustiti do nas....(s.11)

A Lazo Bogdanovit: "Videste 11 kako ga turi onaj Mołkovit vrh sebe u tamnicu?...(5.42)

Auch wenn die Handlung schnell vorangetrleben werden soll, entfallt gelegentlich das Verbum:

Kad na most, vidi Vuko Marka Tanovita...(s.13) 
IV.4.4.6. St1lverfahren der Volkserzahiung

Ljubiba verwendet die Stilmittel des miindlichen Erzahlers nicht allein aufgrund selnes engen Kontakts zur Erzahltradition, sondern in der ausgesprochenen Absicht, fur das volk zu schretben, als dessen Lehrer und geistiger Fuhrer er sich fuinlt. Gewlsse stilprinziplen luBerm stch hierbel nicht nur im Detall, sondern auch in der Makrostruktur selner Texte, so das in der Volksilteratur so bedeutende Formprinzip der Dre1zah 1 .

IV.4.4.6.a. Dre1zahl

$I_{n}$ der Makrostruktur der Novelle "Stepan Mali" erscheint die vreizahl in den Immer weiteren Kreisen, die die Erelenisse um Stepan ziehen: zunächst beschränken sie sich auf das Gebiet der Mahine und anf Crmnlce (Kap.1). greifen dann uber bis nach Cetinje und ganz Crna Gora (Kap.2) und erfassen schl1eislich im Ge1ste den weiten Raum bis Carigrad (Istanbul) und St.Petersburg(Kap.3/4). Noch deutlicher zeigt sich die dreifache steigerung in den Angaben uber die zu Štepan herbelströmenden Menschen: zunachst kommen sie nur aus der engeren Umgebung: Glas se prospe kao munja u obližnje zborove..(5.8, Kap.1) Im 2.Kapitel, In dem er nicht nur als Arzt, sondern berelts als Zar anerkannt wird, erfalst die Bewegung bereits den Raum des gan zen Primorje "von Dubromik bis $\operatorname{Bar}^{\prime}(5.17)$. Im 3.Kapitel Altserbien, Albanien und die Hercegovina:

Iza sred Stare Srbije, 12 Arbanije 1 Hercegovine, dodu poklisari s poklonima te se protrese 1 uzruja sva zemlja s mora na Dunavo. (S.26/27)

Dieses Prinzip der Dreizahl wendet Ljubiša auch in der Anordnung selner Satze haufig an. Die kurze einleltende Naturschilderung zu Beginn des l.Kapitels ist ein Belspiel hierfüs

(1) Jedne veče u bgžitnje poste, bał u oț bratin-dana godišta 1766 b1 jaše prekrila magla Citavu kosu visokijeh planina koje dijele Crnu goru od Primorja; (2) svili joj se eust1 pramovi s Loveena 1 Kolovira do pjene morskey (3) obuzela tama sav onaj prostor da pješą ne vid1 gdje stopom krake. (S.7)

Bereits einlge zeilen weiter folgt ein Satz, In dem dieses Prinzip der breizahl glelch zwelmal hinterelnander in der Beschrelbung des fremder Wanderers auftritt: 
Putmik se jedva uspne na pod, drkt1 od studenl, a sar 1 od etraha 1 od glad1; go, bos,snebden. (5.7)

Das gle1che Prinsip als Ste1gerung - durch die Kumulation Im 3.Satzte11 - enthklt folgender Satz, dessen Inhalt sich auf elnen bestimeten Berelch der Volksuberlififerung, den Aberflauben, bezieht:

Gdje puk vjeruje (1) u urok 1 mastu, (2) u sugreb 1 Earu, (3) u rukodlake, vjezt1ce, tence 1 more, tu se onj jera 11 je Cenje gatanjer, narod trak1 ko boljé roldenik otrara 1 nahod1 (1) uzroke, (2) trajanje 1 (3) 11 jek nenot 1. (s.9).

w1e Im vorhergehenden Belapiel ("Putnik se jedva..") 1st hier das Prinzip der Drelzahl at dem des Parallelismus in Verbindung Rebracht - ein Verfahren, daB auch In der Volksdichtung ge1kur1g 1 :t.

In der abschliebenden Bewertung der Personlichkelt Štepans wechseln dreiteil1g gebaute Satze alt kontrastierenden Strukturen ab:

Štepan Mal1, (1) 1 po orjedodžb1 duždevijeh ljud1, (2) 1 po p1smimo Dolgorukovijema, (3) 1 po kazivanju vrenika mu, b1 o je Covjek zdravog razuma, umjerene rečltost1, vrle razborltost1 1 dobroga orca. Govorio je jasno 1 otresno. Najuite se starao (1) da miri narod, (2) da pretijeca zla 1 (3) da lokorijeni osvetu. B10 je rtedij1v, a ne trrdica, n1 pus toruk, n1 lakom. (S.46)

In der direkten Rede lst dieses Stliverfahren besonders haufig: Nete ga prodat Crnogorcl da je kao žaba gubartca, n1 pljunut1 na gostoprimstro,

n1 prevjerit1 urok. (s.36)

Zvao se car, 111 knez, 111 davo 12 pakla...(S.28)

Nemamo uzdanice ni u Srba, ni u Grka, n1 u Bugara.. (5.41)

Okruniste ga bez krune, pocarlste ga bez carstra, a ukopatete ga gde al vrana ni kost ne ponijela.

(Ste1gerungi S.25)

So setzt sich das traditionelle Drelzahl-Prinzip der volkserzkhlung, uberhaupt der Volksilteratur In Ljublyas Text von der Makroatruktur der rauelichen Entwlcklung der Novel1e b1s In d1e Mikrostruktur der Satzte1le durch.

IV.4.4.6.b. Sprichworter, Sentenzen, Redewendungen

Alle Texte Ljubiăas sind durchsetzt von sprichwörtera, Sentenzen und volkstillichen Redewendungen, die elnen wesentilchen Beitrag zur Schaffung der Atmospháre der Volkserzahlung 101 sten. Iles gilt vor ellem fur die direkte Rede, Insbesondere

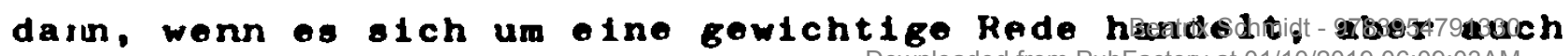


fur den Erzahltext.

Bereits die ersten direkt wiedergegebenen worte śtepane setzen sich aus solchen vorgepragten Formeln zusawen:

Idem s trbuhom za kruhom. Ċepljem crnu zemlju dokle ona mene. ( 5.8$)$

wie In diesem Falle, bestehen die melsten Redewendungen, Sprichworter usw. aus Periphrasen, Metaphern, Verglelchen.

Einige Beispiele:

In der direkten Rede:

o ostozi se vije sijeno. (s.11)

S Blave riba smrd1. (S.25)

To je skitac od bijeloga svijeta...(S.19)

...da sirovo drvo ne 1zgorl uza suho. (S.21)

Nego te kumim tri put od nebe do zemlje...(s.20)

Kakvi su se mrki oblaci nad naśom stromaśnom

zemljom svili...(S.15)

In der Indirekten Rede:

-. počne ga zapitivat1 protopop Abramovit ko je 1

otkuda je, je 11 bijela vrana 111 crna...(5.22)

Je bedeutungsvoller elne Rede lst, umso mehr enthält sie diese typischen Stilmittel volkstümlicher Redekunst, deren ziel ja die besondere Eindringlichkelt lst, z.B. In der Antwort des Janko Staniblt auf das Ansinnen, Stepan Mali zu vertre1ben :

... no se od vałe sijene boj1te...

.. sad hotete da pljunemo na so 1 hljeb...

Śta da se plaśl od praznog lmena?

...naše stare običaje cuvati kao oči u glavi...

...all ga lzagnat1 nipośto, dok ne ostanemo na devojei,

jer su tanje naše terazije na koje mjerimo pośtenje na. rodno. (S.28/29)

Dieser Redest1l erinnert lebhaft an die Sammlungen Vuk Vrëevits, aus denen einige Be1spiele unter III.3.4.angefuhrt wurden.

In den Erzahltexten, In denen es Ljubiła um elne möglichst knappe Hiedergabe der Ereignisse geht, treten diese rhetorischen stilverfahren seltener auf, doch lassen sie sich auch hier nachwe1sen:

Al1 pravoga napretka bez muke nema. (5.46)

Prepane se కtepan 1 Ėiv unre kad prodita 11st...(s.31)

Priskoct mu 211 Cas...(s.44) 
- a Cuvb1 uz to da Turdin vojoti na vrat na nos po

Anatol1J1 1 Rune11J1...(S.29)

- pak se slab sud na one ticu pojunat1. (S.35)

.. 1 blla dovela neodvis crnogoraku na plitki led, od kojega se jedra tzruě potocima krvi ovojijeh v1tełk1 jeh sinova. (S.16).

\section{IV.4.4.6.c. Rhetor 1sche Figuren}

Noben diesen Sprichwbrtern, Sentenzen und Redewendungen verwendet Ljubila elne Relhe weiterer "Kunstgrirre" des Volkserzahlers, die den Elndruck versturken, "als erzuhle das Volk selbst", wie die Zeltschrift "STRAŽ" es formuliert hatte. Hierfur einige Be1spieles

Motapher:

U njega je proc1jedena krv (5.14)

..tri čotiri 12 jeóe, dane bezdanje, koje bl varkom ovijet proydrle. (S.19/20)

Metapher und Porlphraee:

Ako ne otvorlmo zaran očl 1 ne ugasimo plamen b̌to se razvio po primorju...(S.20)

Porlphrase:

Ona te svoje m1lostivo oko od nas dit1 (S.20)

- gde Žena pułtenica vlada, koja je vijence pogazila (s.22)

Vergle1ch:

Bez stege pučina kao stoka bez Cobana (S.11)

Daj t1 ment cara, pak te mu svako oprijenut1 kao muhe medu (S.11)

-.kao da smo al pripasali kudelje (S.31)

semant.Reduplikation:

- . Jer kad in nema ko voditi na pljenove 1 hajdućinu

protiv nekrstu, krvave se 1 kolju medu sobom. (S.12)

..p1smo u kojemu se kune 1 preklinje..(s.29)

Ja so čud1m 1 ne imogu se 1 scud1t1 (Paronomas1e) Éto vi taj nar gost prije 1 . Coru vi je razb10 san.

(S.28 1.d.Rede des mea Stan1št ; v1=vama, vgl.IV.4.4.5)

-Tu t1 se u ružne raetare, kao da n1jesu n1 kunoval1 n1 drugoval1. (S.16)

Ant1these:

Ne znam ko je ni što je, no znam da je mudar 1 Kistac. (S.14)

..m1 pošteno u grobu, a v1 st1dno na zemlj1. (s.28)

A11 so opet u takowe grdnom metežu...ereta eakr11a

u perter1... Narod te ne vid1 no ga ona 11, jepo 1 Zu.je

1 vid1. (S.15) 
U toj muci, koja drắi tut, a mrači um,...(S.11)

..Bog kojl je eve trorlo 1 kojl te eve raetrorit1.(s.37

Kumulat1on:

Zastarale 1znemoglice, napadnute vučcem, l1c1nom, rusom, kostoboljom, olpnjom; pak kljast1, hrom1, sakat1, torl

1 svaki vrote ranjenic1...(S.8)

Tu, 11 jecet1 1 trave kupet1, cuje 12 ust 1 ju naroda na posijelima, na gurnima, umilnima, Eitavu povijest Crne Gore...(s.9)

\section{Flgura etymologica:}

Okruniste ga bez krune, pocariste ga bez caretra..(S.25)

Sve devet gore pomenut1jeh onako vezanijeh odveznu...(S.34)

In der vorliegenden Erzahlung gibt es elne kurze Szene, in der nicht nur solche typischen Figuren der Volkserzahlung verwendet werden, sondern in der insgesamt die metaphorische Redewelse durchgeführt 18t, wie ele an markanten Stelien der Volksmärchen oder -sagen erschelnt.- bel der Begegnung zwischen štepan Mall und dem schlauen Iguman ( $A b t$ ) Todosije, der thn durchschaut:

Todosıje, kao da nije ništa nl čuo ni vidıo, prebaca preko preta brojanice, pak sve odjednom, kao sa bale 1 sprdnje, upita Stepana: b1 li na njega ruku stavio da ga l1jeX1 od zut1ce. Stepan mu odvrati balu za balus

"Nemam 11 jeka da pomladim starca, ni da okrotim naduta." Na to Todosije, zmureti jednijem okon: "To mi prigovaras da sam ja toboz otar 1 nadut." A Štepan njemu lagahno: "T1 nijesi to, koliko n1 ja lijexnik."

So sehr aber die kurzen Repliken an die "rutselhaften" Antworten 1m Volksmarchen anklingen, oo deutlich bewelsen die verbindenden Satze, daß LJubiza trotz Verwendung der formalen Mittel des miindlichen Erzuhlers. Uber deesen sprachliche Gestaltung hinausgeht, Indem or d1e Szene durch knappe real1stische Detalls aus der Anonymtat typlolerender Schilderung in die Individualltut des Finzelfalles, der charakterisierenden Darstellung empor-. hebt.

IV.4.4.7. Charakter1s1erung der Personen

Die Art, In der Ljubila die handelndeń Personen - mit Ausnahwe Štopans - charakterisiert, ontspricht in Ihrer Lapidaritut und Inappheit dem St1l der Volksersuhlune, welcht aber insofern von deren Verfahren ab, als diese melst gans auf d1e Schilderung bzw. Charakteristerung verz1chtet, wie schon ausgefunrt wurde. D1e 


\section{$-240-$}

Charakterisierung erfolgt melst durch Appositionen, die, ohne den Gang der Handlung aufzuhalten, schlaglichtartig die wicht1gsten $Z$ üge des Betreffenden hervorheben:

Viadika Sava, dobri starac bez obtrote 1 hitrine...(S.18)

Todos1je Mrkovit, rodom Mahina, a starinom Baranin, Mǔ oštroumini 1 marlj1vi... (S.18\%1,9)

Tanovit, lijepi 1 govorlj1vi Srb1n...(S.10)

owaj Bubit, oholl čovjek, nadut 1 smeten...(S.17)

Ebenso knapp wird der turk1sche Befehlshaber durch elne ant1thet1sche Wendung beschriebens

Serask1jer nadute narav1, a kratke pamet1...(s.36)

Manchmal =wird die Apposition durch elnen Nebensatz erwe1tert:

- protopop Abramovit, pomukla lisica, koja se 12 dosta Evoźa odapinjala (S.24)

Hier wird eln beliebter volkstiulicher verglelch weiter ausgfuhrt; In den folgenden belden Belspielen dient ebenfalls eln Relativatz zur deutlicheren Charakterisierung:

Kneževao je te godine u Mahinama Janko stanlšlt, trijezn1 1 otresit1 Covjek, koj1 je navikao branit1 kod suda svaku pogreyku svojtjeh 1judi. (5.27)

. gospoda pošlju... Paskala Cikonju, koj1 pod medenım riječlma pokrivaře srdito 1 okruto srce. (s.27).

In ubrigen werden die wichtigen Gestalten durch ihre Worte und inr Verhalten charakterisiert, so z.B. der Abt Todosije in der vorher wledergegebenen kurzen szene mit štepan oder der Knez Janko stanıblt durch selne lange, kunstvolle Rede, die selne aufrechte Haltung kennzelchnet, z.B. durch Sátze wie:

Sad hotete da pl junemo na so 1 hljeb, da pokolebamo vjera.... Bogme netemo, sve nas Turc1 1 jetos 1skopal1.

Trista se cara objavilo, ml se zaklesmo jednom bit vjerni duźdu, ali nałe stare obiłaje Cuvati kao očl u glavi, ovo nijesmo ni predali ni prodali, ovo je junacka dika, koju temo brant 1 kao starinski amanet.(s.28)

(We1tere Belspiele aus dieser Rede wurden bereits unter IV. 4.4.6.b angerührt.)

Der verschlagene Protopop Abramovil versucht den zornigen Abt Todosije zugunsten Štepans umzustimmen und sagt nach einer Anspielung auf dessen Befurchtung, die fuhrende stellung zu verlieren, elnige schmelchelhafte worte, um dann wit folgendem Satz elnzulenken: 
Ja ne broj1m što zborl jetki Todosije, no što te trorit1 Todosije razborit1. (S.25)

Der befehlsgewohnte Beglerbeg wird durch folgende Replik charakterisiert:

Ko me smije pitati što ću ̊njim da radim. Krili ga, ne kr1l1, ja tu ga nat1, ako sve te vaš gore uzrastu nad oblake.

Ljubiša setzt, wie die Belspiele zelgen, den lapidaren Stil der Volkserzahlung als Mittel knapper, aber real1stischer Charakterisierung eln.

Bel dex Figur Stepans lst Ljubiša von dieser Methode abgew1chen; mit besonderer sorgfalt zelchnet er das B1ld einer vielschichtigen Persönlichkelt ohne jede Typisierung, wie sie In seinem Gesamtwerk bel elner Relhe selner Bauerngestalten zu beobachten 1st. In der Beschreibung seines ÄuBeren im 1.Kapitel lst zunachst elne gewisse Symmetrie festzustellen:

Izgledaśe osrednjeg rasta, prikladnog struka; okołtan, mledan,

ospice mu koť napisale a rał̌upane kosmurine pokrile čelo nos zakučast, 1 pale do očlju;

a oč sijere kao u tuka. (s.7/8)

Durch selne Sprechwelse ("kao kroza zuben) und sein Schwelgen über selne herkunft ("al1 koga je soja, porekla 1 vjere, vjerto zataj1",S.8) 1st Stepan Mal1 von Anfang an als eln vorsicht1ger, schlauer Mensch gekennzelchnet.

D1e Fntstehung der Idee, sich als Zar Peter III.auszugeben, 1st ausgesprochen realistisch motiviert: zuerst erfahrt కtepan von der Anhanglichkelt der Mnntenegriner an Russland; dann belauscht er eln Geprach, in dem der Satz fullts

A Ja mnim da Bog proput1 prognanoga Petra, da b1 mu se Srpstvo o vratu objesilo...(S.11)

D1e daran ankenüprenden Erwaungen Štepans stellt Ljubiša als Fleberphantasie dar, die aber st1l1stisch kelneswegs durch den hier zu erwartenden verwirrten Gelsteszustand gepragt 1st; os sind vielmohr die ziemilch sachlicken, in volistandigen Satzen gehaltenen Uberlegungen elnes Menschem, der nichts zu verlieren hat. Nur elneal werden sie durch elnen emotionellen Satz unterbrochen ("Prod1 se od mene, davole, vječna t1 mukal" S.12) un dann, nachden d1e schllws te Mbglichke1t ausgesprochen 1st (" pak mi we nete groba znati",S.12) zur ruhigen Folge der Gedanken zuruckzukehren und in dem EntschluB, das falsche Splel

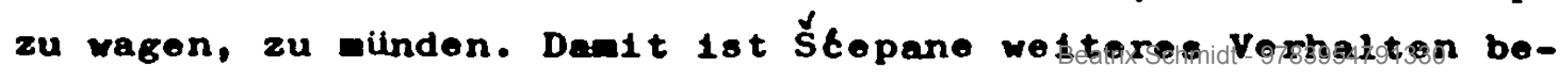
grindet, und durch d1e Form der direkten Rede ermbelichts der 
Autor die Figur eines Mitwissers, der in der weiteren Entwicklung der Fabel elne Rolle spielt.

Im Verlauf der Novelle wird Śépan durch selne Worte und seln Vorgehen konsequent als ein Mensch dargestellt, der sich unter den besonders schwierigen Zeltumstunden irgendwie zurechtfindet, selnen vortell sucht, wo er kann, aber sofort zu einew Ruckzieher bereit 1st, wenn Gefahr droht. Er verweldet es geschlckt, slch ausdrúcklich als Zar Peter zu bezelchnen, bezioht sich aber in selner groben Rede vor dem Volk unklar auf RuBland und hindert die Montenegriner nicht daran, inn zum Zaren auszurufen, da er sich von dieser Situation Annehmlichkelten verspricht; schlieblich 1st er auch berelt, selne Fuhigkelten für Montenegro einzusetzen.

In dieser Charakterlsterung Šćpans löst slch Ljublša ganz von der typlsierenden Darstellung der Volkstradition. Er zelchnet das realistische Blld elnes Menschen mit vielen Schwachen, aber auch einigen Vorzigen, die Gestalt eines kleinen Abenteurere, fur die der loser Verstindnis aufbringen kann, da s 1e überaus glaubwurdig vor dem Hintergrund einer turbulenten Epoche steht, In der ein opportunistisches Verhalten sich als elne der Mbglichkelten des Uberlebens anbot.

IV. 4.4.8. Eth1k und Tendenz

Aus der bewubt nationalen orientierung des Schriftstellers Ljubiša ergibt sich, daB es thm bel der Aufzelchnung der vorliegenden Novelle darum ging, dem Leser elne Episode aus der Vergangenhelt des elgenen volkes nahe zu bringen und zugleich ein eindrucksvolles Blid der herolsch-patriarchallschen Welt zu zelchnen. Die Sorgfalt, wit der die Namen und d1e Herkunft aller Betelligten, die Schauplatze der Handlung und die historischen Zusammenhange notiert worden sind, zeigt, dab das genaue Festhalten aller uberlieferten Elnzelhelten tatsachlich in der Absicht des Verfassers lag. In der Beschaft1gung mit der nationalen Vergangenhelt sah er einen Weg zur Starkung des Nationalbewubtseins; es kam thm aber darauf an, diese Vergangenhe1t als eine ethisch intakte Velt darzustellen. 
Die Ethik, die hier vertreten wird, ist die Ethik der alten, patriarchalischen Lobensform - d.h.. es lst die Ethik der Volkserzahlung in threr spezfisch montenegrinischen Ausprägung. In elner Welt, In der stam, Sippe, Familie die zentralen Werte darstelien, herrscht Gemeinschaftsgelst, persónliche Opferbereltschaft, und der mutige Einsatz für die Gruppe gilt als höchste Leistung. Untrennbar von elner solchen Haltung sind sehr strenge Moralvorstellungen und Ehrbegriffe. Hierzu gehören die unbedingte Achtung des Gastrechtes und die EInhaltung gegebener Versprechen, die in der vorliegenden Kovelle elne so grobe Rolle spielen. Dadurch, dals Ljubiša die Trager dieser Auffassungen zwar nur mit wentgen Strichen, aber doch realistisch skizziert, erscheint diese ethische welt glaubwüdig und nicht ldealisiert, wie dies bel vielen zeitgenössischen Schriftstellern der Fall ist. NEDIĆ nennt in diesem Zusammenhang die historischen Novellen Jakšlts, in denen dieser Dichter eine Vergangenhelt schildere, die nur in seiner Phantasie bestanden habe, und Gavrilovits, der ohne Erfolg, also ohne künstlerische Realisierung, historische Abhandlungen durchforscht habe $(83,5.270)$.

Die Tendenz I,jubisas geht aber uber den historischen Bericht,uber die realistische larstellung des Volkslebens hinaus. Um selnen zeltgenössischen Lesern den elgenen Wert bewulb zu machen, setzt er alles Serbische. Montenegrinische als das Positire an sich in Kontrast zu allem Fremden. Negativen; diese Tendenz läßt sich gerade in der Novelle "Šepan Mali" durchgehend verfolgen. Der Text 1 st durchsetzt mit Hinweisen auf die Elgenschaften, das Verhalten der einzelnen völker - der Serben einerseits, der Venezianer. Tüken und Russen andererseits. Diese antithetische Gegenuberstellung entspricht der allgemeinen Tendenz der 60er und 70er Jahre in der serbischen wie in der kroatischen Literatur.

Als Inkarnation der Falschhelt werden die Venezianer dargestellt, die 1m 2.Kapitel zwelmal, 1m 3. sieben-und Im 4.Kapitel einmal in negativer Welse entweder erwahnt werden oder in Erscheinung treten; uber die rurken gibt es mindestens funr negative ÄuBerungen, und an den Russen wird vor allem Im 4.Kapitel mehrfach Kritik geübt. Als von den Tüken angeworbener Mörder 
Stepans tritt ebenfalls ein Freader - ein Grieche - auf.

Uber die Serben bzw. die Montenegriner gibt es demgegenuber e Ine Anzahl von Bemerkungen, die nur in drel Fullen eine Kritik enthalten, melst aber nationale vorzuge betonen.

Nachstehend sind einige Belsplele dieser ÄuBerungen und Bezugnahmen zusammengestellt:

Uber die Venezianer:

viada mletačka nije htjela propustitl ovu sgodu da ne pedepàe nekoliko ovojih ljudi 12 tri optine, a to obltnom prijevarom 1 vjerolometrom. (s.33)

..1 to plati glavom, jer ga Mločlli otruju kradimice u rak1j1. (s.32)

No su, u to doba što pišemo, Mlecl b111 ljuto poklekl1, pak se 1 sroje sjent bojahu..... zato se oprijatelje Turčlnom da bolje srbe 1 Hrvate gule 1 gnjeXe. (S.18)

Mletacka vlada vide knje joj 210 prijet1....Prosutl atto da Stepan pogine, bilo bl kasno... Ne preostade do lukavstra, obienog oruzja slabih viada. (S.27)

Ferner wird im 3.Kapltel von dem Betrug deo venezianischen Generals bustinian an elner Gruppe von Stameshuuptilngen berichtet, die seinem gegebenen Wort vertrauen ("da im bit1 nete nił̌ta životima", S.33) und zu 1hm kommen, um einen Treueeld zu leisten; or labt sie in der K1rche gefangennehmen und danach aufknipfen. Der moral1sche Verfall Venedigs wird in der Eplsode vom begehrlichen Providur und der schónen Montenegrinerin der sittenstrenge des elgenen volkes gegenubergestelit. (Kapite1 3, Se1te 34/35).

Über die Türken finden sich folgende Bemerkungen:

...tako se ne vlada do u Turčina. (s.29)

No u to doba nijesu u Carigradu 1mali, a Bog zna 1 maju 11 danas, kakav zomljop1s....(S.31)

Sva tri se nagnali stari 1 sijedi da b1 1 m 1 Turdin s grehotom učinio zuluma. (S.36)

nie Turken werden als gewalttatig und unberechenbar, aber der Hinterlist der Venezianer unterlegen dargestelit:

Paše bosansk1, dukadinskl 1 arbanačkl, srpske poturice, ... znall l1jepo da su Mleț 12 lukavstva omotal1 TurËina u ovu rat da tare sile o st1jenu; omili11 im haremi 1 talagajnost...(s.35)

Am vorsichtigsten wird an den Russen Kritik geubt, was alt der traditionelien Anhanglichkelt Montenegros an das grobe, ortho- 
doxe Brudervolk und selne Baren zusamenhingt. Imwerhin wird 1m 4. Kapitel mehrfach auf das Verhalten RuBlands nach jedea Krieg hingewlesen, an dem sich die Montenegriner betelligt haben:

Todosije Mrkovit oporne naravi, začne prvi govoritis "Ovo je, Cestitl kneže, tret1 put da nas Mołkovi podbadaju na rat protivu Turaka, a vazda se bez nas unir18....(5.40/41)

Kao Ito je 1 guman Todosija naprijed pogodio, Rusija se pomiri . Turtinom bez Crne Gore...(5.45)

In dem Berlcht uber die Verlesung des Sendschreibens Katharinas II. wird LJubiša Ironisch:

Na skupštinu Vojnovit prodita gramatu carice Jekaterine, koja poziva narode grčke 1 srpske da vojéte na Turčina za krst časni 1 lijepu slobodu, obetavajuti zlatna brda 1 doline ako nadjacaju. (5.40)

Aus der groben Zahl positiver ïulerungen über Serben und Mnntenegriner seien eintge Belspiele herausgegriffen:

Nije moglo biti naroda na svijetu trrdega u zadanoj vjeri sto srpskoga. Kad Izgubl svoju neodvisnost 1 spusti se u hajdulke borbe za slobodu, nije nikad ni Turčinu prevjerio zadanu riječ. Ako je ova portena 1 junąka vrlina na mogijem mjestima gdje Srbi zive danas smalaksala, to se pripisuje sramotnomu primjeru onljeh koji su s njima himbeno viadali. (s.33)

Čuo govorit' o Crnoj Gorl, pak je zar pomisl1o: Idem tamo gde me nete niko poznat1, to je narod gostoljuban, kojl utok btuje kao svetinju...(s.19)

Moj prijatelj Dr.Valtasar Bogizit, znatni valjatni Srbin. (Autorenkommentar, S.24)

Nijesi t1 pridoß̌1ca, no pravi srb1n. (s.37)

-.ta Moškovit ocrni nam obraz. Kakvi je god Stepan

mi ga jednor zacarismo 1 dadosmo mu tvrdu vjeru.(s.42)

Als negative Züge werden nur die Unwissenhelt und der Aberglaube des montenegrinischen volkes genannt, sein jahzorniges, streltsücht1ges Natureli, das durch eine "elserne Hand" gebänd $1 g$ t werden muB:

.. kad ih nema ko vodit1..krvave ae 1 kolju medu sobom (S.12) .. a nam se hote grozdena ruka da upravlja narodoa.. (5.43)

Nikakar zanat nije korisnije medu prostad1joe 1 neznal1cama kao Xto je vraca. (S.9)

Die vorliegende Novelle lst mithin nicht nur eln Beispiel einer im Hinblick auf St1l, Ethik und Sujet rom Golot des Volkes erfuliten literatur, sondern auch elner tendenzibsen Literatur. wie sie z.B. In Kroatien Šenoa farderte. 
IV.4.4.9. Zusamenfassung; Romant1k und Raal ismus

Im Vergleich zu der "zerfilebenden Formlosigkelt der typischen romantischen Novellen" hat BARAC die Erzahlungen LJubišas als "wie aus Stein geme1Belt, hart, massiv, plastisch....inhaltich und formal absolut national, aber im Ausdruck hochküstlerisch" bezelchnet $(6,5.141$ ). In den vorhergehenden Abschnitten wurde versucht, diesen Elgenschaften nachzuspüren und thre enge Beziehung zur mindlichen Tradition lm elnzelnen aufzudecken. Dieser Zusamenhang wird in elnigen der spateren Novellen, z.B. "Prodaja Patrijare Brk1ta" oder "Kanjoš Macedonovit" möglicherwe1se noch deutlicher, ebenso in den "Pričanja Vuka Dojčevita", In welchen Volkswelshelt und Volkshumor zum Ausdruck kommen. Es wurde aber abslchtlich der versuch unternormen, berelts in der ersten Novelle diese zuge nachzuwe1sen, In der sein typischer stil noch nicht ganz ausgeformt erscheint. Dennoch gilt auch fur sie die Feststeliung LATKOVIĆs :

Und gerade darin, dab er aus Elementen der Volkstradition künstlerische Werke geschaffen und unsere Literatursprache mit volkssprachlichen Elementen berelchert und aufgefrischt hat, besteht das grobe Verdienst Ljubidas als Schriftsteller. $(63,5.18)$.

LATKOVIC betont, dad die Auswahl der Sujets aus der fulle der Uberlieferung und thre Gestaltung als abgerundete Erzanlungen elne kunstlerische lelstung darstelle, die weit uber die blobe Wiedergabe von Volkserzahlungen hinausgehe, als die SKERLIC Ljubišas Gesamtwerk elngestuft hat. Uber die allgemeln anerkannte sprachliche Qualitat selner Werke hat NeDIĆ geschrieben:

Diese Sprache ist nicht nur die echte und reine volkssprache, kernig und kraftroll, sie lat vielmehr einnalig: Worte, Satze, Formen, Konstruktionen, Bllder = alles lst vom Gelste des Volkes erfullt; und wenn Ljublša in selnen Erzahlungen nichts anderes hatte, ware allein seine Sprache ein unschatzbarer Gewinn und wurde thn in die Relhe der groben Schriftsteller stellen, jener, von denen wir zu lernen haben, wie man in serbischer Sprache schreibt...( $83,5.286)$.

Ljublšas Novelien stehen am Ubergang zwischen Romantik und Real1smus. S1e behandeln zwar mit wenlgen Ausnahmen historische Stoffe wie die melsten romantischen Novelien; die Fabel lst oft relch an ungewöhnlichen Geschehnissen (z.B. In "Skočl- 
djevojka"); es gibt die romantische, vollkomene Llebe("Gorde, 111 kako Crnogorka 1 Jub1"). Dennoch ist die romant1sche Novel1. nicht das eigentliche Metier des Schriftstellers, erst sobald er elch von deren Schema entfernt und $81 \mathrm{ch}$ auf den sicheren Boden der mindlichen Tradition stellt, gelingen ine jene lebendigen, knappen Schilderungen, die zu den besonderen Vorzugen selnes Stils zuhlen. Der Humor der "Prićanja Vuka DojCevilan" steht dem der Volkserzahlung - etwa in den Samalungen Vuk Vrčevits - nahe; In der orlginelien, spannungsrelchen Novel1e "Krada 1 prekrada zvona" auBert or $81 \mathrm{ch}$, wie GLIGORIĆ sagt, als der Humor der am Geschehen betelligten Bauern, er is t nicht oberfiachlich und nicht aufdringlich und entspringt spontan und natürlich aus ihren Erwägungen ( $42,5.61 / 62)$.

Vertraut mit der Lobenswelse des Volkes und verwurzelt in der mindlichen Tradition, gelang es Ljubiła als erstem serbischen Schriftsteller, die Atmosphare des Dorfes mit realistischen Gestalten aus Fleisch und Blut tatachlich in die literatur einzubringen. Erzuhlungen zeltgenössischer Autoren aus dem gleichen Milieu wirken demgegenüber unecht und farblos (vgl. z.B. Šapčanin); erst der serbische Realismus, zu dem das Werk Ljubiłas uberle1tet, gibt eln detallilerteres, konkretes B1ld des Dorfes, dem gegenuber die Darstellung Ljubifas st111siert im Sinne der Volkserzahlung wirkt, aus deren formalem Reichtum und geistiger substanz elch die Kunst Ljubifae entwickelt hat. 
IV.4.5. Auguet Ś en o a: "Barun Iv1ca" (1874)

IV.4.5.1. Bedeutung - Gesamtwerk

D1e uberragende Bedeutung Auguet Senoas fü die kroat1sche Literatur $18 t$ unbestritten. Senoa war nicht nur der Autor des ersten kroatischen Romans', der elgentliche Begrunder der Dorfnovelle (nach BARAC; 7,5.54) und uber elnen zeltraum von ca. 20 Jahren hin der richtungwelsende Kritiker; er hat daruber hinaus durch selne Feullietons ("Zagrebul je", $1866 / 67$. 1877. 1879/80) die offentliche Melnung beeinfluBt, und es 1st inm gelungen, ein grobBeres Publikum fü die Junge literatur zu gewinnen und damit der unter seiner Mitwirkung entstehenden Schriftsprache elne Basis zu lhrer Verbreltung und allaăhlichen Durchsetzung zu schaffen. Daß diese Basis zunachst noch sehr bescheiden war, 196 an der uberaus starken deutschen orientierung der bürgerlichen Schicht Kroatiens, von der Zdenloo ŠKRE prema njemačkoj književnosti" (116) eln Blld glbt; diese Situation forderte die antideutsche Einstellung Šenoas heraus. In seinem programmatischen Artikel "Nała knjizevnost" gelangte er zu dem SchluB, dab die neue literatur nicht nur national, sondern tendenziös seln müsse (vgl.II.5.2.7.). Śenoa, dem elnige zeltgenossen selne Herkunft von der Journalistik vorwarfen, war sich bewulst, nicht "für die Ewlgkelt" zu schrelben, sondern den vordringlichen literarischen Anforderungen selner zeit zu genugen. Wenn thm trotz seiner erstaunlich schnelien Arbeltsweise und trotz der sehr konkreten Zielsetzung selner literarischen Produktion elne Re1he hervorragender Werke gelang, so lag dies an selnem ungewönlichen erzählerischen Talent, welches die kroat1sche Prosa trotz aller Mangeil, die die spatere kritik aufgedeckt hat, erstmals zur volien Entfaltung brachte.

Mit seinen historischen Rowanen hatte Senoa den grobten ErFolg be1m Leserpublikum ("Zlatarevo zlato", 1871; "Seljacka buna", 1877; "D1ogenes", 1878; "Kletva", 1881). Wahrend elnige

1 Stanko LASIC hat in seine Analyse "Roman Śeno1na doba 1863-1881" (In: Rad JAZU 341,2agreb 1965,S.163-230, vel. Nr.60 des Lit.verz.) bere1te Kral jevits Rovan "Poterk1 dak" von 1863 elnbezogen, doch g11t "Zlatarevo zlato" al1gevein als der erste küstlerische kroat.Rowan, wie z.B. PRANGES feststellt (37A,S.143). 
selner Novelien ebenfalls historlsche stoffe behandeln ("Turopoljskl top"; "Čuvaj se senjske ruke"), grelfen d1e melsten zeltgenobsische Probleme auf, z.B. den Verfall ds Adels ("Kanarinceva l jubovca"; "Vladimirn), das Verhaltnis zwischen Stadt und Land ("Prosjak Luka"), den Zerfall der biuerlichen Grobramilien ("Barun Ivica"), das Problem der Ausgestobenen der Gesellschaft ("Prijan Lovro"; Barun Irica") etc.

Senoas Lyrik ist im Rahmen seines Gesamtwerkes von untergeordneter Bedeutung, sle hat aber wie selne Prosa spateren Autoren den Weg bereltet und Impulse vermittelt; PRANGes weist auf jene durchgehende linie hin, welche die Lyrik Šenoas-Ha rambašlts-Kranjčevits verbindet $(37 A, S, 142)$.

Die Ubergangsposition, die Senoa in der kroatischen Literatur elnnimmt, charakterisiert FRANGEŚ, indem er selne Werke als idealistisch In den Intentionen, aber realistisch im Detall bezelchnet; die Verblndung bzw. die Koexistenz von Romantik und Realismus rechtfertige FIAKEKs Terminus "kroat1sche Romantik oder Vorreal1smus" (37A,S.141:').

G.DIPIF hat in ihrer Dissertation uber Senoas historische Romane (25A) als hervorstechendes romantisches Element das S1ch-geltend-Machen des Erzahlers herausgearbe1tet (s.149); der allwissende, kommentierende, belehrende autor entspricht der romantischen Erzahltradition, die Senoa, vor allem in selnen Komanen, dank der ze1tlichen Entfernung m1t objekt1vitut und Uberschau zu verbinden wisse; "objektivitut aber 1st elne realistische Verhaltensweise und weltsicht", schreibt sie (25A,S.150). Damit ist eine Selte der "Koexistenz" der belden Stilrichtungen erfabt; eine weltere besteht in der Interpretation eines romantischen Nationalisaus alt tellwelse ausgesprochen realistischen Mitteln - wobel dieser Nationa118 mo sowohl aus der kroatischen Realityt als auch aus der Trad1tion der westeuropalschen Romantik resultiert. Šnoas

'Beim kroatischen Realismus, der bekanntlich in vieles an Senoa anknupft, ist das Verhultnis zwischen den beiden stilrichtungen nach FRANGES gerade umgekehrt - realistische Intentionen werden hauf1g noch mit den Kunstgriffen der Romant1k verwirklicht, auf deren Lbsungen man nicht lmmer verzichten kann; FRANGES spricht daher von "postromantizam". $(37 A, S, 141)$. 
Erzahlst1l, der, wie G.DIPPE formul1ert, "durch die spannung zwischen raschem ze1tungsetil und standiger Poetioierungsabsicht gekennzelchnet ist"(25A,S.159), 1st ebenfalls Ausdruck der von FRANGeS konstatierten Koexistenz zwischen Realismus und Romant1k; dieser Prosast1l, der Elemente aller bisherigen literarischen Mbglichkelten vereinigt, otellt nach FLAKER den ersten "Kanon" der kroatischen Prosa dar $(34,5 \cdot 70)$, der zugle1ch Ausgangsbasis der spateren Deformierungstendenzen wird. Hinstchtilch der geringen Paychologislerung und weitgehenden Typlsierung der Charaktere in den historischen Romanen waren diese der Romantik zuzurechnen; eine solche Darstellungswe1se entspricht, wie G.DIPPE feststellt, dem sozial-aufkiarerischen Anliegen des Autors(25A, S.1134). Andererseits finden sich in einigen Novelien durchaus Individuell gestaltete Figuren (z.B. Prijan Lovro oder die litelgestalt der hier behandelten Novelle), womlt Senoa auch unter diesem Aspekt betrachtet elne Mittierposition zwischen Romantik und Realismus elnnimot.

IV.4.5.2. Vorbllder - Vorlaufer

Whrend seines Studiums der Rechte in Prag hatte Šenoa nicht nur Kenntnisse der politischen Verhaltnisse anderer europáschen Länder, sondern auch ihrer Literatur erworben. Da er, wie schon erwahnt, den in Kroatien vorherrschenden deutschen Einflub in jeder Hinsicht bekampfte, wies er energisch auf das vorbild der franzbsischen und russischen Literatur hin, Insbesnndere auf das Turgenevs und Gogol's. Als šenoas Romane erschienen, hatte in Frankrelch bereits der Naturalismus eingesetzt (2ola: "Thbrdse Raquin", 1867); In der russischen Literatur meldeten sich nach Turgenev und Tolstoj bereits gesellschaftskritische schriftsteller wie Černyšrskij zu Wort ("Čto delat'?", 1863). Śenoa, der uber alle wesentlichen literarischen Erschelnungen der Zelt informiert war, griff fur das eigene schaffen jene Elemente heraus, die den kroatischen Verhaltnissen am besten entsprachen; hier, wo das Leserpublikum immer noch gering an 2 ahl war, galt es, weitere Kreise zu interessieren, um mit Hilfe der Iiteratur das Nationalbewulsein zu starken, den Fremdgelst zu be- 
kumpen und der allgemelnen Aufklarung der Bevblkerung zu dienen. Solchen zielen entsprach elne literatur, die mit vertrauten, fesselnden stofren, also mit romantischen Fabeln, nationale und moralische Tendenzen verband.

Bel elnem Autor mit elnem so weiten literarischen Horizont, dem dazu noch ein Grobtell der europalschen Literatur in der Originalsprache zuganglich ar, l1egt es nahe, in elnzelnen nach Vorbildern und Einflussen zu fragen. Hinsicht$11 \mathrm{ch}$ der russischen und der anderen slav1schen Literaturen hat s 1ch FLAKER' mit diesem Problem auseinandergesetzt; In bezug auf die deutsche Literatur sind BARAC ${ }^{2}$ und ŠKREB ${ }^{3}$ dieser Frage nachgegangen. Es labt slch jedoch in der Prosa Šenoas ke1ne gelstige Abhanglgkelt von 1rgendelnem deutschen Schriftsteller feststelien, obwohl er sich z.B. uber Helne, Lenau und Grillparzer positiv gesubert hat (25A,S.24). G.DIPPE weist in diesem Zusammenhang auf die uberaus vorsichtige Differenzierung ŠKREBs zwischen "Spuren" (tragovi) und "Einflussen" (uticaji) hin und schlagt vor, 1m Hinblick auf Ähnlichkelten, die sich aus uhnlichen voraussetzungen ergeben können, anstelle von E1nfluB, Nachahmung oder Anlehnung von Anklangen zu sprechen (25A,S.28). Diese Formul1erung 110 Be stch auf die Paralielen zwischen den Romanen Śenoas und denen Walter Scotts und Manzonis anwenden, aur die oft hingewiesen worden ist. Ferner kann man - unter Berücksichtigung der von ŠKREB geforderten notwendigen Wahrscheinlichke1t eines Einflusses - neben den schon erwahnten russischen Autoren elne Reihe welterer Schriftsteller nennen, die Šenoa nachwelslich beelndruckt haben - z.B.Mick1ewicz, Krasthoki, Stowack1, Stenkiewlcz und Hugo sowle Neruda, mit dea Senoa befreundet war (nach 25A,S.29-31).

In der kroatischen Novellistik hat Senoa elne Reihe von

'A.Flaker: Hrvatska novela 1 Turgenjev, in: Knjlzerne 2 poredbe, Zagreb 1968, S.83-158.

${ }^{2}$. Barac: Senoin odnos prema njemačkon narodu, in: Zbornik radova fllozofskog fakulteta.

3. Zagreb 1951, S.181-202.

3z.škreb: Tragovi njemacke poezije u Šnolnim otihovima, 1n: RAD JAZU 290, Zagreb 1952, S.129-196. 
Vorlaufern, die ahnliche Stoffe wie er behandelten und deren Fabeln er teilweise ibernommen hat (z.B. Vukotinovic, Perkovac, Demeter). Dennoch sieht BARAC in Senna den eigentlichen Begrinder nicht nur der Dorfnovelle, sondern uberhaupt der kroatischen Novelle:

Ohne den äleren Novelilsten thre Bedeutung abzusprechen, kann man dennoch mit vollem Recht sagen, dais erst Senoa die kroatische Novelie imelgentlichen Sinne begrindet hat. Alle kroatischen Novelisten vor inm.... haben nur das Material vorbereitet, welches erst Senoa als erster küstlerisch zu nutzen wuste (7.5.49).

In den blteren Novelien aus dem dörilchen Milieu steht das Schicksal von Halbintellektuelien im Mittelpunkt (z.B. In Jurkovits "Pavao Čuturıe"), oder es handelt sich um folklorietische Berichte ohne literarische Qualitat (z.B.Bucars "Selske pripovijesti"). In Senoas Novelien tot erstmallg die Fabel aus der zeitgenössischen dörfichen Problematik heraus entwickelt $(7,5.54)$. BARAC nennt "Barun Ivica" und "M1adi gospodin" $(1874 ; 1875)$ die ersten gelungenen kroatischen Dorfnove 1 len.

IV.4.5.3. "Barun Iv1ca": Nove11entyp - Fabe 1 -

\section{Komposition - Tendenz}

Senoas Novelle "Barun Ivica" lst eine Rahmenerabhlung, die zum Typ der "Sonderlings-Novelle" zu rechnen 1st. Deutlich lst das Vorbild Turgenevs ("Zap1sk1 ochotnika", 1852) spürbar. Zunächst zeichnet Šenoa den äulseren Kahmen, der den Hezug zur jepenwart herstellt - hier zur aktuelien Erscheinung der Auftellung des Besitzes der Familiengemeinschaften (zadruge): dann schildert er die Begegnung des Ich-Erazhlers mit elnem ungewöhnlichen Menschen, der thm nach kurzem Gesprach seine Lebensgeschichte erzahlt; nach deren Abschlub kehrt der Erzahler zur Gegenwart zuruck, und die elngango begonnene Handlung - das Schaufeln eines Grabes und eine Beerdigung, wodurch der Inhalt der elgentlichen Erzahlung nochals symbolisiert ist - wird zu Ende gefinrt, so dab der "Rahmen" volistandig ist.

Die Erzahlung des "Barun Irica", die In diesen Rahmen gestelit 1st, ist verhaltnismabig einfach - die Handlung verlauft einsträngig, ohne gröbere Abschweifunpen oder Betrachtungen des Berichtenden. Dem buberen Aufbau der drei Kapitel entopricht 
die Innere Komposition. Kapitel l schildert die helle Welt der alten patriarchalischen Lobensform: Ivica 1 st der Sohn elnes wohlhabenden freien Bauern der Stadtgemelnde Zagreb (varołki slobodnjak); seln Vater 1st eln otrenger, aber gut1ger Hausvater, der selbst kraftig zuzppacken we1p und der seinem Sohn in elner groben Rede die alten Auffassungen von den elgentlichen ethischen Worten geradezu programmatisch darlegt. Ivicas Bauernfleis, sein Stolz, seine grobe Liebe auf den ersten Blick, die Brautwerbung - dies alles fügt sich su elnem Bild vollkommener landlicher Idylle zusammen. Das Kapitel endet mit dem Tod des Vaters, womit der Zusamenbruch der he1len Welt angedeutet 1st, der sich Im 2 .Kapitel schrittwelse volizieht: die Mutter beginnt zu trinken, gerkt zunkchst unter den Einflub des hinterlistigen Vormunds, eines stadischen Winkeladvokaten, und dann unter den eines höchst zwelfelharten Fremden, der angeblich 1 rgendwo in der stelermark durch elnen Brand Haus und Hof verloren hat; die berelts festgesetzte Hochze1t Ivicas wird hinausgezobert, der Besitz zwischen $1 \mathrm{hm}$ und der Mutter aufgete1lt; als or wegen der Tellungsangelegenhe1t nach Zagreb relst, um endlich alle Hindernisse selner Eheschl1eBung aus dem Weg zu ráumen, wird or mit Hilfe eines abgekarteten Splels zwischen dem Vormund und elnem Werber zwangswelse zum Militar verpfilchtet.

Das 3.Kapitel schildert den endgultigen ozialen Untergang des "Barun", In den Kampfen in Italien zeichnet er sich aus und rettet dem Hauptmann das Loben; als er d1esem danach von dem inm widerfahrenen Unrecht erzahlt, setzt sich der Vorgesetzte, ein aufrechter "Grantlar", für ihn e1n, wird aber, ohe er etwas für ihn erreichen kann, unerwartet versetzt. Elnes Tages entfernt sich Ivica unerlaubt von seiner Truppe und versucht, in einem plotzlichen Anfall verzwelfelter Hoffnung, su desertieren, wird gefabt und kommt in schwere Festungshaft; nach seiner vorze1t1gen Entlassung - nach 7 Jahren - kehrt or endlich helm, um dort den Sohn des "abgebrannten" Stelrers als Bestzer selnes Hofes anzutreffen; die Muter, die den Stelrer gehelratet hatte, ist tot, die jungeren Geschileter leben in tiefstem Elend, und or selbst wird mit elnem Betrag von 40 Forint "ausgezahlt", wie dies auferund der undurchsichtigen Manipulationen des Vormunde 
selnerzelt tatsichlich schriftilch festgelegt worden 1 st. Damit 1st sein Schicksal besiegelt; er wird stadtischer straBenkehrer, arbeltet ab und an als Totengraber und ergibt sich gelegentlich - wle seine Mutter und sein jungerer Bruder - dem Alkohol, un zu vergessen.

Uber dem personlichen Schicksal, das sich mit romantisch-unglaubwürdiger Konsequenz ausschlieblich negativ abwickelt. steht a ls Thema der Novelle das Problem des Zerfalls der alten Lebensgemeinschaften, der Auftellung des Gemelnschaftsbesitzes der "zadruge". Der Anfang der Novelle wirkt nach den ersten sachlichen Satzen we eine Paraphrase uber das vort "dijelin: allein auf der ersten Selte wird der Satz "dijeli ter dijeli!" dreimal, der Ausruf "dijeli se "im zweiten Absatz sogar viermal wie elne Beschwörung wlederholt. Was hier im Vorsplel noch fast humoristisch berichtet wird, steht in der elpentlichen Frzahlung, im Zentrum der tragischen fitwicklung (Kap.2); neben allen anderen Ubeln ist es gerade der verlust des Grundbesitzes, vor dem der Vater den Sohn Im l.Kapitel eindringlich gewarnt hat:

Lohro sl zapišl za uho nasu medu, da ti susjedov plug ne preore, da ti drugi na trojem ne viada (S.23).

Im 3.Kapitel wird mit der Erklarung des Senators Martinit iber die Art der sogenannten Tellung der endgultige Schlubstrich unter das Leben Ivicas gezopen, das mit einem absoluten Verlust endet. Das Motiv der Tellung wird mithin in jedem Kapitel an entscheidender stelle aufgepriffen und dariber hinaus mit dem Motiv des Begräbisseg bzw. des Todes in Verbindung gebracht: Im l.Kapitel umschrelbt der "Barun" selne Tatigke1t, wahrend er das Grab schaufelt :

F vidite - dijelim zadnji dio. (S.10).

Im 2.Kapitel, als der vormund, Irica, seine Mutter und sein Bruder zum Rathaus gehen, un die Tellungsurkunde zu unterzelchnen, heibt es:

Idasmo jedan do drugoga, ne govoreti nista, kao pri kakovom sprovodu. (S.58).

Im 3.Kapitel findet Ivica den Vormund, den elnzigen, den er noch zur Verantwortung ziehen könnte, tot in seinem zimer, und den Abschluß der Rahmenhandlung bildet, wie vorhin erwahnt, das Zuschaufeln des Grabes. 
Neben dieser markanten Kompostionselenent stehen kleinere "Zelchen", zwischen denen sich der Bogen der Erzuhlung spannt: d1e Kirche des Helmatdorfes, Svetl Duh, wird lmer wieder erwahnt (S.8, In der Rahmenerzahlunf; S.17, In der Elnleitung der Erzahlung Ivicas; S.61, vor der letzten Begegnung mit der Geliebten; S.67, be10 Abtransport der Soldaten nach Italien; S.77, bel Ivicas Helakehr; S.83, nachdew der "Barun" seinen Bericht beendet hat). - $Z_{11}$ elnew Ze1tpunkt, da d1e Idylle noch volikommen erscheint, befragt die Gellebte ein "Krautchen" nach der Zukunft, und das kindliche orakel fallt unginst1g aus (s.62); der heingekehrte Ivica erinnert sich schwerzlich daran:

Jagıce, Jagıce! mišıjahsi, troja travica nije slagala $(5.77)$.

Ein weiteres Kompositionselement, das zwischen der Rahmenerzahlung und dea Bericht Ivicas eine verbindung schafft, bilden die Hinweise auf die Frau als negative erscheinung: in der Einfihrung ist schon wehrfach von threr Habgier, ihrer Scharfzüglgkelt und threr mangelnden Einsicht die Rede:

A Zene! Malo koja zena ima premalo jezika, pa in reci, da 1 one nekakvo pravo lmaju, na zdravljei (5.7)

Kad mi je bilo dovrh glave, zagrmim ljudsk1. Zenskad se skunj1. a ja la gromko dołapnem: "Żene u kutu, muškarc1 na dvor ln Dobro je b1lo. (s.8/9).

In dem zur elfentlichen Erzahlung uberlettenden Gesprach wird wieder die "zla Zena" als Ursache fur den Untergang des Mannes genannt (S.11), und In Ivicas Geschichte lst es wieder elne Frau, seine Mutter, deren Verhalten alles Ungluck ausgelös hat.

Jedes einselne der drel Kapitel endet alt elner besonderen traglschen Effekt; das erste mit dem Tod des vaters, das zwe te wit Iricas Zwangsekrutierung, das dritte mit dea endgultigen Verlust des Besitzes.

Die Tendenz der Novelle 18t, wle lmer bel Šenoa, elne moralisierende: geze1gt wird der Untergang elner Existenz durch d1e Bbsartigkeit von Intriganten; der nalve Bauer, der an die alten ethischen verte glaubt, wird durch Frende und stadter zugrunde gerichtet. Die didaktische Absicht reranlabt Senoa zur 
Ubertreibung: in Leben Ivicas gibt es seit dem Tode des Vaters nichts als Fehlschlage; aber durch dieses krasse belspiel der Ungerechtigkeit wird auf die alleemelne Lage einer unterprivileglerten Schicht hingewiesen, die den veranderten Umstunden nicht gewachsen war, auch wenn $81 \mathrm{ch}$ der Einzelfall nicht immer so einseitig negativ darstellte. Insofern 1st die Gestalt des Barun Ivica eln direkter Vorläufer des Ivica Kičmanovit in Kovačls Roman "U registraturi"(1888).

Die soziale Problematik 1st in dieser Novelle mithin ausgepragter als die bekannte nationalistische Tendenz Senoas. Immerhin treten als Urheber allen tbels nicht nur der stadtische vormund und die trunksichtige Prau, sondern auch "Steirer", also slovenen, auf. Der Hauptmann, der Ivica helfen wollte, wird durch einen österrelcher ("nekakav Svaba") ersetzt, von dem offenbar keine Hilfe zu erwarten ist, und als Ivica desertiert, wird er von einem unfarischen Husaren mit Gewalt zurickgebracht. Entscheidender aber als die Konfrontation mit dem fremden Element ist in dieser Novelle die Gepeniberstellung von Stadt und land, wie sie auch Kovacits Koman kennzeichnet.

\section{IV.4.5.4. Hranhltechn1k}

Senoa ist ein Meister der szenischen Erzählung und des llialogs; seline besondere Kunst besteht in der geschickten Verbindung der elinzelnen Szenen, wodurch er den Elndruck völlif zwanplosen krzahlens erweckt. Auch in dieser Novelle gehört der Dialop zu den wesentlichsten Bauelementen der Erzählung. Ferner gibt es einen proben Monolop - die Rede des Vaters im l.Kapitel. Die Erzählerberichte sind erstaunlich knapp gehalten; z.B. nehmen sieben Jahre Gefanpenschaft nur eine Selte des Textes ein, das soldatenleben wird aut 1 l/2 Selten skizziert (5.68/69), die Schilderunf der Kämpfe in Italien auf elner selte zusammengedrangt. Das Verháltnis zwischen Frzăhlzelt und erzáhlter Zeit wechselt also Innerhalb dieser Novelle stindig in sehr starkem AusmaB.

Die Landschaftsbeschrelbungen sind ebenfalls knapp, schaffen aber Immer Atmospháre, ebenso wie die Schilderungen der Interleurs, die die Szenerie nachfolgender Dialoge bilden. Diese kurzen Hinweise haben keinen Elgenwert, sie unterstrelchen lediglich die Stimmung. In der Erinnerung an die verlorene helle Welt beginnt der "Barun" seine Erzählung mit einem idyl1 ischen B11d: 
Giedajte onu 11 jepu kutu na drugon brijegus od Crrate je hrastovine. Vele, da ju je grad10 moj pradjed. Oko kute je 11 jep trnac, vrt 1 dalje vinograd. Kraj kute 11 jepa staja, a dalje u jarku mlin na dva kotaca 1 bume 1 oran1ce, 1 rta je znam. To Vam je eoja barunija b11a...(5.14)

D1e bedrohl1che St1woung des herannahenden Gewitters, das Unwetter selbst, In dem slch kunftiges Unhell andeutet, macht Šnoa mit wenigen Sktzen lebendig (Kap.2):

Al' jednog dana oko podne skupljall se mall sivl oblacl u onow kutu nad gorom. Sparina, da jedva d1šeš.... ..Odnikud vjetrita. Jezik mi se 11jep1o uz nebo, a nad goron oblak sve raste 1 raste... ...Al' da. Ono malo kificel sve je to deblje 1 deblje curiio. Nebo sivo, da ne vidir na njem piknjice, a grom puca kao velik bubanj. Trebalo je 161 preko brda. Cesta 1 po suhom da te Bog sačuva, sad se liovała razmekłala bila kao tijesto, a volovi moj1 ove na ovom tragu zapinjal1.... (S.50)

Die armselige Behausung des Vormunds in Zagreb schlldert Šenoa mit rolgenden satzen:

U blatnom dvoriłtu mala, niska komorica. Mi baš nijesmo gospoda kaputaki - mi Duhovljani, all da oprostite, kod moga tutora bilo ko u staj1. Pofarbana stara postelja, Separ stol, razderana stollca od slame, pol lojanice u fları, koledar, salica tinte, tri lule po groš, na polic1 starinska knj1ga 1 polit rakije, nad posteljom zamrijan1 k1p sv.Martina, a po prozoru skakala vrana,noset1 malo zvonce oko vrata. (S.64)

D1e Personenbeschrelbungen sind ebenfalls kurz und oft oher typisierend als charakterisierend, z.B. uhneln sich die Beschreibungen des "abgebrannten" Steirers Bartol und die des Vormunds, d.h. ste sind schon buberlich als Intriganten gekennze1chnet:

Der"Tutor"Martin Špinčil:

B10 to Covjek suh, uska lica, celave glave, łlljasta nosa. Imao zafrkane brkove, a ot 1 kao zaba. (S.47)

Der Steirer Bartol: Muź b1jałe jak, suh, visok, drednj1h god1na. L1ce wu b110 usko, nos tiljast, telo veliko...(s.51)

Uber den Vormund sagt Ivica:

Sa mon je aalo govorio, no govoretl nije al nikad $8 \mathrm{~m} 10$ pogledat 1 u očl. (S.47)

Uber Bartol:

Tom prilikom bi se blo vazda trznuo, kao da ga je noje oko ujelo, a nikad ae nije smio ljudski pogledat1. (s.53)

Das Mudchen Jaglca wird unter Verwendung der geluufigen Vergle1che der Volkserzahlung geschildert: 
...da ste je vidjell pod selenin drreton, kros koje je sunce sijevalol Lice joj bllo ko rulica na snijegu, 11ce f1no, puno, treparice duge, odt crne, ko Itr ugljen, zubl drobn1 - (s.32/33)

Da sowohl d1e Rahmenerzuhlung als auch der Berlcht des "Barun" In Ich-Fora gehalten sind, glbt es in dieser Novelle zwel auktorlale Ersuhler. Der Ersahler I nimet in der Rahmenerzkhlung als stadtischer Beamer und Landvermesser zu den Verhalten der Bauern anlablich der Auftellung des Besitses stellung; or 1st es, der die ersten abfulligen Benerkungen liber die Frauen aussprlcht. Der Erskhler II, der "Barun", der zugle1ch d1e Hauptgestalt selnes autoblographischen Berichtes 1st, formuliert selne grundsatzlichen Auffassungon zunuchst als Ermahnungen des Vaters. In Verlauf der Erzbhlung glbt or seine Ansichten in kurzen Bemerkungen bekannt, $z$.B. am SchluB des l.Kapltels:

... Jer karmine 1 gusle ne 1du skupa. (s.46)

Im 3.Kap1te1:

No ozdravin; bolje da sam um'ro, oprosti mi, Bote, taj Brijeh. (S.75)

Der Erzahler II tritt nicht hinter der Erzahlung zuruck, sondern nimmt gewissermaben zwelfach an thr teil - einmal alo Akteur, zum anderen als komentierender Herichterstattor, so kurz diese Kommentare auch sein mógen.

Wie in alteren Novelien wendet sich der Erzahler II gelegentlich an den Zuhörer, den Erzahler $I$, doch sind diese Hinwendungen sehr unaufdringlich pehalten und durch die situation volikommen motiviert. Auf die unterschiedlichen Geselischaftsschichten welsen Bemerkungen wie die folgenden hin:

Vi ne znate, vi gospodo za zelenim stolom, mnogo

toga, kako se bavi u zelenom lugu. (S.11)

In der Novelle legen stch glelchsam drel Erzahlschichten uber- inander, wenn in Iricas Berlcht eln dritter Erzuhler, der klelne Bruder Niko, eln Gesprach der Eltern wiedergibt und ebenfalls selne Melnung elnfilcht:

Ne ljut1 se, brate, odgovorl mi Niko, nek 81 je Mara,

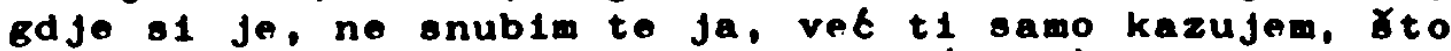
su otac 1 majka o tobl govoril1...(s.37) 
In der vorliegenden Novelle glbt os kelne Ruckblenden; wenn elnige Tatsachen erst nachtraglich bekannt werden, z.B. die Helrat und der Tod der Mutter, so geschieht dies durch kurze Informat1ve Sktze, ohne daß der Erzahler s1ch bel dem zurückliegenden Geschehnis langer aufhalt. D1e Handlung, aus der Perspektive des jungen Irica berichtet und aus der des alten Ivica kommentiert, schreitet kontinulerlich in chronologioch richtiger Relhenfolge voran.

Der Darstellung der hellen Nelt lm l.Kapitel oteht antithetisch die des Niedergangs in den belden folgenden Kapiteln gegeniber. Dleser Niedergang wird von htufigen Vorausdeutungen begleitet, z.B.:

Od onoga ćasa zamrzila majka na mene, pa ako mi je kašto 1 slatkn govorila, nije to b1lo od srca (S.47)

..kad b1h kod kute spomenuo Jagitino 1 me 1 nału svadbu, Gutjela majka, Yut10 tutor.. (S.48)

-No čkaj, vidjet tes tl pogorjelca-1zderese majka. ugrijana od vina - nati te se 1 trojoj tikvi gospodar.(5.54) Hierzu gehört auch der schon erwahnte Verglelch "kao pri kakovom sprovodu", als dif betelligten zur Unterzelchnung der Te1lungsurkunde gehen, und die daran anschliebenden staze deuten welteres Unhe1l an:

Tutor je brbljao 1 brbljao, čas mami nełto šaputao, a ona me gledala lspod oka. Na prozoru krtme kraj ceste opazismo Bartola. U pol smijeha zazmirio ołıma, a mama mu plaho k1mnula. (S.58/59).

Von solchen Hinweisen lst der gesamte Text der Novelle durchsetzt Ein welteres, Atmosphäre ochaffendes Element der Novelle sind die schon vorher erwahnten Erzahlerkommentare, von denen oben ochon einige Belspiele gegeben wurden; Im Bericht Iricas sind sie haufl, In die Form von Sprichwortern oder volkstumllchen Redewendungen gekle1det, auf die noch eingegangen werden ooll.

Alle diese Elemente sind In der Novelle "Barun Ivica" zu einem dichten Gewebe mitelnander verflochten, In dem kein Faden ins Leere lauft, sondern konsequent selnen Endpunkt findet. Es g1bt kelne Abschwelfung um der Abschwelfung willen, und jeder koment1, rende Satz trägt zur Intensivierung der Handlung bel. 
IV.4.5.5. Formale Elemente der Volkserzahlung

In der Novelle "Barun Iv1ca"

Šenoas literarlsches "Programm" erschöpfte slch bekanntlich ke1neswegs in der Forderung nach bloben Nachahmungen der Volkserzahlung, un die sich elne Relhe selner vorlaufer wie auch selner Zeitgenossen bemulte; wenn er dennoch haufig auf die Stilmittel der mundlichen Erzahler und der Volksdichtung zurilckgriff, so hat te dies mehrere Ursachen - einerselts selne realistische Orlentlerung, sein streben nach Lebendigkelt des Ausdrucks, andererselts seine poetisierungstendenz, die dem Wunsch entsprang, die Volkssprache zu heben; vor allem aber gehörten diese wendungen zu jener "Tonart". mit der er den zeitgenbssischen leser am ehesten erreichen konnte, wie auch G.DIPPE reststellt (25A,S.160).

Wie schwerif die Verwirklichung dieser Bemuhungen angesichts der allgemeinen Germanisierung des kroatischen Mittelstandes auch noch nach Beendipung des Bach'schen Absolutismus war, zelpen Šennas "Zagrebulje", die oft gerade diese Erscheinung getieln; welche Probleme Senoa persönlich in dieser Hinstcht zu bewaltigen hatte, geht aus elner bemerkung ŠREBs hervor:

Senoa hat in selnen deutschen Aufsatzen nie jene freihelt universaler Ausdruckswelse von ungehemmter Affektivitat bis zu logischer scharfe errelcht, wie sie sich in selnem kroatischen stil aubert; aber hinsichtilch der Korrektheit unct Reinhelt der Sprache lst sein kroatischer stil welt hinter seinem deutschen Stil zurickgeblieben. (116,5.154)

Zagreh, Varaždin, osijek erweckten in der fipoche, die als "Šenolno doba" bezelchnet wird, auf den ersten Blick den Eindruck deutscher stadte mit deutscher Bevölkerung, und Kroatisch war lmmer noch, trotz aller Anstrengungen der kle 1nen Gruppe kroatischer Jitellektueller um die Hebung dieser Sprache, die Sprache der Diener und Dienstmadchen; diese aber stammten vom Land und brachten Elemente ihrer dörfl1chen Sprache in den Jargon der klelnen stadtischen Handwerker, deren Schicht noch in engem Kontakt mit der Landbevölkerung stand, und auch in die sprache der Gebildeten, deren Normen sich langsam entwickelten. Zur sprachlichen orientierung "nach oben" hin standen den Schriftsteliern nur Karadzits serbisch-deutsches Wörterbuch, selne Sammiungen von volksliedern und -erzahlungen und, ab 1859, Suleks wrr- 
terbuch zur verfugung, ferner evtl. Karadžlts B1belubersetzung und die allmbilich bekannt werdenden Dubrovniker Dichter mit ihrer archalschen Sprache. In der Literatur der 60er Jahre herrschte noch lwer die gleiche sprachliche Unsicherhelt wie zur zelt der Illyrer, aus der lediglich das Werk Mazuranits als grobe Ausnahme herausragte.

In dieser S1tuation gelang es Senoa, unter Elnschmelzung unterschiedlichster Elemente elnen neuen Prosatil zu schaffen, der allgemeln vorblldich wurde. Aus verschiedenen Uuellen herrihrend, flossen in diesen stil auch volkssprach$11 \mathrm{che}$ Wendungen und Stilmittel der Volkserzahlung ein, die er, wenn man an das Vorbild Gogol's denkt, In einer Novelle aus dem dörflichen M1lieu oft sicher bewubt elngesetzt hat.

IV.4.5:5.a. Dre1zah1

Stanko LASIĆ weist in seinem Aufsatz uber den Roman der Epoche Senoas darauf hin, dals diese Ze1t, ebenso wie die europische Romantik, den dreltelligen Aufbau des satzes besonders bevorzuge, wie er durch Chateaubriand in die literatur elngefuhrt worden se1 $(60,5,178)$. In der besonderen situation der kroatischen Literatur könnte man die Bevorzugung der Drelzahl auch auf die volksdichtung zurickfuhren, In der die Dreizahl eines der maBgebendsten Prinzipien bildet, wie unter III.3.4. ausgefuhrt wurde. Im Falle Senoas könnte man in diesem Zusammenhang an elnen Einflub Gogol's denken, der Šenoa durch Ubersetzungen bekannt war. Andrej BELYJ, der In seiner stud1e "Mastersto Gogolja"(12A) zahlrelche stliverfahren der Volksdichtung in der Prosa Gogol's nachgewiesen hat, nennt neben anderen, auf den splelarten der Wlederholung beruhenden Kunstgriffen die dreifache stelgerung des Adjektivs bzw. des Verbs, z.B.

ine ponimaju, ne ponimaju, refitel'no ne ponimaju. ("Zapiski sumaskedsego", zitiert nach 12A,s.236, im Abschnitt: "Figura povtora", S.235-244).

Das Prinzip der Drelzanl wendet Gogol' auch zur Gllederung ganzer Abschnitte an; so lst die elnleltende charakterisierung des Ivan Iranovit in der Erzknlung "Povest' o tom, kak possor111." Ivan Iranovie s Ivanom N1kiforovičom" in dreite11ige, "abfallende" Satzgruppen aufgetellt, bel denen 
einem markanten Ausrufesatz jewe1ls zwel stufenwe1se abfallende Passagen folgen, wie BFLYJ anschaulich darlegt (12A,S.249-251). Auch in dew Kapttel uber den Rhythwus der Gogol'schen Prosa, der weltgohend durch die Anwendung von St1leltteln der Byline bzw. der Dumka entsteht (S.218227), bringt BELYJ Beispiele fur dreitellig aufgebaute Sktze; das nachfolgende Belsplel aus dem Kapitel IX der Erzahlung "Strašnaja mest." verbindet dieses Verrahren mit dem des Parallelismus:

Rubi, kazak!

Guljaj, kazakl

Teš nolodeckoe serdce.

…...

(zitiert nach 12A,S.223).
Kol1, kazak!

Guljaj, kazak!

No ogljanis' nazad..

In khnlicher Welse wie bel Gogol' erschelnt die nretzahl auch bel Šenoa als ordnendes Prinzip sowohl größerer wie kletnerer Textabschnitte, wie das Belspiel der vorliegenden Novelle "Barun Irica" zeigt. Ebenso, wie die ganze Novelle nach dem Prinzip der dreifachen stelgerung aufgebaut ist wenn man die drel Kapttel und ihr jewelliges Ergebnis betrachtet - labt sich ein dreiteiliger Aufbau auch in der Mikrostruktur auf Schritt und Tritt beobachten. Dies gilt fur elnzelne Absätze, etwa für den Anfang, der mit der bereits zitierten, dreifachen Niederholung des Satzes "dijeli ter dijelil" das Thema der Tellung anschlagt, aber ebenso fü die grolse zahl von Säzen, die entweder aus drel Isocola bestahen, wobel nicht selten das dritte colon ein übergewicht und eine Art Pointe aufwelst, oder aber durch Anaphern oder sngar Eplphern drei Satzteile miteinander verbinden, z.B.:

Pa Cemu ajecac1, pa Cemu družina, cemu teżac1? (S.16) Broj1lo se, kroj1lo se, dijelllo se na slanke, na liste, na zrna. ( 5.7$)$

..vino jako, żena slaba, a glava, da oprostite, zbogom! (S.20)

Sad nosi Jagi kolač, sad najljeps̆u jabuku, sad svilenu vrpcu. ( 5.44$)$

Ako ti koje dugme nije oljevalo, batine; ako je kiša padala a troje $\boldsymbol{C}_{12 m e}$ blatne, batine; ako si u glidi klnnuo, batine 1 opet batine. (5.68) 
V1d18̌, Irice, onu 11jepu kutu na brijegu, kako je tista 1 bijela, kako sunce 1 gra oko nje, kalo je ove gus to 1 zeleno pri kul1. Nała je, otara je, portena je. (s.27) Slušao ae, čud1o so, čupao so 11 jev1 brk. (5.70)

Al' on skočl kao mačak, skočl proko žıvice, nasmija oo grehotom - (S.80

Eln besonders eindrucksvolles Belsplel ausgesprochen volkstumlicher Schllderung eines Zustands unter verwendung des Stilprinzips der Dreizahl 1 st das folgendes

a starı Imbro čǔ pa muč za pećju, starl Imbro ni kaplja ni voda. n1 luga ni gospodar. (S.12)

\section{IV.4.5.5.6. Ant 1 these}

Von mindestens gleicher Bedeutung 1st im Stil Šenoas und mithin auch in der vorilegenden Novelle das Prinzip der Antithese. Diesem St1lprinzip, das bekanntlich auch der Volksdichtung e1gen 1st, hat man Šenoas Schwarz-Welb-Malerel der Charaktere zugerechnet. In der vorliegenden Novelle entwickelt sich ubrigens der Charakter der Mutter erst, realistisch motiviert, zur negativen seite hin. Antithetisch 18 das Verhaltnis zwischen stadt und Land gezeichnet, zwischen der "guten alten zeit" und der neuen Ze1t; der Vater des "Barun", der die alte Zeit symbolislert, sagt ausdruckl1chs

Šta vi mladitı̂? Šta te vaše novotarije? staro vino je najbolji 1 drýl se, a ja vam velim, ter velim, sve, što Je ataro, dobro je. (s.16)

Der Kontrast zwischen Stadt und Land kommt in dom antithetisch gebauten Satz zum Ausdruck, der schon oben zitiert wurde:

V1 ne znate, v1 gospodo za zelenim stolom, mnogo toga. kako se bavi u zelenom lugom. (S.11)

Satze, die wie dieser antithetisch gestaltet sind, finden sich sehr haufib, z.B.:

Ti druge karaš, a za sebe ne odgovară̌ v tebe, vidila, lag dosta sol1, a svoju panet druglaa poklanjar. (S.12)

lrugl gospodari sede 1 glede. Al' nije moj stari. (S.15) A1. to to je b10 etar, b10 vrayjl gospodar. (S.15)

Ako je dobar gospodar blo, nije b10 skupac, ako oštar, b1o jo 1 dobar - (5.17)

..o čen es drugl mučll1 po vas dan, ja to preskot1o u jedan mah. (S.22)

Der für die ganze Novelle bedeutende sata liber die Prau, der lelcht abgewandelt dreial wiederholtwird, let ebenfalla ein 
Be10p1el elnes antithetischen Ausepruchs:

Dobra žna je andeo cuvar, zla Ěeng jo grnt vrag. (S.26)

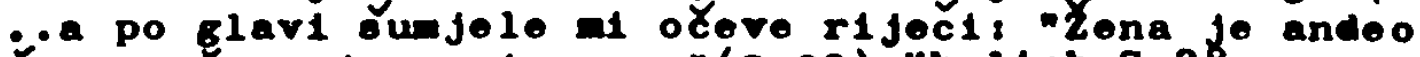

cuvar. Yena je crnt rrag."(5.32); Uhilich $5.28^{\circ}$

Auf den Gegensatz wlochen stadt und Land welot der antlthot1ech gestaltete Satz der Rahmenerzthlung hins

Pokojl oeljak odnıo ponjacki ytap, a ostavir gladnim kaputałina pune dદ̌pore. (S.7).

\section{IV.4.5.5.c. Sprichwdrter, Senternes Redewendungen}

Der Text der Novelle enthklt oowohl in der direkten Rede alo auch im Erzahltext eine Reihe von Sprichwbrtern, Redewendungen und Sentenzen. D1ese Auedruckeweloe lot durch den Erakhler II mot1viert, kennzelchnet aber berelto die Rahmenerakhlung. $2 . B$.

Ima 1 gorka 1 glatka 11 jeka. (S.8)

- a miel1 letjele daleko - dalekoi njth bar nitko ne vex̌e. (s.9).

-. a kad ou av1 skupa, ovaj onako, onaj onako lupa, a po or1jed1 prazno. (S.7)

Den Erzahler Ivica labt Senoa Immer wieder gelkuflge Volkawe1ghelten u.H. auseprechen, z.B.:

Ljud1 gu zl1, lajavi. Xemu gvoju gramotu 1 zalogt otaviti na svačljt jeatki (s.13)

210 ode, gore dode. (S.18)

Besonders htufig oind solche Sentenzen in der groben Rede dea Vaters, die Ivica ausfihrlich wiedergibt:

Groá je gladak, pa lako 1 spuze 1 z ruku, ako ne oveźề Evrato kese....

- Gdje glave nema, lde ove na komade; gdje nema erca nt poł́tenja, pada ovako zrno na suho kamen. A Božja se ruka etsene. (S.25)

..tko o visoka padne, okrha ot lako vrat. (\$.26).

Auch in der direkten Rede anderer Pereonen verwendet Ivica lmmer wieder elche Wendungens

Kako ol proströ. tako to̊̆ aparatı (S.49)

bugo se oblak skuplja, al' se najedanput k1 áa 18trese.(S.37) Um den "Volkston" zu trefren, elnd auch typleche Redewendungen in den Text wie in die direkte Rede eingefiochten, $2 . B$.

Strpljen spaeen. ( 5.44$)$

-. zdrav, hrala Bogu, 1 na evetak 1 na petak. (S.21)

-.pa upregent (Imperat1r alo Ind1kat1vi) n1 pot n1 Eeet kola $\ldots(5 \cdot 50)$

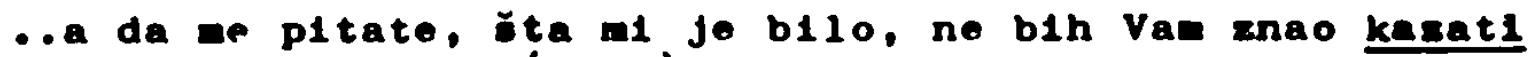
ni bile1e ni crne. (S.27) 
In den Text der Novelle fugen sich solche Wendungen ein, ohne al Fremdkörper zu wirken, da sie von der gleichen Knappheit und gelegentilchen Lapidaritut gepragt sind wie die Frzahlwelse des Autors Senoa selbst, etwa In der haufigen Formulierung:

Nebo Jasno kao staklo. ( 5.9 , In der Rahmenerzahlung)

Krasan b1o dan. Nebo ko staklo. (S.22/23)

Sunce sve 1gralo, nebo ko staklo, moje noge lagane.(5.63)

Ebenso knapp gehalten lst die srkinrung des diteren Bruders an den juingeren, der sich um die Zukunft sorgt:

Ne boj se. Oženit temo se, podijelit temo se. T1 1

Jelica $k$ menl a Bartol nek 1de pure past1. Je 1'?

Je 1 , N1ko? (S.63)

\section{IV $4 \cdot 5 \cdot 5 \cdot d$. Rhetorische Figuren}

Bereits die wenigen Sutze des letztgenanten Beispiels zeigen, wie glatt sich bestimmte St1lverfahren, die auch dem Volkserzahler gelaufle sind, In den Stll dieser Novelle Senoas elnfüBen :

Isocolon: oźentt...spod1jel1t...

Ant1these: T1 1 Jelica...: a Bartol..

Periphrase: . .nek 1de pure past1

In der Novelle findet sich elne Reihe der unterIII3.4. behandelten stilistischen Kunstgriffe der Volkserzahlung, die Senoa sowohl in unmittelbarer, d.h. wörtlicher tbernahme als auch in Form elgener Pragungen gebraucht, ohne dab hieraus ein Widerspruch entsteht. Fur die typischsten dieser Figuren nachstehend elntge Be1splele:

Metaphern baw. Periphrasen aus dem lándlichen Leben bzw. allgemein aus der Natur:

Vergle1ch (besonders hiuf1B)
Ne te trojoj zelenojglarl b̌kod1t1 ta rana k1צica $(5.23)$

..1 Ja gospodar bez te suhe $\gamma_{1} \mathrm{j} 1 \mathrm{ve}$, toga Ypicastoga tutora (5.54)

..nego s1 t1 el1jepa kokoš, koja

je drag1 kamen naria..(s.42)

Čkajte, kume ... 1mam VaY p1 jesak c1me zalijeratil- (s.31) (d.h., 1ch kann Ihnen etwas zu trinken geben)

Dječko b1o sun ko gladna godina(s.53 -.pa udarl akokom uzbrd1ce kao erna. (S.39)

..kao da ou pred aene zapregnuta tet1r1 konja (S.61)

..kao da eam lmao potplate od grožda (s.77)

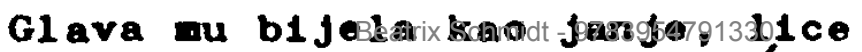

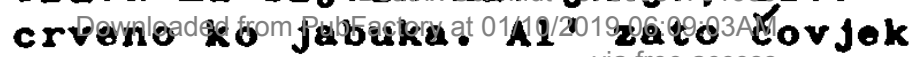
kao dren. $(s .15)$ 
Kumulation

- von Substantiven:

- von Verbens

Polysyndeton:

Wiederho lung:

(zugletch 3 Isocola): pisao 1 pisao, profus gledao 1 gledao,
al napokon auditor zavirio u debelu

Semant 1sche Reduplikation: knjigu - u zakon, a zakon nema srca. (S.75)

U Zagrebu bio sajam. Sve puno svijeta. V1ke, marve, 1 jud1, luka, blata, goepodine, blata, kao kod nas pri svetom Duhu. (s.63)

Kuhala, parila, Givala, pekla kruh, prela, tkala, pače katkad 1 krave doj11a. (s.19)

Sve se kradomice Gurkale. Gledale me Ispod oka 1 hubkale 1 surkale, da onm se Eitavo rasrd1o b1o. Izide Jagica 12 crkve. Sad je tekar huškalo 1 ร̆ư̌kalo, Cas mene Gledalo, Cas Jaglcu, daml je zobun Cisto t1jesan b10. (S.40)

- pa se tu p1lo, jelo, rušllo, motalo, pogadalo - (S.64)

Tjerao sam zelenka... čak nijesam putem vidio ni crkve, ni kube, ni križa, ni plasta, ni źtvice. (S.33)

. pa plakala, plakala tako milo...(5.43)

Govor111 smo dugo 1 dugo.(S.02)

Doł̆la na debele kese 1 pune vrete.(S.12)

Pa krotio set1, kako te volja...

pa srd10 se t1, kako t1 drago...(5.41)

Tko bi Im kruha dao, tko bi im vino preso? (s.26)

- ne krad1, ne robl, batine su kod nas jevtine, a 1 uze nije skupol (s.77)

za svakim hrastom, za svakom żivicom vidio sam samo Jagu 1 opet Jaeu.(S.45)

Für den gedrängten Erzahlstil Śenoas ist es bezelchnend, daß er das Wortspiel in selnen verschiedenen Abwandlungen verhaltnismalis wentg verwendet und odch auf bestehende Wendungen beschränkt, die die sprechwelse der borfler kennzelchnen sollen, Z.B.: śtajerci nemaju ni ruha ni kruha (s.52). Alle Figuren dienen bei Šnoa lediglich der plastizitut der Schilderung, der Intensivierung des Ausdrucks, der Lebendigkeit der Rede, der Schaffung von Atmosphure, nicht aber der Ausschmückung des Textes, wie sie im bizarren, manirierten stil anderor Autoren zum Selbstzweck wird. 
IV $4.5,5.0$. Elemente der muindlichen Rede

Durch die Stilisierung auf den narrativen Monolog hin flieben in den Text eine Rethe von typischen E1genhelten der múndlichen Rede ein. die die Illusion unmittelbaren zuhörens verstarken. Hierzu gehören ell1ptische Satze im Erzahlerbericht, Im Dialog, In den Autorenkommentaren; sie beschleunigen den Flub der Erzahlung, die von der handlung lebt, und tragen dazu bel, die Spannung aufrecht zu erhalten. Der von Senoas historischen Komanen bekannte Chronikstil kommt in der vorliegenden Novelle nicht elimal in den Schilderungen lang zuruckliegender Zelten zum Ausdruck; so werden z.B. die Zustande wahrend der napoleonischen okkupation und die nachrolgenden Hungerjahre, die der erzahlende "Barun" selbst gar nicht erlebt hat, durch elnzelne Eplsoden 111ustriert, z.B. die Explosion des Schiebpulvers in der Klrche oder die kurz,aber plastisch geschilderte Geschichte elnes "Posavac", der nach langem Kungern endlich Brot kaufen konnte und so viel davon ab, dals er daran starb und die lakonisch endet:

zajeo se, prejeo se 1 un'ro. Djeca ostala bez kruha. $(\mathrm{s} \cdot 18)$.

Die Paronomasie lst hier nicht Schmuckform, sondern dramatisches Moment (zajeo:prejeo); das Fehlen elnes Kommentars macht die Erzăhlung umso eindrucksvoller. Elne solche Art der Berichterstatung, die nicht abstrahiert und nicht summert, sondern Elnzelheiten konkretisiert, ist kennzelchnend fur die spontane mindl 1 che Erzahlweise.

Für die elngangs erwahnten elliptischen Satze nachstehend ein1ge Beispiele:

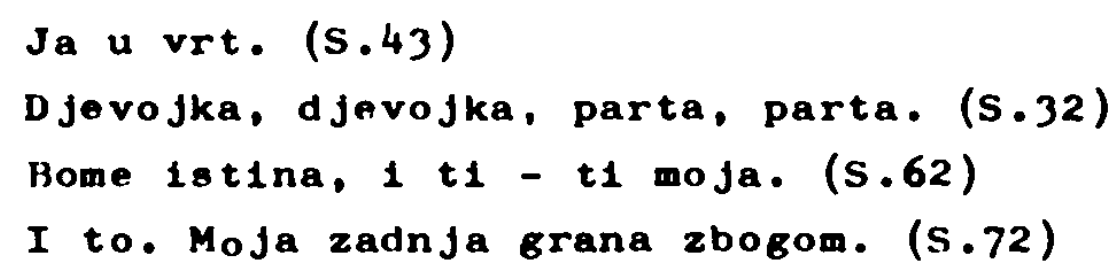

$Z_{u}$ den "mündlichen" Elementen gehören auch die direkten Hinwendungen an den zuhörer und E1nschübe wle:

..da po dušı kazem..(S.52)

..A1. da.(S.50) 5.46$)$

..N1je šale. (S.50) 
Durch rhetorische Fragen, gelegentliche Verwendung des Dativus ethicus, Gebrauch des Imperativs anstelle des Indikativs, des Futurs anstelle des Praeteritums erhalt der rext uber längere Passagen hin den Charakter der mundlichen Rede: Krenem glavom, pa koga to vidim? Moga Niku. (s.35) Vojnikl Hml Šta je to sad? Ništa. Šala, da puhnę. (5.68) Ja sam vam stojao kao drvo..(5.41)

Ja skočı u Crnomerce kao preko plota, pa rec1 vukovitu.. (5.45 Niko veseo sjedio na vozu... ja tjeraj brže bolje.(s.50) -A,al - ret1 te mi majka,- pa ste sretno dovezli sijeno? (S.51)

- A kako trojotac, Japice? - pitat te starac dalje.(5.31)

An den stil des miindlichen Erzahlers klingen jene satze an, die mit "da" eingeleitet werden (vgl.III.3.4.8):

Kad ozdravih, budem kaprolom, Jer da sam kapetana spasio. (S.70)

Majka da se udala za poporjelca Bartola, on da je u kuti pospodar, Jagica da $1 \mathrm{ma}$ pod Jesen poti za seljaka 12 Horvata. $(S .70)$

vie Revorzugung der Parataxe vor der Hypotaxe und das Uberwiegen kurzer, ubersichtlicher satze, gelegentliche Ausrufe und schlielilich Bemerkungen wie "Bog mu dao dusi lako-"(S.15) sind weitere Elemente,die den Eindruck mindlichen Erzahlens verstärken.

\section{IV.4.5.6. Vas patriarchal1sche Weltb1ld}

Zu den aulgezahlten, rein sprachlichen klementen volkstiumlichen Frzahlstils treten weltere Komponenten, die eine Beziehung der vorliegenden Novelle zur Volkserzahlung schaffen. Hierzu gehören Bezugnahmen auf Aberglauben und Brăuche (wenn ein Mardchen an einem bestimmen Tag fastet, sieht es Im Traum den zukinftigen Gatten, S.31/32; d1e Wallfahrt zur Mutergottes von Bistrica; die nicht mehr wörtich zu nehmende Wendung "dobit1 jabuku", S.37,S.28).

liese Dinge sind geschickt in die Novelle eingeflochten, ohne einen so großen Raum elnzunehmen, daß der Eindruck elner volkskundlichen Abhandlung entsteht; sie schaffen nur eln bestimmes Lokalkolorit. 
Insbesondere jedoch besteht ein innerer Zusammenhang zwischen der Welt der Volkserzählung und der dieser Novelle, was die ethischen Vorstellungen betrifft. In der groben Ansprache des Vaters Im 1.Kapitel wird das patriarchalische Weltbild in selnen wesentlichsten Aspekten umrissen: die Ehre der Familie, die Wahrung der Tradition, die Erbaltung des Besitzes stehen hier im Mittelpunkt:

Gledaj, sinko, da temorati svako kapu skinut1, kad se somene lme Krứćévo. ( $\$ .27)$

Dobru gospodarstru hote pametne glave 1 połtena srca, pa te biti 1 Bozjeg blagoslova. (S.25)

(Uber das haug):

Nas̆i oc1, naše majke rodiše se u njoj, umriješe u njoj. (5.27)

Nicht Berelcherung durch unlautere Geschafte, sondern Fleib und Stetigkeit fuhren zum Ziel:

Bog nas je stvorio, da radimo, pošteno radimo. Tko putem jednakim korakom ide, doti te u horu na svoje mjesto. (S.25)

Dem Hausvater ist jeder absoluten Gehorsam schuldig:

Moj otac nije pod svojim krovom primmo ni prigovora ni odgovora, Jer "Ja sam kut1 gospodar" znao bi kriknuti bez sebe. (S.20)

Die Frau muls "gut", d.h. gehorsam und fleibig sein, aber nicht unbedingt schön:

.. ako je dobra 1 nelijepa, našo si gorku medicinu, al' dobru medicinu. (S.26)

Bog je strorıo ženu za preslicu 1 kuhaču, a muška glava 1 svijetu je glava. (S.23)

Der jüngere Bruder sagt $1 \mathrm{~m}$ Hinblick auf eine kunftige Schwagerin:

Samo ako ti je mlada dobra 1 poslušna. (5.39)

Im ubrigen mul man sich vor den frauen hiten, aber auch vor dem Alkohol:

.. žensko oko je vrazjt vabac. (s.26)

Kanı se vina 1 rakije -...jer od krǒtena čovjeka budne nijema zvijer; ja to znam, dobro znam. (S.26)

Gerade diese grobe Rede des Vaters, aus der bereits im $A b-$ schnitt über Sprichwörter und Sentenzen elne Reihe von Beispielen zitiert wurde, hat Šenoa besonders sorgfaltig auf die volkstimliche Rede hin stilisiert, so daB bereits die buBere Form den Bezug zur Volksuberlieferung andeutet, deren Ethik hier formuliert wird. 


\section{IV.4.5.7. Charakter181erung oder Typ181erung?}

D1e Schwarz-Ne1B-Malerel der Charaktere w1rd 1 allgemelnen alo typlscher Zug in Ersuhlwerk Šnoas bezelchnet. Aufschlubrelch ind hierau d1e Avefuhrungen G.DIPPEs Uber die Charakterdaretellung in den hletoriechen Romanen Šnoae (25A,S.133149). Auch G.DIPPL betont, dab es bel Šenoa ke1ne 2w18chentypen zwichen Gut und Bdse gebe, und welot auf die fehlende Entwicklung der Charaktero und die angelnde PoycholoGiolerung hin; die Uroache hierfur sieht G.DIPPI in den so21al-aufklarerischen Anl1egen deo Autors:

Selne Gestalten... Ind oozial-typisch feetunriseone Charaktere und individuel1 durch Ihrer Rol1e ento prechende und kennzelchnende Merkmale bestimnt... . d1e soziale Typ1e1erung und Motivierung 18t...das wicht1gote Element, das auch allo Handlungon erklart und fur das Bewubtsein der Personen ausechlaggobend

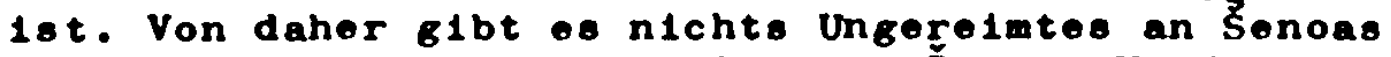
Personen, deshalb entwickeln olch Šenoas Helden 1m Laufe der Handlung auch nlcht.... Senoas Helden rerlektleren nicht, dazu ble1bt thnen gar keine ze1t... (25A.S.134-136).

Mira SERTIC vertritt in ihrer Abhandlung "Stiloke osobine hrvatskog historljokog romana"(102) die Ansicht, dab nicht alle Romanfiguren Senoas In relner Schwarz-We1B-Manter gezelchnet selen; oo entwickle sich der Charakter Pavles in "Zlatarovo zlato" in Laufe der Handlung, und auch andere F1guren selen nicht volikommen ochablonenhaft dargestellt. Das Verhalten der "feme fatale" Klara Grubarova werde z.B. durch eInen langen Inneren Monolog paychologisch wot1viert(102.S. 200/201). Led1glich d1e Intriganten sind, nach SERTIĆ, absolut negativ, allerdingo untereinander differenziert, gezelchnet.

Von der Monumentalitkt der Romanfiguren Šnoas opricht FRANGES Im Vergleich zu den Flguren in Kovacite Roman "U regietraturi"(37A,S.164); d1eser Vergle1ch labt sich auf das Verhaltnis zwischen den Roun- und den Novelienflguren Šnoas ubertragen. Da in den Novelien zeltgendselsche Probleme an Hand von "privateren" Belopielen entwickelt werden, werden die Gestalten auf alltbglichere Mabetabe reduziert. Damit haben olp etwas wehr 1ndividuelien Splelraum - elno Möglichkelt, von der Senoa gelegentlich Gebrauch wacht. 
In der vorliegenden Novelle ind die Intriganten wie in Senoas Romanen vollstandig negativ - und dazu noch elnander recht ahnlich - geschildert; wan könnte se also dea Typ des Bbsewlohts zurechnen, wie er in der volkserzuhlung auftritt und nur die Funktion des Negativen, aber keine Individualitat besitzt. Dennoch ind diese figuren nicht unbedingt typlsch fur die Volkserzuhlung, welt oher fur d1e romantische Novelle; os glbt aber In Senoas "Barun Irica" einige andere Gestalten, die eine unaittelbarere Beziehung zu der Welt der Volkserzahlung verraten. Die Gestalt der Mutter entwickelt sich Im Laufe der Novel10, real1stisch motiviert durch 1hr jthes Temperament, die S1tuation nach dem Tod des Gatten und durch 1hro Ne1gung zur Alkohol, zur "bösen Frau" der Volkserskhlung, d1e Ihre Kinder schlagt, Ihnen kein gutes wort gibt und den Besitz durchbringt. Schon zu Lebzelten des Vaters kennzelchnen sie Elgenschaften, die denen der "guten Frau" kontrar sind: s1e wagt es, 1hm zu widersprechen und $1 \mathrm{hm}$ sogar selnen allzu großen Fle1B, diese so wesentliche Bauerntugend, vorzuhalten. In der Endphase 1hrer Entwicklung vereint sie in $81 \mathrm{ch}$ zwel negative Typen der Volkserzahlung - d1e böse Stiefmutter (1m Verhalten gegen die eigenen Kinder) und die "zla žena", nur ist sie nicht, wie diese, typisierend, sondern individuell charakterisierend dargestellt.

D1e liebevoll und detailliert ausgefuhrte Gestalt des Vaters erschelnt demgegenüber, als allzu makellose verkörperung dęs patrlarchalischen Ideals, typisiert, obwohl Senoa gerade bel der Zelchnung dieser Figur elne der bevorzugten Charakterisierungsmethoden des Reallsmus anwendet - d1e Charakterzelchnung durch die direkten Äußerungen des Betrerrenden.

D1e Braut Ivicas, Jagica, entspricht vollkommen dom Madchentdeal der Volkserakhlung; d1e Beschrelbung thres ÄuBeren erfolgt denn auch unter verwendung der dort ublichen Epltheta. Dieses Ideal lot allerdings alt dem der Roment1k und des Sentieental ismus Identisch, und bezelchnenderwe1se rinden blch gerade In den Szenen, in denen Jaglea 
ersche1nt, d1e deutlichsten Anklunge an d1ese St11richtungen. D1es gilt ubrigens ganz allgemeln fur die lieberszenen In Senoas Novelien und Romanen.

Der "Barun" selbst verkörpert in Jungen Jahren den Typ des natren Helden der Volkserakhlung, der kelne Aufgabe zu schwer 1st, der aber bel der Konfrontation alt der neuen, fremden Welt der Stadt, symbollsiert durch den intrigierenden Vormund, zun Scheltern verurtelit lot. Selne charakterliche Entwicklung vom gutgluubigen und gutwiligen Optinisten zum verbitterten Pessinisten lst glaubwurd1g, obwohl dte Kumulation der verhangniovolien Umstande, die dazu fuhren, unglaubwirdig lot. Ivica 1st mithin eine realistisch und individuell gezelchnete Gestalt.

D1e Frage nach Typlsierung oder Charakterisierung labt slch fur die vorliegende Novelle dahingehend beantworten, daß Šnoa hler von belden Möglichkelten der Personendarstellung, entsprechend dem Anliegen selner Erzbhlung, Gebrauch macht.

\section{IV.4.5.8. Senoas künstler 1 scher skaz}

In selnem Aufsatz "Problema skaza $v$ st11lstike" (119) hat sich VINOGRANOV mit EJCHENBA UMs Äuberungen uber den skaz kritisch auseinandergesetzt. VINOGRaDOV stelit fest, dall die Definition des Skaz als Intention auf die miindliche Rede nicht ausrelche und dais man diesen Begriff nicht als Symonym fur "lebendiges Wort", als Symbol der mindlichen Rede, der Illusion elner freien Improvisation aufrassen durfe (119,s. 176/77, 172/73). VINOGRADOV beze1chnet den skaz als kunstlerische Enteprechung zu elner der formen von mündltcher monolog1scher Rede $(119,5 \cdot 178 / 79)$ und gibt u.a. rolgende Derinit1on:

Der ska $k$ ist die elgenw1111ge 11 terarisch-kinstlerische Orientierung an Eundlichen Monolog des narrat1ven Typs, er $18 t$ die kinstlerische Imitation der nonologlechen Rede, welche, die Erzahlfabel gestaltend, $81 \mathrm{ch}$ schelnbar als unittelbarer Sprechvorgang aur baut. (1 19,5.190/191).

VINOGRADOV unterscheidet zwischen dem Skaz, der an bestiano fiktive Personen gebunden 1st, und dem vom Autor-Ich gefuhrten Skaz, der sch frel entralten und alle Elemente der aundlichen Rede wie der Schriftsprache in olch aufnehmen kann(s.202/203). 
In Šnoas Novelle "Barun Ivica" erscheint der Skaz durch die Erzahlsituation an die Person des "Barun" gebunden, doch handelt es alch in Wahrheit um einen Erzählstil, der weder durch die Gesellschaftsschicht noch durch das Bildungsniveau des fiktiven Erzahlers bestimmt ist. Dies wird u.a. deutlich, wenn man die einleitende Erzăhlung, die den Hahmen bildet, mit dem Bericht Ivicas vergleicht. Gerade die ersten Absätze des Textes, aus denen zahlreiche Beisplele angefuhrt wurden, sind ebenso im Stil der "großen Rede" volkstülichen stils gehalten wie die Ansprache des alten Bauern an seinen Sohn zu Beginn der eifentlichen Geschichte. Hier wie dort bedient sich Senoa klassischer Kunstgriffe der volkstumlichen stilistik, wie sie in den Sammlungen vrěevićs und Karadžits zu beobachten sind.

Das bedeutet, daß der Erzähler Ivica in der vorliegenden Novelle trotz aller realistischen Details der Rahmenerzahlung nur eine vorgeschobene figur ist, hinter der sich der Frzahler der Kahmenerzâhlung und damit der Autor Senoa selbst abzeichnet. Hier wird nicht die Redeweise eines Bauern imitiert, sondern der mündliche Érzăhlstil eines Mannes vom Niveau Šenoas, der an mehr Vorbildern geschult ist als nur an dem der Volkserzählung. Hier erzählt jemand, der seinen stoff klar ubersieht und der Akzente und Wendepunkte sorgsam anordnet, in einem stil, der ganz bewulst auf Anschaulichkeit einerseits, auf flottes Voranschreiten der Handlung andererseits abgestimmt ist. Die eingeschobenen Hinwendungen an den Zuhörer, die kurzen Unterbrechungen durch Bemerkungen über den Erzahler Ivica erscheinen in der deutichen Absicht eingesetzt, die Illusion der mindlichen brzählung aufrecht zu erhalten un dem ieser die Situation in Erinnerung zu bringen. In diesem Erzahlstil Ivicas sind selbstverstandlich Elemente der Volksuberlieferung enthalten. wie eingehend gezelgt wurde; daneben aber glbt es ausgesprochen schriftsprachliche Elemente, z.B. In den Liebesszenen, auf deren sentimentale stilisierung schon hingewlesen wurde, oder in den Beschrelbungen, so knapp diese auch gehalten seln mögen; man vergleiche nur Šnoas Text mit dem der Volkserzählungen, selbst der Stilisterungen Vuks, In denen Landschafts- oder Interieur-"Beschreibungen" auf einzelne Epitheta beschränkt bleiben. Šenoas Beschreibungen stehen hinsichtlich ihrer Vorliebe für Vergleiche der Volkserzählung zwar nahe, in ihrem Inhalt gehen sie aber weit uber das hinaus, was im Zusammenhang mit der serbo- 
kroatischen Volkserzälung als Nelfune zum realistischen Detail bezeichnet wurde.

Ein weiterer lunkt, der deutlich zelet, dilis hier nicht der Erzählstil eines llauern imitiert wird, ist die beginnende psychologisierunf. und realistische Notivierung des Verhaltens der einzelnell Personen. Trotz gewiser Ankläge an Typen der Volkserzihlung ist auch hier eine Weiterentwicklung zu bemerken, die einen lirzählor mit unfassenclerem llorizont verrät. Die stärkere Psychologisierung kount u.a. durch die hiufigere Verwendung der erlebten liede zun Ausdruck, die in der Volkserzihlung bekanntlich nur in auberst beschraintem Malse auftritt. linice beisplele:

Pa nijesaill si mnog̣o razbijan plave. I zašto bi? Čemo se zadijevati? Za tri mjeseca bit er Jalical i onako moja. (ब.4प)

In diesem falle kïunte "I zišto bl?" auch noch zur erlebten Rede rerechuct werlen, ebenso wie "Cemu se zallijeviti?" noch zum autorenkomilentir gehören könnte. lie erlebte Rede erscheint in der Novel le in der ersten person, da der Icherzihler zuGle1ch Nkteur ist.

Seite 53:

Doinatélh težaki našlo se u nas uvijek dosta, pa ćemu pod krov uzimati ljucle strane, Hepoznate? Pa bogzna jesu 11 to pravi pogorjelci?

Seite 73:

Sunce zilail lo, nebo se rumentlo nacl Eorom. Mina mlada. inoja liritil! Sta li oni sada rade? Imal 11 pravice na svijetu? Zazvonilo zvonce na zolravumariju. Imojim negdje zvoncezvont pri sv.luhu, gaje je otev erob. llilo ini tucino; 1̧̌ao sall dal je. Potelo se mratiti, za mnom u fradu vet se žirile svijete, lzâleka šunjelat rijeka, a nat nelu bljesnula zlatna zvjezdica. Tu neguje i moja Japa vidi. Bože moj! što sirota negdje trpi muce je, sile je, da pode za neljubl jena - za crucogal - Nel Nikidl Protreslo me, zazelilo me, krvmi j" smutila ofi, ulivilin sablju. Nel Nikad ne te zal drujroga poti:

llier, wo alwecliselnd Aussalen des Irherzihlers, des alten Ivica, und les Akteurs, des junfen Irica, erfolfen, handelt es sich um jenen Typ der erlebten Rede, den l..silkulova, die bestimmte Typen der erlebten llede unter dem Ciesichtspunkt der Wechselwirkung zwischen Nutor und Held unterscheidet, als form der besoncters enfen Wechselwirkung, der Glelchberechtieung von Autor und lleld bezelchnet: 
Die zwe1te Gruppe 1st durch elne engere Wechselwirkung zwischen Autor und Held gekennzelchnet; an der Darlegung des Geschehens nehmen sie glelchberechtigt te11. wobel sie elnander haufig abwechseln. $(105,5.26)$

D1e kunstlerische Synthese aus unterschiedlichen Elementen 1st Senoa aufgrund seines erzahlerischen Talente möglich, d.h. der Fahigke1t, Tatsachen geschickt miteinander zu verbinden und einen fiktiven Zuhörer zu fesseln und dabel sprachliche Mittel verschiedenster Herkunft so zu verschme1zen, daß sie elnen elnheltichen Gesamttenor ergeben. Aufgrund selner oprachlichen Intultion gelingt Šenoa diese Verschmelzung meist mit der glelchen Zwanglosigke1t wie das Uberleiten von Szene zu szene, so daB, - un die Formulierung VINOGRADOVs zu gebrauchen - der Eindruck eines unmittelbaren Sprechrorgangs entsteht.

Volkstimliche Stilmittel verwendet Senoa nicht, weil er ole als notwendiges Attribut einer nationalen Literatur ansient; diesen Begriff fabt er viel welter als seine vorganger und auch viele Ze1tgenossen. Er setzt sie eln, well er jedes zur Verfigung stehende stilmittel aufgreift, das zur Anschaulichke1t, zur Lebendigke1t und zur Atmosphare beitragt. In der vorliegenden Novelle sind sle daruber hinaus durch den fiktiven Erzahler motiviert. DaB der "müdliche" Stil bel Śenoa aber kelnen solchen Erzahler voraussetzt, zelgen seine Romane und seine Peullletons, In denen sich ebenfalls entsprechende stilelemente finden, d.h., der skaz der Novelle "Barun Ivica" lot der freie Skaz des Autors Šnoa, In dem mündliche und volkstiimllche filemente etwas starker als sonst in den Vordergrund treten. Die Einschmelzung volksliterarischer stilelemente und Tendenzen wird erlelchtert durch die ahnliche Ausgangspostion und die verwandte Zielsetzung Śenoas und des Volkserzahlers: belde haben eine didaktische Absicht, belde wahlen handlungsrelche Fabeln, um zu fesseln, und belde streben deshalb den knappen, aber plastischen Ausdruck an.

Da die volkserzahlung den Ansprüchen des zeltgenobsischen Lesers nicht mehr genilgt, verbindet Śenoa elnige threr bewhrten, durch die Tradition legitimierten Elemente mit seinen elgenen realistischen bestrebungen und gewlssen Konzessionen an den herrschenden Publikumsgeschmack, der $1 \mathrm{~m}-$ 
mer noch die romant 1sche Idylle, d1e vollkomene liebe, d1e makellose Schonhe1t und Unschuld dargestellt sehen w111. Trotz elner solchen Tollorlentlerung an liberholten vorstellungen und trotz sprachlicher Mangel, z.B. der ron LASIĆ und SKREB kritisierten Germanismen (60; 116), gelingt Šnoa erstmals die Realisierung des kunstlerischen Skaz In kroatischer Sprache. 
IV.5. Zus ammenfassung

Mit den in den vorhergehenden Abschnitten behandelten Be1spielen solite gezelgt werden, wie die theoretisch aufgestelite forderung nach einer nationalen literatur von einzelnen Schriftstellern aufgefaßt wurde und welche unterschiedlichen Hege sie bel threr Verwirklichung einschlugen. Neben der Orientierung an den großen, "gesetzgebenden" europaischen Literaturen, die sich elner jungen, von ihrer elgenen álteren Tradition aus mancherlel Grinden abgeschnittenen literatur anbot, mulste sich als weltere Möglichkelt die Einbeziehung von Elementen der mündlchen Uberlieferung ergeben: $31 e$ stand Im sidslavischen Raum in uberreichem Maße zur Verfugung, in ihr erblickte man, der romantischen Konzeption folgend, den Ursprung der Kunst und den Hort der nationalen Kraft, und in thr hatte jene Sprache bereits kiinstlerische Gestalt angenommen, um deren Formung sich die Literaten bemuhten. Je schwächer die Bezlehung der einzelnen Autoren zur miindlichen Tradition war, umso mehr blieb die "Volkstimlichkeit" threr Werke auf additive Äußerlichkelten beschränkt. Gelegentilch aber gelang es elnzelnen Schriftstellern, uber Addition und Imitation hinaus einen Stil zu entwickeln, in welchen neben anderen auch volksliterarische Elemente fast "nahtlos" einbezogen wurden. Die behandelten Beisplele soliten dazu dienen, dies anschaulich zu machen, wobel zu bemerken 1st, wie unterschiedlich elne solche Integration erfolgte. Der Humorist Nemeit verflocht die Stilmittel des mündlichen Erzăhlers mit anderen, um seinen feuliletonistischen stil zu realisieren; Korajac, der ihm in vieler Hinsicht folgte, gelangte daruber hinaus zu einer milden Ironisierung volksilterarischer Formen. Ljubiša knuipfte unmittelbar an elne lebendige Tradition an; er war fast ein Volkserzahler alten Schlages, dessen Individualitát jedoch nicht mehr durch die Kritik elnes Kollektive unterdrückt wurde, sondern sich frel entfalten konnte. Botits lyrische Disposition ermöglichte elne synthese aus romant1schem Erzahlstil und volksiledhafter Poetisierung. In den St1l eines Erzahlers vom Range Šenoas flossen volksliterarische Elemente zwanglos e1n und trugen zur Gestaltung elnes kunstierischen Skaz bel. 
v Weltere Fntwicklungen

v. 1. Serblsche Literatur

Die von den Schriftstellern der "Vukova škola" erschlossene dörfliche Thematik fand ihre endgiltige Gestaltung durch die serblschen Realisten der b0er bzw. 90er Jahre. Die Begeisterung fur alles Volkstumliche, für Volkspoesie, volkstrachten, Volkstänze und -bräuche, wie sie die nationale Richtung der Literatur und inshesondere die Omladina-Bewegung kennzelchnet, verband $\mathrm{sich}$ - teils unter dem Finflub Svetozar Markovits, der von der Literatur mehr Lebensechtheit verlangte, teils dank der literarischen Bildung einzelner Schriftsteller mit höheren Ansprichen an das eigene Werk, und zwar sowohl hinsichtlich seiner Annaherung an die virklichkelt als an seine ästhetischen (ualitaten. Fü diese Annaherung an die Wirklichkeit hatten jene schriftsteller wertvolle Vorarbelt geleistet, die zunachst iberhaupt die dörfliche Thematik aufgegriffen und durch das Zusamentrapen folkloristischen Materials das Interesse der Leser geweckt hatten und deren literarische Aktivitat sich zeitlich z.Ti. mit der der serbischen Realisten uberschneidet. So erschienen die ersten erzahlerischen Versuche Milan C. Miličevits, "Zlimnje večeri", die der Autor selbst nur eine "Sammluig von kurzen Geschichten, Skizzen, Notizen, Szenen, fiplsoden und Findrucken" (103,S.327) nannte, "so bearbeitet, wie sie ein Autodidakt bearbeiten kann", 1879, wahrend die Zeitschrift "OTAlžuIiA" schon ab 1875 Glisıts reaistische Frzählungen abdruckte. Die bepeisterte Aufnahme der "Zimnje večeri", z.B. durch Danićlt und šenoa, zelet, dab das Terrain fü die realistische Dorfnovelle gut vorbereitet war; sie ist zuglelch ein Anzelchen dafiu, dals gerade von der Selte der folkloristisch-ethnographischen Schriftsteller eine sprachliche Berelcherung der Literatur erfolete, wenn ein Mann wie Danitit, dessen Hauptanliegen die Sprache war, betonte, dab so wie Miličevit eln serbischer Novellist schreiben miisse $(103,5.327)$.

Von allen an der Volksuberlieferung orlentierten serbischen schriftstellern ist Ljubiša das charakteristischste Bindeglied zwischen der romantischen und der realistischen Perlode; es lst bezelchnend, dals sein Werk sowohl von Miroslav Jerkov im Rah- 
men der"Romantilari" 1 als auch in dem Buch Velibor Gilgortts "Srpski real1st1" (42) behandelt wird. Der Erfolg Ljubibas beruhte darauf, dab er eben nicht nur folkloristisches Material zusamentrug und die aktuelle Tendenz vertrat, sondern da $B$ or mit den stilmitteln der Volksuberlieferung und unter Beibehaltung ihrer Thematik Erzahlungen schuf, die den wachsenden Ansprichen an Komposition und Lebensechthe1t genugten.

Diese uber Ljubiša führende Linle setzten die serblschen Realisten fort. Milovan Glišlt, der dem Milieu des serbischen Dorfes entstamme und der in Zuge der Begelsterung fur alles volkstibliche auch als Samuler von Volksliedern tatlg war, schrieb Erzahlungen, In denen die Mentalitut des serbischen Bauern, seine Nelgung zu Scherz und Spott lebendig wird; trotz aller liebe Glistcs zur alten patriarchalischen cobensform gibt es bel $1 \mathrm{hm}$ kelne subliche Idealisierung des Dorfes, sondern kernige, real1stische Typen, und der Volksaberglaube wird nicht mehr kritiklos als Tell wertvoller Uberlieferung dargestellt, sondern unter deutlicher Distanzlerung des Autors (vgl. "Posle devedeset godina" hier Fugt Glišlt den Untertitel hinzu: "Po narodnom verovanju").

Bel dem sensiblen Laza Lazarevit, der als Junger Mann wie Glišlt unter dem Elnflub Svetozar Markovits stand, sich aber opter von dessen Ideen abwandte, entsteht in den Dorfschilderungen tellwe1se ein poetischer Realismus, der auf der Hohe der besten zeltgenossichen Werke Europas steht. Einige seiner mit buberster Sorbfalt gestalteten Novelien erreichen Jene Geschlossenhelt der Form und Jenen knappen, bls lns Detall ausgefeliten St1l, der die besten Belspiele dieser anspruchsvolien literarischen Gattung ausze1chnet.

Janko Veselinovit gelingt elne liebevolle, wenngleich manchmal Idealisierende Darstellung der dorflichen Idylle unter E1nbez1ehung der ganz spezfischen Elgenart und Atmosphare seiner Helmatlandschaft, der Madva, deren Menschen or lebendig vor den Augen des Lesers erstehen labt; selne tiefe Verwurzelung in dieser Welt kuBert sich in der klaren, geschmeidigen und bildhaften, volkstum. lichen Sprache seiner Novelien und Romane.

Sima Matavuljs Novelien und Romane zeugen von der kritischen Beobachtungegabe dieses Autors, wit der er lnsbesondere das dalmat1

1 Miroslav Jerkov: Jugoslavenski pripovedačl. I. Romantičarl. Novi Sad 1956. 
nische Dorf plastisch, manchmal mit elnea bis zur satire und zur Karikatur gehenden Hunor zelchnet; zur Charakterisierung seiner Figuren verwendet or elne Individualisierende Sprechwelse, die seine genaue Kenntnis des volkstumlichen Ausdrucks deutlich macht, obenso wie seln Erzahltext, In dem er uber lange Streoken hin den Ton des Volkserzahlers trifft.

Fur diese Erzahler f11t, wle fur die anderen serblschen Realisten, z.B. Stevan Sremac, Petar Kočlt oder Ivo Cipiko, daB 1hre Kunst auf der Tradition jener Schriftsteller rubt, die,ausehend von elnem oft natven National1smus, mit der volkstumlichen Thematik auch die volkstuml lche Sprache in der serbischen Literatur helmisch machten. Auf Zusammenhäge zwischen Sapčanin und Lazarevit, auf die mögliche Herkunft bestlmmter Themenkre1se

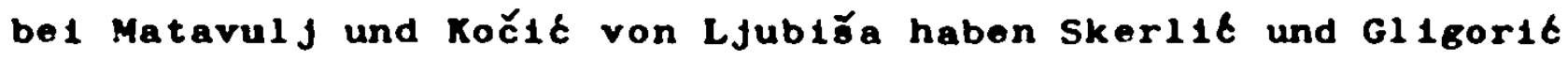
hingewiesen; ohne dem genauen Verlauf dieser Verbindungen im einzelnen nachzugehen, kann man sagen, dab jedenfalls die genannten Schriftstelier - ob direkt oder indirekt - wie thre Vorlaufer an die Erzahltradition des Volkes anknupfen, eines Volkes, In dem mundliche Erzahlkunst lmmer hoch geschktzt war und von elner groBen Zahl anonymer Talente gepflegt wurde. Diese Anknüpfung besteht, wie bel den Vorgangern, nicht nur in der Wahl des Milieus, sondern nicht minder in der Gestaltung der Mentalitat des dörflichen Menschen, selner Lebensform und selner Ethik, die nur deshalb so überaus realistisch möglich 1st, well die Schriftsteller auf die adaquaten stilmitel der Volkserzahlung zuruckgrelfen, die sle aber melst sparsamer und gezielter elnsetzen. Fü manche Dialoge und Repliken in Lazarevits "Školoka Ikona" oder Matavuljo Roman "Bakonja fra Brne", dessen beste Kapitel herausgegriffen kleine Novellen bilden, glit dasselbe, was selnerzelt uber Ljubisa gesagt wurde - es 1st, als hörte man das Volk selbst erzahlen. In den besten Schöpfungen der serblschen Realisten errelcht die dörfliche Novelle kilnstlerische Hóhepunkte. 


\section{v.2. Kroatische Literatur}

In der kroatischen Literatur stellt sich bereits gegen Ende der sog. "Epoche Senoas" elne Reaktion der jungeren Autoren sowohl auf Senoas "milden" Realismus als auch auf die betont volkstümliche Richtung e1n. Entscheldend ist jedoch vor allem, das gegen Ende der 70ar Jahre durch die Tatigkelt von Schriftstellern und Journalisten, wobel Senoa in belden Gruppen mitzanlt, die Sprache der kroatischen Prosa ihre kanonisierte Form gefunden hat, wie FlaksR sagt(33,5.34). Diese Sprache hat, wie am Beisplel von Senoas Novelle "Barun Irica" geze1gt wurde, viele volkstumliche Elemente assimiliert und ubt durch das Inzwlschen zahlreicher gewordene Leserpublikum eine unittelbare Nirkung auf die Umgangssprache aus.

B1e nationale Tendenz der Literatur iberschneidet $81 \mathrm{ch} m 1 t$ realistisch-gesellschaftskritischen Bestrebungen, die tellweise von auben herangetragen, tellwelse aufgrund der einhelmischen Gegebenheiten notwendig werden, wie das Beispiel Eugen Kumitits ze1gt. D1e N1derspruchlichke1t der herrschenden Tendenzen wird bel elnem Schriftstelier wie Balski durch eine Poetisierung des aus der Wirklichke1t bezogenen stoffes uberwunden oder, bel Kozarac, durch die Unterordnung realistischer strukturen unter nationale, geradezu aufklarer1sche Tendenzen (33,5.36). Der Verzicht auf elne bewulte Einbeziehung von volkssprache oder Berufsjargon, dieses so wichtige Stilmittel des Realismus, steht dariber hinaus der vollen Ausbildung des realistischen St1ls entgegen und gibt der kroatischen Prosa der 8ner Jahre einen ausgesprochen "literarischen" Charakter. Eine Ausnahme blldet hier das eruptive Temperament Ante Kovatits, der sich zwar ausdrucklich gegen die Fortsetzer der nationalen Linie (Jorganovit, $C_{1}$ rak1) und gegen Senoa wendet und auch wit dem Kult des Illyrismus durch selne Travestie "Sart babe čengitkinje(1880) abrechnet, selbst aber sogar sentimentalistische und romantische stilverfahren aufgreift und in seinem beruhmten Roman "U registratur1"(1889) mit dem St11 der "Pravaji", vor allem Starcevits, und realistischen Schilderungen sowohl den studtischen Jargon als auch volkstimliche Elemente zu jenem Interessanten Mosalk verbindet, das der Vorsteliung von "Literaturhaftigkeit" (11teraturnost)so sehr widerspricht. Hiervon 
kann man dagegen in besug auf d1e Verke Ivo Vojnovits sprechen, dessen Nelgung zur Psychologisierung und Symbolielerung bich schon In seiner ereten, 1880 erscheinenden Novelle "Geranium" andeutet und diesen Autor der dem Realisms folgenden Perlode zuordnet. Die durch Leskovars Erzkhlung "Misao na vječnost"(1891) und Matošs "Mot savjesț" (1892) bezelchnete Wende zur Psychologlsierung leltet nach Flaker die Perlode der Auflósung des Realiemus e1n, der damit in der kroatischen literatur einen enr kurzen ze1traum umfaBt.

Im Rahmen der um die Jahrhundertwende elneetzenden, vielfyltigen kroatischen Moderne erscheint das Werk Dinko Šimunovite m1t selnen auf die Volksuberlieferung zurickgehenden Sujets, seinen archaisch-rudimentiren charakteren und seinem an die Volkeerzahlung anklingenden Erzahlstil als Abwelchung von der allgemelnen Linie der Literatur, obwohl gerade in Šmunovito Novelien die tragische Sehnsucht des verstobenen modernen Menschen nach elner heilen Welt mit besonderer Intensitbt zur Ausdruck koment. 
VI. $\quad$ Z $u$ :

D1e Anfange der neueren L1teratur der serben und roaten im 19.Jahrhundert müssen in unmittelbarem $\mathrm{zusammenhang}$ mit der Entstehung der Literatursprache gesehen werden; nur unter diesem Aspekt lst es möglich, die in einem relativ kurzen Zeltraum vollbrachte Lelstung richtig elnzuschatzen und den elnzelnen Erschelnungen dieser literatur gerecht zu werden.

Der Impuls zur Entfaltung einer neuen literarischen Aktivitat ging bel den serben und Kroaten wie bel elner Reihe anderer klelnerer Vilker Europas von dem erwachenden Nationalbewubtsein aus. Die sich selt Herder durchsetzende Erkenntnis von der Individualitut der völker als bestimmendem Faktor threr Existenz und als Quelle spezifischer schöpferischer Fuhlgkelten resultierte in der Kultivierung völkischer E1genart, aus der sich als Reaktion auf politischen Druck der Nationaliswus, diese Triebfeder und Krankhelt des 19. und 20. Jahrhunderts, entwickelte. Der National ismus mobilisierte jene Krafte, deren es zur politischen Befrelung elner Anzahl von völkern bedurfte, die die Voraussetzung lhrer unbehinderten nationalen Entfaltung war; im Nationalismus aber oind gleicherwelse nationale tiberheblichkelt und nationale vormachtansprüche verwurzelt.

Die aulserliterarische Funktion der L1teratur im Verein mit der von den Romantikern ausgehenden hohen Einschatzung der Volksdichtung bedingte bel den Serben und Kroaten den Ruckgriff auf die mundliche Uberlieferung, die sich neben auslandischen Vorbildern als Orientierungshilfe anbot, zumal die Verbindung zu den ulteren schriftsprachlichen Traditionen aus verschledenen Grinden abgerissen war. Der unter II.5. in der vorliegenden Arbelt gegebene Uberblick uber die theoretischen Forderungen, die an die Literatur gestellt wurden, verdeutlicht die Uberbetonung der nationalen Komponente, die zunkchst ein Hintanstelien kunstlerischer Ansprüche zur polge hatte. 
Die In Mesteuropa als Rückkehr zur "Naturpoesie" Im Sinne der Romantiker verstandene Beschaftigung mit der mundlichen Literatur war im sudslavischen Raum nicht nur Ausdruck nationaler Selbstbesinnung, sondern hat te daruber hinaus den konkreten Zweck, sprachliche Muster zur Verfüung zu stellen, wie dies Vuk Karadite ausdruckl1ch formuliert hat. Diesem Anspruch genugten allerdings zunkchst nur die von thm selbst bearbelteten Samelungen, d1e sowohl die sprache opaterer Sammler als auch die nachfolgende muindliche tberlieferung otllbildend beelnflubten.

Selbstrerstandlich darf der Beltrag anderer olavischen Sprachen, vor allem des Russischen und des Tschechischen, zur Formung der serbischen und kroatischen Literatursprache ebenso wente ubersehen werden wie der Antell des Kirchenslavischen hinsichtilch der Abstracta; dieses Thema liegt aber auberhalb des Rahmens dieser Arbeit.

D1e vorrealistische Epoche der serblschen und kroatiochen 'Literatur, mit der sich diese Untersuchung auseinandersetzt, lot mithin durch das Zusammenwirken mehrerer Komponenten gekennzelchnet: ihr Stil wird elnerselts durch die westeuropälsche Romantik, den Feuilletonismus und die Nachklange des Sentimentalismus, andererseits durch die muindliche L1teratur in Verbindung mit der Dubrovniker Dichtung und, schlielilch, durch die ersten Andeutungen des Realismus geprät. (Aus diesem Grunde erscheint die haufig gebrauchte Bezelchnung "Romantiker" für die Autoren dieser Perlode als nicht ganz präzise).

Die Analyse der hier zusammengestellten Novelien hat das interessante Frgebnis erbracht, dals diese glelchzeltig aurtretenden Krafte nicht selten in ein und derselben Richtung wirksam wurden.

Da die Finflusse der in westeuropa bzw. In RuBland ausgebildeten stile auf die entstehenden sudslavischen Literaturen berelts wiederholt untersucht worden olnd, war es zunachst das Ziel dieser Arbelt, AusmaB und Art der oft am Rande erwahnten, jedoch nicht prazisierten Auswirkungen 
der milindlichen Uberlieferung auf die neue Hochliteratur im elnzelnen nachzuweisen. An Hand der ausgewahlten Novellen, die das oben erwahnte Zusammenspiel unterschiedlicher Krafte spiegeln und damit beispielhaft fü die Novellistik der vorrealistischen Epoche sein können, wurde gezelgt, dal der Beltrap der mindlichen Literatur zur Formung des 11 terarischen stils und der literarischen sprache nicht unterschatzt werden darf. Die Textuntersuchungen belegen diese Tatsache durch zahlrelche Belsplele; die Beziehung zur miindlichen Literatur auisert sich nicht allein in der Hauflgke1t der dort gebräuchlichen kunstgriffe (bel allen finf Autoren). sondern auch in der ibernahme von Kompositionsprinzipien (Ljubiša, Šenoa), von Sujets (Korajac, Ljubiša), von Leitbildern und ethischen Grundsatzen (Šenoa, Ljubtßa, Hot 1 t).

Da, wip schon gesagt wurde, die Entstehune bestimmter stilzïge vielfach sowohl durch die herrschenden europaischen stilrichtungen als auch dirch die mindliche literatur beginstigt wurde, besteht die Gefahr, dab die Bedeutung des einen oder des anderen Faktors ibersehen bzw. unterbewertet wird; eine kntscheldung daruber, welcher Faktor der maligebendere fewesen ist, lielse sich nur für den einzelnen Autor, nicht aber für die fanze Epoche treffen. Die Frage, worauf denn elne solche Parallelwirkung der stllbildenden Krafte zurickzufihren $18 \mathrm{t}$, kann durch den Hinwels auf thre zahlrelchen Gemeinsamkelten beantwortet werden:

Charakteristisch fur die romantische wie fiir die münliche Erzahltradition ist die Bedeutung des immer anwesenden, allwisenden, kommentierenden und antellnehmenden Erzahlers, dessen Kontakt zum Leser (bzw. ursprunelich zum Zuhbrer) in feullietonistischen Texten bis zum fikt1ven Gespräch mit diasem gehen kann: hieraus ergibt sich das Uberwiegen "münd1 cher" Elemente, worin ein auffall1ger Beruhrungspunkt zw1schen feullletonistischer und volkserzahlung besteht; hinzu kommt der beiden gemelnsame Hang zur ornamentalen Rhetorik (die, wiederum, ein wesentlicher stilzug der Dubrovniker vichtung ist). All diese Gemelnsamkelten beruhen auf der fiktiven bzw. realen Erzahlsituation. 
Komantik und Volksliteratur verbinden welterhini die Verwendung feststehender, oft ldentischer Klischees (die den Kl1schess der Dubrovniker Dichtung entsprechen), ferner d1e typ1sierende Charakterdarstellung, die den Verzicht auf Psychologisierung bedingt, sowie die melst stark ausgepragte nationalistische Tendenz. Diese gemeinsamen stilzüge ergeben $81 \mathrm{ch}$ aus der Ruckwendung der Romantiker zur "Naturpoesia" = "Volkspoesie" und aus der historisch mot1vierten nationalistischen Orientierung der Romant1k, die die wesentlichste Voraussetzung für thren starken widerhall be 1 den Sudslaven war.

Schl1eBlich besteht elne gewisse Uberelnstlumung zwischen den sich in der Novelilstik andeutenden realistischen Tendenzen und der Nelgung der serbokroatischen Volkserzahlung zum realistischen Detall, das zum Lokalkolorit beltragt.

Dipse Verhaltnisse erklaren die koharente wirkung jener Strömungen, deren EinfluB die vorrealistische Novellistik ausgesetzt war. Im Hinblick auf lhre Entstehungszelt, deren besondere Aufgeschlossenhelt allew Volkstumlichen, Volkhaften gegenuber bekannt ist, erschelnt mir jedoch die Behauptung perechtfertigt, dals der Antell der Volksilteratur an der fintstehung elnes neuen frabhlstils im allemeinen bisher zu niedrif veranschlagt worden $18 t$, da es das $21 e l$ der melsten einschlagigen Studien war, gesamteuropalsche Bezüge herzustellen.

Anderersetts hat gerade das Vorhandenseln analoger stilverfahren bel den auslandischen vorbildern slcher dazu belgetragen, dab sich die aus der mundlichen tiberlieferung ubernommenen Kunstgriffe umso zwangloser in einen heterogenen neuen Prosastil einbeziehen lieben. Bei der Auswahl der Novelien habe ich mich davon letten lassen. Belspiele fur elne möglichst gegluckte Integration volksilterarischer Elemente in die Textstruktur zu finden, die entsprechend herausgearbeltet wurde. 
Für die noch unsichere Literatursprache bedeutete das Eindringen volksoprachlicher Ausdrucke elne Berelcherung ihrer Lexik und Idiomatik und damit lhrer kinstlerischen Entfal tungsmöglichkelten. Da Sprichwörter, Verglelche und Redensarten, wie sie der mundliche Erzahler elnzuflechten pflegt, Immer die Mentalitut der Gruppe widerspiegeln, die sie gepragt hat, drang mit ihnen auch die Denkwelse und Ethik des einfachen Volkes in die Literatur eln; durch die Rhythmisierung des Textes mit Hilfe ornamentaler Figuren der Volksdichtung konnte deren Atmosphare, die von solchen formalen Mitteln getragen wird, In literarische Werke E1ngang finden. Da die Stilmittel der serbokroatischen volksliteratur zu einem groben Tell aus oprachlichen Figentiolichkelten entwickelt sind, die das Serbokroatische mit anderen slavischen Sprachen gemeinsam hat, bedeutete eine Integration solcher Verfahren zugletch elne Betonung des spezifisch olavischen Charakters der citeratursprache.

Obwohl mit der Anwendung volksliterarischer Kunstgriffe u.a. eine Poetisierung des Prosastlls angestrebt wurde, erfolgte hierdurch glelchzeltig elne Annaherung an den echten "Volkston", an die volkstüliche Rhetorik, d.h., der Text gewann auch an realistischen Qualititen, die die Fntstehung des $S k$ a $z$ heginstigen. Damit wirkten die Autoren, die an die muindliche tberlieferung anknupften, der Gefahr allzu groBer "literaturnost" entgegen, der bekanntlich gerade die kroatische Literatur ausgesetzt war, und es war auberdem von vornherein jener Kontakt zur urspringlichen Erzahlkunst hergestellt, der in den Werken opterer Schriftsteller 1amer wleder spürbar wird, z.B. bel Šlmunovit, Čopit, Bulatovit. In dieser Elgentülichkelt der serbischen wie der kroat18chen Literatur besteht möglicherwelse eln Te1l thres unverwechselbaren, Individuelien Beltrags zur europalschen isteratur.

Abschließend kann die Frage nach Stllelementen der muindl1chen Literatur in der vorrealistischen Novellistik der Serben und Kroaten wit folgenden sutzen beantwortet werden: 
1. Ausgehend von den theoretischen Forderungen an die jungen Literaturen und von den ausfuhrlich dargestellten Charakteristika der serbokroatiochen volksersahlung, zeigt die vorliegende Arbelt, dab elne Re1he der serbiochen und kroatischen Novellisten der vorrealizt1achen Epoche volksilterarische Elemente in relchem Mabe in Ihren Prosast1l elnbezieht, wobel diese stilelttel a.Tl. it denen der herrochenden europalschen st11richtungen Identisch sind.

2. Diese lberraschende Kohkrens zwischen der st1lbildenden virkung gesamteuropischer und volksliterarischer vorbilder erklurt olch durch elne Anzahl von Beruhrungspunkten dieser etilistischen Bereiche. Die Kumulation von Kunstgriffen der münlichen Literatur sowle die thernahme threr Kompositioneprinzipien und ihrer weltslcht deuten jedoch auf elne starkere Anlehnung an die Volksuberlieferung, wofür neben der persönltchen Einstellung der betreffenden Autoren auch die allgemeine Wertschatzung der Volksdichtung whrend der Entstehungsze1t dieser Novellen spricht.

3. Obwohl die Uberbetonung der nationalen Funktion der L1teratur die orientierung der jungen literaturen an allRemeinen kunstlerischen Malsotaben zunkchst verzögert, leloten die hier herangezogenen Schrifteteller durch die Integration volksliterarischer Stilverfahren in den neuen prosastll einen wertvolien Beltrag zur Berelcherung der literatursprache und eroffnen glelchzeltig kunftigen Autoren zustizliche stilistische Moglichkeiten, auch wenn diese u.a. als Destruktion der vorgegebenen Stilmittel wahrgenommen werden. 
In Abochnitt III.3("St111etieche Merken10 der corbokroatiechen Volkeersuhlung") werden fur d1. Sammlungen, denen dio olnzelnen Belepiele entnommen elnd, fol gende Abkurzungen verwendets

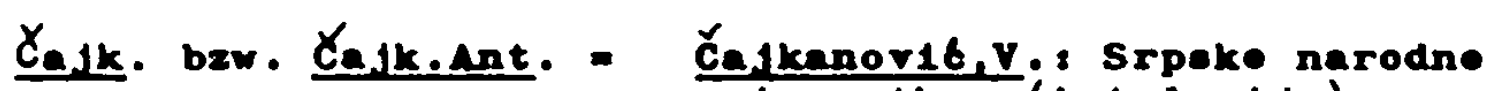
priporetke. (Antologi ja). Boograd 1929 .

$\stackrel{\text { cub. }}{ }$ $(=N r .22$ d.L1t.verz.)

Dar. bzw. Deruver =

Cubel1l, $T$. I Izbor 12 narodne knj1Zernost1,3, Narodne pripoI jetke. Zacreb 1952

(-Nr.24 d.L1t.vers.)

Dar. bzw. Daruver = Zečerll, D.8 Useena kesiranja u okol1c1 Daruvara. "Narodna unjotnost" kn J . 7, 2 Gb. 1970 S. 27-70

(aNr.126 d.L1t.vers.)

Nar.prip.PSHT

- M.Bolkovil-stul11: Narodne pr1povijetke. Pot tol jeba hrvatoke kn J1Ẽomoet1 knj.26.2agreb 1963 (=Nr.16 d.L1t.vers.)

$\underline{\sin 1}$

- M.BoYkov18-Stul11: Narodne pripovijetke 1 prodajo einjoke krajine. "Narodna ujetnoet"knj,5-6, zagreb 1868, S. 303-4111 (-Nr.17 d.L1t.verz.)

Vrčer1t 1868

= Vrǒerif, v. isrpeke narodne pripovetke ponajvile kratke 1 ealjlre. B10grad 1868

(aNr.123 d.L1t.vers.)

Vrěerit 1890

- Vrčovil, v. Navodne pripovijeet1 1 preaude. Dubromik 1890 (-Nr. 122 d.L1t.vers.)

$\underline{\text { vuk }}$

Vuk st.Keraď̌le, Srpeke narodne priporijetke 1 sagonetke,I. B106rad 1897.

$(=\pi r \cdot 54$ d.L1t.vers.)

\section{Abkurzung im Literaturverze1chnie:}

PSHK

= Pot etoljeta hrvateko knjižernocti. 
1. Barac, A.

2. Barac, A.

3. Barac, A.

4. Barac, A.

5. Barac, A.

6. Barac, A.

7. Barac, A.

8. Barac, A.

9. Hausinger, H.

10. Hel1t, A.

11. He11t, A.

12. He $11 t, A$.

12A. Bely J, A.

13. Bogdanovit, D.

14. Boskovit-Stull1, M.

15. Borkovit-Stul11, M.

16. Boškovit-Stul11, M. (Hrsg.)
August Senoa. Predgovor. In: A.S., Djela (=RSHX 39), Zagreb 1962, s. $7-34$.

Evropskt okvir jugoslavenskih knjtzevnost1. In: Izraz, Sarajevo 1954, S.245-255.

Hrvatska književna kritika.

Zagreb 1938.

Hrvatska knjizevna kritika(=Hrvatska knjizevna kritika VII). Zagreb 1962 .

Hrvatska knj1źevnost od Preporoda do stvaranja Jugosiavije.

Knj.I Knj1żevnost 111 rizma, Zagreb 1954

Knj.II Knjlzevnost pedesetih 1 bezdosetih godina, Zagreb 1960.

Juposlavenska književnost.

Zagreb 1963.

Hrvatska novela do Śenolne smrti.

In: Rad JAZU 290, Zagreb 1952. S. 5-64.

Mirko Bopovit. In: Rad JAZU 245. Zapreb 1933.

rormen der "Volkspoesie".

Berlin 1968.

Oko našeg književnof jezika.

Beograd 1951.

Vuk 1 Danic1t. Beograd 1947.

Vukova borba za narodni 1 književni jezik. Beoprad 1948.

Masterstro Gogolja. Milnchen 1969.

Pregled književnosti hrvatske 1 srpske. I, II. Zagreb 1916.

Drvo nasred svijeta. In: Vukov zbornik, Beograd 1960, S.663-694.

Narodna predaja o vladaravoj tajni. Zagreb 1965.

Narodne pripovijetke. (=PSHK 26). Zagreb 1963 (Uvod: $5.7-26$ ) 
17. Borkovit-stul11, M. (Hrag.)

18. Bozkovit-stull1, M.

19. Bośkovit-Stull1, M.

20. Bos̆kov1t-Stull1, M. (Hrsg.)

21. Bot 1C,L.

22. Čajkanovit, $v$.

23. Čajkanovit, $v$.

24. Cube116, $T$.

25. Demeter, D./

Bof ov 1C, M.

25A. D1 ppe, G.

20. Dizdar, H.

27. Donat, B.

28. Dukat, vi.

29. Duk1t, $\mathrm{T}$.

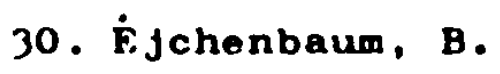

Narodne pripovijetke 1 predaje oinjoke krajine. In: Narodna undotnost, kn J.5-6, Zagreb 1968, S.303-411 .

o recenici usmenog pripovjedaca. In: Umjetnost rijec1, Zagreb 1969. S .255-272.

Regionalne razlike medu narodnim pripovijetkama. In: Narodna umjetnost. knj.7. 2agreb 1970,5.3-15.

Uemena knj1zevnost. Zagreb 1971.

Djela. Zagreb 1949.

Srpske narodne pripovetke.

Antologija. Boograd 1929.

Srpoke narodne umotvorine, knj.l. $I_{n}$ : Srpsk1 etnografsk1 zborntk. Heograd-2emun, 1929.

Izbor narodne knjlževnost 1 . Zapreb 1952 .

I: Epoke narodne pjesme.

II: Lirske narodne pjeswe.

III: Narodne priporijetke.

Djela (=PSHK 31), Zagreb 1968.

August Śenoas historische Romane. (aslavistische Beitrage 58).

Munchen 1972 .

Narodne pripovijetke 12 Bosne 1 Hercegovine. Sarajevo 1952.

V111m Korajac. Predgovor. In:

Perkovac/Jurkov1t/Korajac/C1rak1/ Tordinac: Djela (=PSHK 38), Zagreb 1968, S.241-252.

O nắ1 jem hưoristima: Antunu Neme1tu, Janku Jurkovitu, V111mu Korajcu. In: Rad JAZU 197, Zagreb 1913. S. 139-260.

Pregled knjlževnog rada Crne Gore. Cetinje 1951.

Kak sdelana "Slnel" Gogolja. In: Jurif Striedter(Hrsg.):Texte der russischen Formalisten, Bd.1. Munchen 1969, S.122-159. 
31. E jchenbaum, B.

32. Flaker, A./Pranj1t, K. (Hrsg.)

33. Flaker, A.

34. Fiaker, A.

35. Flaker, A.

36. Flaker, A./Škreb, Z.

37. Frange है, I.

37A. Franpeš, I.

36. Franges, I.

39. Gesemann, G.

40. Gesemann, G.

41. Gesemann, G.

42. G11gorit, v.

43. Grafenauer, B.

44. Hafner, St.

45. H1rsch, A.

46. Jakobson, R.
Illjuzija skaza. In: J.Striedter:

(Hrsb.): Texte der russischen Formalisten, Bd.1. Múnchen 1969, S. 160-167.

Hrvatoka knjizevnost prema evropskim knjizevnostima. Zagreb 1970.

Knjiz̈evne poredbe. Zagreb 1968.

Osebujnost hrvatskog knjtzernopovijesnog procesa XIX stoljeta. In: Radovi zavoda za slavensku filologiju, sv.10, Zagreb 1.968, S.69-85 .

O real1zmu. In: Umjetnost rijeci, Zagreb 1969, S.111-127.

St1lov1 1 razdobl ja. Zagreb 1964.

Eine stilistische Figenschaft von Krlezas "Davni dani". In: The Art of the Word (Umjetnost rijed1). Selected Studies, ed. by Zdenko Skreb, Zagreb 1969, S.235-258.

Śnolna baxtina u hrvatskom rea$112 \mathrm{mu}$. In: Croatica I, Zagreb 1970, S. 137-166.

Umjetnost Ivana Mazuranita. In: I.Mažranit, Smrt Smajl-age Čengita, Zagreb 1465, s.9-37.

Der montenegrintsche Mensch. Prag 1934.

Helden, Hirten und Hajduken. Miinchen 1935.

Heroische lebensform. Herlin 1943.

Srpsk1 real1st1. Beograd 1954.

Historija naroda Jugoslavije. Zagreb 1953.

Schriftsprache als Kulturfaktor be 1 den Slaven. In: Aus der Gelsteswelt der Slaven, Miinchen 1967,S.32-54.

Der Gattungsbegriff "Novelle". Berlin 1928.

Selected Writings IV: Slavic Epic Stud1es. The Hague/Paris 1966/1971. 
47. Jarneviteva, D.

48. Jezit, S.

49. Jonke, LJ.

50. Jovanovit, J.

51. Kadach, D.

52. Karadzit, V.St.

53. Karadzit, V.St.

54. Karadzit, V.St.

55. Kayser, W.

56. Kerbler, D.

56A. Xlait, B.

57. Perkovac/Jurkovit / Korajac/Ciraki/ Tordinac

58. Krauss, W.

59. Lammert, E.

60. Lasit, St.

61. Latkovit,v./ /Cadenovit, J.
Žrtve 121 jubavi 1 vjernost1 za domovinu. In: Hrvatoki narodni preporod II (-PSHK 29), Zagreb 1965. S. 15-38.

Antun Newrit. Mirko Bogovit. Ins A.Nort1t/M.Bogovit: Djela, Zegreb 1957, S.7-34 und S.341-349.

D1. Entetehung der neueren Schriftsprache bel den Kroaten und Serben im 19. Jahrhundert. In: Aus der Ge1steswelt der Slaven, Munchen 1967. S.55-67.

Stvaranje crnogorske drzave 1 razvo $j$ crnogoreke nacionalnost1. Cetinje 1947.

Die Anfinge der Literaturkritik bei den Serben. Munchen 1960.

o knjizevnosti 1 književnicima. Beograd 1964.

Pisma. (Izbor). Beograd 1947.

Srpoke narodne pripovijetke 1 zagonetke,I. Biograd 1897.

Das sprachliche Kunstwerk.

Bern/Munchen 1948.

St.H.Ljubiza 1 njegova okolina. Ini Rad JAZU 229, Zagreb 1924. S.I01-187.

oblici. Sintaksa. Ins M.Bolkov1tStulli (Hrs8.): Narodne pripovijetke (=PSHK 26). Zagreb 1963. S. 386-398.

Djela (=PSHK 38), Zagreb 1968.

Grundprobleme der Literaturwienenschaft. Reinbek b. Hambure 1968.

Bauformen des Erzbihlens. Stuttgart 1968.

Le roman de l'bpoque de Šenoa. Ins The Art of the World (Unjetnost riject) Selected Studies, ed. by Zdenko Skreb, Zagreb 1969, S.155$-179$.

Epske nerodne poeaija Crne Gore. Ti to grad 1964. 
62. Iatkovit, v.

63. Latkovit, v.

64. Leskien, A.

65. L1chatschow, D.

66. LJubiza, St.M.

67. LJub18a, St.M.

68. L jub18̌a, St.M.

69. Ljubiša, St.M.

70. Lotman, J.M.

71. Luth1, M.

72. Luktacs, G.

73. Maretit, T.

74. Markovit, Sv.

75. Martinovit, N.S.

76. Mator, A.G.

77. Michel/Starke/Graehn

78. M11 janov, M.

79. Milovit, J.M.

80. Mis̆tt, Z .

81. Mojab̧evit, M.
Narodna knj1ževnost. Beograd 1957.

St.M.Lfubisa. Predgovor. Ins St.M.Lf.. Priporijesti 1 prizanja. Beograd 1949, S. $11-20$.

Handbuch der al tbulgarischen Sprache. He 1delbere 1962 .

Nach dem Formal1smus. Munchen 1968.

Izabrane pripovijetke. Zagreb 1946.

Pripovijesti. Beograd 1964.

Priporijesti 1 prizanja. Beograd 1949.

Pucko krasnorjexje. T1tograd 1964.

D1e Struktur des klinstlerischen

Textes. Frankfurt/M. 1973.

Volksliteratur und Hochliteratur.

Bern 1970 .

Russische Revolution - russische

Literatur. Neuwied/Berlin 1969.

Naśa narodna epika. Zagreb 1909.

o Srbij1 1 o spskojknjizevnost1.

(Srbija na 1stoku. Pevanje 1 misljenje.

Realnost u poezij1). Beograd 1957.

Evandel je po narodu. Antolopija crnogorskih posiovica 1 izreka. Titograd 1969.

Kritike, esej1, studije 1 Clanc1 (=PSHK 66), Zagreb 1967.

Finfuhrung in die Methodik der St1luntersuchung. Berlin 1968.

Primjeri čojstra 1 junaštra.

Beograd 1901 .

Goethe, selne Zeltgenossen und die serbokroatische Volkspoesie. Lo1pe1g 1941.

Antologija srpske književne kritike. Beograd 1958.

o Vukovoj stilizaciji spokih narodnih pripovedaka. In: Zbornik etnografskof muzeja u Beogradu 1901-1951. Beograd 1953. S.3001-314. 
82. Mukarovsky, J.

83. Ned1t, LJ.

84. Neme 1t, A.

85. Nemt 1t, A./Bogovit, M.

86. Palavestra, P.

87. Pavicevit, M.

88. Peukert, H.

89. Petrd,F./Skreb,Z.

90. Pollok, K. -H.

91. Popovit, Miodrag

92. Popovit, Pavle

93. Popov1t, Pavle

94. Ravl1t, J.(HrsR.)

95. Ravl1t, J. (HrsG.)

96. Ravl1t, J. (Hrsg.)

97. Ravl1t, J.

98. Schmaus, A.
Kapitel aus der Poetik. Frankfurt/M. 1967.

Celokupna dela I/II (=Biblioteka srpskih p1saca knj.26/55), Beograd $1929 / 1933$.

Putositnice. Udes l Judsk1. (=PSHK 34), Zagreb 1965.

Djela. Zagreb 1957.

Posleratna srpska knjlzevnost. Beorrad 1972 .

Crnogorci u pricama 1 anegdotama,I. Beorrad 1928.

Serbokroat 1 sche und makedon $18 \mathrm{che}$ volkslyrik. Berlin 1961.

Urod u knjtževnost. Zagreb 1969.

Studien zur Poetik und Komposition des balkanslavischen lyrischen Volksliedes (zOpera Slavica Bd.5)

Gottingen 1.964 .

Istorija srpske knj1ževnost1.

I: Komant1zam. Beograd 1968.

II:Romant 1zam. Beograd 1972 .

II :Romant 1zam. Beograd 1972.

Knjtzerni lotoricari 1 kriticari. Nov1 Sad/Beograd 1963.

Pregled srpske knjlzevnost1.

Beograd 1913.

Hrvatsk1 narodn1 preporod, I. (=PSHK 28), Zagreb 1965.

Hrvatak1 narodn1 preporod, II. ( =PSHK 29), Zagreb 1965.

Hrvatsk1 narodni preporod u Dalmac1j1 I Iotri. Zagreb 1969.

Luka Bot1t(Kratka biografija. Knj1ževni rad. Napomena). In: l..bot1t: Djela. Zagreb 1949, S.5-26.

Gesammel te slavistische und balkanologloche Abhandlungen, I.Tell. Munchen 1971. 
99. Schmaus, A.

10n. Schmaus, A.

101. Sekul1t, LJ.

102. Sert16, M.

103. Sker11t, J.

104. S1 amn1R, I .

105. Sokolova. L.

106. Spitzer, L.

1n7. Stender-Petersen. A. Geschichte der russischen Literatur.

10H. Striedter, J.(Hrsg.) Texte der russischen Formalisten, I.

1n9. Senoa, A.

11n. Šenoa, A.

111. Śenoa, A.

112. Šnoa, A.

113. Sice1, M. Bd.II, München 1957. München 1969.

Heldentum und Hybr1s. In: Ph11080phischer Eros in Wandel der Zelt. (Festgabe für Manfred Schrobter). Miunchen 1965, S.49-65.

Suds lavisch-deutsche Literaturbeziehungen. Deutsche Philologie

Literarna tradicija u novelistici Mirka Bogovita. In: A.Flaker/K.Pranjlt (HrsG.):Hrvatska knjltevnost prema evropskim knjlzevnostima, Zagreb 1970, S.135-147.

St1lske osobine hrvatskor historifskog romana. In: A.Flaker/K.Pranj1t: (Hrsg.) Hrvatska književnost prema evropskim knjlzevnostima, Zagreb 1970, s.175-255.

Istorlja nove srpske knj1Zevnost 1. (Izdanje o pedesetogodibnj1c1 smrt1 Jovana Skerlita). Beograd 1967.

Hrvatska knjlzevnost prije preporoda kao organski dio evropskog književnog kretanja. In: A.Plaker/K.Pranj1t: Hrvatska knjiźevnost prema evropskim knj1ževnost 1ma, Zagreb 1970,s.19-49.

Nesobstrenno-avtorskaja (nesobstrenno-prjamaja) rec' kak stilistileskaja kategorija. Tomsk 1968.

St11studien I: Sprachst11e. Munchen 1961 .

Sabrana djela II. (Glas od gradne. Zaprebul je II-V. Nă̌a knjlževnost. O hrvatskom kazalistu.) Zagreb 1932.

Sabrana djela IV. (Pripovijesti II). Zagreb 1932 .

Sabrana djela XIV. (Članci l krit1ke). Zagreb 1934.

$\check{C}_{1}$ anci/Fel jtoni/Pjesme/Pripovijest 1 . (=PSHK 39). Zagreb 1962.

Pregled novije hrvatske knj1ževnost1. Zagreb 1960. 1m Aufris, Bd.II. Berlin 195/. 
114. Sklovak1 J, V.

115. Sklovsk1J, V.

116. Škreb, $\mathrm{z}$.

117. Skreb, Z. (Hrs B.)

118. Tynjanov, J .

119. Vinogradov, V.

120. Vodntk, B.

121. Vraz, St./

Preradovit, P.

122. Vrčov16, v.

123. Vrčev1t, v.

124. Wellek,K./Warren, A.

125. v.w11pert, G.

126. Začevit, D. (Hrsg.)

127. ¿ivanterit, M.

128. Ż1vkov16, D.
Iskusstro, kak prien. In: J.Striedter

(Hrsg.): Texte der russischen Forma-

11 sten I. Munchen 1969, S.2-35.

Svjaz prienor juketoslozenija. obscimi priemani st11ja. In: JuriJ Striedter(Hrsg.): Texte der ruse. Formal1sten I, Milnchen 1969,S.36-121.

Senoa 1 njegovo doba prema njemackoj knjtíevnost1(1860-1881). In: A.Flaker/K.Pranj16(Hrog.) : Hrvatska knjizevnost prema evropskim knjtzernost1ma, Zagreb 1970, S.151-173.

The Art of the Word (Umjetnost riject) 1957-1967. Selected Studies, Zagreb 1969.

Die 11 terarischen Kunstmittel und d1e Evolution in der Literatur.

Frankfurt/M. 1967.

Problema skaza $v$ stillotike. In: J.Strledter(Hrsg.): Texte der russ1schen Formalisten I, Milnchen 1969, S . 168-207.

Povijest hrvatske knjlzernost 1. Zagrab 1913.

Djela (a PSHK 30). Zagreb 1965.

Narodne pripovijesti 1 presude. Dubrovn1k 1890 .

Srpske narodne priporetke, ponajviŏe kratke 1 falj1ve. Blograd 1868.

Theorle der Literatur. Berlin 1968.

Sachwörterbuch der L1teratur. Stuttgart 1964.

Usmena kazivanja u okol1c1 Daruvara. In: Narodna umjetnost, knj. 7. Zagreb 1970, s.27-70.

Vukovi prijatelj1 Il1rci. In: Vukor zbornik, Beograd 1966, S.229-259.

Potec1 orpoke knjlzevne kritike. Beograd 1957. 
Sa1to 9 (...u dosadadnj1m nadim povijest1aa knj1zsvnost1...) Ponajvise su upozorill na motivske utlcaje 1 na inena epskih junaka u knjtzernia djelima, dok su o utjecaju 1 uzajamim prel1jevanjina 1zrazajnih oblika, npr. stiha, govorlil znatno manje 1 najcerce impresionistiek1. N1ou u dovoljnoj mjeri nastojall predociti koliko je 1 na kojl nacin prisutnost usmene knjlzernostl pridonijela atvaranju unjetnickih obllezja pojedinih pisaca 111 knjizernosti c1jelih razdoblja.

Se1te 20 ..ono je narjecje 1 u dubrovackih spisatelja, 1 tako se samo crez njega mozeno ujedinit1 s nabom bracom rimokoga zakona koja sadobtu nama ruku prużaju.

Se1te 21 Znajut1 da jedan narod treba jednu knjtievnost da lona, 1 potom sa zalosti gledajut 1 kako nam je knj1zevnost razkomadana, ne samo po bukvic1, nego jos 1 po jeziku 1 po pravopisu, sastajall emo se ovijeh dana da se razgovorimo, kako bismo se, 5to se zasad viłe moze, u knjlzevnost1 slotili 1 ujedinil1. I tako smo jednoglasice priznali, da ne valja miješajut1 narjelja graditi novo, kojega u narodu nema. nego da je bol je od narodnijeh narjexja lzabrat 1 jedno, da bude knjtževnl jezik;...

...Jednoglasice smo priznal1, da je najpravije 1 najbolje primiti juzni narjecje, da bude knjizerno... Ako da Boe, te se ove misli naše u narodu prime, mi smo uvjereni da te se velike smetnje knjizevnosti našoj suta ukionit1, 1 da temo se $k$ pravome jedinstru mnogo približiti. To zamolimo sve književnike, koj1 upravo tele sretu 1 napredak narodu svojemu, da bi na ove wisli nase pristali, 1 po njima djela p1sa11...

Selte 22 Trnski svija, krojl 1 kuje svoj "lirskin vokabular bez lkakra sustezanja.

Seite 23 Srpski knjlzevnici privikli si nekim crkvenim 1 ruskim lzrazima vet na toliko, da se hojati bilo da bl za sada jos nagazilo na prevelik upor ako bl se sasvim ostranlil; s druge strane, tako buduc 1 da su sasvim protiv duhu tivutega jugoslavenskoga jezika, nisu se mogli primiti u hrvatsko narjeçje. koje je stopram u novije vreme podignuto na pismeni jezik 1 zato se je vetma uzddržlo u svojoj lzvornoj 1 puckoj prostot 1 . 
Seite 25 Sve sto se god Slovenskog naroda ot Adriatskog, do Ledenog, 1 ot Baltickog do Crnog Mora voobzé; a osobito to se nas Srbalja tike, 1 to u knjlzevnom prizreniju - sve je to predmet Srbake letopisi.

Selte 25 Pred 1848, Sxb1, u ldejama svojih neposrednin uEitelja Jana Kolara 1 Ljudevita Stura, zovu se "Slavjani" 1 snevaju o "Velikoj Slavij1" 1 "Slavjanskom Carstru", al1 1 osetanje "srbstra" 1 Ideal "srbskost1" uvek su jak1. 1848 Je vrhunac slovenskog osetanja kod Srba; posie toga to osecanje slabl, a lskljuclvo nacionalno osetanje jaca. Srakako, slovensko osetanje kod Srba 1 docnije je jako, 1 to se vidilo prilikon krimekog rata, prilikom slovenske etnografske 1zlozbe u Moskv1(1867), tome su svedok bratske reze sa ruskom omladinom, zajednicki rad a bugarskom emigracijom 1 hrvatskim 1 slovenačkim rodoljublma, all pored svega toga zavladuje ono sto je śtur gorko nazivao"seb1 Eno rodoljublje". Mesto Ideala "Slavjanskog Carstra" dolazi Ideal "Dusanovog Carstra", 1 iz panslavizma Cetrdesetih godina lzlazi uzi srpski nacional1zam.

Se1te 31 ...ja one vrijednosti nabijeh narodnijeh pjesama, koju su Grim 1 Gete 1 Kopitar u njima naśli 1 svijetu je kazali, ni jesam poznavao ni onda kada sam prvu knjiźlcu ftampao...

Selte 33 vige cu recenzirati stvar 1 jezik, a u poeziju netu da se mijegam.

Seite 34 Sroje osetanje za umetnicku lstinitost u knjlzernom delu 1 za umetnicku motivisanost junaka 1 njihovih postupaka Vuk je nesumnjivo stekao na jedinoj belestristlikoj lektiri koju je on čitao...na našoj narodnoj pesmi 1 pripoveci.

Se1te 34 ...onda te se koj1 nati kojega je bor darom pjesnotrorstra obrario 1 dao mu slucaj da može na latinskom 111 na njemazkom jeziku pravila toga razumjet1; onaj te pokupiti sva ova sobranija 1 pretresti, a neke pjesme 1 sam po vkusu 1 po načlnu roda svoga soliniti, 1 tako od sviju oni mali sobranija jedno veliko celo načiniti. 
Se1te 34 Tako je Vuk prvi 1 stakao znacaj narodne poezije za umetnicku naclonalnu poeziju. U to doba je usamljen u tome mišljenju; pohvale koje se lzrizu našlm narodnim pesmama dolaze od stranaca (Grima, Kopitara), u raznim prikazima orpskih narodnih pesama u stranim 1 istovima 1 Casopisima. Srpski p1sci, uglavnom pod uticajem tih stranih pohvala, prihvataju narodne pesme kao "narodno blago", kojlm se Srb1 mogu ponositi, al1...joś su daloko od toga da Im te "slepacke pesme" poslute kao osnova 1 uzor u umetnilkom stvaranju.

Se1te 36 A pravoga splsatelja recenzent1...dovode u vele savrónstro: zajto zna da te pred ovijetom davat1 odgovor za svaku riję svoju, pa se pišuti stara da moze za svaku riječ kazati zasto je onako up1sao, a ne drukě $1 j e \ldots$

Seite 37 Strar je u tome to u pesnickom stvaranju ne udestvuje jezik kao gramaticka kategorija nego jezik kao 1 zraz narodnog nacina misljenja 1 osetanja, kao $12-$ raz narodnog duha. A Branko je taj narodni duh usvojio ne prosto 12 narodnog jezika kao takvog, nego iz narodnog jezika kao izrazajnog sredstva kojim su ispevane nase narodne pesme. U njima, u narodnim pesmama 1 narodnim umotvorima, koje su ovi drugl pesnici stavljall lspod ućenog sthotvorstra, otkrlo je Branko narodni duh 1 usvojto ga u svojim pesnickim delima.

Seite 38 Kao fo je Siler smatrao da je umetnost most koji spaja carstro prirodne nužnosti sa carstrom slobodne volje covekove, tako 1 Maletit vell da je umetnost "onaj hram u kom bl trebalo da se razdvojene sile naše - Cuvstrene 1 duševne - nadmotijem visprenoga čuvstra (ustrari: estetiðkog osetanja) sajedine"...

...kao Stler, 1 on zahteva da umetnik "ne vife u dejstritelnosti, vet u Idejama trazi čoveka..."

...poput Silera, 1 on vidi krajnji cilj umetnost 1 u prevazilazenju stramosti putem umetnost1, u straranju moralnog 1deala kome ljud1 treba da teze. Ali i ovde Maletit ponavlja svoj uski zahter racionalisticke estetike: "Sila uobrazenja u stihotvorstvu sama po sebi nije nikad nigta u stanju proizvest 1 ako je razum ne rukovodi".

Se1te 39 Maletit je verovao u 1dealno lepo, u večne 1 stalne estetlcke lstine, u retorična pravila 1 śablone 1 nije hteo drugu poeziju do onu koja je po estetickim pravilima 1 koja je racionalna, refleksivna 1 objektivna. 
Nałe narodne pesme uobłte ne mogu nam u ovou predmetu za pravac slułit1. U njlma je sama prosta priroda, bez svake veštine, ogranileno znanje 1 izkustro u šarenoj odet1 o11e uobražnja.

A "olla uobraženja" je, po Maletilu, za umetnost "pogubna".

Mnogl su uXent l judi lzrekl1 svoj sud o narim narodnia pesmama satrajuti ih o dobre strane, a drugi, mote b1t1 zbog nesposobnost1, uzere taj sud kao obłt1, takc da su ih omatrali kao obrazac u svenu b́to se tiłe lepe vertine. Od tuda u najnovije vreme onolike grube pogreške zbog olepog podražavanja.

Se1te 41 .obrazovan, trudoljub1v 1 dobronameran pisac, sposoban da radi po tudim obrascima, all bez originalnosti, bez nadahnuta, bez poezije 1 poleta...

Se1te 42 Dejetvitelnost je ono sto u srbakia narodnim pesmama čitatelja ushitava, dejstvitelnost skroza poetičeska, 1 opet sasvim lotina (1stinita). Jednistro materijo 1 forme - druga je velika zasluga orbske narodne poez je; a osobitost u 1zvodu (u 1zvodenju, u obrad1) kao narodni značaj, trote óto lotim pesmama osobito mesto u poezijl sveta, u redu o drugim samostalnima daje... Srbska je poezija, kao 1 grcka, prava osoba, sa opredeljenim, sobstrenim, odlikujuetim značajem; u njoj je Individualna materija, Individualna forma 1 ind $1-$ vidualna boja: podpuni dakle harakter...Srbske narodne pesme nisu Volkslieder nego National-lieder...

Seite 43 Ne valja uzeti poletak eposkog pesmotroretva kod Grka, pa eposka pesmotroretva oviju drugi naroda kao produzaranje onoga smatrati. Eposka poezija postojala je toliko puta nanovo kod koliko je različnt naroda narodnom nalazimo.

Se1te 43 Ako kakvo delo hote da bude orbskom epopejom, a ne grtkom, onda ga treba po prirodi 1 zakonima orbske epopeje sudit1.

Se1te 46 Kad bl poetu enanje straralo, onda B.Maletit ne bi blo rdav poeta; all poetu otvaraju vrline koje Branka krase, koj1 1 ne Zudet 1 za blavom utenl znanja Ima vrotnote otvarajuteg duha...

-.on laa ono što Šlier osobito od poete zahteva: ima duhal

Se1te 46 On letlč da se "nacionalni pravac u novijoj orpokoj književnostl lopoljara u ne urek ztetnoj asimilacijl ponekih pozajaica tudeg duha 1 u prilagodavanju glavnim smernicama narodne poeslje: u onoj jednostarnoj veliCanstrenost1, u nalvnost1 1 epsko-plastilnoj savrenosti". 
Se1te 50 Naúa poesija mora b1t1 11 čna našen narodnon ind1vidua11tetu. Nemc1ma te se dopadati jedan cenau 111 sinrok. a naml te se Xiniti kao da su ovi pevel samo 1 sraxaj bolestnog Cuvatra $111 \ldots$...bolesne volje, koja zdravia l Judian ne prilici.

Srbska ladez u poslednjoj desetini koliko je valmanije bacila na narodnu poezlju 1 na one splsatelje kojl su u narodnit duhon pisati počel1. Ista mladez u svojim opeviara počela je reproduclrati one misli, ona čuvstra, koja se u narodnia pesmana nalaze. Ovo je bio velikl korak jer je sa tim tud elesenat kod nas k1dat1 počo.

Branko haditevit pokazao se kao meteor na nebu novog pesniťtra srbskog.

Čtajuti Brankove...pesme, svak1 je uvideti mogao da tek a svojim sobstrenia curetrom 1 krojem moke Srbin pesnickoj struci to oavrsentje proizvesti. U njemu je duh srbski kao finiks vaskresao...

Selte 52 One lilnosti u narodu koje su dublje 1 silnije osetile sve patnje fto tifte ceo narod 1 koje su kadre da $18-$ każu ta osetanja u veštačkoj formi - to su pravi pesntc1.

Selte 52 ..eto šta je nužno za pesnika: da je on pokrenuti deo naroda, tj. da je on źiveo onim źlvotom kojim narod źlvi: da je on patio one patnje, 111 bar da su mu tako bliske, koje narod pat1...

lide su ti pesnicl kod nas? znaju 11 ont narod, njegove nuzde 1 patnje? Ogetaju 11 on 1 to to narod oseta 1 gto on1 treba da lskažu? ntkud može da peva ko o stradanju raje u bosnt 111 u Boci, kad ne zna ni Bosnu ni Boku, ni po novlnarskim člancima? Eto załto je naše peoniłtivo prazno, bto se vrze jednako oko lista l leptirova, 111 pute 1 cmate se sa svojom "dragon", a ako se kojiput bac1 u "patrlotaku pozituru", onda je to tako nerto jadno, prazno, nategnuto, bez lkakva osetanja - radi parade... Život narodni, to je sadržina - realnost poez 1 je.

Selte 53 Kad se poezija tako shvati: da je ona pojarljtuanje źivota druxtrenog 111 narodnog 1 da je to ona vazda, ma $u$ kojoj se formi pojavljivala, u proizvodima pojedinih l judi 111 celoga naroda, u epskoj, lirskoj. dramskoj poezijl, 1td. - samo tada moze da se shvati njeno pravo znacenje 1 da se objasne takve pojave kao b to je, naprimer, njeno opadanje u zapadnoj Evrop1.

Selte 53 Narodi uvideše da nije dovoljno pesničko oduševljenje pa da se postigne c1lj za kojim oni žude; ont doznaze da složeno socialno pitanje ne može resiti nijedan pesnik pa ma kako on genijalan bio; da se rés to pitanje, od kojega zavisi sloboda naroda, nuźna je ukupna umna snaga mase naroda. 
Se1te 53 Eto zaŏto nema "poezije" na danarnjem zapadu. Sadrżna pesniłtva, Zivot narodn1, toliko se razvio da se sad počinju ostrarivati onl 1deali koje su nekada jedino pesnicl nazidall 1 shvatall 1 koje ou 12nosili pred narod u svetiln bojama. Pesnici ou ratinom dostigli svoj zadatak. Nastalo je vreme praktİ̌nog rada.

Selte 56 DANICA ILIRSKA...eadržavat te u duhu SIAvo-ILIRSKOM različne 1 unogovrstne tako na lahku zabavu 1 uveselenje, kako 1 na primărno prosvĕtljenje, ter ugodno. 1 koristno podučanje opajajut strari.

Budut pako da $k$ lzobraženju jezika t duha najvǐe doprinašaju... narodne 1 domorodne pésme, zato DANICA naša kakgod dosad tako 1 u napredak s 1zabranim pésnietva crětjem, ukrasena 1 nakitjena bude.

Selte 56 Ovakve presude neka brane ovojljub1 u kojih nema prave lokre domorodetva.

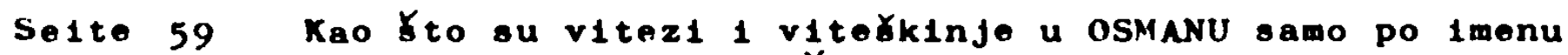
slovinski a orce 1 dura unjlh je romanska, tako 18 to priznat te svaki nestran 18 trazivalac otvari da su Du brovčant năsi više po licu (formi) jezika negoll po materiji (duhu) 111 skladu njegovom slovinci.

Se1te 59 ..vedrost 1 lagahnost u 1 zrazu, jakost 1 okretnost $u$ rizmi $(r \ln 1) \ldots$

Selte 59 Kod narodnih pjesama ne smije se nifta prenadinjati promijenjati 11 popravijati, nego ih valja biljezitl onako kako $12 v 1$ ru 12 ust 1 ju naroda. Ljepote 1 mane njthove, sve je sveta baśtina praotaca najih. U njlma kao u staringkom nekakvom zrcalu čtamo nacin od mlăl nja 1 tutjena njihovih.

Seite 60 I tekar u danažnje stoljete krenuo je književni duh naroda drugim putem, vratajut1 se $k$ ovome pravom cistom izvoru kojl udara lopod korijena zivog domateg 18 pod srca 18 tog puka...

Seite 60 Razvit Eovjek 1ma 1zob1lje misli, o koj1h njegov zaostavsl brat ni ne sanja. Budut 1 da je pako jezik tjelotrorba misil po zvuku, jezik razvitog Covjeka (knjltevni jezik) mora dakie imati natoliko vike rijed negoli jezik, kojl so naučili po ophodenju 8 prostiml ljudmi, nakoliko više misli lma 1 zobrazent čovjek od nelzobrazenoga.

Se1te 62 Zato evo razvijemo barjak narodnog napretka, da kupim pod njega ove one rodol jube kojl u Zivotu naroda svoj život, u njegovoj emrti svoju emrt vide. A po napretk naroda razumijeramo njegor razvitak politikk1, dubevn 1 materijalni.

Seite 62 Gdje su, pitamo, posebno naye ovelano garantirane ursdbe (institucijone)? - gdje toll hvaljena ravnopravnost naroda 1 jezika? gdje zemaljok1 saborl 1 ostala druga toll svetano obetana... 
Se1te 62 ..stuplte u ko10 nake... rodoljubl 1 slaven1 od juga, pa podupirajte rijetju 1 Cinoe poduzete naxe, pokałite ovijetu: da juyna slavija jor vjernih inova lmade, kojl ou pripravni svojoj bijednoj domovini ovestrano u ponot pritet1..

Selte 69 Sveta je duKnost evakoga Hrvata 1 Slavonca da on toll l 1 jepl, bogati 1 slavni svoj jezik kojl au je njegova majka tako rokut u srce usadila, kojim su se nekot njegovi hrabri djedovi s pravom ponosil1...1 kojt bl sada drugl radi utamani11, da ovaj ovoj jezik kano sveto blago Cuva, Ytuje, branl 1 ljubl. - osobito pako duzne su rodoljubne ljepotice hrvatske 1 saronske l jubar prema domovini 1 narodnost 1 u mladano srce nježne svoje djece duboko ucijepit1...

Se1te 64 ..sadałnjl beletrista treba da bude zajedno historik. arheolog, etnograf, gramatik, pučki učitelj 1 bopzna ta ove job...

Se1te 64 Politicka bloboda sastojl u tom da narod sam sobom uprav1ja...

... slobodni narod plata danak, nu sam 1 ga mete a ne kralj.

Selte 65 Pjesnik je nał pokazao da umije ne samo više čestl tako stopiti u cijelost, kano da su salivene, vet da in znade 1 zadahnuti pobožnim duhom kreposti 1 narodnosti. potem mu djelo postaje drarocjeno blago ukupnog našega naroda, koj mu je dužan što vetom zahvalnołtu.

Selte 65 ..njegovi su junaci ( $t j$. Banovi), osim nekoliko pogrełaka, uvijek isti, uvijek doslijedni 1 vjerni 111 krepostim 111 manam, a pobjeda je odredena Elstojkreposti. Tim postaje djelo vrlo poutno 1 ukrepno, premda nije liłeno prekrasne romantike...

Selte 65 ... Jjepo je samo ono bto je ujedno 1 moralno, pjesnik ne smije koptrati narav, nego mora je idealizovati. ... Kod nas neka se ne op1suje junak kojt nije tto pridonio ostrarenju narodne slobode, djevojka se u pjesmi smije samo onda slaviti, ako je krasl rodo1 jubl je.

Selte 66 Śtujemo narodne pjesme kao najdragocjentjl zalog duha našega naroda, al1 ne mislim da umjetni pjesnicl ne bi omjell opjevati nit1 druge stvari do junaka, niti drugat 1 je stihom nego narodnim, niti drugimi figurami do narodnih. Pjesme ove treba da budu temelj na kojem da umjetni pjesnik samostalno podlgne novu zgradu... 
Se1te 66 Poez1ja mu je Čista narodna, kojoj ou misl1, tropl 1 flgure 1 izrazi oenovant na narodnih zorovih, al1 tankim ukusom uzdignutih do visine 1 ugladsnost 1 umjetna pjesnib̌tra.

Se1te 67 .unjima se vidi hvalevrijedna revnoat čstita učitelja 1 prijatelja prosvjete narodne...

.1 zato sem ja tlanke one osobltom pozornoytu čitao.. Ja sam evo uhvatio iz posijednjega broja NEVENa onu misao o korlet1 1 shodnosti Ċtanja Jaljivih oplea sa noralnim postavor, kao sredetro pouke za mladez koja cita...

Se1te 68 Uajetnik valja da najprije otuje u sebl glas erca, nutarnje ono nukanje koje ga gont za ldealom..

Se1te 68 Vidif da pjesnik nije obilan Covjek; danije svakomu nj1m bit1 dano; da valja biti 1 jublmcem bogova; da se treba rod1t1, a postat1 da je vele mutno, da ne raknem bal nemogute.

Se1te 68 Nu gdje sv1 pjevaju, tud je siguran znak da narod ozb1ljnost1 zivota jor shvat1o nije.

- Ta ozb1ljnost Elvota Izražava se u prozl.

Se1te 68 ..ne vjeruj nikada prvoj ruc1...

..tako 1 1z lob̆ıjeg posla mora naposijetku 12161 djelo levreno.

Se1te 69 . ppuk naš l jub1 nauku, osob1to kada mu se umije preodložit1 naব̌inow umu 1 duhu njegovomu pristupnim. Zato b1 sadržaj pučk1m kaiendarima lmao bit1 bar pretežnifim dijelom poučan, otprilike dobri 1 lijepo plsani povijesni članci kojima se budi ovijest 1 ponos narodn1..

Selte 69 Naśa zadata mora prije ovega da bude ovestran razvita s voje narodne Individualnost $1 .$.

Selte 70 Ja mislia da je upravo u sven naéen razvitku 1 pokret oocijalni momenat najvažnıj1.

Dok nam ne bude sel jak obražen1j1, dok se duh narodn1 ne Ivrijeżl ne sano u ovakon gradu, u ovakon uredu 1 u svakoj bko11, vet upravo 1 u obltelj1, koja je prav temelj 1 narodnoga 1 držarnoga žlvota, dotle neme ni krøpku, složnu narodnu životul

Zadata, oenažiț 1 utvrd1t1 narodni žlvot, 1de upravo popularnu, poučnu 1 zabavnu etruku knjtłornosti.

Selte 70 osobito ou znamentte ove etruke (knjlfernost1) u onil naroda, kojl ou nakanl otvorit1 sanostalnu civilizaci da sacuraju svoj individualitet proti tudenu upl1ru. Kod takovih naroda wora da je knjltevnost tendenciozn. 
Seite 71 Socijalni roman rodi nas neumoljtrom anal1zom eamih sebe do epoznanja.

Seite 72 Pjesnika lma puno po svijetu...all rijetk1 ou oni nebeskim plamenom nadahnut 1 ljud1, koj1, nikl1 12 naroda, vade pjesničko zlato 12 dułe roda, te ot 1 stiv ga plamenom ovoga pjesnitkoga genija, rrataju ga narodu u dionih pjesmah...

Se1te 72 Čnt mi se po nom lokustru da vetina 1 judl kojl su se dall na plsanje novela ne shrata taj posao ozb11jno..

..Pa ako plóuti ne vidiź pred sobon evaki kraj, sraki predmet, ovaku osobu... ako ne tutiǒ oa svojil uniłl jen1m osobama svaku Žalost 1 radost...onda t1 pooao ne valja, jer nemaé enage u sobl, onda bacl pero..

Sraki čorjek na ulicl nosi u sebl manju 111 vetu priporıjetku, katkad ju čıtă upravo na licu, a tko ne umije čltat1...taj neka ne pibe..

Se1te 72 Mi hotemo da dignemo narod, da ga osvijestimo, da mane prošlostl popravimo, da budino u njem omisao za sve fto je 11 jepo, dobro 1 plementio.

Se1te 73 Sloboda 1 narodnost nerazdruživi ou pojwovi.

Selte 74 Vrijednost pjesnitkoga trora ne toj1 do predmeta, vet do oblika njegova. Dakako da se pod oblikom nema razumijevatt samo metrickl 1 govorni oblik pjesni, vet Ideja, sastarba, značajl, psihologicka razlożtost.

Selte 75 Gdje se god dramatidna umjetnost njegovala kao oredstro, a ne kao samosvojna ovrha, ne razvijałe se ona naravitim samontklim natinom, ret bijaye tek slaba kopija tudih uzora.

.. -ne vrljedi dramatična knj1ga, ko ni uopé nikakva umjetnost, ako sp gojl samo kao sredstro za politilke avrhe, najpare kad se te protive glasu povijesti 1 Covječanstra.

Sraka tendencija kad se u knjlzernosti pojavi, loprva je na ubtrb savrónosti formalnoj, te se tek bremenom plementtomu smjeru nade 1 l1jep estetilkl oblik.

Selte 76 Markovitevi pogledi na estetiku važil1 su u Hrvatskoj gotovo kroz 3 decentja kao nesto ǧto je $12 \mathrm{van}$ diskusije.

Selte 85 Uopłteno govoret1, useono pesniłtro razvija se u takrim drubtrenim zajednicama koje su na niskom stupnju ekonomokog pa prema tome 1 kulturnog razvitka 1 ne poeeduju raz vijenu pismenost. Primitivnost društvenog rasitka karakt riłe u ekonomici narodito nedovoljna razvijenoet posebnih zanimanja.... a oblast1 duhorne kulture odsudstro pode1. unnog 1 f 121 Zkog rada....nedostatak jednog brojnijeg društrenog loja kojl b1 se bav1o $18 k 1 j u c t v o$ unim radom 1 sadoroljavao potrebe sajednice u tom pogledu. 
Selte 89 Na početku... vat se napomenulo kako tradicija, kojoj je duh kolektiva udario pecat, odreduje otil 1 mot1viku narodne pripovijetke. Ali o druge strane, bez - traralačkog udjela darovitih pojedinaca, kojl ovak 1 put iznova uobličju tu tradic1ju u konkretan $12 r a z$ a ujedno probijaju jedva primjetno 1 njesine okvire, pridoneseti tako njenom razvoju 1 postopenim $12 \mathrm{mje}-$ nama, tradicije zapravo ne bi niti bilo, ona bi be ugas 11 a.

Seite 125 Zac1jelo se ta njegova koncepcija moze prihratiti barem u formulacijl da jezidne mogudnosti radaju otanovite poeticke principe. Tako olavenoki jezic1, bogat1 flekc1jom, lsticat te se Cestim zajedničkim otimološkim figurama.

Selte 130 Rečenica usmenog pripovjedaća, kao 1 govorena recenica uopte, razlikuje se od pisane, uz ostalo, ob1lnim devijacijama od normativne gramatike, slobodnom upotrebom dijalektalnih oblika, jednostamim recenićnim konstrukcijama, elipticnim formulacijama, nacinima lokazivanja afekata.

Se1te 142 Time, zto pravedan 1 porten covjek u borb1 $2 a$ bolje konaćno pobjeduje, u njima tako dolazi do izrazaja optimizam 1 humanistilki herolzam, kojl su ujedno osnovni elemenat 1 najveta vrijednost narodnih pripovijedaka.

Selte 153 Kad danas govorimo o narodnom stilu pripovedanja, m1 mislimo na stil Vukovih narodnin priporedaka.

Selte 154 Kan što su pjesme ugled jezika nafe narodne poez1je, tako te ove priporijetke biti ugled narodnoga jezika u proz1.

Se1te 154 ...al1 u p1sanju priporijedaka vet treba misilt1 1 riječi namjełtati (al1 opet ne po svome vkusu, nego po svojatvu srpakoga jezika).

Seite 1155 ...tako da je zapravo onaj narodni govor koj1 obilno vaż kao osnova naše... gramat1ke, sam po seb1, u 1zvornim oblicima, prilično dalek od gramatičke norme kojoj je posluzio kao osnova.

Se1te 156 Narodn1 jez1k, 1 to pretezno jezik narodn1h urotvorina, zaista je bio osnova za normativnu gramatiku (orpoku kao 1 hrvatskospsku), all ne u 12vornome usmenom obliku nego u onom prodixćenom obliku koj1 su mu dal1 Vuk Karadzit 1 njegovi ouradnicl 1 oljedbenic 
Selte 156 Usnovina Vukuva teźnja... jeste ne ta se, u pranicama jezil̆ne pravilnost1. nstavi śto doslovnija stilizacija onopa kojl mu je zaplsan pripovetku nego - da se stvo$r 1$ sto lep̧̧a 1 ujedno narodskija 1. prema tome, što jasnija 1 što težnija recenica.

Seite 163 Od suih napomenutih pisaca ona je po svojim sklonostima bila najbliza novelistici.

Selte 164 U našoj se terminolopiji odrzavaju još 1 nazivi priła. pripovijetka 1 pripovijest, all se sve vise udomaćuje 1 u nas optl llaziv "novela" za kraci prozni oblik 1 "roman" za duljl prozni oblik. Ne ulazell u povijesni postallak th razlicitih termina i njlhovo razlitito značenje " razlititim razdobljima 1 u raznih naroda, mi th mox́mo danas tako i primjenjivat 1 . Kako je nekada teßko lučti novelu od romana, mopao bi sp za oblik knjl stoji lzmeetu te dvije književne vrste saćuvati 1 optentti domati izraz pripovijeat. Pojam price mogli bismn oatavitl za ono sto Englezi l Amerikallci zovu short story. t.j. za kratku 1 sažetu novellstičku podvrstuknja so" pročlta" u jednom dahu" i karakteristlćna je za suvremena sredstva masovne knmunlkacije, a prema potrehi mozemo se sluziti l terminom mall roman kojl je 1 u nas u novije vrijeme stekao, ne samo kan termin, pravo pratianstva...

Selte 164 Noveloin Eemn nazvatl sue priče razvijenijep siźea sa predinetom 12 stvarnog fradskof 111 seoskog žlvota, realistički shvačanog i prikazanof.

Selte 175 Takn 1 narod ko.jl se je jedva latio posla svof dusevnof, lzobrazaja, ne ronl ndimah u dubljine ozhiljnopa zunajia. On prilićl 12 bube lzis̆avs̆emu metulju (leptiru). knji ne sjeda na hilje ljekovito. vet na sareno crijeće... Uvall razlog učlni što sam se odlučio ove listove stampl predati.

Selte 179 Glavino je nastojanje humorističkopa plsca, da bude zabavan, zanimljî 1 šaljiv.

Seite 189 Od svili hrvatskih linvelista pedesetih fodina on je bio najuişe umjetntk l llajviáp plsac, koji je stvarao 12 unutrałnjih potreba, s najmanjo suho intelektuajistikkih napora, a s najulise osječanja, mašte. poznavanja bljede 1 sirotinje...

Se1te 212 Sa svijem tijem opaža se u njepovu stilu jak tuAlnskl uticaj. Korajac je mnopo čltao, nsoblto njemadke humorlste...pa je dobro proucio njihovu maniru; a kakn je sam bio skion svijem hirima subjektivna pripovjedača, nilje Eudo, da se ono. šo je u njega orletinalno, tijesno udruzilo s onljem, sto je prihvatio od drupijeh, takn da su se prirndene viastitosti stopile s tufljem elementima u...cjelinu...

Selte 216 Sternijancl svi odreda pokusavaju taj Jaz izmedu pripovjedaca 1 Cttaoca premostiti liuzijom skaza. 
Se1te 217 On priporjeda, kao bl priporljedao u veselu elaronskom drub̆tvu uz cału vina, da oo olułąl njegovi razonode 1 od srca nasmiju. A kako u veselu drułtru pripovijetke ne silju bit1 dugatke, da se napetoet ne unor 1 vet kratke 1 zb1te, 1 uzato woraju da se zavróe zgodnom, ołtro 1otaknutom polntom, da lagodne olušace lako podraž na sajJeh, tako Korajac 1 kao pleac nastojl da ¿itačevo zanimanje bude vazda budnos njegove pripovije ke gotovo 1 nijesu drugo vet okupina zabavnijeh epizod -.poput zivijeh varnica olpa na pregrŏt1 bale 1 doskocice, polgrava oe rijecima, gradi anijeśne metarore 1 uporedbe, unete u govor narodne fraze 1 poelovice,koje ako nijesu balj1ve, kontrastom pobuduju na saljeh...

Se1te 226 Dok kod mnogijeh recenica Nemcitevijeh osjetamo, da su njemadk1 zamibljene, a onda $18 t 0 m$ mukom pretotene $u$ hrvatsku besedu, Korajac pibe c1st1jem jezikom, kojl je pored oviju tudinskijeh natruna gacuvao narodni kolorit.

Se1te 233 Te su priporijesti onilile s c1stote jezika, s narodnijeh oblika, 1 stoga rto ou ogledalo naroda nałega.

Se1te 233 ..da Ljubiła n1jo uclo orpokog jezika na retoric1 knjlga, vel 12 ustiju naroda našga na jugu, gdje natica 1 kovnica puckih umotvorina.

Se1te 246 I bay $u$ tome zto je 12 elemenata narodne tradicije otvarao umetnicka dola 1 bto je narodnim olementima bogat1o 1 posvežavao nab knj1zern1 jezik 1 jeste velika Ljubizina zasluga kao plsca.

Se1te 246 Jezik taj nije samo pravi 1 c1st narodni jezik, jedar 1 pun snage, nego je on jedinstreni rell, reCen1ce, obl1c1, konstrukc1je, s1ke - eve je u duhu narodnom; 1 da Ljubiła u svojim pripovetkama nema nicega drugoga, jezik b1 njegor sam neocenj1vi dob1t 1 stavio b1 ga u red velikih plsaca srpokih, onth u kojih nam se valja uXtiti kako se pize orpokim jezikom...

Se1te 252 Ne poritut1 znatenja starijin noveligtima, mote se lpak s punim pravon ret1, da je tek Senoa trarno osnovao hrvatsku novelu u punom smielu. Svi hrvatok1 priporjedačı prije njega... amo ou epremal1 materijal. koj1 je Senoa znao prvi umjetnitk1 1skorlet1t1.

Se1te 260 Senoa n1je nikada u svojim njemark1m sastarcima post1gao onu slobodu svestranoga loražavanja od nesputane afokt1rnost1 do logltke ortrine kako se ona otituje u njegovu hrvatskon st1lu; al1 u pogledu korektnost 1 lietote jezika njegor je hrvatak1 stll daleko zaostao a njegoria njearkil.

Se1te 275 II razrjad otlicaets ja boleo avtora 1 geroja; $v$ 12lozen11 eobyt1j on1 ubastrujut .. na ravnych pravach, často emenjaja drug druga. 
Die vorliegende Arbett wurde 10 Wintersemester $1973 / 74$ von der Philosophischen Fakultit der Ludwig-MaximiliansUniversitit zu Munchen als Dissertation angenommen.

Das Thema dieser Untersuchung ergab eich in seiner end- . gultigen Fassung in Laufe mehrerer Gespriche mit meinem hochgeschlizten Lehrer, Herrn Prof.Dr. Johannes Hol thusen, der die Arbeit wihrend Ihrer Entetehung in jeder Weise gefirdert hat. Fur diese Betreuung, die ebenso durch stindige Hilfobereitschaft wie durch das Elngehen auf neine Koneeption des Themas gekennzelchnet war, möchte 1 ch an dieser Stelle Herrn Prof.Dr. Hol thusen meinen aufichtigen Dank aussprechen.

Danken wobchte Ich auch Herrn Prof.Dr. Aleksandar Flaker fur eine Relbe von klitrenden Hinwelsen und Frau Prof.Dr. Maja Borkovit-stull1, deren kundige Ratschll̆ge mir bel der Auswahl des Materials und der Sekundirliteratur von grobem Nutzen gewesen ind.

Mein Dank gilt ferner den Herausgebern und dem Verleger der "Slavistischen Beiträge", Herrn otto Sagner, fur die Aufnahme meiner Arbeit in diese Reihe, sowle Herrn Dr. Peter Rehder, in dessen Hinden die redaktionelle Betreung 1 a.g.

In den Kreis derer, denen Ich zu danken habe, wöchte 1ch auch meinen vers torbenen Lehrer Herrn Prof.Dr. Alot: Schmaus einbeziehen, der seit Beginn meines Studiuns mein Interesse an der serbokroatischen Literatur gefördert hat.

Bayerische

Staatsbibllotho'k München 